\title{
ANÁLISE COMPUTACIONAL DE ESFORÇOS HEMODINÂMICOS EM ANEURISMA DE AORTA ABDOMINAL INFRA-RENAL ANTES E APÓS A INSTALAÇÃO DE ENDOPRÓTESES
}

\author{
Dissertação apresentada à Escola Politécnica \\ da Universidade de São Paulo para obtenção \\ do Título de Mestre em Engenharia Mecânica.
}

SÃO PAULO 


\section{ANÁLISE COMPUTACIONAL DE ESFORÇOS HEMODINÂMICOS EM ANEURISMA DE AORTA ABDOMINAL INFRA-RENAL ANTES E APÓS A INSTALAÇÃO DE ENDOPRÓTESES}

Dissertação apresentada à Escola Politécnica da Universidade de São Paulo para obtenção do Título de Mestre em Engenharia Mecânica.

Área de Concentração:

Engenharia Mecânica de Energia e Fluidos

Orientador:

Prof. Dr. Jayme Pinto Ortiz

SÃO PAULO 
Este exemplar foi revisado e alterado em relação à versão original, sob responsabilidade única do autor e com a anuência de seu orientador.

São Paulo, de de 20

Assinatura do autor

Assinatura do orientador

\section{FICHA CATALOGRÁFICA}

\section{Tabacow, Fabio Bittencourt Dutra}

Análise computacional de esforços hemodinâmicos em aneurisma de aorta abdominal infra-renal antes e após a instalação de endopróteses / F.B.D. Tabacow. -- versão corr. -- São Paulo, 2014.

$125 \mathrm{p}$.

Dissertação (Mestrado) - Escola Politécnica da Universidade de São Paulo. Departamento de Engenharia Mecânica.

1.Simulação 2. Aneurisma 3.Aorta-abdominal

4.Endopróteses

I.Universidade de São Paulo. Escola Politécnica. Departamento de Engenharia Mecânica Il.t. 
"Quanto mais aumenta nosso conhecimento, mais evidente fica a nossa ignorância”. (John F. Kennedy) 


\section{AGRADECIMENTOS}

Agradeço ao professor Jayme Pinto Ortiz pela orientação no trabalho. Agradeço ao Guilherme Agrelli e à Braile Biomédica pelo fornecimento de geometrias de aneurismas e informações extremamente úteis para este trabalho. Aos amigos Ovandir Bazan, Milton Gallo-Neto, Cadu Mady e Thierre Zulzke pelas ajudas técnicas no trabalho e nas disciplinas durante o mestrado. A todos os amigos e agregados ao prédio Colombe D'or, a todos os MFS e aos amigos de hobby que foram essenciais nos momentos difíceis que foram passados durante este mestrado. Não vou colocar nomes dos amigos, senão precisaria de mais umas 30 páginas e ainda faltaria alguém. Agradeço a Bruna pelo companheirismo e força na época final do trabalho e por toda força e confiança para o término deste trabalho. Agradeço também a Paulinha pelo companheirismo, ajuda e empréstimos de livros de medicina que me ajudaram muito. Agradeço aos meus pais Miguel Adolfo Tabacow e Kathia M. Bittencourt Dutra Tabacow pela ajuda financeira, suporte técnico na área da medicina $\mathrm{e}$ apoio nas horas mais difíceis. Agradeço a toda a minha família que me ajudou e me apoiou nos momentos de maiores dificuldades. 


\section{RESUMO}

Aneurismas são dilatações permanentes iguais ou superiores a $50 \%$ do diâmetro original de uma artéria ou do diâmetro proximal da mesma, de acordo com consenso publicado pela Sociedade de Cirurgia Vascular da América do Norte e Sociedade Internacional de Cirurgia Cardiovascular em 1991 (Vliet e Boll, 1997). Aneurisma de aorta é uma doença vascular que afeta mais de $5 \%$ da população masculina com mais de 55 anos de idade (How et al., 2005). Desde 1991 um novo método vem sendo utilizado como tratamento deste quadro clínico. Este novo método é considerado menos invasivo e com menor comorbidade, uma vez que se trata da instalação de uma endoprótese por meio de catéter através da artéria femoral. Neste trabalho, será verificado o escoamento através de três aneurismas de aorta abdominal (AAA) e das endopróteses indicadas para o tratamento de cada um dos aneurismas. Foram feitas simulações computacionais afim de se obter as pressões, as velocidades do escoamento sanguíneo e as tensões de cisalhamento na parede das geometrias, usando pulsos de pressão e velocidade fisiológico de um individuo adulto, normotenso, em repouso. No modelo de escoamento simulado, foi adotado o sangue como fluido Newtoniano, incompressível e homogêneo. Foi usado um modelo de turbulência $\mathrm{K}-\varepsilon$, com interpolador upwind de $2^{\mathrm{a}}$ ordem e tratamento de parede nas geometrias, para que se fosse possível obter resultados satisfatórios (das camadas próximas à parede, e de todos os vórtices). Os resultados obtidos no trabalho foram satisfatórios, uma vez que eles expressaram de forma realista o comportamento do escoamento sanguíneo pelos aneurismas e endopróteses. Foi possível justificar com esse trabalho a instalação de endopróteses em pacientes, quando necessário, com o objetivo de diminuir significativamente a degradação do vaso, causando a ruptura do aneurisma.

Palavras-chaves: Simulação DFC, Aneurisma de Aorta Abdominal(AAA), Endopróteses. 


\begin{abstract}
Aneurisms are permanently dilatation higher than $50 \%$ of the original diameter of an artery or of the proximal diameter of them, according to the published consensus of the Vascular Surgery Society of North America and International Society of Cardiovascular Surgery on 1991 (Vliet and Boll, 1997). Aorta's Aneurism is a vascular disease that affects more than $5 \%$ of the male population, with more than 55 years old (How et al, 2005). Since 1991, a new method is used in the treatment of these diseases. This new method is less invasive and has less comorbidity. This method is provided by the installation of an endoprosthesis through the catheter through the femoral artery. In this work, the flow will be verified through three abdominal aortic aneurysms (AAA) and the endoprosthesis indicated for the treatment of each of the aneurysms. Computational simulations were made in order to obtain the pressures, velocities of the blood flow and the shear stresses on the wall of geometries, using a pulse pressure and velocity of an individual physiological adult normotensive at rest. For the fluid simulations, it was adopted the blood as Newtonian fluid, incompressible and homogeneous. In simulations, it was used a K- $\varepsilon$ model of turbulence, with $2^{\text {nd }}$ order upwind interpolator and wall geometry treatment in order to obtain satisfied results (on the layers near the walls, and all the vortices). The results obtained in this work were satisfied, once they expressed the realistic behavior of the blood flow through the aneurysm and the endoprosthesis. It was possible to justify with this work the installation of an endoprosthesis inside patients, when it is necessary, in order to decrease significantly the vessel's degradation, causing the aneurysm rupture.
\end{abstract}

Keywords: CFD Simulation, Abdominal Aorta's Aneurisms(AAA), Endoprosthesis. 


\section{Sumário}

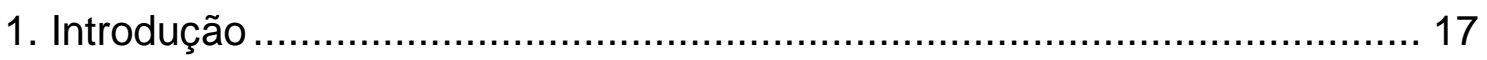

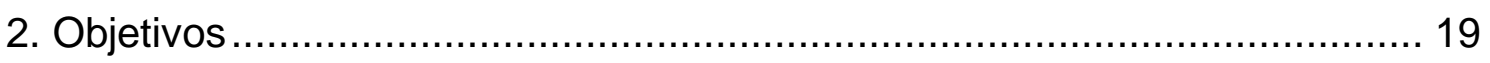

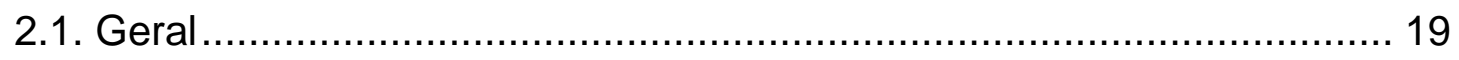

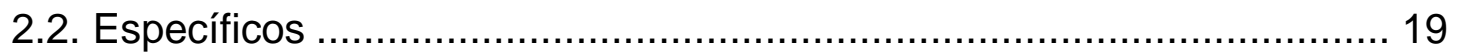

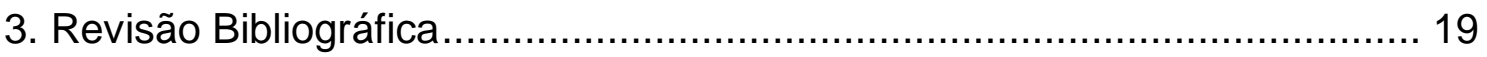

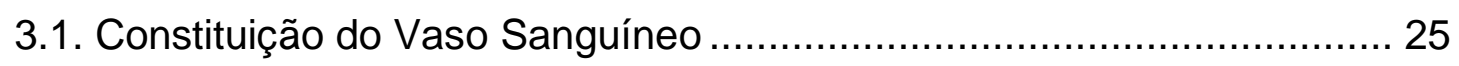

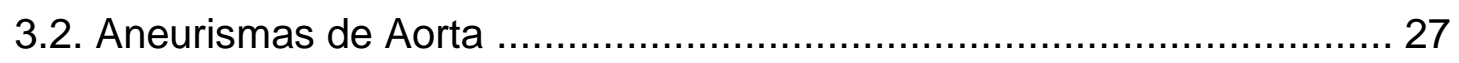

3.2.1. Aneurismas de Aorta Abdominal................................................. 28

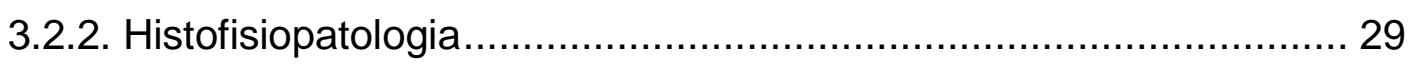

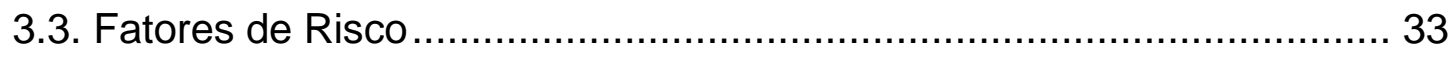

3.3.1. Idade Avançada ....................................................................... 33

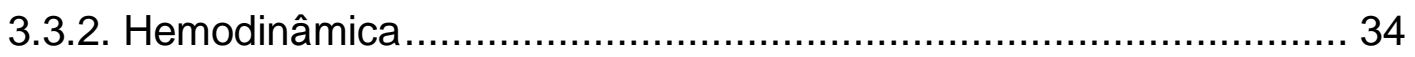

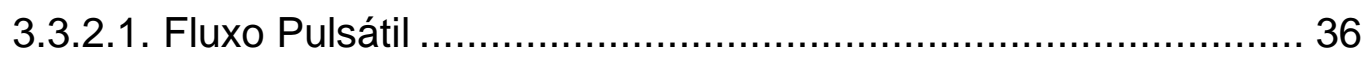

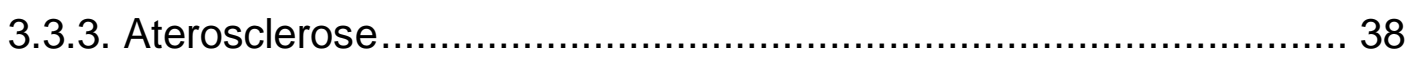

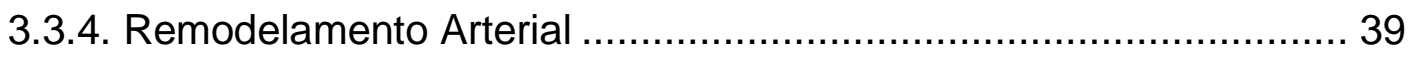

3.4. Diagnóstico e Exames Subsidiários ……………….......................... 39

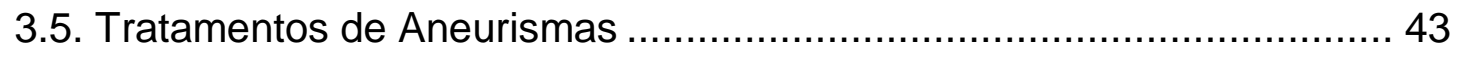

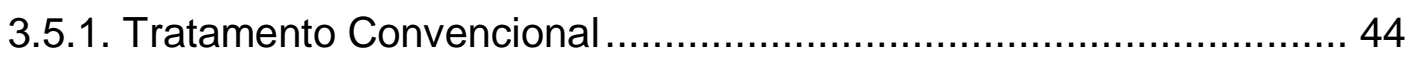

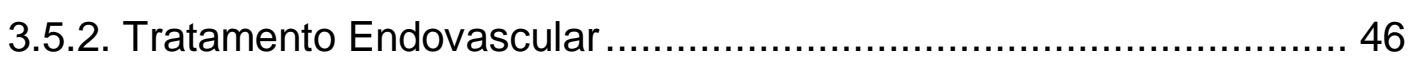

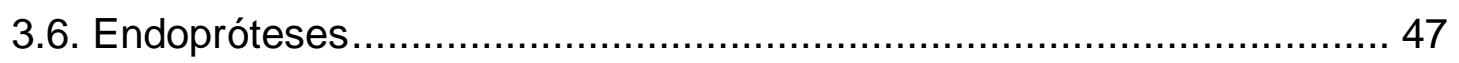

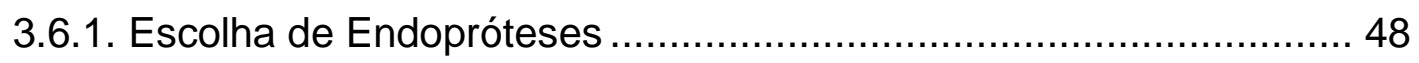

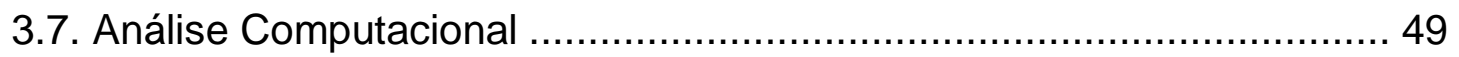

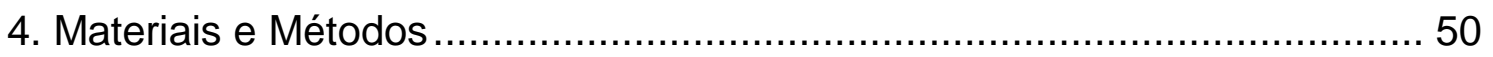

4.1. Modelagem de Aneurisma Real ..................................................... 50

4.1.1. Geração de Modelo a partir de Exame Multi-fatias ........................ 50

4.1.2. Tratamento Superficial de Imagens ............................................. 52

4.2. Simulação Computacional do Aneurisma............................................ 54

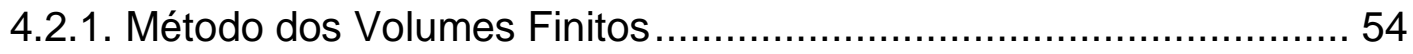

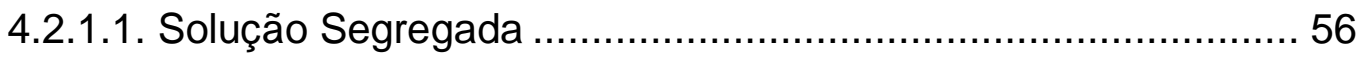

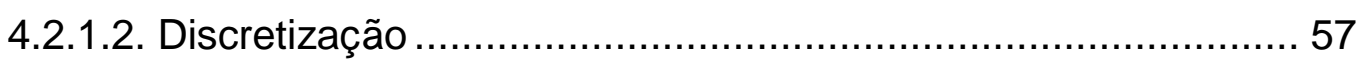

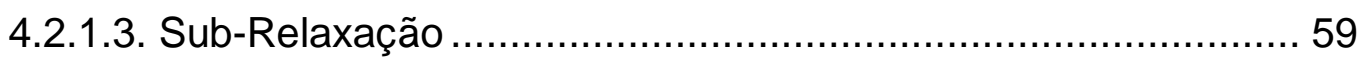


4.2.1.4. Acoplamento Pressão-Velocidade ......................................... 59

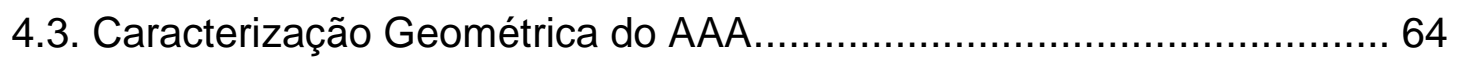

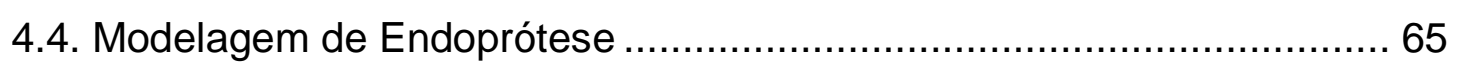

4.5. Simulação Computacional do Escoamento pelas Endopróteses ............ 67

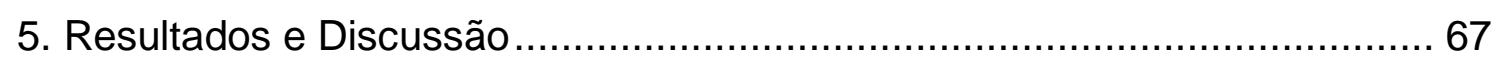

5.1. Modelagem Tridimensional de Aneurismas Reais................................. 67

5.1.1. Campo de Pressões ............................................................. 70

5.1.1.1 Aneurisma de Legendre .................................................. 71

5.1.1.2 Endoprótese Bifurcada para Aneurisma de Legendre ............... 73

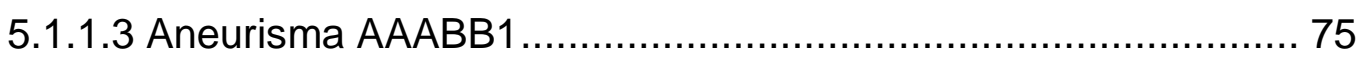

5.1.1.4 Endoprótese Bifurcada para AAABB1 …................................ 77

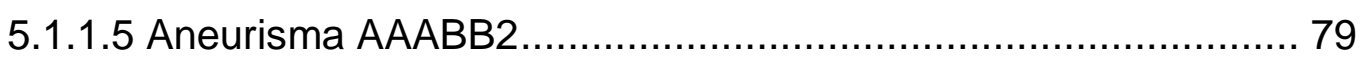

5.1.1.6 Endoprótese Cilíndrica para AAABB2 ..................................... 81

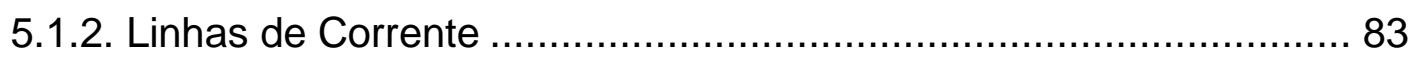

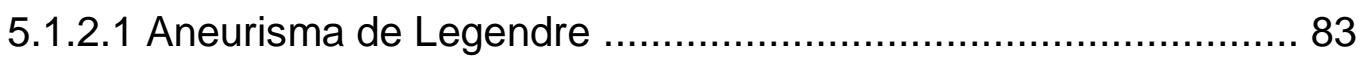

5.1.2.2 Endoprótese Bifurcada para Aneurisma de Legendre ............... 85

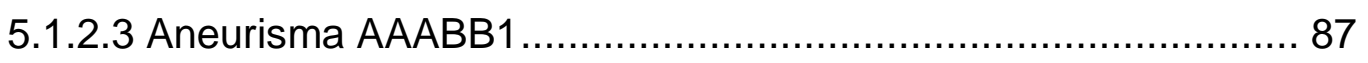

5.1.2.4 Endoprótese Bifurcada para AAABB1 …................................ 89

5.1.2.5 Aneurisma AAABB2 ........................................................ 91

5.1.2.6 Endoprótese Cilíndrica para AAABB2 ……............................. 93

5.1.3. Tensões de Cisalhamento na Parede ........................................... 95

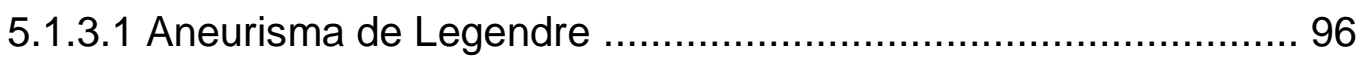

5.1.3.2 Endoprótese Bifurcada para Aneurisma de Legendre............... 98

5.1.3.3 Aneurisma AAABB1 .........................................................100

5.1.3.4 Endoprótese Bifurcada para AAABB1 ..................................102

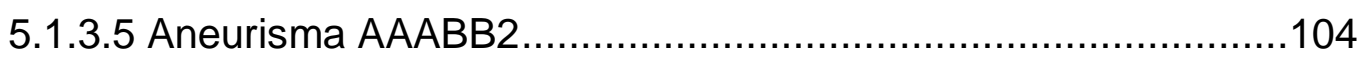

5.1.3.6 Endoprótese Cilíndrica para AAABB2 ....................................106

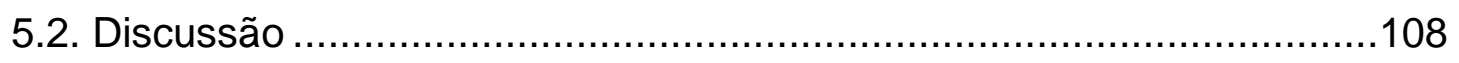

5.2.1. Aneurisma de Legendre e Endoprótese Bifurcada para Aneurisma de

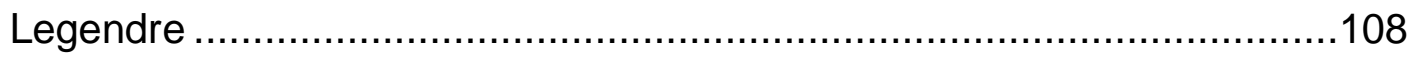

5.2.2. Aneurisma AAABB1 e Endoprótese para AAABB1 ......................118

5.2.3. Aneurisma AAABB2 e Endoprótese para AAABB2 .......................118

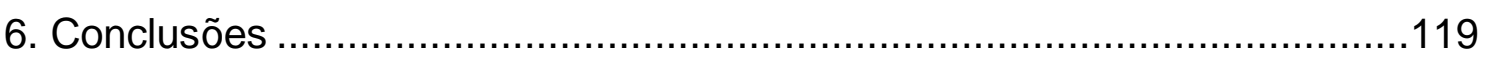

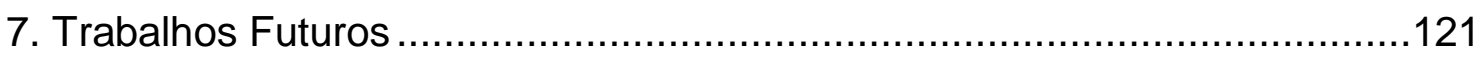


8. Referências Bibliográficas . 


\section{Índice de Figuras}

FIGURA 1 - AAA ROTO CRÔNICO COM EROSÃO DE VERTEBRA LOMBAR (BAPTISTA-SILVA, 2003) ............20

FIGURA 2 - REPRESENTAÇÃO ESQUEMÁTICA PARA A APLICAÇÃO DA LEI DE LAPLACE.............................21

FIGURA 3 - TENSÕES DE CISALHAMENTO NA PAREDE DOS VASOS SANGUÍNEOS E ALGUMAS

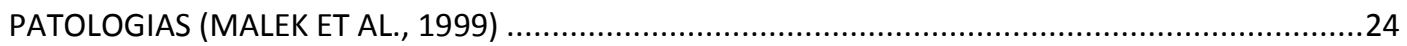

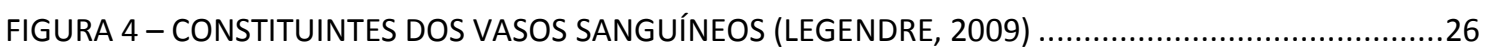

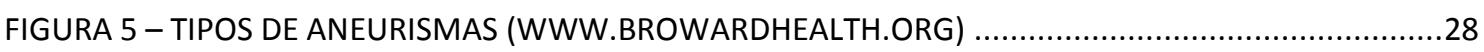

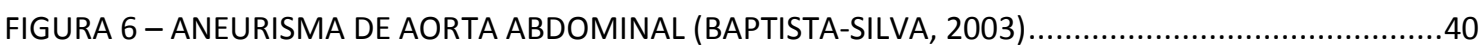

FIGURA 7 - RADIOGRAFIA SIMPLES DE ABDÔMEN MOSTRANDO CALCIFICAÇÃO EM ANEURISMA E

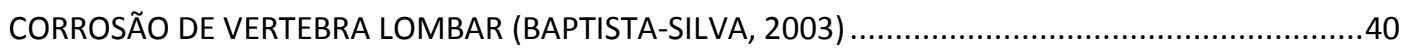

FIGURA 8 - ULTRASSOM LONGITUDINAL DE ABDÔMEN MOSTRANDO UM AAA INFRE-RENAL (BAPTISTA-

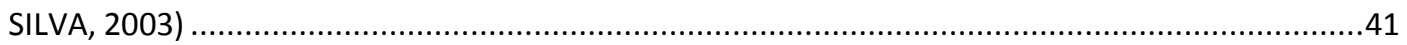

FIGURA 9 - TOMOGRAFIA COMPUTADORIZADA DE AAA INFRA-RENAL (BAPTISTA-SILVA, 2003) .............42

FIGURA 10 - ANGIOGRAFIA (ARAÚJO E RODRIGUES, 2003) ….....................................................

FIGURA 11 - MOMENTOS DA CIRURGIA ABERTA PARA TRATAMENTO DE ANEURISMA DE AORTA ABDOMINAL, ILUSTRANDO PINÇAMENTO DA AORTA ABDOMINAL E ARTÉRIAS ILÍACAS E SUTURA DO ENXERTO NA PORÇÃO SUPERIOR DA AORTA (A); APÓS INSTALAÇÃO DO ENXERTO, FECHAMENTO DO SACO ANEURISMÁTICO (B) (HEALTHLIBRARY)

FIGURA 12 - INSERÇÃO DE ENDOPRÓTESE COM CATETER POR MEIO DE ARTÉRIA FEMORAL (A); ENDOPRÓTESE BIFURCADA JÁ INSTALADA EM PACIENTE (B) E (C). (LEGENDRE, 2009).

FIGURA 13 - ENDOPRÓTESE BIFURCADA USADA NO TRATAMENTO DE AAA COM SEGMENTOS PARA ILÍACAS DE COMPRIMENTOS DIFERENCIADOS(A);DETALHE DA ESTRUTURA METÁLICA COM O REVESTIMENTO POLIÉSTER(B); DETALHE DA ESTRUTURA METÁLICA DE UMA ENDOPRÓTESE(C); ENDOPRÓTESE BIFURCADA USADA NO TRATAMENTO DE AAA COM SEGMENTOS PARA ILÍACAS DE

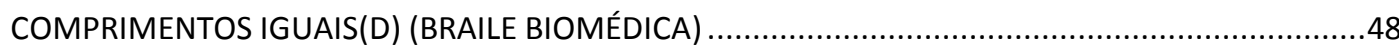
FIGURA 14 - IMAGENS OBTIDAS POR EXAMES DE TOMOGRAFIA DE PACIENTES (LEGENDRE, 2009) .......51 FIGURA 15 - CONSTRUÇÃO DO MODELO TRIDIMENSIONAL DE AAA (INVESALIUS 3.0) ............................51 FIGURA 16 - FLUXOGRAMA PARA RECONSTRUÇÃO DE IMAGENS MÉDICAS (LEGENDRE, 2009) ...............52 FIGURA 17 - CONSTRUÇÃO DE MODELO TRIDIMENSIONAL A PARTIR DE EXAME MULTI-FATIAS (INVESALIUS 3.0).

FIGURA 18 - MODELO TRIDIMENSIONAL DE ANEURISMA DE AORTA ABDOMINAL INFRA-RENAL OBTIDO

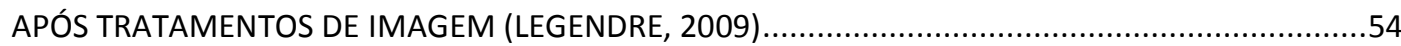
FIGURA 19 - ALGORITMO DO MÉTODO DE SOLUÇÃO SEGREGADA (LEGENDRE, 2009) .............................57 FIGURA 20 - VOLUME DE CONTROLE UTILIZADO PARA ILUSTRAR A DISCRETIZAÇÃO DA EQUAÇÃO DE

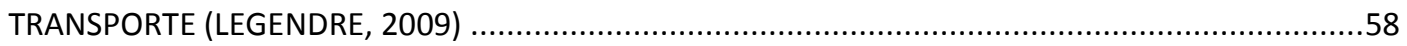

FIGURA 21 - EXEMPLO DA MALHA USADA PARA REALIZAÇÃO DAS SIMULAÇÕES (AAABB1)....................62 FIGURA 22 - PULSO DE VELOCIDADE E PRESSÃO USADOS NO MODELO (MILLS ET AL., 1970) ..................64 FIGURA 23 - CONSTRUÇÃO DO MODELO TRIDIMENSIONAL DA ENDOPRÓTESE PARA O AAA LEGENDRE66 FIGURA 24 - CONSTRUÇÃO DO MODELO TRIDIMENSIONAL DA ENDOPRÓTESE PARA O AAABB1 ............66 FIGURA 25 - CONSTRUÇÃO DO MODELO TRIDIMENSIONAL DA ENDOPRÓTESE PARA O AAABB2 ............67 FIGURA 26 - ANEURISMA DE AORTA ABDOMINAL INFRA-RENAL (LEGENDRE, 2009) ...............................68

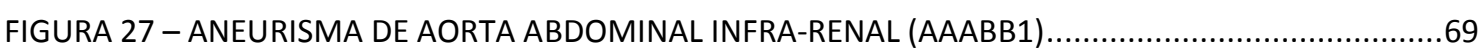
FIGURA 28 - ANEURISMA DE AORTA ABDOMINAL INFRA-RENAL (AAABB2) ........................................ FIGURA 29 - RESULTADO DE PRESSÃO EM AAA NO INSTANTE T=0,2 SEGUNDO (AAA LEGENDRE) ...........71 FIGURA 30 - RESULTADO DE PRESSÃO EM AAA NO INSTANTE T=0,4 SEGUNDO (AAA LEGENDRE) ...........71 FIGURA 31 - RESULTADO DE PRESSÃO EM AAA NO INSTANTE T=0,6 SEGUNDO (AAA LEGENDRE) ...........72 FIGURA 32 - RESULTADO DE PRESSÃO EM AAA NO INSTANTE T=0,8 SEGUNDO (AAA LEGENDRE) ...........72 
FIGURA 33 - RESULTADO DE PRESSÃO EM ENDOPRÓTESE PARA AAA NO INSTANTE T=0,2 SEGUNDO (ENDOPRÓTESE AAA LEGENDRE)

FIGURA 34 - RESULTADO DE PRESSÃO EM ENDOPRÓTESE PARA AAA NO INSTANTE T=0,4 SEGUNDO

(ENDOPRÓTESE AAA LEGENDRE).

FIGURA 35 - RESULTADO DE PRESSÃO EM ENDOPRÓTESE PARA AAA NO INSTANTE T=0,6 SEGUNDO

(ENDOPRÓTESE AAA LEGENDRE)

FIGURA 36 - RESULTADO DE PRESSÃO EM ENDOPRÓTESE PARA AAA NO INSTANTE T=0,8 SEGUNDO

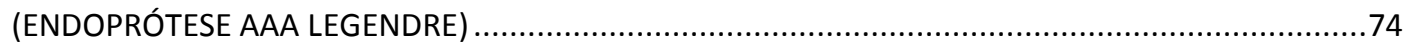

FIGURA 37 - RESULTADO DE PRESSÃO EM AAA NO INSTANTE T=0,2 SEGUNDO (AAABB1) ….................75

FIGURA 38 - RESULTADO DE PRESSÃO EM AAA NO INSTANTE T=0,4 SEGUNDO (AAABB1) ….................75

FIGURA 39 - RESULTADO DE PRESSÃO EM AAA NO INSTANTE T=0,6 SEGUNDO (AAABB1) .....................76

FIGURA 40 - RESULTADO DE PRESSÃO EM AAA NO INSTANTE T=0,8 SEGUNDO (AAABB1) ......................76

FIGURA 41 - RESULTADO DE PRESSÃO EM ENDOPRÓTESE PARA AAA NO INSTANTE T=0,2 SEGUNDO

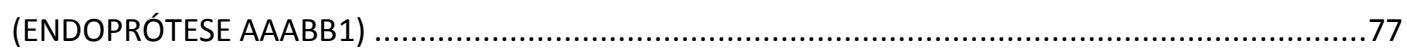

FIGURA 42 - RESULTADO DE PRESSÃO EM ENDOPRÓTESE PARA AAA NO INSTANTE T=0,4 SEGUNDO

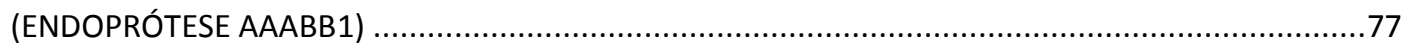

FIGURA 43 - RESULTADO DE PRESSÃO EM ENDOPRÓTESE PARA AAA NO INSTANTE T=0,6 SEGUNDO

(ENDOPRÓTESE AAABB1) .................................................................................................

FIGURA 44 - RESULTADO DE PRESSÃO EM ENDOPRÓTESE PARA AAA NO INSTANTE T=0,8 SEGUNDO

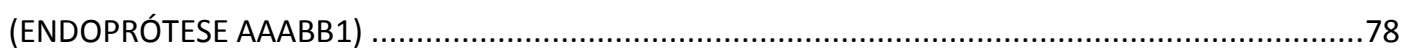

FIGURA 45 - RESULTADO DE PRESSÃO EM AAA NO INSTANTE T=0,2 SEGUNDO (AAABB2) …..................79

FIGURA 46 - RESULTADO DE PRESSÃO EM AAA NO INSTANTE T=0,4 SEGUNDO (AAABB2) ......................79

FIGURA 47 - RESULTADO DE PRESSÃO EM AAA NO INSTANTE T=0,6 SEGUNDO (AAABB2) ......................80

FIGURA 48 - RESULTADO DE PRESSÃO EM AAA NO INSTANTE T=0,8 SEGUNDO (AAABB2) .....................80

FIGURA 49 - RESULTADO DE PRESSÃO EM ENDOPRÓTESE PARA AAA NO INSTANTE T=0,2 SEGUNDO

(ENDOPRÓTESE PARA AAABB2)

FIGURA 50 - RESULTADO DE PRESSÃO EM ENDOPRÓTESE PARA AAA NO INSTANTE T=0,4 SEGUNDO

(ENDOPRÓTESE PARA AAABB2)

. .81

FIGURA 51 - RESULTADO DE PRESSÃO EM ENDOPRÓTESE PARA AAA NO INSTANTE T=0,6 SEGUNDO

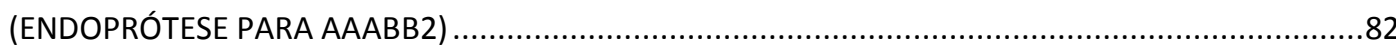

FIGURA 52 - RESULTADO DE PRESSÃO EM ENDOPRÓTESE PARA AAA NO INSTANTE T=0,8 SEGUNDO

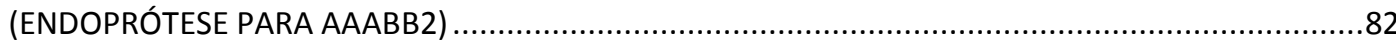

FIGURA 53 - RESULTADO DE LINHAS DE CORRENTE EM AAA NO INSTANTE T=0,2 SEGUNDO (AAA LEGENDRE)

FIGURA 54 - RESULTADO DE LINHAS DE CORRENTE EM AAA NO INSTANTE T=0,4 SEGUNDO (AAA

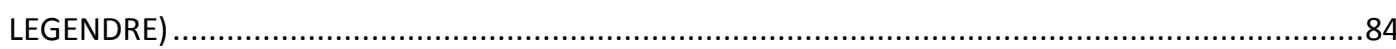

FIGURA 55 - RESULTADO DE LINHAS DE CORRENTE EM AAA NO INSTANTE T=0,6 SEGUNDO (AAA

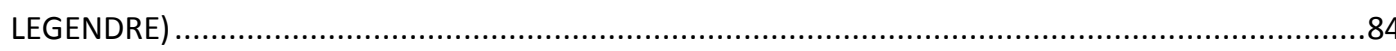

FIGURA 56 - RESULTADO DE LINHAS DE CORRENTE EM AAA NO INSTANTE T=0,8 SEGUNDO (AAA

LEGENDRE)

FIGURA 57 - RESULTADO DE LINHAS DE CORRENTE EM ENDOPRÓTESE PARA AAA NO INSTANTE T=0,2 SEGUNDO (ENDOPRÓTESE PARA AAA LEGENDRE)

FIGURA 58 - RESULTADO DE LINHAS DE CORRENTE EM ENDOPRÓTESE PARA AAA NO INSTANTE T=0,4 SEGUNDO (ENDOPRÓTESE PARA AAA LEGENDRE)

FIGURA 59 - RESULTADO DE LINHAS DE CORRENTE EM ENDOPRÓTESE PARA AAA NO INSTANTE T=0,6 SEGUNDO (ENDOPRÓTESE PARA AAA LEGENDRE)

FIGURA 60 - RESULTADO DE LINHAS DE CORRENTE EM ENDOPRÓTESE PARA AAA NO INSTANTE T=0,8 SEGUNDO (ENDOPRÓTESE PARA AAA LEGENDRE)

FIGURA 61 - RESULTADO DE LINHAS DE CORRENTE EM AAA NO INSTANTE T=0,2 SEGUNDO (AAABB1) 87 FIGURA 62 - RESULTADO DE LINHAS DE CORRENTE EM AAA NO INSTANTE T=0,4 SEGUNDO (AAABB1) .88 
FIGURA 63 - RESULTADO DE LINHAS DE CORRENTE EM AAA NO INSTANTE T=0,6 SEGUNDO (AAABB1) 88 FIGURA 64 - RESULTADO DE LINHAS DE CORRENTE EM AAA NO INSTANTE T=0,8 SEGUNDO (AAABB1) .89 FIGURA 65 - RESULTADO DE LINHAS DE CORRENTE EM ENDOPRÓTESE PARA AAA NO INSTANTE T=0,2 SEGUNDO (ENDOPRÓTESE PARA AAABB1)

FIGURA 66 - RESULTADO DE LINHAS DE CORRENTE EM ENDOPRÓTESE PARA AAA NO INSTANTE T=0,4 SEGUNDO (ENDOPRÓTESE PARA AAABB1)

FIGURA 67 - RESULTADO DE LINHAS DE CORRENTE EM ENDOPRÓTESE PARA AAA NO INSTANTE T=0,6

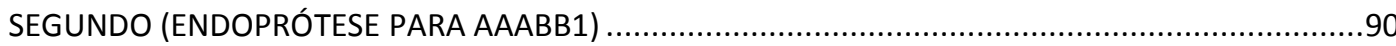

FIGURA 68 - RESULTADO DE LINHAS DE CORRENTE EM ENDOPRÓTESE PARA AAA NO INSTANTE T=0,8

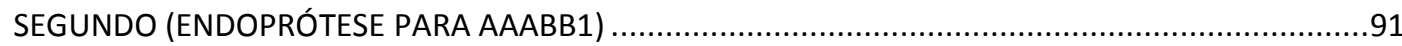
FIGURA 69 - RESULTADO DE LINHAS DE CORRENTE EM AAA NO INSTANTE T=0,2 SEGUNDO (AAABB2) .91 FIGURA 70 - RESULTADO DE LINHAS DE CORRENTE EM AAA NO INSTANTE T=0,4 SEGUNDO (AAABB2) .92 FIGURA 71 - RESULTADO DE LINHAS DE CORRENTE EM AAA NO INSTANTE T=0,6 SEGUNDO (AAABB2) .92 FIGURA 72 - RESULTADO DE LINHAS DE CORRENTE EM AAA NO INSTANTE T=0,8 SEGUNDO (AAABB2) 93 FIGURA 73 - RESULTADO DE LINHAS DE CORRENTE EM ENDOPRÓTESE PARA AAA NO INSTANTE T=0,2 SEGUNDO (ENDOPRÓTESE PARA AAABB2)

FIGURA 74 - RESULTADO DE LINHAS DE CORRENTE EM ENDOPRÓTESE PARA AAA NO INSTANTE T=0,4 SEGUNDO (ENDOPRÓTESE PARA AAABB2) ………................................................................

FIGURA 75 - RESULTADO DE LINHAS DE CORRENTE EM ENDOPRÓTESE PARA AAA NO INSTANTE T=0,6 SEGUNDO (ENDOPRÓTESE PARA AAABB2)

FIGURA 76 - RESULTADO DE LINHAS DE CORRENTE EM ENDOPRÓTESE PARA AAA NO INSTANTE T=0,8 SEGUNDO (ENDOPRÓTESE PARA AAABB2)

FIGURA 77 - RESULTADO DE TENSÃO DE CISALHAMENTO NA PAREDE DE AAA NO INSTANTE T=0,2 SEGUNDO (AAA LEGENDRE)

FIGURA 78 - RESULTADO DE TENSÃO DE CISALHAMENTO NA PAREDE DE AAA NO INSTANTE T=0,4 SEGUNDO (AAA LEGENDRE)

FIGURA 79 - RESULTADO DE TENSÃO DE CISALHAMENTO NA PAREDE DE AAA NO INSTANTE T=0,6 SEGUNDO (AAA LEGENDRE)

FIGURA 80 - RESULTADO DE TENSÃO DE CISALHAMENTO NA PAREDE DE AAA NO INSTANTE T=0,8 SEGUNDO (AAA LEGENDRE) .

FIGURA 81 - RESULTADO DE TENSÃO DE CISALHAMENTO NA PAREDE DE ENDOPRÓTESE PARA AAA NO INSTANTE T=0,2 SEGUNDO (ENDOPRÓTESE AAA LEGENDRE) …............................................98

FIGURA 82 - RESULTADO DE TENSÃO DE CISALHAMENTO NA PAREDE DE ENDOPRÓTESE PARA AAA NO INSTANTE T=0,4 SEGUNDO (ENDOPRÓTESE AAA LEGENDRE).

FIGURA 83 - RESULTADO DE TENSÃO DE CISALHAMENTO NA PAREDE DE ENDOPRÓTESE PARA AAA NO INSTANTE T=0,6 SEGUNDO (ENDOPRÓTESE AAA LEGENDRE) ….................................................99

FIGURA 84 - RESULTADO DE TENSÃO DE CISALHAMENTO NA PAREDE DE ENDOPRÓTESE PARA AAA NO INSTANTE T=0,8 SEGUNDO (ENDOPRÓTESE AAA LEGENDRE) ...................................................99

FIGURA 85 - RESULTADO DE TENSÃO DE CISALHAMENTO NA PAREDE DE AAA NO INSTANTE T=0,2 SEGUNDO (AAABB1).

FIGURA 86 - RESULTADO DE TENSÃO DE CISALHAMENTO NA PAREDE DE AAA NO INSTANTE T=0,4 SEGUNDO (AAABB1)

FIGURA 87 - RESULTADO DE TENSÃO DE CISALHAMENTO NA PAREDE DE AAA NO INSTANTE T=0,6 SEGUNDO (AAABB1)

FIGURA 88 - RESULTADO DE TENSÃO DE CISALHAMENTO NA PAREDE DE AAA NO INSTANTE T=0,8 SEGUNDO (AAABB1)

FIGURA 89 - RESULTADO DE TENSÃO DE CISALHAMENTO NA PAREDE DE ENDOPRÓTESE PARA AAA NO INSTANTE T=0,2 SEGUNDO (ENDOPRÓTESE PARA AAABB1) 
FIGURA 91 - RESULTADO DE TENSÃO DE CISALHAMENTO NA PAREDE DE ENDOPRÓTESE PARA AAA NO INSTANTE T=0,6 SEGUNDO (ENDOPRÓTESE PARA AAABB1) …...........................................103

FIGURA 92 - RESULTADO DE TENSÃO DE CISALHAMENTO NA PAREDE DE ENDOPRÓTESE PARA AAA NO

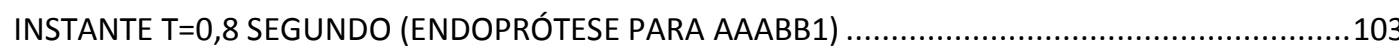

FIGURA 93 - RESULTADO DE TENSÃO DE CISALHAMENTO NA PAREDE DE AAA NO INSTANTE T=0,2 SEGUNDO (AAABB2) 104

FIGURA 94 - RESULTADO DE TENSÃO DE CISALHAMENTO NA PAREDE DE AAA NO INSTANTE T=0,4

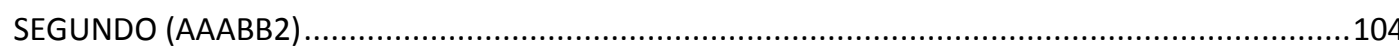

FIGURA 95 - RESULTADO DE TENSÃO DE CISALHAMENTO NA PAREDE DE AAA NO INSTANTE T=0,6 SEGUNDO (AAABB2) 105

FIGURA 96 - RESULTADO DE TENSÃO DE CISALHAMENTO NA PAREDE DE AAA NO INSTANTE T=0,8 SEGUNDO (AAABB2) 105

FIGURA 97 - RESULTADO DE TENSÃO DE CISALHAMENTO NA PAREDE DE ENDOPRÓTESE PARA AAA NO INSTANTE T=0,2 SEGUNDO (ENDOPRÓTESE PARA AAABB2) ….......................................................

FIGURA 98 - RESULTADO DE TENSÃO DE CISALHAMENTO NA PAREDE DE ENDOPRÓTESE PARA AAA NO

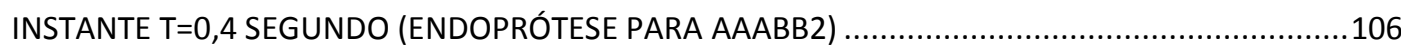

FIGURA 99 - RESULTADO DE TENSÃO DE CISALHAMENTO NA PAREDE DE ENDOPRÓTESE PARA AAA NO INSTANTE T=0,6 SEGUNDO (ENDOPRÓTESE PARA AAABB2) …..................................................107

FIGURA 100 - RESULTADO DE TENSÃO DE CISALHAMENTO NA PAREDE DE ENDOPRÓTESE PARA AAA NO INSTANTE T=0,8 SEGUNDO (ENDOPRÓTESE PARA AAABB2)

FIGURA 101 - COMPARAÇÃO DAS PRESSÕES EM AAA NO INSTANTE T = 0,4 SEGUNDO. RESULTADO DOTRABALHO DE LEGENDRE ACIMA E DESTE TRABALHO ABAIXO (AAA LEGENDRE)....................109

FIGURA 102 - COMPARAÇÃO DAS PRESSÕES EM AAA NO INSTANTE T = 0,8 SEGUNDO. RESULTADO DO TRABALHO DE LEGENDRE ACIMA E DESTE TRABALHO ABAIXO (AAA LEGENDRE) ........................110

FIGURA 103 - COMPARAÇÃO DAS VELOCIDADES EM AAA NO INSTANTE T = 0,2 SEGUNDO. RESULTADO DO TRABALHO DE LEGENDRE ACIMA E DESTE TRABALHO ABAIXO (AAA LEGENDRE).

FIGURA 104 - COMPARAÇÃO DAS VELOCIDADES EM AAA NO INSTANTE T = 0,8 SEGUNDO. RESULTADO DO TRABALHO DE LEGENDRE ACIMA E DESTE TRABALHO ABAIXO (AAA LEGENDRE).

FIGURA 105 - COMPARAÇÃO DAS TENSÕES DE CISALHAMENTO EM AAA NO INSTANTE T $=0,4$ SEGUNDO. RESULTADO DO TRABALHO DE LEGENDRE ACIMA E DESTE TRABALHO ABAIXO (AAA LEGENDRE).

FIGURA 106 - COMPARAÇÃO DAS TENSÕES DE CISALHAMENTO EM AAA NO INSTANTE $T=0,8$ SEGUNDO. RESULTADO DO TRABALHO DE LEGENDRE ACIMA E DESTE TRABALHO ABAIXO (AAA LEGENDRE).

FIGURA 107 - DETALHE DAS LINHAS DE CORRENTE NO AAA NO INSTANTE T = 0,2 SEGUNDO (ANEURISMA LEGENDRE)

FIGURA 108 - DETALHE DAS LINHAS DE CORRENTE NO AAA NO INSTANTE T = 0,4 SEGUNDO (ANEURISMA LEGENDRE)

FIGURA 109 - DETALHE DAS LINHAS DE CORRENTE NO AAA NO INSTANTE T = 0,6 SEGUNDO (ANEURISMA LEGENDRE)

FIGURA 110 - DETALHE DAS LINHAS DE CORRENTE EM ENDOPRÓTESE PARA AAA NO INSTANTE T = 0,6 SEGUNDO (ANEURISMA LEGENDRE). 


\section{Lista de Símbolos}
A - Área transversal
E - módulo de elasticidade
$\varepsilon$ - deformação devido à tensão.
$\mathrm{h}$ - espessura da parede do vaso
$\mathrm{L}$ - Comprimento
$\mathrm{p}$ - pressão transmural

$Q(t)$ - vazão em função do tempo

$\mathrm{R}$ - raio do vaso

$r$ - raio do tubo

$S_{h}$ - tensão na parede

$T_{L}$ - tensão luminal

$\mathrm{t}$ - instante de tempo

$v_{r}-$ velocidade do escoamento no sentido radial

$\mathrm{v}_{\theta}-$ velocidade de rotação do escoamento

$\sigma$ - tensão normal agindo no plano

$\bar{u}$ - velocidade média do escoamento no sentindo longitudinal

$\phi_{f}$ - propriedade da face

$\phi_{u p}$ - propriedade da célula a montante em relação ao escoamento

$\phi_{C 0}$ - valor da propriedade $\phi$ da célula central

$(\nabla \phi)_{u p}$ - valor do gradiente da propriedade $\phi$ no volume de controle que está a montante do escoamento 
$\vec{r}$ - vetor deslocamento que faz conexão do centro do volume a face do volume de controle

$\omega$ - frequência de oscilação

$\rho$ - massa específica do fluido

$\mu$ - a viscosidade dinâmica

$\mathrm{p}_{\mathrm{s}}(\mathrm{x})$ - parcela estática de pressão em função da posição no escoamento

$\mathrm{p}_{\emptyset}(\mathrm{x}, \mathrm{t})$ - parcela pulsátil de pressão em função do local e instante

$p(x, t)$ - pressão pulsátil total em função do local e instante

$\mathrm{u}_{\mathrm{s}}(\mathrm{r})$ - parcela estática da velocidade em função da posição no escoamento

$\mathrm{u}_{\emptyset}(\mathrm{r}, \mathrm{t})$ - parcela pulsátil da velocidade em função do local e instante

$u(r, t)$ - velocidade pulsátil total em função do local e instante

\section{Abreviaturas}

AAA - Aneurisma de Aorta Abdominal

MVF - Método dos Volumes Finitos

DFC - Dinâmica dos Fluidos Computacional 


\section{Introdução}

O transporte do sangue pelo corpo humano é feito por uma rede de vasos com diferentes construções de acordo com suas funções, geometria e localização no corpo. O sangue é bombeado pelo coração com uma frequência cardíaca que varia de 50 a 70 batimentos por minuto, em uma pessoa adulta, saudável e em repouso.

As artérias são os vasos que tem origem no coração, resistem a pressões maiores que os vasos de retorno, as veias, e por este motivo, suas paredes possuem propriedades elásticas que variam de acordo com a região em que a artéria está localizada e com o órgão o qual ela irriga. Esta elasticidade da artéria é necessária para que ela consiga propagar o pulso de pressão que o coração produz, exercendo assim, um fluxo pulsátil de sangue.

O fluxo pulsátil do coração, se dá em pulsos que transmitem de 50 a 70 $\mathrm{ml}$ de sangue em um pulso de pressão que varia de $80 \mathrm{mmHg}$ (pressão diastólica) a $120 \mathrm{mmHg}$ (pressão sistólica) (Despopoulos e Silbernagl, 2003). A diferença entre estas pressões é denominada de pulso de pressão (Guyton e Hall, 2006).

Além da elasticidade que a artéria necessita ter para que haja um fluxo de sangue do coração para toda a rede de vasos e órgãos, a artéria necessita suportar todo um carregamento mecânico devido ao fluxo sanguíneo. Para suportar tal esforço, as paredes arteriais necessitam ter propriedades de resiliência cíclica e resistência à ruptura.

As propriedades elásticas da artéria são devidas à parede arterial, e a rigidez é devida a atividade regulatória de células endoteliais, que se localizam entre a parede arterial e o tecido sanguíneo. Como as artérias devem permanecer intactas durante toda a vida de um individuo, as células arteriais, assim como a maioria das células do corpo humano, devem se regenerar e se remodelar, porém podem haver falhas nessa regeneração, tornando as paredes arteriais mais finas e frágeis, e aumentando o diâmetro arterial. Este processo é multifatorial e degenerativo sendo resultante de fatores biológicos e 
hemodinâmicos. Quando este aumento é permanente e igual ou maior que $50 \%$ do diâmetro original do vaso, podemos caracterizar como um aneurisma.

Aneurisma de aorta é uma doença vascular que afeta mais de $5 \%$ da população masculina com mais de 55 anos de idade no hemisfério leste. (How et al., 2005). Estudos recentes feitos no Brasil indicam que a incidência de aneurismas de aorta varia de $1,8 \%$ a $3 \%$ numa população acima de 50 anos, subindo para $4,3 \%$ a $8 \%$ num subgrupo de homens acima de 60 anos (Orra, 2005). Esta patologia que pode ocorrer na maioria dos vasos sanguíneos é mais comum na aorta abdominal infra-renal, sendo denominado de Aneurisma de Aorta Abdominal (AAA).

O AAA pode superar em $30 \mathrm{~mm}$ o diâmetro original da aorta, alcançando $55 \mathrm{~mm}$ de diâmetro. Deste modo, o risco de ruptura é grande, o que ocasionaria hemorragia e possível óbito.

Todavia, um novo método vem sendo usado desde 1991 (Parodi et al., 1991) para o tratamento do AAA. Diferentemente do método convencional que faz uso de uma cirurgia aberta e agressiva, o novo tratamento é considerado menos invasivo e com menores comorbidades, uma vez que se trata da instalação de uma endoprótese por meio de um cateter.

De acordo com o estudo feito por Mendonça et al. (2005), não existe grande diferença entre a taxa de mortalidade considerando os diferentes métodos de tratamento. As maiores diferenças se dão no tempo de internação na unidade de tratamento intensivo (UTI), no tempo total de internação e no volume de sangue perdido durante a cirurgia. Os valores referentes a essas diferenças de tratamento mostradas pelo estudo de Mendonça et al. para o tratamento aberto e endovascular são, respectivamente: 65,6 horas versus 34,1 horas, 9 dias versus 5,6 dias e $932 \mathrm{ml}$ versus $225 \mathrm{ml}$. Apesar de todas essas vantagens, de acordo com Mendonça et al., o tratamento endovascular é mais caro que o tratamento convencional. De acordo com o mesmo estudo, este custo mais elevado em relação ao tratamento aberto se dá pelo custo da endoprótese e dos materiais adjuvantes utilizados no tratamento endovascular, aproximadamente $77,5 \%$ do custo total. 


\section{Objetivos}

\subsection{Geral}

Este trabalho tem como objetivo geral analisar computacionalmente, com base em volumes finitos, os esforços devidos ao fluxo sanguíneo através de um aneurisma de aorta abdominal real sem e com a instalação de uma endoprótese.

\subsection{Específicos}

- Gerar modelo de AAA virtual, com as características do AAA real.

- Simular por meio de computador, o comportamento do fluxo sanguíneo no interior do AAA.

- Caracterizar geometricamente o AAA, por meio de fatores biomecânicos e geométricos, FBG's.

- Gerar modelo virtual de endopróteses para os aneurismas.

- Simular por meio de computador o comportamento do fluxo sanguíneo no interior da endoprótese (técnica de volumes finitos).

- Caracterizar a funcionalidade da endoprótese.

\section{Revisão Bibliográfica}

O aneurisma é uma patologia que pode acometer qualquer vaso sanguíneo, porém o aparecimento é mais comum em artérias lisas (Waite e Fine, 2007). De acordo com um consenso publicado pela Sociedade de Cirurgia Vascular da América do Norte e pela Sociedade Internacional de Cirurgia Cardiovascular em 1991, a definição de aneurisma é uma dilatação localizada permanente radial na artéria maior que 50\% da dimensão original do diâmetro da artéria ou do diâmetro proximal da mesma. (Vliet e Boll, 1997).

No caso de aneurismas de aorta, $80 \%$ dos casos são aneurismas de aorta abdominal infra-renal (Araújo e Rodrigues, 2003). Trata-se de uma patologia que geralmente é assintomática, com maior incidência em indivíduos do sexo masculino e com idade acima de 65 anos. Como são assintomáticos, 
geralmente são diagnosticados por exames físicos em consultas médicas ou exames de imagens a procura de outras patologias.

De acordo com o estudo feito por Lasheras, 2007, a patogênese do aneurisma arterial compreende um processo multifatorial e predominantemente degenerativo, resultado da interação entre processos biológicos e hemodinâmicos na parede da artéria.

Após o surgimento do aneurisma, os efeitos hemodinâmicos causados pelo fluxo pulsátil sobre a parede fragilizada da aorta tendem a degradar ainda mais a parede do vaso, aumentando a dilatação do aneurisma. Conforme o vaso se dilata, mais fragilizado ele se torna, facilitando uma rotura do mesmo, que acontecerá, quando os esforços hemodinâmicos na parede se tornarem maiores que as tensões de ruptura da parede arterial.

Os aneurismas podem causar diversos problemas para o indivíduo, dentre estes problemas estão a trombose, devido a queda de pressão pontual no escoamento e a embolia arterial. De acordo com Araújo e Rodrigues (2003) podem causar dores se houver erosão vertebral, como podemos ver na Figura 1, e inflamação, além de algumas vezes esta dor ser causada por fissura, expansão rápida ou até mesmo rotura do vaso.

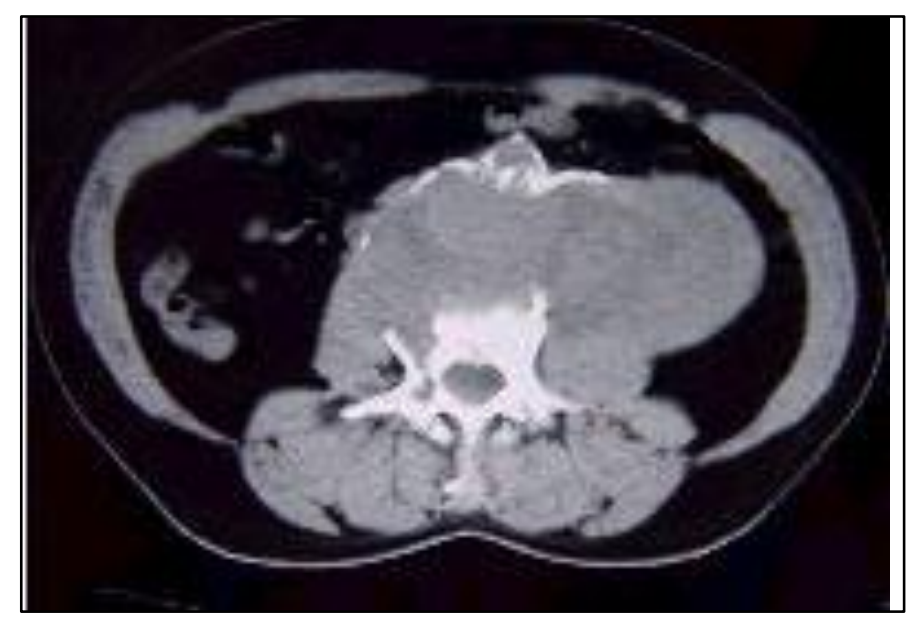

Figura 1 - AAA roto crônico com erosão de vertebra lombar (Baptista-Silva, 2003)

O problema mais grave dos aneurismas de aorta abdominal (AAA) é a ruptura do aneurisma (Baptista-Silva, 2003). De acordo com o estudo de Baptista-Silva, 2003, a ruptura dos aneurismas é a causa da morte de $63 \%$ dos 
pacientes acometidos pela patologia e no caso de AAA infra-renal, a taxa de incidência varia de 30 a 63\% dos pacientes. De acordo com o mesmo estudo, $50 \%$ das mortes com ruptura acontecem antes da chegada aos hospitais e os outros $50 \%$ dos casos que chegam com vida aos hospitais, de 30 a $50 \%$ morrem devido a cirurgias de emergência. A taxa de mortalidade desta patologia é de $80 \%$ dos casos.

É aceito atualmente como melhor preditor ao risco de ruptura o diâmetro do aneurisma ou a taxa de crescimento. Entretanto, de acordo com BaptistaSilva, que faz uso de analogia com a lei de Laplace, há outros sinais que podem gerar rotura do vaso, sendo eles, a espessura de parede e a hipertensão arterial. A lei de Laplace pode ser descrita como:

$$
S_{h}=\frac{R \cdot p}{h}
$$

Sendo, $S_{h}, \mathrm{R}, \mathrm{p}$ e $\mathrm{h}$, respectivamente, a tensão na parede, o raio do vaso, a pressão transmural e a espessura da parede. Pode-se visualizar estas variáveis no esquema a seguir (Figura 2).

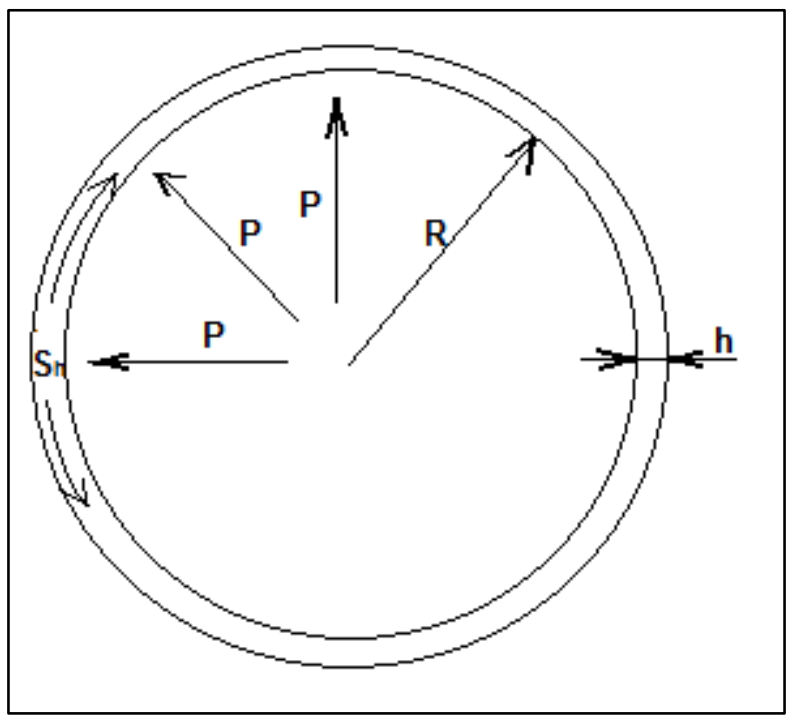

Figura 2 - Representação esquemática para a aplicação da Lei de Laplace

Cronenwett e Katz (1993) citam como principais fatores de risco de ruptura hipertensão arterial, doença pulmonar obstrutiva crônica, diâmetro do aneurisma, tabagismo, sexo masculino, insuficiência renal, histórico familiar, 
doença cardíaca, taxa de crescimento do AAA e relação entre diâmetro do AAA com diâmetro da aorta proximal.

Atualmente, os indicativos para tratamento cirúrgico corretivo de AAA, são diâmetro do aneurisma, que tem de ser maior que $5 \mathrm{~cm}$, ou a taxa de crescimento do aneurisma, que tem de ser maior que $5 \mathrm{~mm} / \mathrm{semestre}$ (BaptistaSilva, 2003). O diâmetro médio de aortas sadias é próximo de $22 \mathrm{~cm}$.

Sabe-se que conforme o diâmetro do aneurisma aumenta, a espessura da parede arterial diminui, diminuindo assim a sua resistência a rotura. Existem muitos estudos a respeito da taxa de crescimento de aneurismas, porém de acordo com Puech-Leão e Kauffman (1998), não é possível afirmar que este sintoma seja um fator preditivo de risco. Pode-se dizer que é intuitivo, e é interessante ao paciente que a taxa de crescimento do aneurisma seja a menor possível, tendendo a zero, retardando assim, uma eventual cirurgia que para muitos pacientes desta patologia teria um risco muito grande, podendo levar ao óbito.

A tensão de escoamento máxima que o tecido endotelial suporta é de $379 \pm 85 \mathrm{dyna} / \mathrm{cm} 2$ (37,9 $\pm 8,5 \mathrm{~Pa}$ ). Expondo o tecido endotelial a esta tensão, ele sofre deterioração num intervalo menor que 1 hora (Fry, 1968). Por outro lado, o estudo de Caro et al. (1971) diz que a distribuição normalmente observada de estrias gordurosas e placas de gorduras iniciais são coincidentes com uma taxa de cisalhamento baixa nas paredes dos vasos, por este motivo, pode haver surgimento de aterosclerose nesta região, pois existirá um tempo de contato entre o vaso e a substância lipídica maior que o normal.

De acordo com Chiu e Chien (2011), pode-se verificar que existem regiões de recirculação de sangue dentro do aneurisma. Esta recirculação em baixas velocidades é ideal para a formação de coágulos (Malek et al., 1999) que podem se fixar na parede do vaso, formando uma barreira para a sua nutrição local.

Algumas doenças podem fragilizar as artérias, ajudando na formação de aneurismas. A aterosclerose é uma destas doenças, pois enrijece as paredes arteriais e como consequência da perda de elasticidade faz com que a artéria 
perca a capacidade de se remodelar. Exemplificando o mecanismo de enrijecimento do vaso por estas placas, pode-se dizer que a placa se deposita sobre o endotélio do vaso, criando uma superfície rígida (de acordo com as características da placa), tornando-o rígido e portanto diminuindo sua capacidade de se automodelar.

As células endoteliais são as células que constituem a fatia mais interna da artéria e por este motivo, estas células sofrem as consequências diretas das variações das tensões de cisalhamento hemodinâmico e da pressão arterial. A tensão de cisalhamento e a pressão na parede da artéria são variáveis de extrema importância na análise que será feita neste trabalho.

De acordo com o trabalho de Malek et al. (1999), existem faixas de valores de tensões de cisalhamento que podem gerar danos às células endoteliais (figura 3). Nesta figura, observa-se que os valores normais para as tensões de cisalhamento estão na faixa de 1 a $7 \mathrm{~Pa}$. Com tensões baixas, na faixa de -0,4 a 0,4 $\mathrm{Pa}$, há propensão ao surgimento de placas de ateromas, causadoras de aterosclerose. Com faixas de tensões acima de $7 \mathrm{~Pa}$, há também a propensão ao surgimento de trombos, porém com tensões de cisalhamento acima de $35 \mathrm{~Pa}$ pode surgir o problema de degradação do endotélio por desgaste mecânico (Ortiz et al., 2007). 


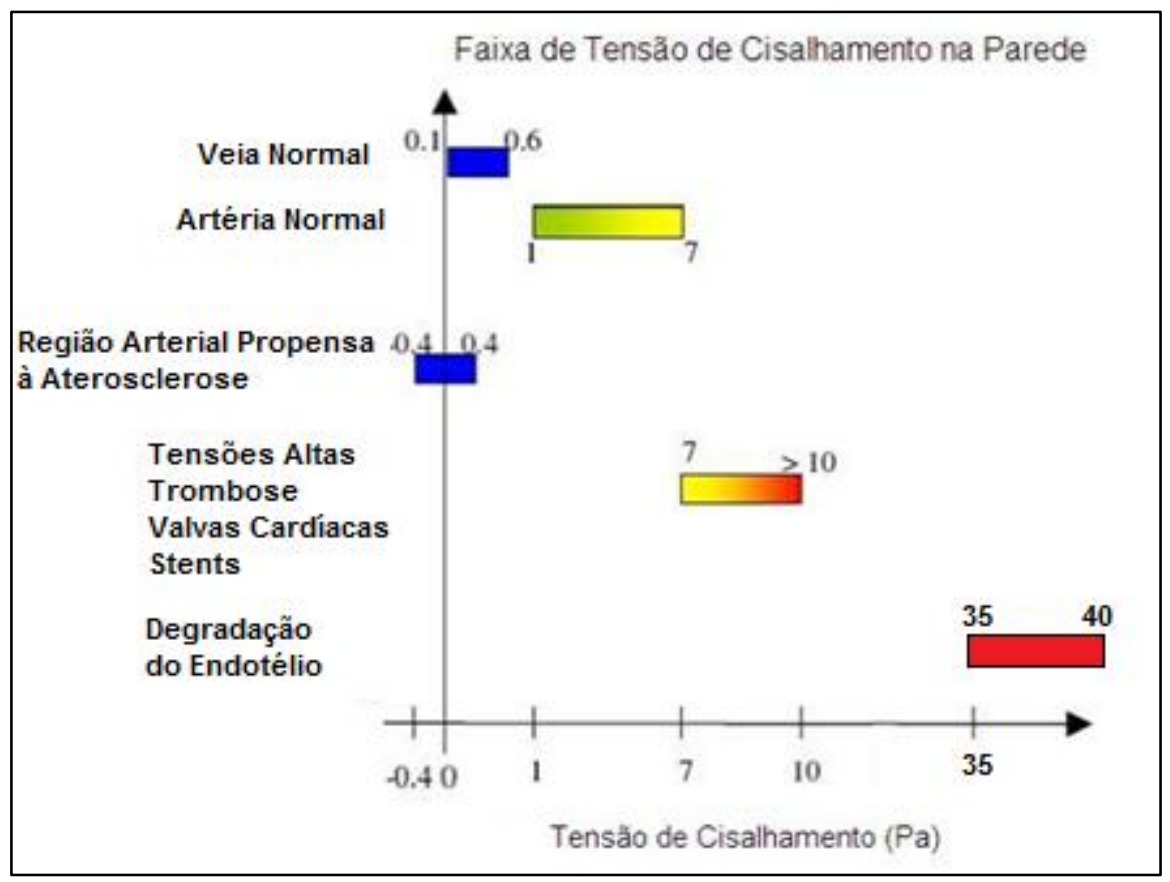

Figura 3 - Tensões de Cisalhamento na Parede dos vasos sanguíneos e algumas patologias (Malek et al., 1999)

De acordo com o estudo feito por Ortiz et al. (2007), nas regiões da artéria onde há maior complexidade geométrica, como bifurcações e tortuosidades, e que estão sujeitas a diminuição da velocidade e recirculação sanguínea, pode-se promover a geração de placas de ateroma, em consequência das baixas tensões de cisalhamento.

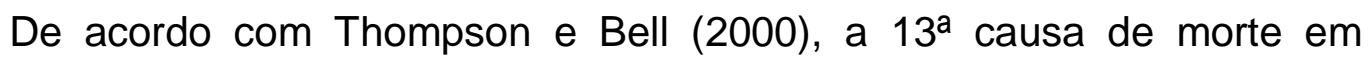
países ocidentais é a ruptura de AAAs.

Numa revisão de 75 AAA's que não sofreram tratamento cirúrgico, dos doentes que vieram a óbito por ruptura, $75 \%$ tinham hipertensão diastólica (Foster et al., 1969).

Os tratamentos para este tipo de patologia são tratamentos cirúrgicos, sendo um deles a cirurgia aberta, que necessita de clampeamento da artéria aorta e é um procedimento extremamente invasivo, e o tratamento endovascular relativamente menos invasivo. O tratamento endovascular começou a seu usado a partir de 1991, desenvolvido por Parodi (Parodi et al., 1991), em que passou-se a instalar no interior do vaso uma endoprótese, por 
meio de um cateter, que protege o endotélio das forças hemodinâmicas, impedindo assim que o vaso se rompa.

Muitos estudos têm sido feitos na área da fluidodinâmica em aneurismas porém, em muitos desses estudos, foram utilizados, de acordo com Yu et al., 1999 e Wang et al, 2002, geometrias idealizadas de aneurismas. Alguns estudos, porém tem utilizado modelos com geometrias reais originários de imagens bidimensionais de exames de tomografias computadorizadas voltados ao cálculo dos esforços na parede do aneurisma com o intuito de avaliar a resistência do vaso (Yu et al., 1999, Wang et al., 2002).

\subsection{Constituição do Vaso Sanguíneo}

Os vasos sanguíneos possuem diversas constituições, cada uma com suas particularidades. As artérias são os vasos sanguíneos que suportam grandes pressões transportando o sangue do coração para as artérias menores, para as arteríolas e por fim para os capilares. Já as veias, fazem o caminho inverso, trazendo o sangue dos capilares até o coração, sendo o percurso de menor pressão em todo o sistema vascular do corpo humano.

Artérias, capilares e veias possuem diferentes estruturas por serem especializados em diferentes funções, sendo elas respectivamente troca, capacitância e perfusão, porém, todas possuem a camada interna com o mesmo tipo de célula, as células endoteliais (Waite e Fine, 2007).

Como neste trabalho iremos analisar os aneurismas de aorta abdominal, mais precisamente infra-renal, será descrito a seguir mais detalhadamente apenas a constituição das artérias, enfatizando a constituição da aorta. As artérias são divididas em três tipos de acordo com seu tamanho e estrutura, sendo que a aorta se encaixa na classificação das artérias elásticas, que são artérias de maior diâmetro e que possuem maior número de fibras elásticas (Waite e Fine, 2007).

De acordo com Waite e Fine (2007), as três camadas que formam as artérias são a túnica intima, que é a camada elástica mais interna do vaso, a túnica média, que é a camada elástica mediana, e a túnica externa que é a camada elástica mais externa da artéria. O lúmen é o interior da artéria, onde o 
sangue flui, e é nesta camada que se encontram as células endoteliais. Observando de maneira fisiológica, pode-se pensar em como todas essas camadas são irrigadas e alimentadas, pois há sangue correndo apenas no interior da artéria. Procurando uma resposta para tal dúvida, encontram-se pequenos vasos sanguíneos que irrigam as artérias. Estes vasos são chamados de "vasa vasorum". Na figura 4, pode-se observar todas estas estruturas constituintes das artérias.

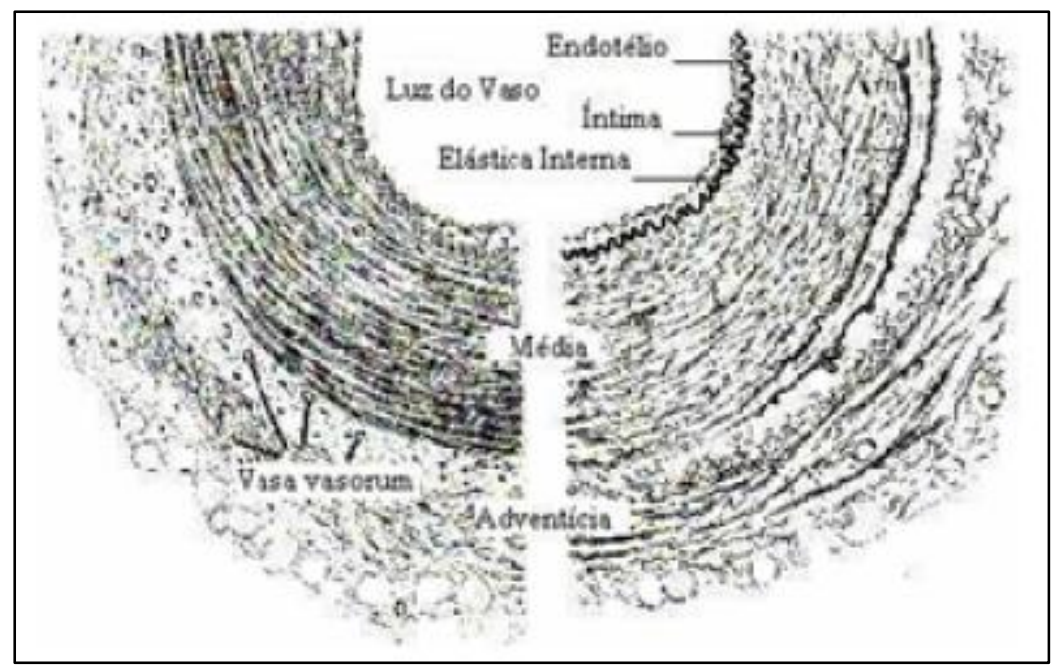

Figura 4 - Constituintes dos Vasos Sanguíneos (Legendre, 2009)

Em artérias grandes, como por exemplo a aorta, a túnica intima é formada por duas subcamadas, uma delas unicamente formada por células endoteliais vasculares orientadas no sentido do fluxo sanguíneo a fim de facilitar o escoamento e outra subendotelial de tecido conjuntivo formada por glicoproteínas, colágeno e elastina. Conforme o individuo envelhece, esta subcamada aumenta de tamanho pelo acumulo de deposição de tecido conjuntivo, placas de colesterol, sais de cálcio podendo ser alterada também devido a alguma patologia. A túnica intima, é envolvida por uma rede de fibras elásticas, gerando assim um limite para o crescimento da espessura.

A túnica média, também conhecida como muscular, é constituída primariamente por células musculares lisas (Waite e Fine, 2007), e de acordo com Legendre (2009), ela também é formada por fibras de elastina e colágeno. Como esta camada possui células musculares em sua constituição, ela proporciona resistência a parede arterial, tendo predominância ao seu 
comportamento mecânico. A quantidade de material elástico nas artérias é grande, possibilitando assim, que elas se remodelem mantendo a pressão arterial durante a diástole, onde a pressão é menor. Conforme a idade do paciente avança, as substâncias elásticas se deterioram, diminuindo a elasticidade do vaso (Legendre, 2009). Vasoconstrição é o nome dado a diminuição de volume causada pela contração das células musculares do vaso. Quando há relaxação destes músculos, o vaso se dilata devido à pressão arterial e é dado o nome de vasodilatação (Waite e Fine, 2007). Esses fenômenos são artifícios que o corpo usa muitas vezes para controlar a pressão, temperatura corpórea e fornecer nutrientes por exemplo.

A túnica externa, também conhecida como adventícia, é formada por fibras elásticas passivas e colágeno. As fibras de elastina são encontradas mais internamente à túnica externa, formando a membrana elástica externa. Os "vasa vasorum" são encontrados na túnica adventícia, e sua função é nutrir a parede vascular e tecidos nervosos que enervam as fibras musculares da túnica média (Legendre, 2009).

As células endoteliais vasculares formam uma barreira semipermeável não deixando que algumas substâncias do sangue penetrem na parede arterial. Estas células endoteliais são frágeis sob a ação de tensões de cisalhamento elevadas, como podemos verificar na Figura 3 (Malek et al., 1999).

\subsection{Aneurismas de Aorta}

Tomando como referência a definição de aneurisma e como base um diâmetro de artéria aorta infra-renal com aproximadamente $2 \mathrm{~cm}$ de um individuo adulto saudável, uma dilatação no diâmetro de apenas $1 \mathrm{~cm}$, já se diagnosticaria como um aneurisma de aorta abdominal (AAA). Existem basicamente dois tipos de aneurismas: os verdadeiros, que se subdividem em fusiformes, que acometem geralmente a aorta abdominal e a artéria poplítea, e os saculares que acometem geralmente as artérias cerebrais. Existem também os falsos aneurismas, que são hematomas pulsáteis que surgem devido a um extravasamento de sangue por um furo nas camadas internas da parede arterial (íntima e média) que é contido pelos tecidos adjacentes (adventícia) 
(Baptista-Silva, 2003). Na figura 5, pode-se verificar exemplos dos tipos de aneurismas acima descritos.

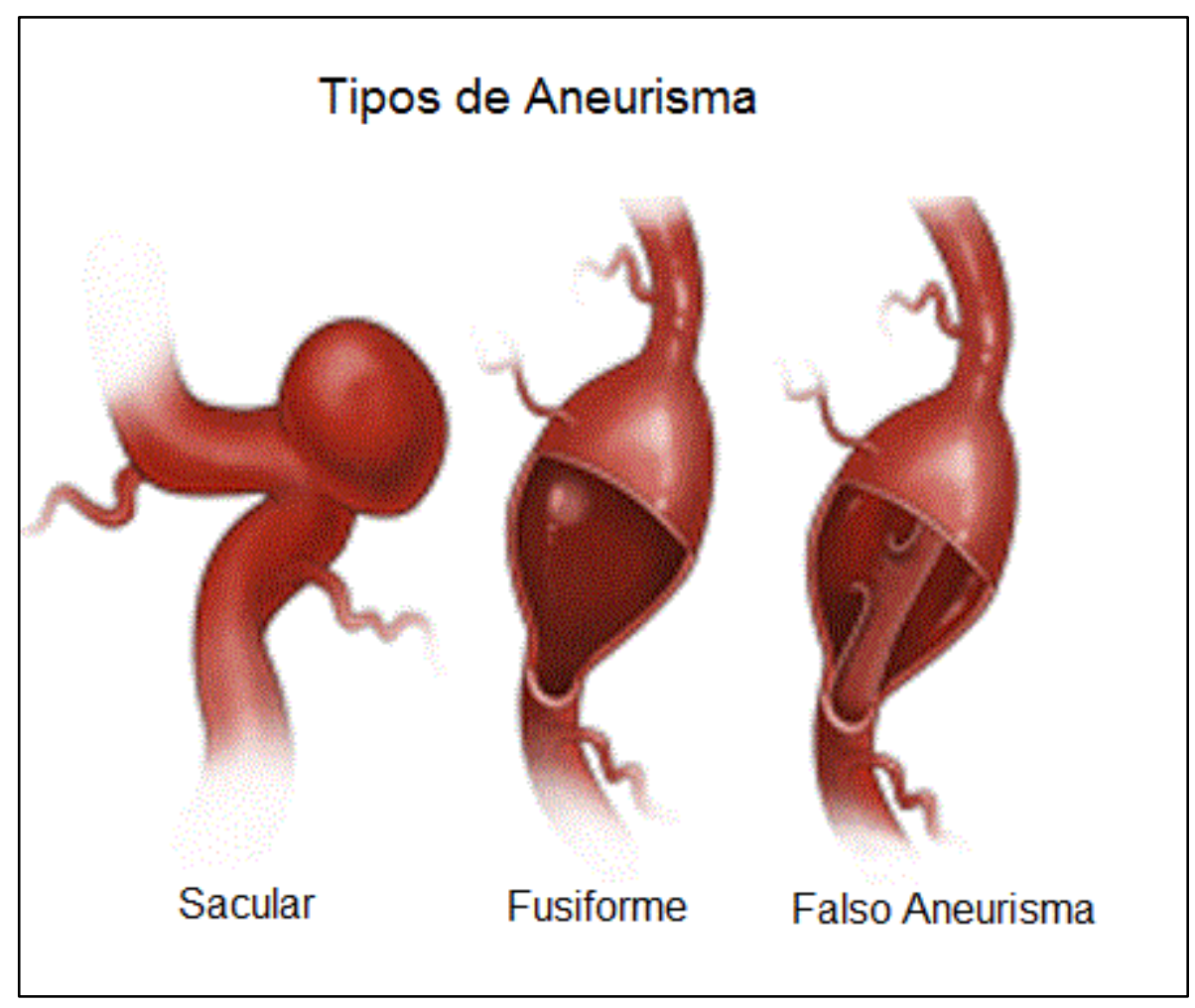

Figura 5 - Tipos de Aneurismas (www.browardhealth.org)

\subsubsection{Aneurismas de Aorta Abdominal}

Os aneurismas de aorta abdominal acometem cerca de $5 \%$ da população mundial ocidental (How et at, 2005), e $80 \%$ dos casos de aneurisma de aorta abdominal estão localizados abaixo das artérias renais (Baptista-Silva, 2003 e Araújo e Rodrigues, 2003).

Em 1935 estudos na Santa Casa de Misericórdia de São Paulo descreveram que aneurismas de aorta abdominal eram muito raros, acometendo aproximadamente $0,04 \%$ dos pacientes (Baptista-Silva, 2011). Este baixo número de casos, ocorria devido à falta de exames precisos nos pacientes. De acordo com o mesmo autor, existem estudos que mostram que nos Estados Unidos, $6 \%$ da população com mais de 65 anos de idade possuem este tipo de aneurisma. Outro estudo abordou pacientes com mais de 80 anos, e o índice subiu para 10\%. Este fato se explica pelo aumento significativo da expectativa de vida da população mundial. Outros fatores para o aumento da 
quantidade de casos de AAA é a melhoria dos métodos de diagnósticos e o conhecimento em relação a esta patologia pelos médicos (Legendre, 2009).

Num estudo revendo 24000 necrópsias, foi verificado que a incidência de morte por ruptura em AAA com aneurismas com diâmetros menores de 4 $\mathrm{cm}$ foi de $9,5 \%$, entre 4 e $7 \mathrm{~cm}$ de diâmetro foi $25 \%$, entre 7 a $10 \mathrm{~cm}$ foi de $45,6 \%$ e para aneurismas com mais de $10 \mathrm{~cm}$ de diâmetro uma probabilidade de $60,5 \%$ (Baptista-Silva, 2011). Por este motivo, o entendimento da patologia e a pesquisa para outros métodos de diagnósticos é tão importante no caso de aneurismas. Existem estudos que dizem que a mortalidade geral devido a ruptura de AAA é maior que $80 \%$.

\subsubsection{Histofisiopatologia}

A base estrutural da túnica média é formada por colágeno, elastina e fibras musculares, que são arranjadas de maneira concêntrica, que suportam os esforços hemodinâmicos na parede do vaso (Vliet e Boll, 1997).

O colágeno que é constituinte da parede arterial, não possui grande capacidade de se deformar, porém resiste a uma grande tensão, com suas fibras espiraladas, contêm o aumento de diâmetro. Já as fibras de elastina são elásticas, deixando com que o vaso se dilate. Quando esta malha é destruída de algum modo, o aneurisma começa a se formar, dilatando a artéria.

Esta destruição da malha se dá pela degradação da elastina, que conforme o envelhecimento avança, ocorrem alteração do espaçamento, calcificação e fragmentação das fibras de elastina, que não é sintetizada na aorta. As fibras de elastina tem uma vida média de 70 anos (Vliet e Boll, 1997).

A musculatura lisa, que se encontra nos vasos, ajuda a impulsionar o sangue, com movimentos peristálticos controlados pelo sistema nervoso autônomo. Estas células podem reagir também a estímulos de células vizinhas ou de hormônios (Legendre, 2009) como, por exemplo, a adrenalina que causa vasoconstrição.

A destruição da elastina e do colágeno desarranja a estrutura da malha até então segura, passando a gerar pontos de menor resistência ao fluxo 
pulsátil do coração, permitindo que nesses pontos se inicie uma dilatação. Uma vez dilatada a artéria, essa nova geometria começa a interferir na evolução do aneurisma. O aparecimento de um processo crônico de distensão da parede arterial, faz com que ela sofra uma lesão lamelar e deformação estrutural da camada media, havendo assim lesão progressiva que enfraquece a parede da artéria (Puech-Leão e Kaufmann, 1998).

Analisando biomecanicamente o caso de ruptura de um AAA, dar-se-á ênfase à tensão sobre a parede arterial como um fator que leva a rotura da mesma. O fator tido como premissa básica para a rotura de qualquer aneurisma é o aumento de tensão na parede do vaso alcançando valores superiores a tensão de ruptura da parede arterial. A lei de Laplace, equação 1, estabelece esta relação entre tensão circunferencial e pressão do escoamento sanguíneo dentro do limite elástico do vaso. Pode-se verificar que o aumento de pressão gera um aumento proporcional na tensão na parede.

No entanto, sabe-se que a distribuição de tensões no aneurisma não está de acordo com as aproximações de Laplace, onde as tensões são estimadas numa parede fina de cilindros, diferentemente de aneurismas que possuem geometrias complexas (Choke et al., 2005). Entretanto, para se entender o comportamento do mecanismo de falha, pode-se partir da lei de Laplace:

$$
\begin{aligned}
& S_{h}=R \cdot \frac{P}{h} \\
& T_{L}=R \cdot P
\end{aligned}
$$

Pode-se verificar que a tensão não varia linearmente com a pressão, mesmo que consideremos as propriedades elásticas da artéria, de acordo com a Lei de Hooke, portanto a relação pressão-volume não se linearizará. Considerando que um pequeno aumento da pressão gere um pequeno aumento de tensão, a equação 2 pode ser reescrita:

$$
\begin{aligned}
& \left(T_{L}+\delta T_{L}\right)=(R+\delta R) \cdot(P+\delta P) \\
& \left(T_{L}+\delta T_{L}\right)=R P+R \delta P+P \delta R+\delta R \delta P
\end{aligned}
$$


Supondo que as variações de pressão e do raio são muito pequenas, desconsideraremos a ultima parcela da equação 4, e então temos:

$$
\left(T_{L}+\delta T_{L}\right)=R P+R \delta P+P \delta R
$$

E de acordo com a Lei de Laplace, temos a dimensão da tensão:

$$
\delta T_{L}=R \delta P+P \delta R
$$

Como a tensão é circunferencial e a deformação da artéria também, a deformação do comprimento circunferencial da parede é dada por $\left(\frac{2 \pi \delta R}{2 \pi R}\right)$, podese utilizar adaptando a equação do módulo de elasticidade de Young (equação 7) para a equação 6 , em que tem-se:

$$
\sigma=E \varepsilon
$$

Em que $\sigma$ é a tensão normal agindo no plano, E é o módulo de elasticidade de Young e $\varepsilon$ é a deformação devido à tensão.

$$
\begin{aligned}
& \delta T_{L}=E A \frac{2 \pi \delta R}{2 \pi R} \\
& \delta T_{L}=E A \frac{\delta R}{R}
\end{aligned}
$$

Para simplificar a expressão acima, consideremos um vaso de comprimento total $\mathrm{L}$, que permanecerá constante, isotrópico, e com isso, temos a área transversal da parede do tubo, que é a área resistiva a tensão, como:

$$
A=h L
$$

Substituindo a equação 10 na equação 9, temos:

$$
\delta T_{L}=E h L \frac{\delta R}{R}
$$

Podemos substituir ainda a equação 11 na equação 6 e rearranjando os termos tem-se que:

$$
\begin{aligned}
& E h L \frac{\delta R}{R}=R \delta P+P \delta R \\
& E h L \frac{\delta R}{R}-P \delta R=R \delta P \\
& \left(\frac{E h L}{R}-P\right) \delta R=R \delta P
\end{aligned}
$$




$$
\frac{\delta R}{\delta P}=\frac{R}{\frac{E h L}{R}-P}
$$

De acordo com a equação 13, quando a pressão se tornar igual ao valor de (EhL/R), a variação do raio com a variação da pressão tenderá ao infinito, o que fisicamente, corresponde ao rompimento do vaso sanguíneo. De acordo com a literatura, o coeficiente de elasticidade aumenta de acordo com o aumento do diâmetro permitindo que artérias e veias consigam trabalhar em diversas pressões diferentes sem entrarem em colapso (Legendre, 2009).

A ruptura do aneurisma se dá onde a espessura de parede arterial for menor, porém a medição da espessura de parede aórtica é muito difícil de ser feita. De acordo com Legendre (2009), existem dados que indicam que a formação do AAA resulta na diminuição da parede arterial, sendo assim, o ponto provável de rotura do aneurisma será o local de maior diâmetro. Muitos estudos feitos indicam que um crescimento rápido do aneurisma, $>5 \mathrm{~mm} / \mathrm{ano}$, é um fator de risco para rotura de aneurisma e de acordo com Araújo e Rodrigues (2003) o crescimento normal de um aneurisma é de $3 \mathrm{~mm} / \mathrm{ano}$. De acordo com Puech-Leão e Kaufmann (1998), não se pode confirmar que a taxa de crescimento do aneurisma é um fator preditivo para a ruptura do AAA.

Enquanto os métodos numéricos aplicando técnicas de volumes $\mathrm{e}$ elementos finitos levam em consideração o fator de forma, a Lei de Laplace, não o considera. Estudos com modelos de aneurismas fusiformes e axisimétricos reais e análises de elementos finitos descobriram que a máxima tensão era preferencialmente uma função de forma das paredes dos AAA's do que do próprio diâmetro do aneurisma (Choke et al., 2005). O estudo de Raghavan et al. (2000) analisa o assunto utilizando o método dos elementos finitos para estimar os esforços na parede de AAA's reais, obtidos por imagens de tomografias computadorizadas. Este estudo demonstra que as tensões na parede arterial são distribuídas complexamente, possuindo grande variação pontual. Adotando a hipótese de que a resistência da parede é constante ao longo de toda a artéria, fica claro que o ponto de rotura do vaso seria o ponto onde possui maior tensão. 
Alguns estudos dizem que um trombo intraluminal no vaso pode causar diminuição da tensão do vaso, por outro lado, alguns pesquisadores dizem que um trombo aumenta a expansão do aneurisma, aumentando assim, o risco de ruptura. Outros estudos não consideram que a espessura da parede dos vasos é constante e desconsideram a presença de trombos intraluminais. De acordo com Legendre (2009), há presença de trombo intraluminal em aproximadamente $75 \%$ dos casos de aneurisma de aorta abdominal.

Muitos estudos consideram o fator de forma, com geometrias complexas, porém não levam em consideração o fato de que as propriedades elásticas no aneurisma são localizadas, podendo variar em um mesmo paciente. Vallabhaneni et al. (apud Choke et al., 2005) mediram as propriedades elásticas de paredes de aneurismas e tecidos moles, confirmando em seus estudos que as propriedades elásticas da parede do aneurisma apresentam grandes diferenças em um mesmo paciente ou em pacientes diferentes. Isto demonstra que muitos estudos que apresentam análises de elementos finitos considerando as propriedades da parede aneurismática como sendo homogêneas, partem de uma hipótese incorreta. Alguns estudos demonstram também, que vasos sadios possuem propriedades anisotrópicas, e assim, podemos concluir que os aneurismas não perdem tal propriedade.

\subsection{Fatores de Risco}

Nesta seção, abordaremos alguns dos fatores de risco que aumentam a chance de uma pessoa ter um aneurisma de aorta abdominal. Atualmente há um consenso sobre os possíveis fatores de risco para o aparecimento desta patologia, sendo uma interação entre alguns problemas biológicos causados por idade avançada, infecção ou doença que pode evoluir concomitantemente, alguns fatores hemodinâmicos, e problemas estruturais causados por degeneração das propriedades da parede arterial.

\subsubsection{Idade Avançada}

O envelhecimento dos indivíduos traz consigo alguns problemas para as artérias, pois com o envelhecimento arterial, e a não síntese de elastina na artéria, esta perde suas propriedades elásticas com o tempo. Até mesmo 
quando não há dilatação das artérias, são encontrados espessamentos, calcificação e fragmentação das fibras de elastina (Orra, 2005). Se levarmos em consideração a dinâmica de fatores hemodinâmicos em contato direto com esta estrutura fragilizada, verificamos que o risco de surgimento de um aneurisma é grande. Toda esta degeneração da parede arterial se dá na túnica media, onde podem ser encontradas as fibras de elastina e de colágeno. Como não há síntese de elastina na artéria, diferentemente do colágeno, a estrutura passa a ter muito mais colágeno que elastina, o que faz com que a rigidez arterial eleve-se. Esse enrijecimento provoca um aumento da velocidade da onda do pulso, alterando o perfil do pulso e a magnitude da pressão (Legendre, 2009). De acordo com o mesmo estudo, existe uma hipótese sobre o mecanismo de degeneração arterial ligado ao envelhecimento que é baseada na falha por fadiga de componentes por carregamentos cíclicos.

\subsubsection{Hemodinâmica}

Este fator vem sendo associado à formação e evolução dos aneurismas de aorta. Sabe-se que em humanos, a quantidade de "vasa-vasorum" é menor no trecho abdominal da aorta em relação à porção torácica. Por este motivo, acredita-se que aconteça menor suplementação na parte abdominal, adiantando a degradação das fibras de elastina. Além deste fator de degradação, o segmento torácico da aorta possui maior quantidade de elastina, sendo assim mais elástico e resistindo por uma maior vida útil.

A seção abdominal da aorta por possuir geometria extremamente mais complexa que a região torácica, está exposta a regiões de carregamentos hemodinâmicos de diferentes tipos e grandezas. Regiões como a bifurcação da aorta para as artérias ilíacas são sujeitas a padrões de fluxo sanguíneos particulares, que resultam em reflexão de ondas de pressão e padrões turbulentos do escoamento (Ortiz et al., 2007). Estas regiões turbulentas expõem as paredes da aorta à regiões de baixa e alta tensões de cisalhamento, e esta variação é conhecida como fator principal para a formação de placas de ateroma (Fry, 1968).

Outro fator de forma que temos que levar em consideração é o formato cônico do vaso, causando também aumento de pressão e que por possuir 
menor quantidade de fibras elásticas na parede, tem menor elasticidade. $\mathrm{Na}$ bifurcação, existe uma reflexão das ondas de pressão, que é dependente da secção das áreas das artérias aorta e ilíacas, sendo a relação ideal a de 1,5:1 que acontece quando o individuo é apenas uma criança (Puech-Leão e Kaufmann, 1998). Esta relação, conforme a idade avança, se reduz para 1,5:0,75 aos 50 anos de idade. Esta relação leva em consideração as áreas das duas ilíacas somadas em relação ao diâmetro da aorta imediatamente anterior a bifurcação. Este efeito de diminuição da relação determina uma relação aumento de pulso, facilitando a expansão aneurismática. Placas de ateroma são fatores que ajudam a diminuição desta relação, o que podemos concluir que as placas de ateroma são facilitadoras para o crescimento do aneurisma.

As regiões já expandidas da artéria geram uma região de turbulência, que com variações de tensões de cisalhamento, causam a formação de trombos luminais. Estes trombos são coágulos sanguíneos que se instalam na parede da artéria e restringem a passagem de sangue. Como a vazão sanguínea tende a ser constante, este estrangulamento na luz do vaso aumenta a velocidade do pulso de pressão sistólica na parede do vaso, aumentando assim a tensão de cisalhamento. Todos estes fatores podem aumentar se o paciente fumar, for hipertenso, sedentário, tiver uma dieta favorável à patologia, entre outros fatores ambientais (Puech-Leão e Kaufmann, 1998).

A hipertensão pode ser encarada como um fator agravante, pois pode provocar o aumento da velocidade do pulso, o que aumentaria a tensão de cisalhamento, a degradação da parede arterial, o enrijecimento e assim, o envelhecimento da artéria (Legendre, 2009).

Internamente às artérias, acontecem vaso dilatações e constrições dependendo do instante em que o pulso está acontecendo. Dentro de um aneurisma, o fluxo sanguíneo "enxerga" uma vaso dilatação na sua trajetória normal. Analisando matematicamente este fenômeno para se entender o escoamento, começaremos inserindo a equação da continuidade do escoamento: 


$$
\bar{u} A=Q(t)
$$

Em que $\mathrm{A}$ é a área transversal do vaso, $\bar{u}$ é a velocidade média do escoamento e $Q(t)$ é a vazão em função do tempo. Para facilitar o entendimento do comportamento das pressões internamente ao aneurisma, se fará uso da equação de Euler (equação 15) para um fluido não viscoso e escoamento apenas na direção longitudinal.

$$
\begin{aligned}
& \rho\left(\frac{\partial \mathrm{u}}{\partial \mathrm{t}}+u \frac{\partial u}{\partial x}\right)=-\frac{\partial \mathrm{p}}{\partial \mathrm{x}} \\
& \frac{\partial \mathrm{u}}{\partial \mathrm{t}}+u \frac{\partial u}{\partial x}=-\frac{1}{\rho} \frac{\partial \mathrm{p}}{\partial \mathrm{x}} \\
& \frac{\partial \mathrm{u}}{\partial \mathrm{t}}=-\mathrm{u} \frac{\partial \mathrm{u}}{\partial \mathrm{x}}-\frac{1}{\rho} \frac{\partial \mathrm{p}}{\partial \mathrm{x}}
\end{aligned}
$$

Substituindo a equação 14 na equação 16 , tem-se:

$$
\frac{1}{A} \frac{\partial \mathrm{Q}}{\partial \mathrm{t}}=\frac{Q}{A} \frac{\partial\left(\frac{Q}{A}\right)}{\partial x}-\frac{1}{\rho} \frac{\partial \mathrm{p}}{\partial \mathrm{x}}
$$

Rearranjando a equação, tem-se:

$$
\frac{\partial \mathrm{p}}{\partial \mathrm{x}}=\rho \frac{\mathrm{Q}^{2}}{\mathrm{~A}^{3}} \frac{\partial \mathrm{A}}{\partial \mathrm{x}}-\frac{\rho}{\mathrm{A}} \frac{\partial \mathrm{Q}}{\partial \mathrm{t}}
$$

Analisando a equação 18 , pode-se verificar que há um gradiente negativo de pressão com o aumento da vazão e com uma área convergente, como é o caso de uma artéria sadia. Por outro lado, pode-se verificar que quando a área é divergente (entrada do aneurisma) e um gradiente de vazão negativo (final do pulso de pressão) o gradiente de pressão se torna adverso e isso faz com que possa surgir um fluxo em duas frentes, o que acontece num aneurisma real.

\subsubsection{Fluxo Pulsátil}

O escoamento sanguíneo em grandes vasos é um típico exemplo de escoamento pulsátil. As artérias transportam sangue pelo corpo dos seres vivos devido ao fluxo pulsátil que é gerado pelo coração. Para se estudar 0 fluxo pulsátil do sangue, deve-se possuir alguns dados, como o pulso de pressão, a geometria por onde o fluido escoa e algumas propriedades do fluido. 
De acordo com Waite e Fine, 2007, dois métodos são usados para o cálculo das características do fluxo pulsátil dentro de vasos sanguíneos. O método que mais se identifica com os grandes vasos sanguíneos, como a artéria aorta, é o método de Womersley. Neste método, algumas hipóteses simplicadoras devem ser adotadas para que se chegue nos resultados. Dentre estas hipóteses estão a de fluido Newtoniano, fluxo desenvolvido, uniforme, laminar, com simetria axial, e será adotado também que a artéria é um tubo com parede rígida.

O número de Womersley é um numero adimensional que relaciona forças transientes e viscosas e é dado por:

$$
\propto=r \sqrt{\frac{\omega \rho}{\mu}}=r \sqrt{\frac{\omega}{\vartheta}}
$$

Onde $\omega \rho$ corresponde às forças inerciais, e $\mu$ corresponde às forças viscosas. É necessário lembrar que os símbolos não são as forças, eles apenas correspondem a elas. Os símbolos na equação do número de Womersley tem o seguinte significado: $r$ é o raio do tubo, $\omega$ é frequência de oscilação, $\rho$ é a massa específica do fluido e $\mu$ é a viscosidade dinâmica.

Como grande parte das análises de dinâmica de fluidos, a equação de Navier-Stokes é usada no equacionamento do fenômeno pulsátil, e normalmente é subdividida nas três direções ortogonais para facilitar o desenvolvimento. Abaixo tem-se a equação de Navier-Stokes na direção longitudinal ao escoamento:

$$
\rho \frac{\partial \mathrm{u}}{\partial \mathrm{t}}+\rho\left(\mathrm{u} \frac{\partial \mathrm{u}}{\partial \mathrm{x}}+\mathrm{v}_{\mathrm{r}} \frac{\partial \mathrm{u}}{\partial \mathrm{r}}+\frac{\mathrm{v}_{\theta}}{\mathrm{r}} \frac{\partial \mathrm{u}}{\partial \theta}\right)=\rho \mathrm{g}_{\mathrm{x}}-\frac{\partial \mathrm{P}}{\partial \mathrm{x}}+\mu\left(\frac{\partial^{2} \mathrm{u}}{\partial \mathrm{x}^{2}}+\frac{\partial^{2} \mathrm{u}}{\partial \mathrm{r}^{2}}+\frac{1}{\mathrm{r}} \frac{\partial \mathrm{u}}{\partial \mathrm{r}}+\frac{1}{\mathrm{r}^{2}} \frac{\partial^{2} \mathrm{u}}{\partial \theta^{2}}\right)(20)
$$

Todo fluxo pulsátil, possui uma parcela de regime permanente (escoamento de Poiseuille) e uma parcela oscilatória (Bessa, 2008). Identificando tais parcelas podemos descrever a pressão e a velocidade como sendo:

$$
\begin{aligned}
& p(x, t)=p_{s}(x)+p_{\varnothing}(x, t) \\
& u(r, t)=u_{s}(r)+u_{\varnothing}(r, t)
\end{aligned}
$$


Simplificando a equação 20 , de acordo com as hipóteses sugeridas anteriormente e adotando que o escoamento é desenvolvido, a equação se dá por:

$$
\rho \frac{\partial u}{\partial t}+\frac{\partial P}{\partial x}=\mu\left(\frac{\partial^{2} u}{\partial r^{2}}+\frac{1}{r} \frac{\partial u}{\partial r}\right)
$$

Substituindo as equações 21 e 22 na equação 23 , tem-se:

$$
\left[\frac{\partial p_{s}}{\partial x}-\mu\left(\frac{\partial^{2} u_{s}}{\partial r^{2}}+\frac{1}{r} \frac{\partial u_{s}}{\partial r}\right)\right]+\left[\rho \frac{\partial \mathrm{u}_{\emptyset}}{\partial t}+\frac{\partial \mathrm{p}_{\emptyset}}{\partial x}+\mu\left(\frac{\partial^{2} u_{\emptyset}}{\partial r^{2}}+\frac{1}{r} \frac{\partial u_{\emptyset}}{\partial r}\right)\right]=0
$$

A equação 24 é a equação que rege o escoamento pulsátil, levando em consideração todas as hipóteses simplicadoras anteriormente citadas.

Para a simulação numérica, que é o objetivo do trabalho, será inserido um fluxo pulsátil, por meio do pulso de pressão fisiológico adquirido do trabalho de Legendre (2009).

\subsubsection{Aterosclerose}

O AAA é um processo degenerativo não específico, que na maioria das vezes é considerado aterosclerótico, porém ainda não é bem conhecida a causa da degeneração do aneurisma e a relação com a aterosclerose. Esta afirmação se dá pois ambas tem suas prevalências em anciões. Sabe-se que a maioria dos AAA's acomete a aorta infra renal com degeneração aterosclerótica severa, e grande parte dos pacientes com aneurismas apresentam fatores de risco para aterosclerose e algumas manifestações de aterosclerose com oclusão de artérias periféricas ou coronárias. Apesar de apresentarem-se muitas vezes concomitantemente, aterosclerose oclusiva de aorta e dilatação aneurismática apresentam algumas diferenças. Entre os doentes com AAA, há uma maior presença de pacientes diabéticos. No entanto, aneurismas raramente aparecem em artérias como a carótida e as ilíacas externas que são geralmente afetadas pela aterosclerose oclusiva (Legendre, 2009). A aterosclerose é uma patologia que se apresenta na túnica intima do vaso, diferentemente dos AAA's que são doenças degenerativas da túnica média. 
Como a porção abdominal da aorta humana possui menos "vasavasorum" do que outros segmentos da aorta, e sua camada média suplementa sua nutrição por absorção de nutrientes pelo endotélio vindos do sangue, os estudos feitos por Puech-Leão e Kaufmann (1998) sugerem que a presença de aterosclerose poderia interferir no mecanismo de nutrição, causando um enfraquecimento parietal.

\subsubsection{Remodelamento Arterial}

Remodelamento arterial pode ser entendido como a mudança no diâmetro da artéria. Este fenômeno pode acontecer como controle da temperatura corpórea, para aumentar a vascularização de certo membro em ocasiões de perigo, ou até mesmo pode ser associado à formação de aterosclerose. Este é um fator que pode ser relacionado com a formação e expansão do aneurisma. Quando se presencia placas de ateroma, há também uma compensação fisiológica com dilatação destas artérias para compensar a estenose do lúmen da mesma. De acordo com Glagov et al. (1987), este fenômeno sugere que o remodelamento arterial pode ser um fator que tem relação com a degeneração aneurismática.

\subsection{Diagnóstico e Exames Subsidiários}

Aneurisma de aorta abdominal é uma doença vascular que pode ser sintomática, causando dores abdominal, lombar ou isquemia de membros inferiores, ou assintomática que é descoberta por acaso, quando se está fazendo um exame físico, ou por imagens como é o caso de radiografias, ressonância magnética, tomografia computadorizada e ultrassonografia.

De acordo com Araújo e Rodrigues (2003), metade dos pacientes que possuem AAA tem uma tumoração pulsátil no abdômen, palpável e que lembra o aspecto de um coração pulsando. É sempre recomendado quando se consegue palpar um AAA, palpar outras regiões a procura de outros aneurismas. Palpar os aneurismas não é tarefa fácil, pois de acordo com 0 estudo de Araújo e Rodrigues (2003) 33,3\% dos aneurismas não são palpados facilmente por causa do tamanho do aneurisma, diâmetro abdominal do paciente e experiência do examinador. 
O exame físico de um paciente com AAA pode revelar expansão transversal do pulso e alargamento da aorta abdominal como é verificado na figura 6 .

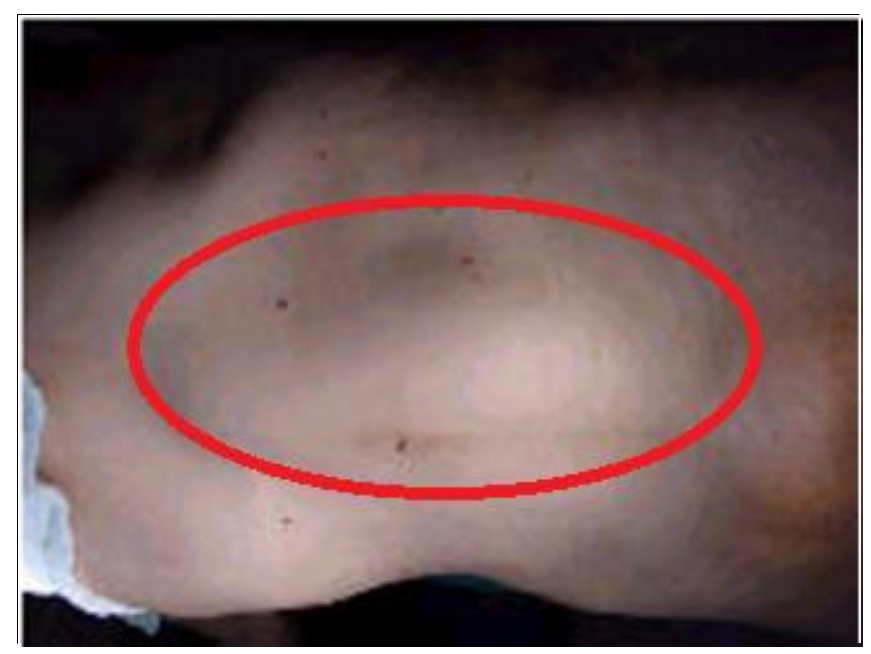

Figura 6 - Aneurisma de Aorta Abdominal (Baptista-Silva, 2003)

Radiografias de coluna lombar e abdômen podem revelar em torno de $65 \%$ de esboços calcificados de um aneurisma. Alguns estudos compararam as medidas de aneurismas em radiografias simples e em cirurgias, e notaram uma diferença nos diâmetros. Na figura 7 , nota-se a calcificação de um aneurisma de aorta e corrosão de vertebra lombar pelo aneurisma.

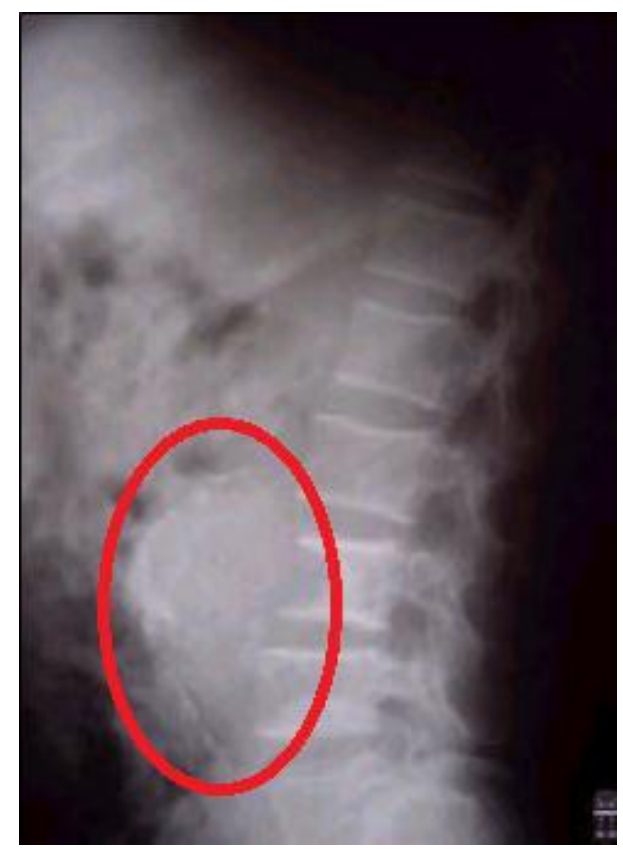

Figura 7 - Radiografia Simples de abdômen mostrando calcificação em aneurisma e corrosão de vertebra lombar (Baptista-Silva, 2003) 
A ultrassonografia é o método que vem sendo utilizado na triagem de aneurismas por ser preciso nas medições, não é invasivo e é sensível, tendo sido encontrados diferenças entre as medidas de $4,2 \mathrm{~mm}$ na transversal, além destes fatores, este exame é relativamente barato. $O$ uso rotineiro deste método para avaliar a evolução de doentes acima de 50 anos com AAA assintomático pode reduzir o risco de rotura de $49 \%$ para $45 \%$ (Wilmink et al., (1999) apud Baptista-Silva(2003)). A figura 8 mostra uma imagem deste tipo de exame.

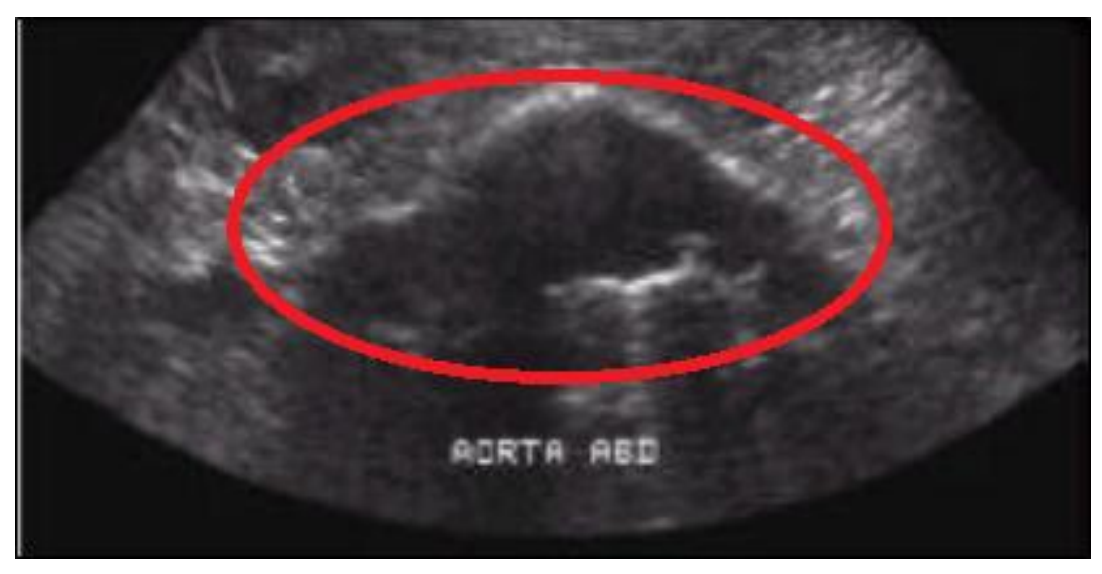

Figura 8 - Ultrassom longitudinal de abdômen mostrando um AAA infre-renal (Baptista-Silva, 2003)

A tomografia computadorizada é um exame de imagens mais preciso que a ultra-sonografia, porém é um exame que tem maior custo. A tomografia pode ser realizada com ou sem o uso de contraste, dependendo de que estruturas se deseja visualizar (Baptista-Silva, 2003). Sem o uso de contrastes, pode se visualizar calcificações parietais e eventuais hematomas. Quando se usa contraste, examina-se toda a aorta desde o plano superior do arco aórtico até a bifurcação. $O$ uso de contraste na tomografia pode ser prejudicial a pacientes que possuam função renal alterada (Baptista-Silva, 2003). Quando algum paciente que se saiba que tem um AAA e não é possível palpar o colo proximal, e nem visualizar por meio de ultrassom, usa-se a tomografia, pois ela pode definir o colo com precisão, ajudando também no planejamento da cirurgia (Baptista-Silva, 2003). Na figura 9, visualiza-se uma imagem em corte axial de tomografia computadorizada de um AAA. 


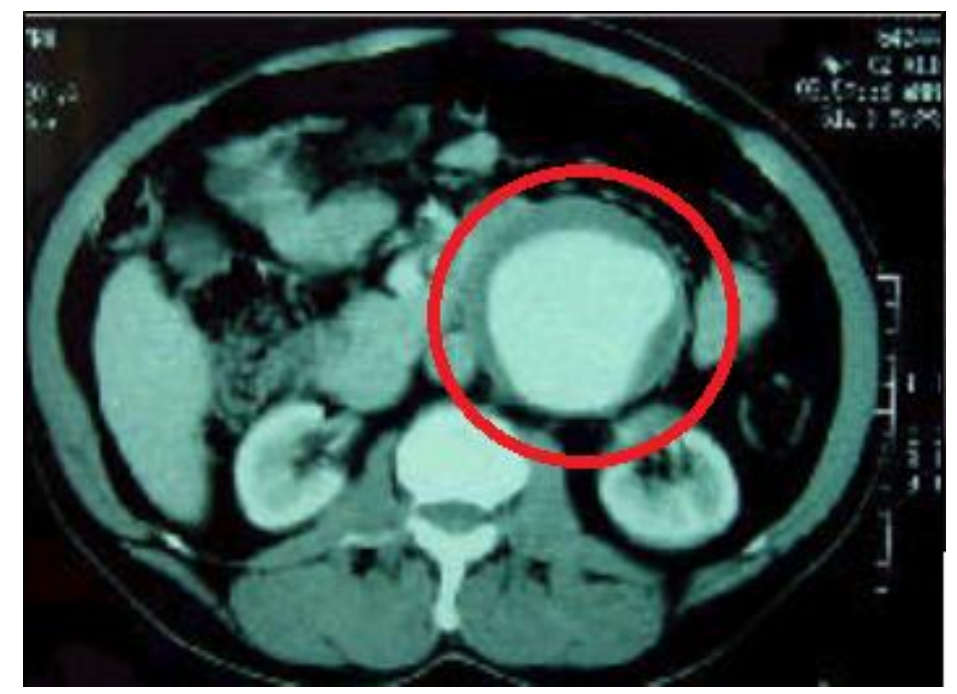

Figura 9 - Tomografia computadorizada de AAA infra-renal (Baptista-Silva, 2003)

Em alguns doentes com dor abdominal ou lombar e com suspeita de aneurisma abdominal sintomático, mas ainda com dúvidas sobre o diagnóstico, é aconselhável o exame de tomografia computadorizada, quando se há disponibilidade, para assim, retirar alguma dúvida sobre o diagnóstico (Baptista-Silva, 2003).

AAA's sintomáticos tem indicação para cirurgia de emergência, pois aneurismas sintomáticos podem possuir rápido crescimento, e com isso, o risco de rotura aumenta consideravelmente. Outro caso onde há necessidade de cirurgia de emergência é o paciente que apresenta quadro instável, com hipotensão ou choque hemorrágico devido à ruptura de aneurisma (BaptistaSilva, 2003).

Existe também outro exame para diagnóstico e reavaliação de aneurismas de aorta. Trata-se da angio-ressonância magnética que possui ótima resolução e não usa contraste iodado, portanto não exerce risco a pacientes com insuficiência renal. O contraste usado neste exame é um agente paramagnético, que apesar de não colocar em risco pacientes com problemas renais, é contraindicado para pacientes que possuam instalados em seus corpos, próteses metálicas, marca passo ou ainda serem claustrofóbicos (Baptista-Silva, 2003).

Existe um consenso por parte dos especialistas que dizem que a angiografia é um exame ruim para triagem de AAA, pois geralmente apresenta 
erroneamente trombos dentro do aneurisma (Baptista-Silva, 2003). Por outro lado, vários autores demonstram o beneficio da angiografia como exame de rotina para descobrir alguma alteração vascular que pode alterar o planejamento cirúrgico, como estenose de artéria renal assintomática, anomalias renais, doença oclusiva ilíaca, entre outras alterações. A figura 10 ilustra o exame de angiografia.

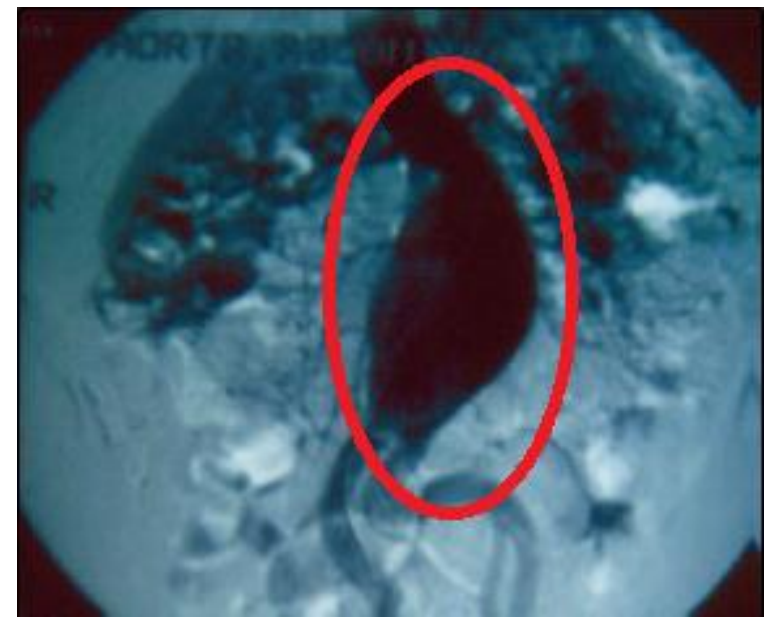

Figura 10 - Angiografia (Araújo e Rodrigues, 2003)

\subsection{Tratamentos de Aneurismas}

Como se sabe, aneurisma de aorta é uma doença vascular que possui crescimento constante, até que a parede arterial não suporte a pressão interna e rompa.

Desde Dubost em 1952, precursor das cirurgias de aneurisma de aorta, AAA's vem sendo tratados cirurgicamente (Puech-Leão e Kaufmann, 1998). Por outro lado, desde 1991, existe um tratamento endovascular, utilizado por Parodi et al. (1991) que se baseia na instalação de uma endoprótese, fazendo com que o fluxo sanguíneo flua internamente à prótese, não exercendo esforços na parede arterial e não degradando ainda mais as paredes arteriais em consequência dos esforços hemodinâmicos.

Um fator muito importante que tem de ser levado em consideração para o tratamento cirúrgico, independente se aberto ou endovascular, é que o risco do tratamento tem de ser menor que o risco de rotura do aneurisma. 
Muitos pacientes portadores de aneurismas de aorta possuem também outras doenças associadas, que podem levar a complicações na evolução do aneurisma ou até alterar o resultado de um tratamento cirúrgico. Uma doença que comumente é encontrada em pacientes que tem AAA é a doença coronariana, e é considerada a principal doença, não só pela gravidade, mas pela frequência a qual ocorre. De acordo com Puech-Leão e Kaufmann (1998), os eventos coronarianos são responsáveis por 50 a $60 \%$ das mortes que acontecem em cirurgia de correção de aneurismas.

Com relação a urgência do tratamento cirúrgico, procura-se chegar num consenso quanto ao diâmetro dilatado. Aneurismas que possuam diâmetro igual ou maior que $6 \mathrm{~cm}$, devem ter tratamento cirúrgico eletivo, devido ao risco de ruptura. Se o aneurisma possuir de 5 a $6 \mathrm{~cm}$ de diâmetro, deve-se analisar as patologias associadas, e prever o risco da cirurgia, principalmente levando em consideração doenças coronárias. Se o risco não for excessivamente alto, o tratamento cirúrgico deve ser considerado. Se o diâmetro aneurismático é menor que $5 \mathrm{~cm}$, o paciente pode ser apenas observado clinicamente, com exames regulares a cada 6 meses, para verificar o crescimento da bolsa por meio de ultra sonografia ou tomografia. Se a taxa de crescimento do aneurisma for maior que $5 \mathrm{~mm} / \mathrm{semestre}$, seu diâmetro alcançar os $6 \mathrm{~cm}$, ou o paciente se queixar de dores na região do aneurisma, a correção cirúrgica passa a ser prioritária. Esta conduta clínica, tem como referencia o trabalho de Puech-Leão e Kaufmann (1998).

\subsubsection{Tratamento Convencional}

Nesta seção abordaremos o tratamento convencional de aneurismas de aorta abdominal. Este tratamento é uma cirurgia aberta, extremamente invasiva.

Este método foi desenvolvido por Dubost, em 1952, e trata-se da exposição da aorta na região onde ocorre o aneurisma, para que se possa executar a substituição do trecho danificado pela dilatação por enxerto artificial de material poliéster (Dacron). Após a exposição da aorta, faz-se o pinçamento nos dois extremos da região afetada pelo aneurisma para que se tenha obstrução temporária do fluxo sanguíneo a partir do aneurisma no sentido dos 
membros inferiores. Após a obstrução, o saco aneurismático é aberto longitudinalmente, para que se tenha acesso ao lúmen arterial e possa ser feita a remoção de trombos ali existentes. $O$ enxerto é então instalado na região dilatada e fixado na parte saudável superior da artéria. Seguindo o processo, é feito teste de vazamentos liberando o pinçamento superior, deixando a aorta bloqueada na porção inferior. Não havendo vazamentos, o enxerto é ajustado no comprimento correto e suturado na parte inferior saudável da aorta (Figura 11A). Os pinçamentos são liberados e a parede do aneurisma é fechada sobre o enxerto. Este fechamento é feito para que não haja contato do enxerto com as vísceras (Figura 11B). Finalmente, o abdome do paciente é fechado (PuechLeão e Kaufmann, 1998).

Este tratamento aberto, ainda é usado para reparar aneurismas de aorta abdominal, porém este método, por conta dos riscos da cirurgia, não é adequado para todos os casos de aneurisma. Como foi citado anteriormente, o melhor tratamento é aquele no qual o risco é o menor possível e que seja sempre, menor que o risco de ruptura do aneurisma.

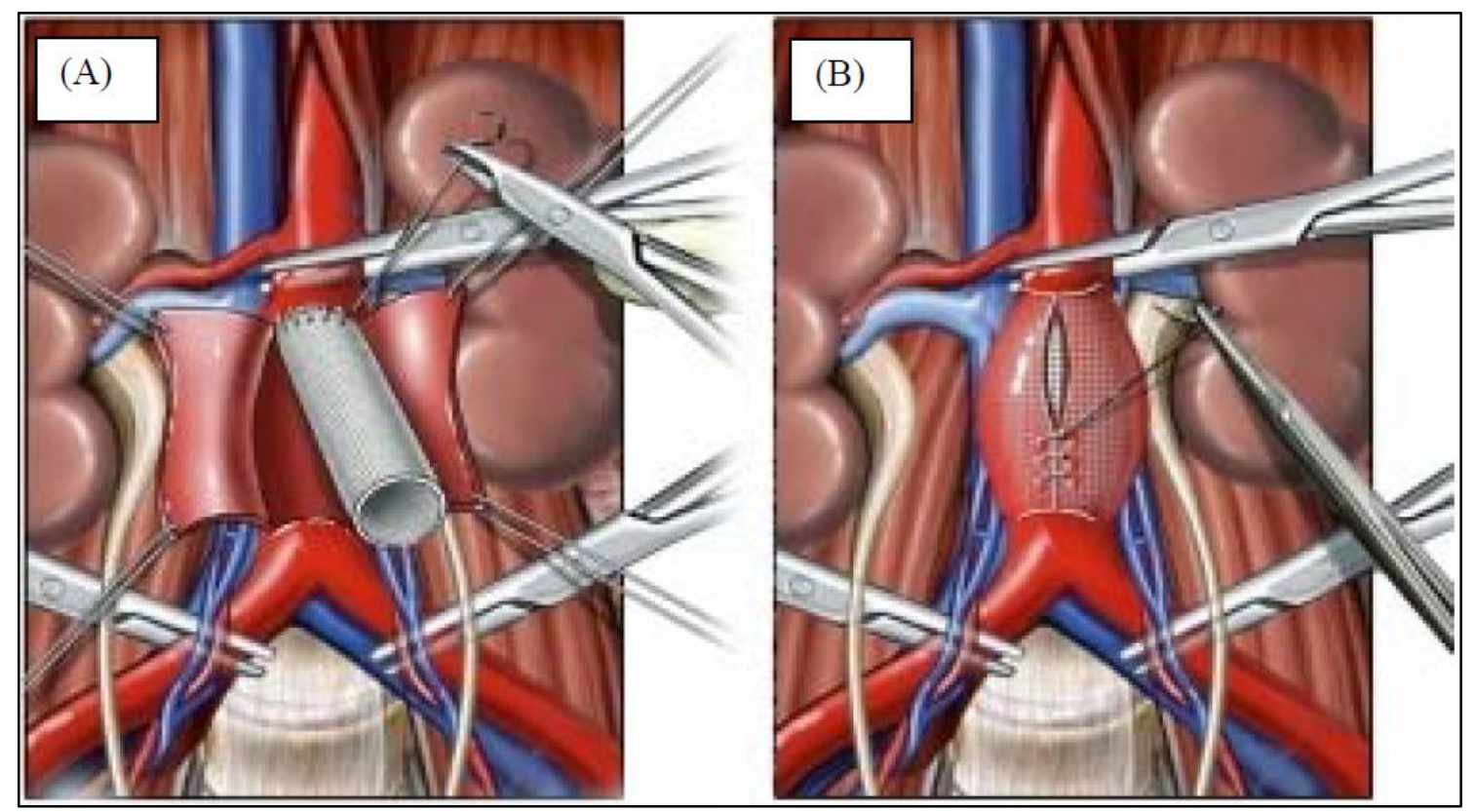

Figura 11 - Momentos da cirurgia aberta para tratamento de aneurisma de aorta abdominal, ilustrando pinçamento da aorta abdominal e artérias ilíacas e sutura do enxerto na porção superior da aorta (A); após instalação do enxerto, fechamento do saco aneurismático (B)

(Healthlibrary) 


\subsubsection{Tratamento Endovascular}

Até 1991 os aneurismas eram tratados com o método convencional, que foi citado anteriormente, quando Parodi realizou a primeira cirurgia para tratamentos de aneurismas de aorta endovascular (Parodi et al., 1991). Esta possibilidade de tratamento se deu com o desenvolvimento de próteses metálicas, conhecidas pelo termo em inglês de stents. As próteses são introduzidas no paciente por meio de cateterismo, diferentemente do método convencional aberto, de alto risco. Um ponto muito favorável ao tratamento endovascular em relação ao convencional é a diferença de volume de sangue perdido durante a cirurgia, 932 versus $225 \mathrm{ml}$, sendo o de menor valor, referente ao tratamento endovascular (Mendonça et al., 2005).

A princípio, os métodos são parecidos, pois em ambos são instalados próteses internas ao aneurisma, aliviando a parede aneurismática dos esforços hemodinâmicos. A maior diferença é que no tratamento endovascular, a prótese é introduzida através de uma artéria femoral, e fixada na aorta por meio de endopróteses (Puech-Leão e Kaufmann, 1998). O princípio básico deste novo método consiste na introdução de um ou mais endopróteses revestidos por um substituto arterial sintético ou autólogo, a partir de uma artéria distante ao aneurisma.

Durante o procedimento endovascular, dependendo de onde está localizado o aneurisma, são feitos uma ou duas incisões na virilha para que se tenha acesso as artérias femorais. Quando o aneurisma não é próximo a bifurcação e é capaz de se utilizar um enxerto aorto-aórtico ou reto, é necessário apenas uma incisão pequena para que seja introduzido o enxerto por meio de cateterismo. Porém quando é necessário utilizar uma endoprótese bifurcada, duas incisões são necessárias para que se consiga introduzir as duas pernas da bifurcação (Figura 12).

Após o procedimento de instalação propriamente dito, é feito uma arteriografia para verificar a localização do implante e assegurar que não haja nenhum vazamento de sangue no saco aneurismático. 
De acordo com o estudo de Mendonça et al. (2005), este método de tratamento é menos traumático para o paciente, do ponto de vista de que é um método menos invasivo que o convencional, o tempo de permanência do paciente na unidade de tratamento intensivo (UTI) é menor e o tempo total de permanência no hospital também é menor.

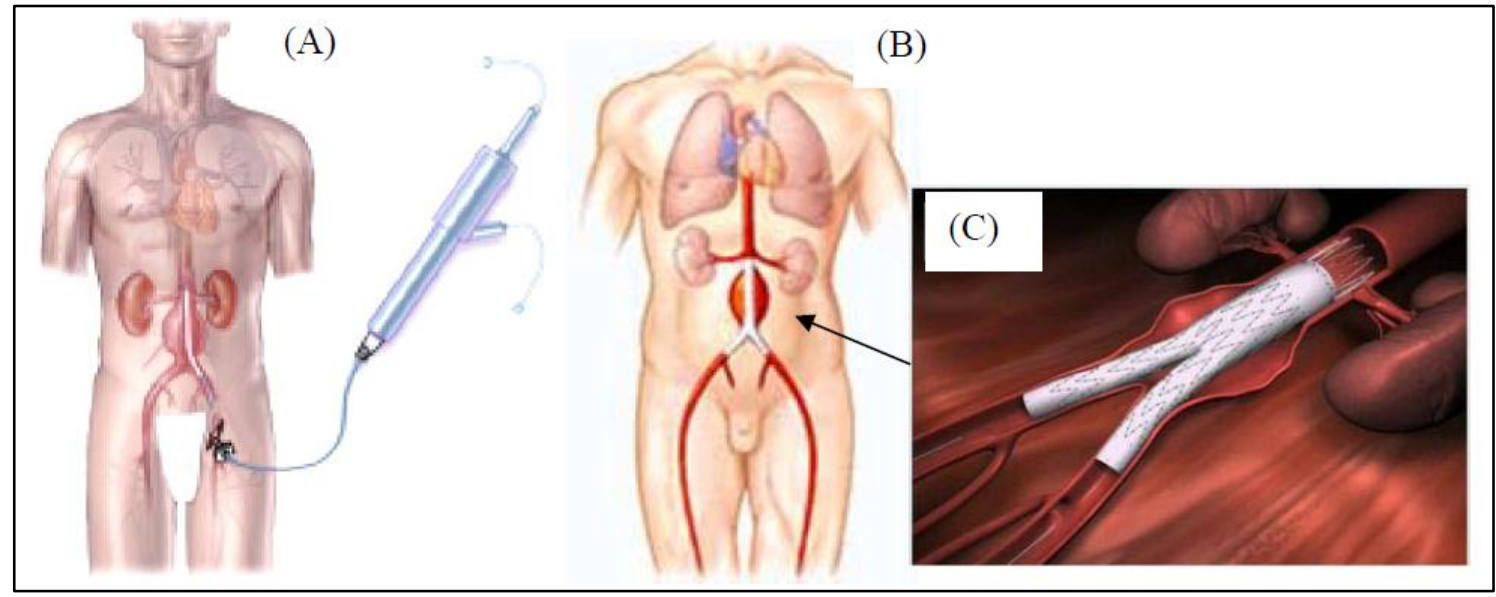

Figura 12 - Inserção de endoprótese com cateter por meio de artéria femoral (A); Endoprótese bifurcada já instalada em paciente (B) e (C). (Legendre, 2009).

A sobrevida de pacientes que obtiveram sucesso na instalação da endoprotese, é de $97 \%$ nos 30 primeiros dias. Se levarmos em consideração a sobrevida num período de 5 anos, ela é de 65\% (Baptista-Silva, 2011).

\subsection{Endopróteses}

Como já citado acima, existem modelos de endopróteses que são diferenciados quanto à geometria e ao número de componentes que a formam. Um exemplo disso são as endopróteses usadas no tratamento de AAA's que se localizam próximos às ilíacas. De acordo com Legendre (2009), existem endopróteses expansíveis por balão interno, utilizada por Parodi em 1991 e existem as endopróteses auto expansíveis, que são mais modernas.

O tipo de prótese geralmente usada no tratamento endovascular de AAA's corresponde às próteses bifurcadas porém dependendo da localização da dilatação, pode-se utilizar uma endoprótese que não seja bifurcada. Estas próteses são constituídas por uma estrutura metálica, e revestidas por material de poliéster (Dacron), assim como os enxertos para tratamento convencional. 
A estrutura metálica das próteses tem como principal função sustentar o revestimento de Dacron, que por sua vez, funciona como a parede do vaso, impedindo o contato da parede aneurismática com o sangue, dirigindo o fluxo sanguíneo até o fim da região afetada pelo aneurisma. A figura 13 ilustra alguns dos modelos que podem ser instalados no reparo de AAA's.

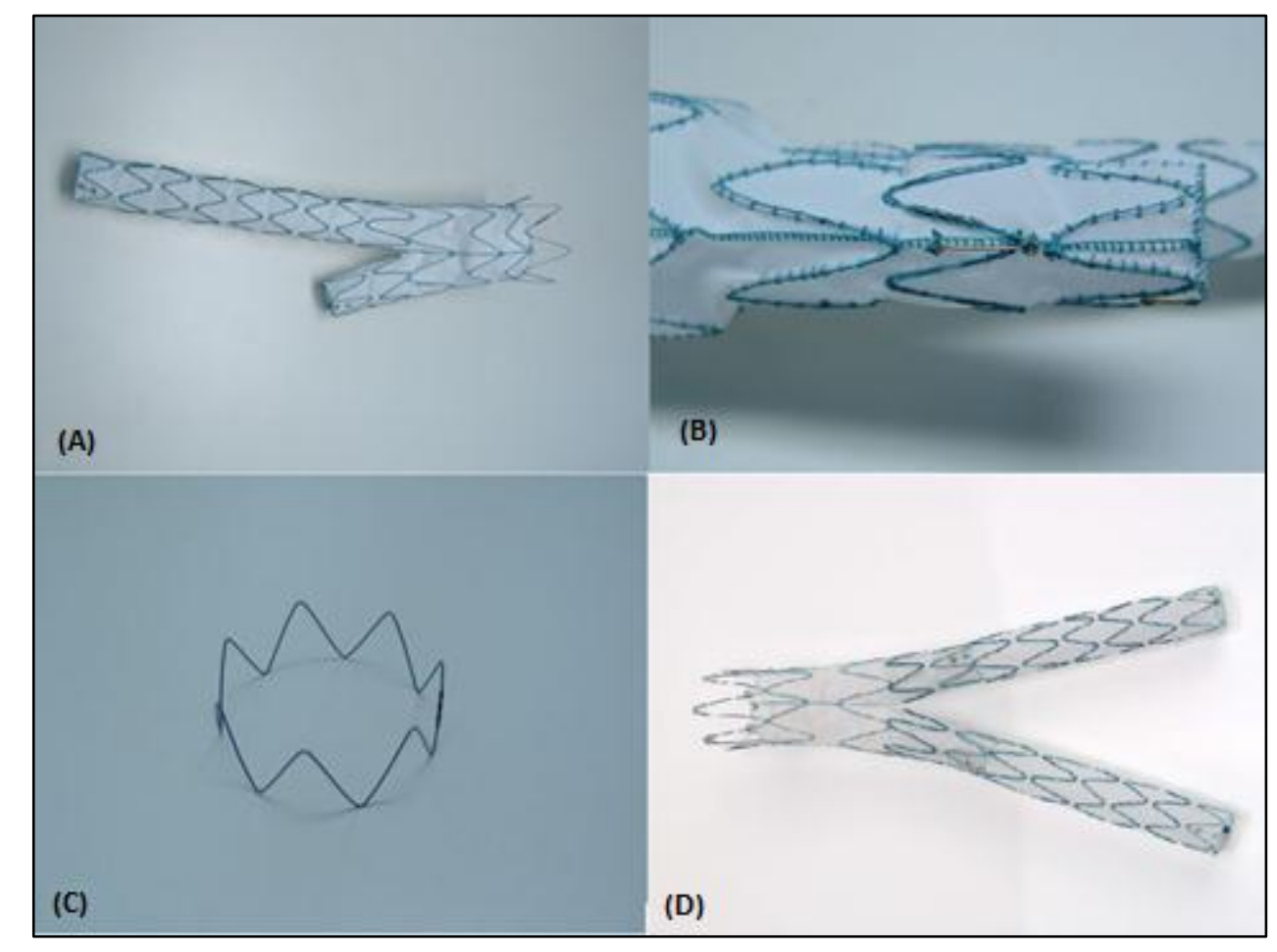

Figura 13 - Endoprótese bifurcada usada no tratamento de AAA com segmentos para ilíacas de comprimentos diferenciados(A);Detalhe da estrutura metálica com o revestimento poliéster(B); Detalhe da estrutura metálica de uma endoprótese(C); Endoprótese bifurcada usada no tratamento de AAA com segmentos para ilíacas de comprimentos iguais(D) (Braile Biomédica)

A estrutura metálica das endopróteses é composta de ligas Níquel Titânio, Cromo Cobalto, Aços Inoxidáveis e Tantalum (Saadi, 2009). Com o avanço da tecnologia de materiais, novos materiais e/ou compostos podem ser inseridos na construção das endopróteses. Algumas endopróteses podem apresentar como mecanismos de fixação, ganchos ou barbs (Saadi, 2009).

\subsubsection{Escolha de Endopróteses}

Com a grande diversidade de aneurismas encontrados em pacientes, tanto em relação à geometria, quanto em relação à localização na artéria, existe no mercado uma grande quantidade de modelos de endopróteses. Cada 
modelo é indicado especialmente para o aneurisma que está sendo estudado. A escolha de uma prótese para o aneurisma se dá inicialmente verificando as dimensões e localização da dilatação através de exames de imagens como tomografia computadorizada ou angiografia. Após a medição dos diâmetros e comprimentos da dilatação é necessário verificar uma endoprótese para o mesmo. Geralmente é utilizado um diâmetro de prótese de 15 a $25 \%$ maior que o diâmetro proximal da artéria. Quando a seção transversal da artéria se aproxima de uma elipse, é sugerido fazer uma proporção em área ao invés da proporção linear. O critério utilizado na escolha das endopróteses para este trabalho foi o critério que utiliza os diâmetros de 15 a $25 \%$ maior que o diâmetro proximal da aorta.

\subsection{Análise Computacional}

Recentemente, muitos estudos tem usado a análise computacional para verificar estruturas biológicas ou fenômenos que acontecem dentro do corpo humano (Bachmann et al., 2000, Barbosa, 1996, Bessa, 2008, Legendre, 2009, Legendre et al., 2006, Noronha et al., 2007 e Ortiz et al., 2007).

Há muitas diferenças entre os estudos, pois cada um deles adota uma hipótese simplificadora para a solução. No trabalho de Noronha et al., 2007 o escoamento em aneurisma de aorta é simulado utilizando as hipóteses de fluidos Newtoniano e não Newtoniano. Já outros trabalhos como o de Legendre 2009 e Yamane et al. 2004, consideram o fluido de trabalho como um fluido Newtoniano, chegando a resultados concretos e satisfatórios, se comparados aos estudos feitos considerando o sangue como um fluido não Newtoniano. Estudos demonstram que a hipótese de parede rígida, quando a artéria possui placas de ateroma é aceitável, pois a artéria perde elasticidade e ganha rigidez com a degradação das fibras de elastina e a aterosclerose.

Raghavan et al. 2000, estudaram com base no método de elementos finitos a ruptura de aneurismas de aorta abdominal. A tensão interna à parede da aorta de pacientes que possuíam AAA era de até 3,75 vezes maior que a tensão de um paciente que não possuía a patologia. Os aneurismas que foram estudados neste trabalho foram obtidos por tomografia computadorizada e tratados para que gerassem um modelo tridimensional. 
Estudos citam também a hipótese de que o sangue é um fluido incompressível (Bertelli et al., 2008, Raghavan, 2000), simplificando o problema e as equações envolvidas e também o modelo do fluido.

Alguns estudos como o de Lantz et al. (2011), demonstram que as simulações levando em consideração a complacência da artéria resultam em resultados mais realistas, porém considerando a parede da artéria rígida, os resultados como a pressão e tensão na parede do vaso se tornam mais conservadores, com valores mais elevados.

De acordo com o trabalho de Ortiz et al. (2007), uma característica das simulações que tem que ser considerada, é a geometria. Locais que contenham bifurcações, por exemplo, tendem a gerar turbulência no escoamento. Já geometrias mais simples, tendem a ter escoamentos mais suaves.

\section{Materiais e Métodos}

\subsection{Modelagem de Aneurisma Real}

\subsubsection{Geração de Modelo a partir de Exame Multi-fatias}

Neste trabalho, foram cedidas imagens de exames de tomografias computadorizadas de pacientes portadores de aneurisma de aorta abdominal infra-renal (figura 14). Estas imagens são conhecidas como multi-fatias e possuem um formato especial. Este formato de imagem é conhecido pela sua abreviação, DICOM (Digital Imaging and Communications in Medicine) que em português, quer dizer Comunicação de Imagens Digitais em Medicina. Este arquivo segue na realidade um conjunto de normas para o tratamento, armazenamento e transmissão de informações (imagens) médicas num formato eletrônico padronizado. 


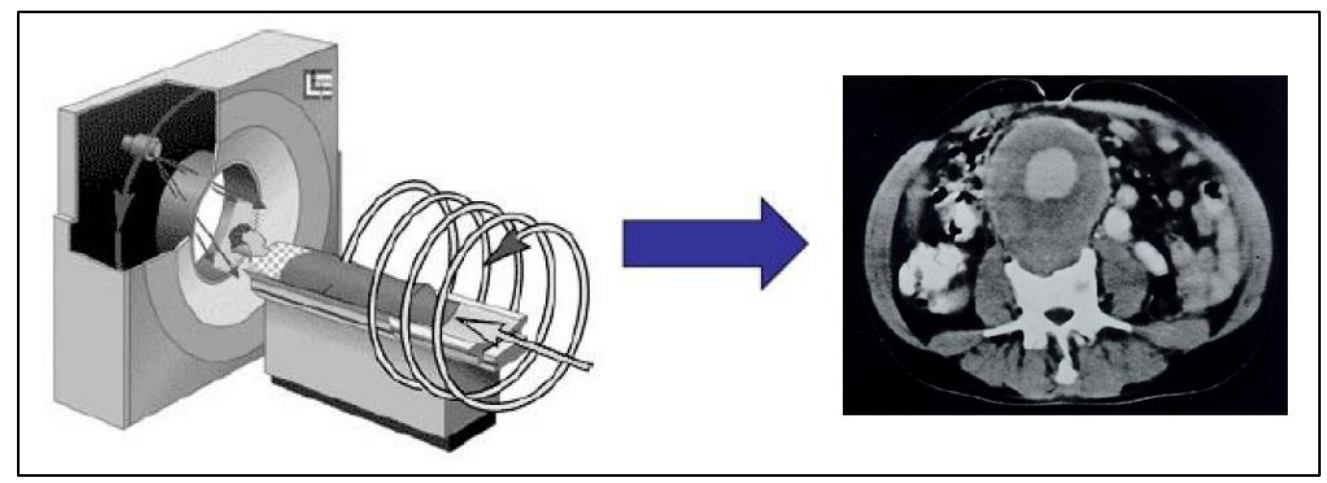

Figura 14 - Imagens obtidas por exames de tomografia de pacientes (Legendre, 2009)

As imagens do arquivo DICOM são devidamente tratadas por meio do software InVesalius (v3.0 beta2, Campinas, SP, BR) selecionando as áreas de interesse, que no caso deste estudo são os aneurismas (Figura 15). Depois de todo o tratamento das imagens obtidas na tomografia, o software une as fatias, interpolando-as, gerando um modelo tridimensional, que é exportado na extensão stl (estereolitografia). Este tipo de arquivo é geralmente usado na reconstrução de superfícies por prototipagem rápida. As regiões que são interessantes neste estudo, são a aorta infra-renal e as artérias ilíacas.

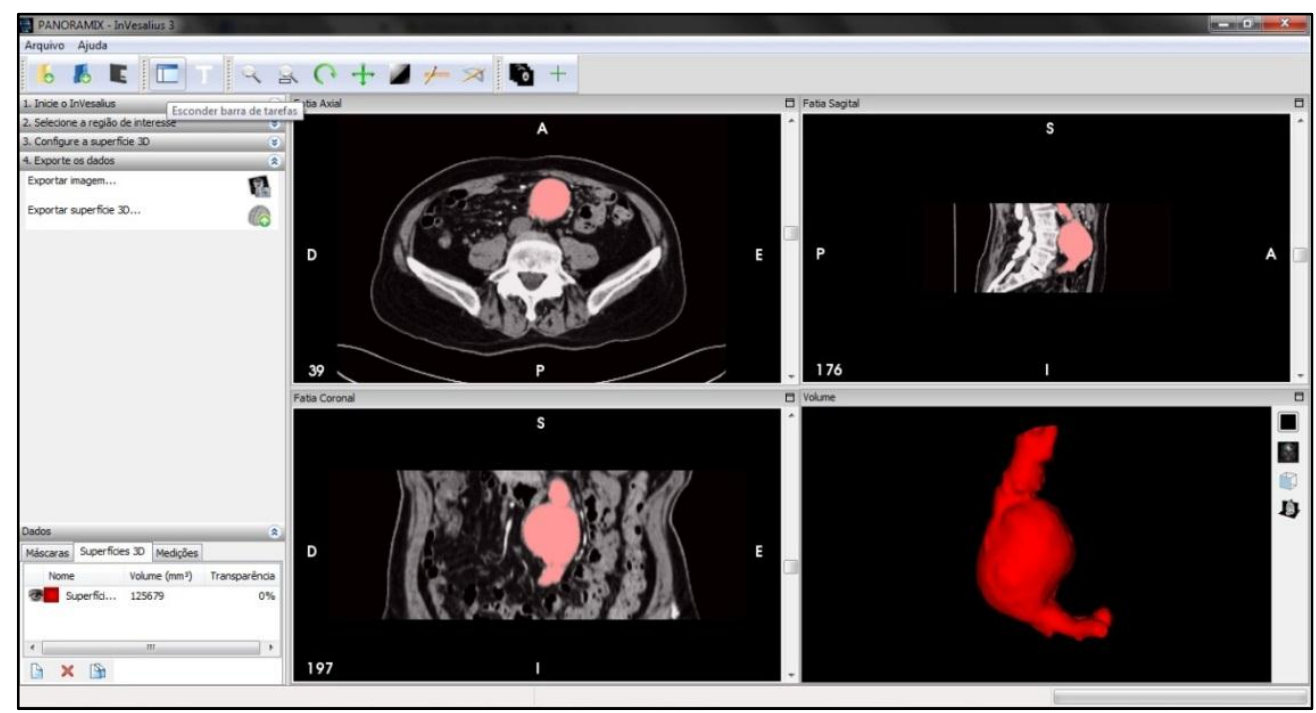

Figura 15 - Construção do modelo tridimensional de AAA (InVesalius 3.0)

O software InVesalius é uma ferramenta médica, pública que auxilia o diagnóstico médico e o planejamento do tratamento cirúrgico. O processo que ele utiliza para gerar modelos tridimensionais é a sobreposição das fatias provindas do exame tomográfico e a interpolação dos espaços entre as fatias para que haja a união. Com isso, as estruturas com geometrias complexas do 
corpo humano podem ser reconstruídas (Figura 16). As fatias possuem uma espessura e um afastamento entre elas. O exame ideal em termos de qualidade seria aquele onde a espessura da fatia tenda a zero, e o afastamento entre elas também.

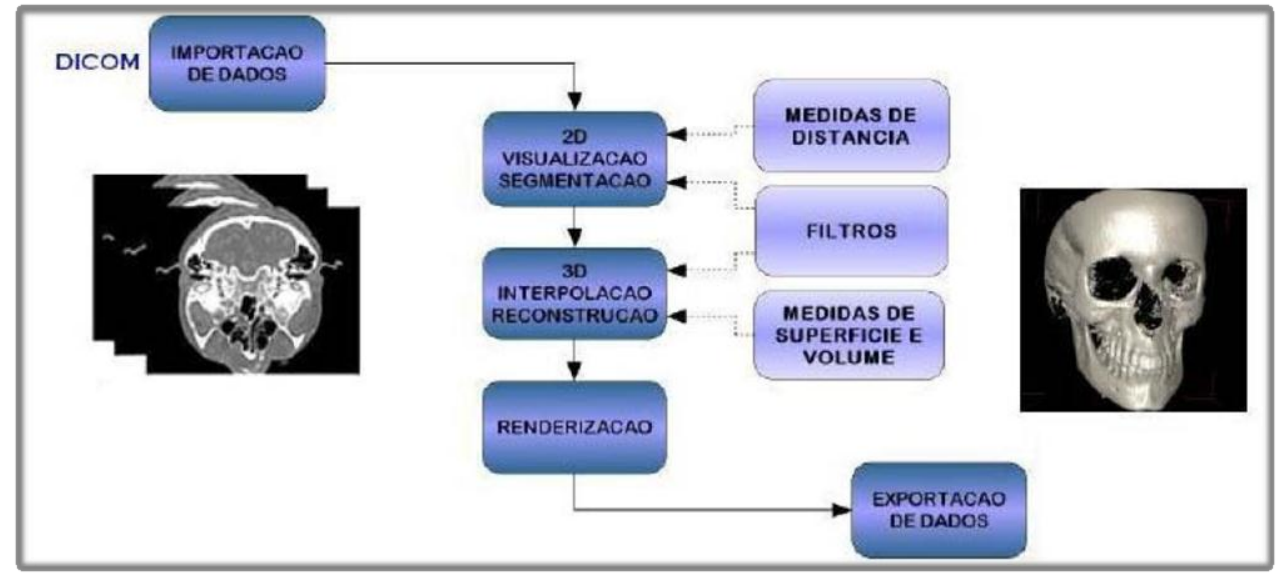

Figura 16 - Fluxograma para reconstrução de imagens médicas (Legendre, 2009)

Com a obtenção de imagens de tomografias, o programa nos permite criar um modelo computacional (virtual) com a mesma geometria e dimensões das estruturas corpóreas reais como por exemplo crânios, estruturas vasculares. Este software permite também exportar a geometria real do aneurisma para a execução de prototipagem. Esses modelos virtuais podem ser utilizados em simulações computacionais. Para a representação mais realista do fenômeno interno ao corpo do paciente, é possível, em alguns casos, a utilização de dados do escoamento, como por exemplo a pressão sanguínea.

\subsubsection{Tratamento Superficial de Imagens}

Os modelos criados com a ajuda do software, podem ser vistos da maneira que melhor agradar o usuário, alterando ângulos de visualização, visualização com aproximação de uma região, para se obter maiores detalhes. Há também a possibilidade de separação das estruturas de acordo com o interesse do estudo, e, considerando o brilho ou a densidade dos materiais visualizados. A diferenciação das estruturas corpóreas é feita pela diferença das densidades, facilmente verificadas entre ossos e tecidos moles, com a ajuda de um mapa de cores (Figura 17). O software permite a utilização de tal 
recurso, transformando-o numa ótima ferramenta de trabalho na criação de modelos computacionais.

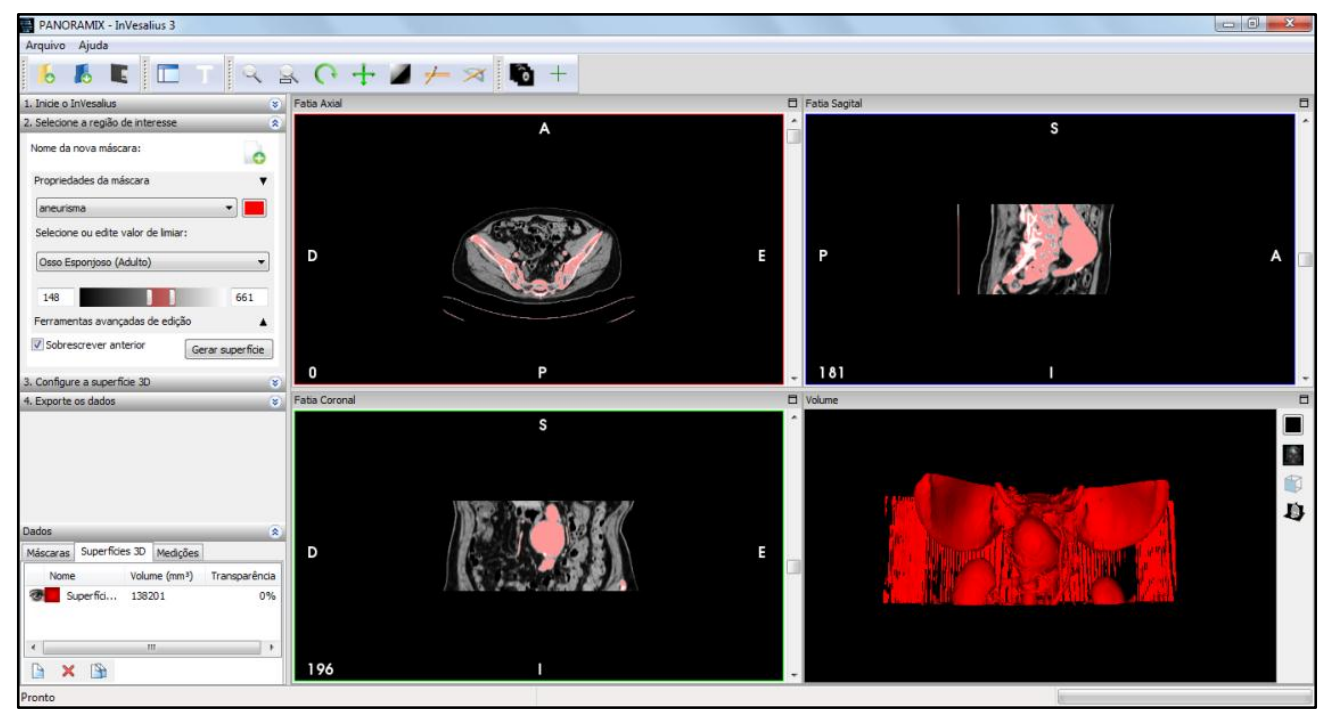

Figura 17 - Construção de modelo tridimensional a partir de exame multi-fatias (InVesalius 3.0).

No tratamento das imagens foram usados os seguintes métodos de segmentação de volume: a limiarização e a conectividade, ambas muito importantes para que seja possível a separação adequada das estruturas úteis para o estudo. Estes métodos agrupam os pixels que possuam as mesmas propriedades, como por exemplo, intensidade e cor. Na limiarização, como o próprio nome sugere, é definida uma faixa limiar, onde todos os valores abaixo ou acima dos configurados são desprezados. Desta maneira, é possível separar mais facilmente tecidos diferentes que possam estar unidos na imagem bidimensional.

O método anteriormente chamado de conectividade é um método de separação de regiões. Ele exclui as regiões do modelo onde não há ligação com a região de interesse, previamente demarcada pelo método da limiarização. Deste modo, com a ajuda destas ferramentas, é possível fazer uma separação das regiões e estruturas indesejadas, por exemplo, algum implante que o paciente possuir, ou até mesmo algum material metálico. 
Com o auxílio deste software, foi obtido um modelo tridimensional da artéria aorta, seu aneurisma, e parte das artérias ilíacas, que por sua vez, foi exportado com a extensão stl (Figura 18).

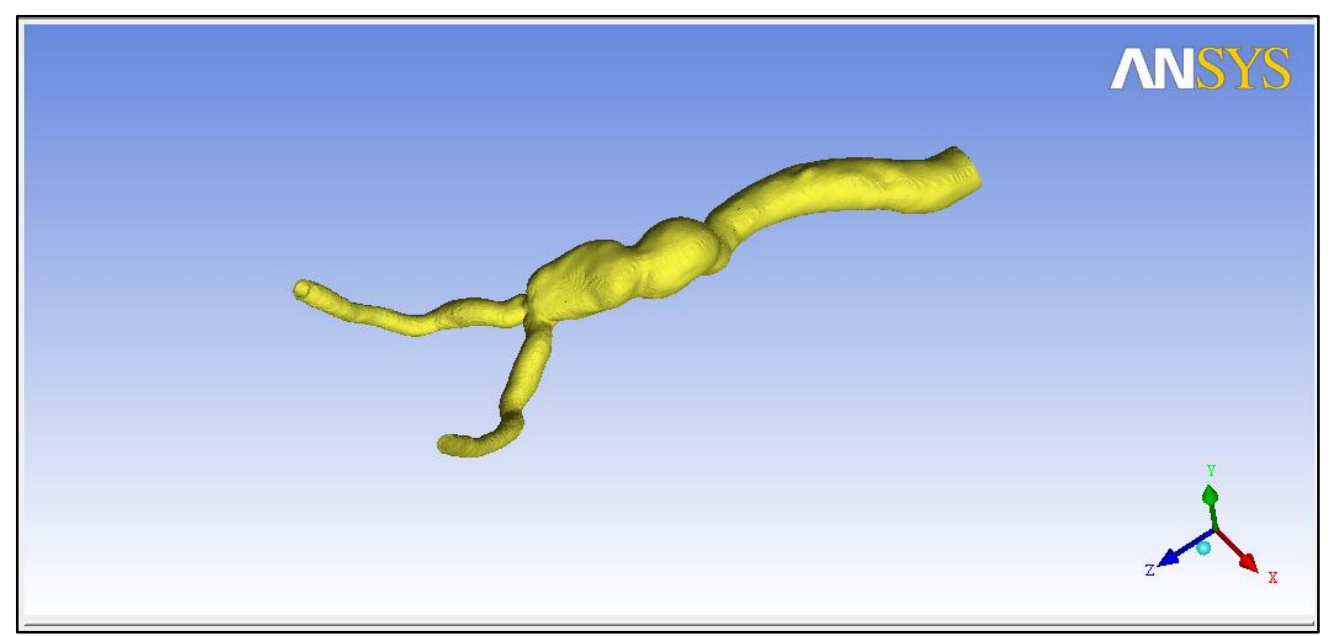

Figura 18 - Modelo tridimensional de aneurisma de aorta abdominal infra-renal obtido após tratamentos de imagem (Legendre, 2009)

\subsection{Simulação Computacional do Aneurisma}

\subsubsection{Método dos Volumes Finitos}

Equações diferenciais parciais possuem alguns métodos para serem resolvidas. Uma destas técnicas é a solução pelo método dos volumes finitos (MVF). Para a solução usando este método, a geometria é subdividida em volumes de controles infinitesimais. Este método consiste em integrar as equações parciais que regem o fenômeno estudado sobre cada um dos volumes de controle. As soluções para os problemas em que é usado o MVF apresentam diferenças, erros numéricos ou problemas que são chamados de falsa difusão (Patankar, 1975). As difusões são na realidade, a diferença entre o valor exato e o valor demonstrado pela solução do método numérico. As falsas difusões podem ser interpretadas, como sendo um efeito que amortece gradientes ou descontinuidades presentes na solução exata do problema. $O$ método upwind de segunda ordem é uma das funções existentes que é utilizada na resolução de alguns problemas para minimizar os efeitos da falsa difusão. O método upwind de segunda ordem foi o escolhido para ser utilizado neste trabalho. 
De acordo com Patankar (1975), o método upwind é baseado no fato de que as variáveis são transmitidas na direção do escoamento, ou seja, a propriedade da face é obtida através da quantidade da célula que está a montante em relação à velocidade do escoamento.

$$
\phi_{f}=\phi_{u p}
$$

Em que $\phi_{f}$ é a propriedade da face e $\phi_{u p}$ é a propriedade da célula a montante em relação ao escoamento. Este esquema apresentado na equação 25 é denominado de upwind de primeira ordem. Para se obter resultados com maior precisão, foi usado o método upwind de segunda ordem. Aumentando a ordem do método interpolador, as funções dependem de um maior número de nós, ou seja, com uma quantidade de volumes maiores nas malhas. Interpolando a propriedade $\phi_{f}$ através de uma expansão de Taylor da solução da propriedade $\phi$ em torno do volume de controle como mostrado na equação 26:

$$
\phi_{f}=\phi_{C 0}+(\nabla \phi \bullet \vec{r})_{u p}
$$

Em que $\phi_{C 0}$ e $(\nabla \phi)_{u p}$ são os valores da propriedade $\phi$ da célula central e seu gradiente no volume de controle que está a montante do escoamento, e $\vec{r}$ é o vetor deslocamento que faz conexão do centro do volume à face do volume de controle. Esse esquema apresentado pela equação 26 é chamado de upwind de segunda ordem.

O software CFX baseia-se na técnica de volumes finitos e é comumente usado na solução de problemas de Dinâmica dos Fluidos Computacional DFC, resolvendo as equações de conservação da massa e quantidade de movimento. Este software permite a utilização de modelos de turbulência, quando há necessidade de aplicação destes modelos. Neste trabalho, foi utilizado o modelo de turbulência $k-\varepsilon$ que é fornecido pelo software com função de parede.

O método, que utiliza volume de controle, baseia-se em três etapas básicas. Divisão de domínio em volumes de controle infinitesimais, usando uma 
malha computacional. Integração das equações que regem o fenômeno estudado no volume de controle individualmente para assim, construir equações algébricas para as variáveis dependentes discretas, como, por exemplo, pressão e velocidade. Linearização das equações discretizadas e solução do sistema de equação linear resultante para atualizar o campo de valores das variáveis independentes.

\subsubsection{Solução Segregada}

O software que é utilizado neste trabalho utiliza o método de solução segregada, em que as equações que regem o fenômeno são resolvidas sucessivamente. Para cada etapa de cálculo, as equações são solucionadas diversas vezes, para se obter a convergência dos resultados, obtendo assim uma solução cujo erro seja o mínimo possível. Cada uma dessas interações consiste em algumas etapas, que serão discriminadas a seguir:

- As propriedades do fluido são atualizadas com base nas propriedades do instante. Ou seja, o valor da propriedade do instante (t) será atualizado dando origem ao valor da propriedade do instante $(t+d t)$.

- As equações da quantidade de movimento nas três direções ortogonais $\mathrm{x}, \mathrm{y}, \mathrm{z}$, são resolvidas separadamente, utilizando os valores de pressão e fluxo de massa atuais nas faces para atualizar o campo de velocidade.

- Se as equações da etapa anterior não satisfizerem as condições de continuidade, a pressão será corrigida para que se obtenham estas condições.

- Quando a região do volume é uma região onde há o aparecimento de turbulência, os valores de outras variáveis serão usados para que se obtenham valores corretos, dependendo do modelo de turbulência usado no estudo.

- Após todos os cálculos, é verificado se os resultados dos conjuntos de equações convergiram ou divergiram.

Todas estas etapas são repetidas até que o critério de convergência estipulado seja alcançado (Figura 19). 


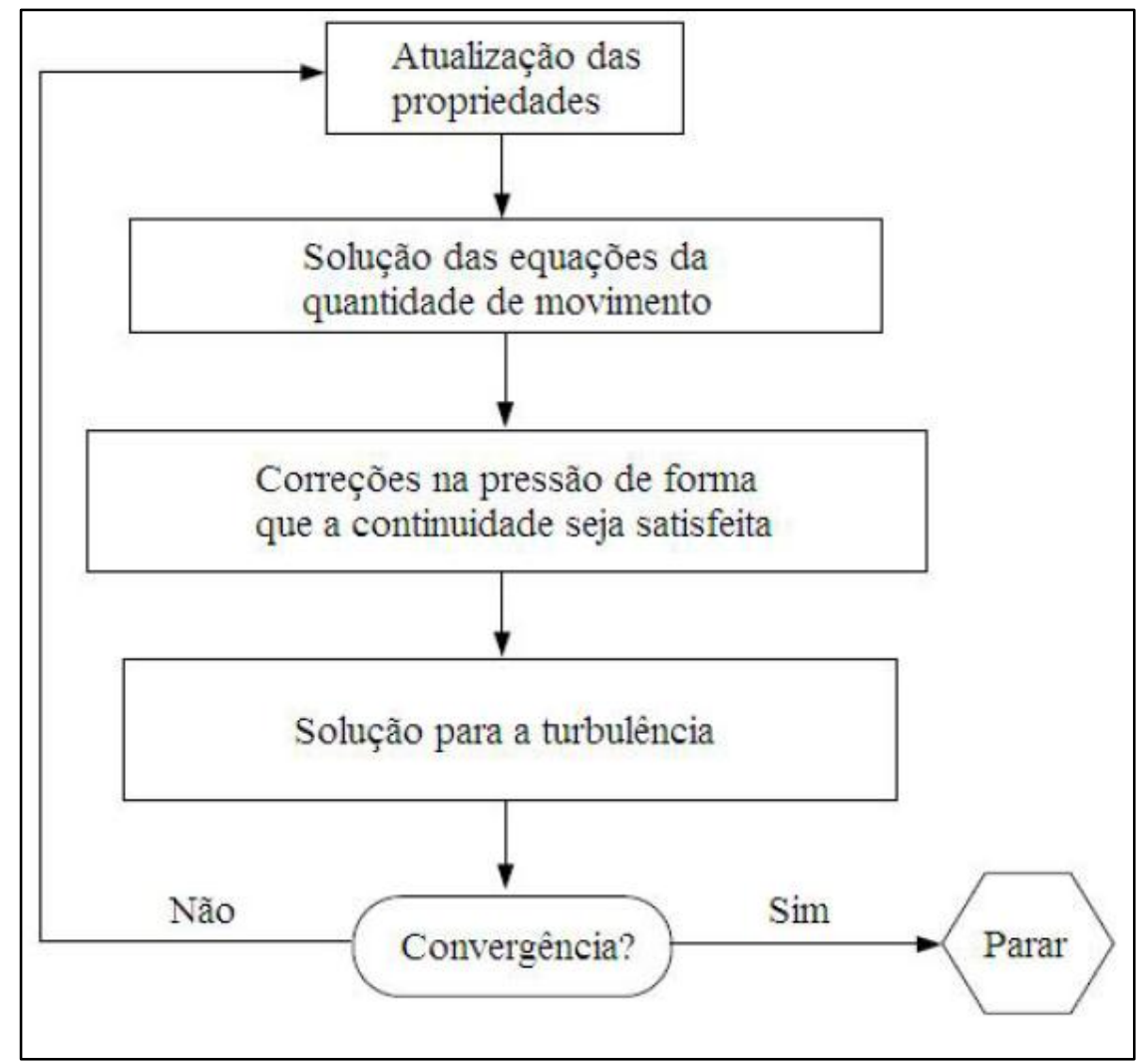

Figura 19 - Algoritmo do método de solução segregada (Legendre, 2009)

Neste trabalho, foi ajustado todo o cálculo com o intuito de se estabelecer um erro máximo na ordem de $10^{-5}$ ou um máximo de 100 interações. Foi limitado o número máximo de interações para cada passo da simulação para que o custo computacional não se tornasse alto demais. Quando o critério de 100 interações foi alcançado, o erro máximo era da ordem de $10^{-4}$.

\subsubsection{Discretização}

O CFX utiliza a técnica anteriormente descrita para solucionar as equações que regem o escoamento sanguíneo pela artéria aorta. A técnica como já foi dito, integra as equações para cada volume de controle, gerando equações discretas que conservam a quantidade de movimento do volume de controle. A equação de transporte é dada por:

$$
\partial \frac{(\rho \phi)}{\partial t}+\operatorname{div}(\rho \phi \vec{u})=\operatorname{div}(\Gamma \operatorname{grad} \phi)+S_{\phi}
$$


Em que $\rho$ é a massa específica, $\phi$ é a propriedade intensiva que está sendo transportada, $\vec{u}$ é o vetor velocidade, $\Gamma$ é o coeficiente de difusão. $O$ primeiro termo é referente a variação de $\phi$ no tempo, o segundo é referente ao fluxo líquido de $\phi$ pelas fronteiras dos volumes, também conhecido como termo convectivo, o terceiro termo da equação, se refere a taxa de variação de $\phi$ referente a difusão, sendo $\phi$ ligado ao coeficiente difusivo e por último mas não menos importante, o fator referente a uma fonte $\left(S_{\phi}\right)$. A equação é integrada para cada volume de controle. A equação depois de integrada é aplicada em todas as células computacionais, onde os valores das propriedades escalares são armazenadas no centro das células e interpolados para as faces das células (Figura 20). O método upwind, faz com que o valor de $\phi$ que atravessa a face seja tomado na célula a montante, em relação ao vetor normal da velocidade do escoamento.

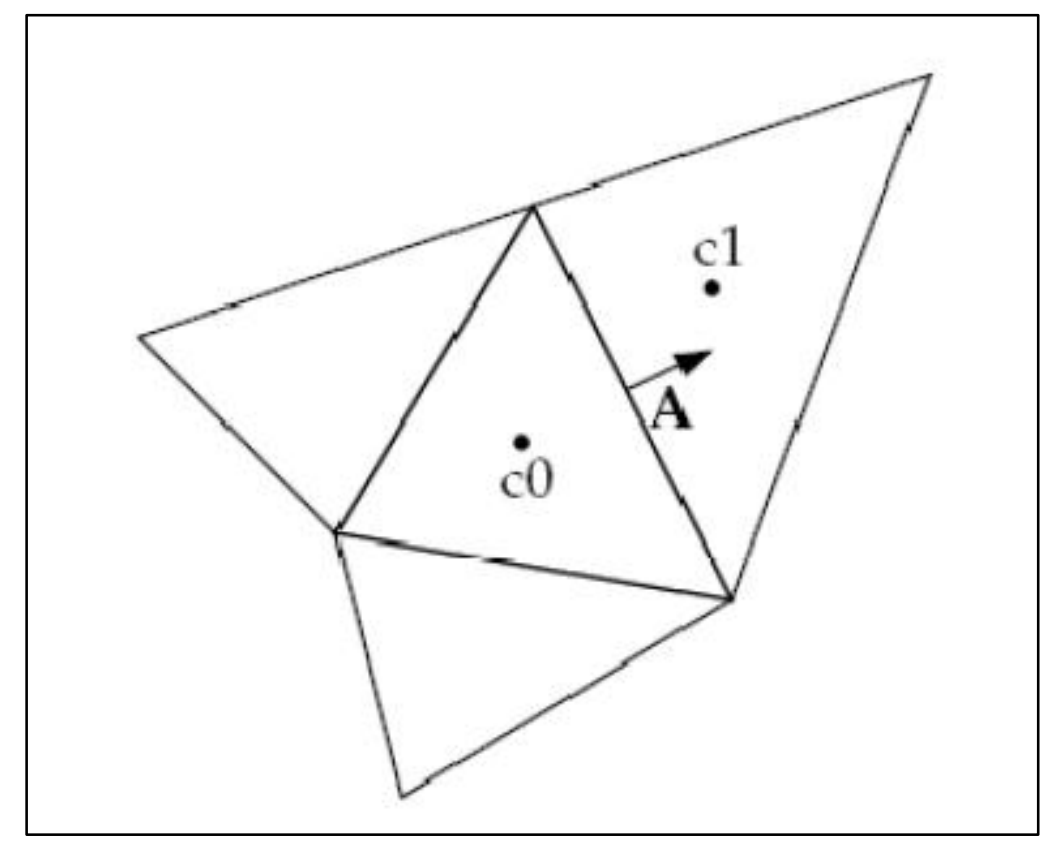

Figura 20 - Volume de controle utilizado para ilustrar a discretização da equação de transporte (Legendre, 2009)

Para obter a solução do problema deste trabalho, foi usado o método upwind de segunda ordem, pois com ele, é possível alcançar uma maior precisão nos resultados. Neste método, as quantidades das propriedades nas faces são calculadas utilizando um método de reconstrução multidimensional linear. É utilizada para uma maior precisão do método, série de expansão de 
Taylor. Utilizando o método upwind de segunda ordem, o valor da propriedade que sofre convecção pela face da célula $\phi_{f}$, pode ser calculado como:

$$
\phi_{f}=\phi+\operatorname{grad} \phi \Delta \vec{s}
$$

Em que $\phi$ é o valor do centro da célula e $\operatorname{grad} \phi$ os seus gradientes na célula a montante e $\Delta \vec{s}$ é o vetor deslocamento do centro da célula a montante ao centro da face, respectivamente.

\subsubsection{Sub-Relaxação}

A não linearidade acontece nas soluções das equações, por este motivo, é necessário um método de controle para as variações de $\phi$ entre as interações. Este controle pode ser obtido com ajuda de sub-relaxação que reduz as variações. Resumindo este método, afirma-se que o novo valor de $\phi$ na célula, depende do $\phi$ antigo, associado a uma variação de $\phi$ e um fator de sub-relaxação $\alpha$. Pode-se calcular a nova propriedade $\phi$ do seguinte modo:

$$
\phi=\phi_{\text {antigo }}+\alpha \Delta \phi
$$

\subsubsection{Acoplamento Pressão-Velocidade}

Existem algoritmos descritos na literatura que são usados para corrigir e predizer os valores das grandezas em estudo para o próximo passo da interação. O algoritmo SIMPLE (Método Semi-Implícito de Equações Acopladas à Pressão) é um desses algoritmos, que tentam predizer e corrigir o cálculo da pressão nas células. $O$ algoritmo utiliza inicialmente o campo de pressão $p^{*}$, para calcular o campo de velocidade $u^{\star}$ da seguinte maneira:

$$
J_{f}^{*}=\hat{J}_{f}^{*}+d_{f}\left(p_{c 0}^{*}-p_{c 1}^{*}\right)
$$

Em que $J_{f}^{*}$ é uma função de fluxo de massa por unidade de área ( $\rho u^{*}$ ) através da face $f, d_{f}$ a função da razão da área da célula em relação aos coeficientes lineares $a_{p}$ que é apresentado na equação 33. A condição de continuidade tem de ser sempre satisfeita, por este motivo, é inserida a função 
de correção de pressão ${ }^{J_{f}^{\prime}}$ na função de fluxo, dando origem a seguinte expressão:

$$
J_{f}=J_{f}^{*}+J_{f}^{\prime}
$$

Em que a função de correção é dada por:

$$
J_{f}^{\prime}=d_{f}\left(p_{c 0}^{\prime}-p_{c 1}^{\prime}\right)
$$

Em que as pressões p' são as pressões corrigidas. As equações de correção de fluxo são substituídas pelo algoritmo do SIMPLE.

$$
a_{p} p^{\prime}=\sum_{n b} a_{n b} p_{n b}^{\prime}+b
$$

Em que b é o fluxo de massa através da célula computacional.

$$
b=\sum_{f}^{N_{\text {frees }}} J_{f}^{*} A_{f}
$$

Para se calcular os valores das pressões de correção, resolve-se a equação das pressões até que haja convergência nos resultados, sempre havendo a chance neste processo dos valores divergirem. Para que não haja tal chance, é inserido à formulação, um processo de sub-relaxação $\alpha_{p}$ nas correções de pressão e fluxo, permanecendo da seguinte forma:

$$
\begin{aligned}
& p=p^{*}+\alpha_{p} p^{\prime} \\
& J_{f}=J_{f}^{*}+d_{f}\left(p_{c 0}^{\prime}-p_{c 1}^{\prime}\right)
\end{aligned}
$$

Pode-se dizer, que a análise computacional é um meio interpolador, no qual a qualidade dos resultados dependerá da riqueza de detalhes cujo modelo adotado possui, das condições de contorno adotadas e do refinamento da malha. Os modelos dos segmentos de aorta aneurismáticas utilizados neste estudo, serão capazes de representar da maneira mais fiel possível um modelo real de aneurisma de aorta abdominal infra-renal. Com relação às condições de contorno, devem ser empregadas ao modelo corretamente, afim de não causar desvios nos resultados numéricos. Para a simulação computacional do 
problema do escoamento será empregado o método dos volumes finitos MVF, que por sua vez, tem de ser discretizado corretamente para possibilitar uma convergência da análise, minimizando as incertezas de resultados. Em relação a malha, necessita-se adotar bom senso no critério de refinamento dela, pois com um grande refinamento de malha, gera-se bons resultados, porém elevase o custo computacional, por outro lado, com pouco refinamento de malha, os resultados podem não representar adequadamente a real situação do problema. A convergência dos resultados está interligada com o tamanho dos elementos de malha do modelo. A qualidade da malha é verificada por um critério de assimetria que é representado por:

$$
\text { Assimetria }=\frac{\text { tamanho ótimo }- \text { tamanho da célula }}{\text { tamanho ótimo }}
$$

Em que o tamanho ótimo é o tamanho de uma célula cujos lados são equiláteros. $O$ valor da assimetria pode variar de 0 a 1 , sendo o limite inferior considerado ótimo. Pode-se verificar que o valor de 0 será obtido quando 0 tamanho da célula for igual ao tamanho ótimo.

A malha ideal para a resolução da análise computacional deve considerar a precisão dos resultados e o desempenho. O desempenho está diretamente ligado ao número de elementos que constituem a malha, logo, uma malha muito refinada, com elementos muito pequenos, possue uma enorme quantidade de elementos, porém será necessário um custo computacional grande para a simulação. Por outro lado, uma malha com baixo refinamento, possuirá uma menor quantidade de elementos para preencher o mesmo volume, o que ocasionará um menor custo computacional, podendo levar a maiores incertezas dos resultados.

A análise feita, como citado acima, será uma análise de dinâmica dos fluidos computacional (DFC). Com este tipo de análise, é possível de se obter tensões junto à parede arterial, na região do endotélio, regiões de recirculação, perfis de pressões e velocidades nas regiões de interesse. 
Neste estudo, será adotado um padrão de pulso de pressão normotenso e os resultados serão em função dos campos de pressões, velocidades e tensões junto à parede arterial.

Os modelos computacionais importados do software InVesalius, tem formato stl que é uma malha triangular superficial, que representa a estrutura da parede arterial. Para a análise em DFC, é necessário que se tenha um bloco tridimensional da luz do vaso, isto é, toda a região por onde o sangue escoa. Por este motivo, é usado um software especial, gerador de malha, onde o modelo com malha superficial é importado. Dentro deste software é criada uma malha não estruturada tetraédrica devido à complexidade geométrica envolvida. Desta maneira é possível obter uma malha de qualidade para a análise conforme ilustrado na figura 21. Próximo à parede das geometrias verifica-se um refinamento nos tamanhos dos volumes para que se obtenha resolução nos resultados devido à turbulência do escoamento.

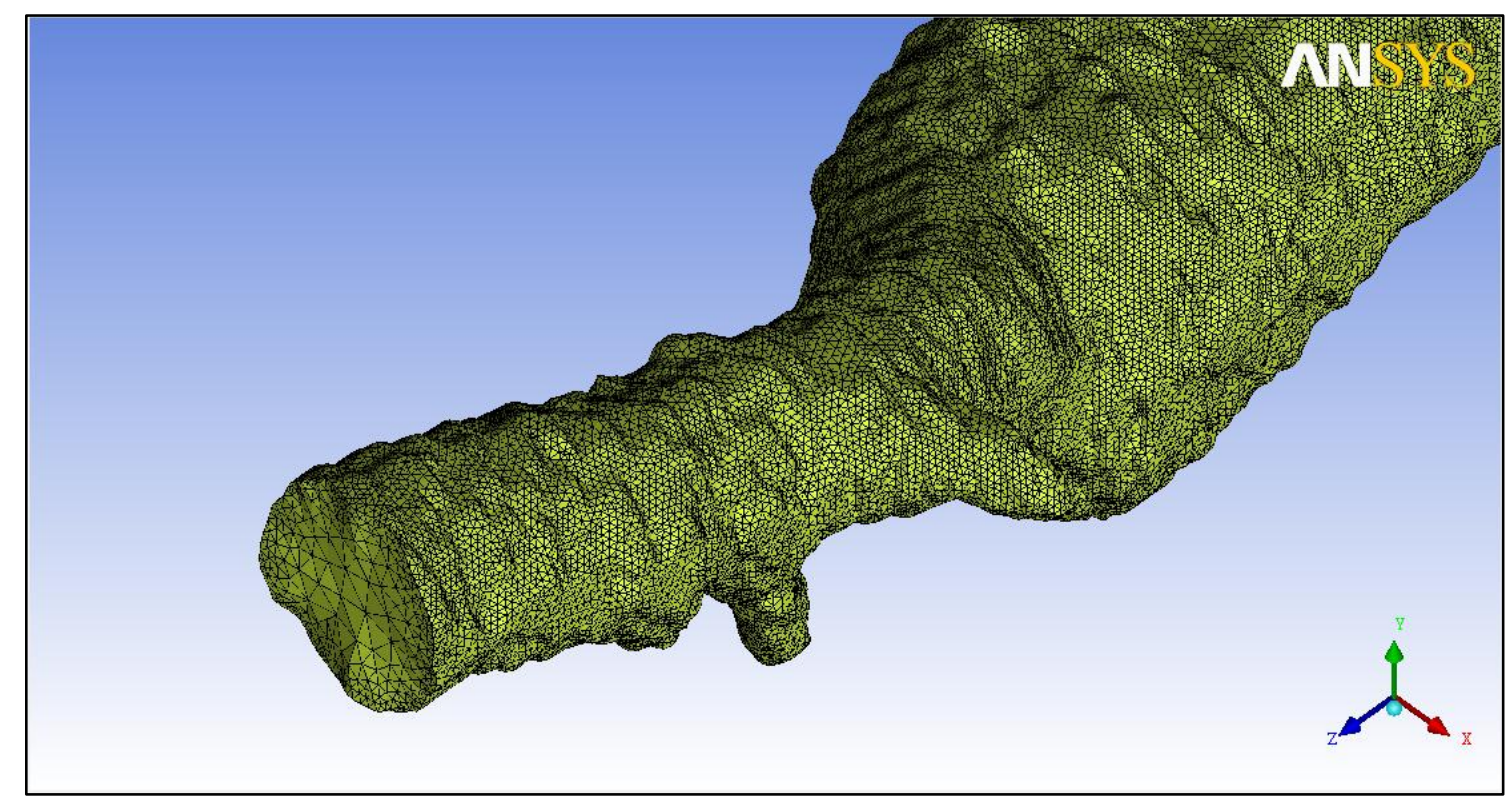

Figura 21 - Exemplo da malha usada para realização das simulações (AAABB1)

O nome do software gerador de malha utilizado neste trabalho é o ICEM CFD, versão 13.0, que é um dos componentes da versão do ANSYS utilizada para os cálculos das análises. Foram geradas as malhas para a simulação dos três aneurismas e das três endopróteses conforme tabela 1 apresentada a seguir. 
Tabela 1. Números de nós e Volumes das malhas simuladas

\begin{tabular}{|c|c|c|}
\hline Geometrias & Volumes das Malhas & Número de Nós \\
\hline AAA Legendre & 2426609 & 439928 \\
\hline AAABB1 & 2103420 & 380360 \\
\hline AAABB2 & 2485450 & 450046 \\
\hline Endoprótese Legendre & 2901141 & 524871 \\
\hline Endoprótese AAABB1 & 2103420 & 380360 \\
\hline Endoprótese AAABB2 & 762350 & 137480 \\
\hline
\end{tabular}

O estudo assume a parede do vaso como sendo rígida e o sangue como sendo um fluido incompressível, Newtoniano e homogêneo (Yamane et al., 2004). A análise foi feita utilizando escoamento pulsátil, conforme pulso de velocidade sanguínea encontrado na literatura (Figura 22) e regime turbulento. Foram considerados também variações de geometria ao longo dos modelos dos aneurismas. $O$ modelo de turbulência utilizado na análise é o $k-\varepsilon$, com tratamento de parede na malha e interpolador upwind de segunda ordem. Este modelo de turbulência foi utilizado pois é o modelo mais utilizado na literatura de referência deste trabalho (Yamane et al., 2004; How et al., 2005; Lengendre et al., 2006; Legendre, 2009). Foi utilizado tratamento de parede em todas as geometrias para que se obtenha qualidade nos resultados próximos à parede onde a velocidade é mais baixa em relação ao centro do escoamento. Este tratamento de parede consiste em diminuir o tamanho dos elementos da malha próximo a parede, aumentando os volumes de acordo com a proximidade com o centro da geometria. Apresenta-se a seguir na figura 22 os pulsos de pressão e velocidade de um paciente adulto, normotenso, em repouso e estes pulsos de pressão e velocidade são correspondentes. Estas funções são pulsos trifásicos apropriados para condições hemodinâmicas normais no segmento infra-renal da aorta humana, como foi reportado por Mill et al. 1970 e tem sido utilizadas com muito sucesso (Xenos et al. 2011, Sheidaei et al. 2011). Com a experiência adquirida neste trabalho, foi verificado que o software CFX fornece melhores resultados, quando se impõe um pulso de velocidade na entrada das geometrias e um pulso de saída como condição de contorno de saída da geometria envolvida. 


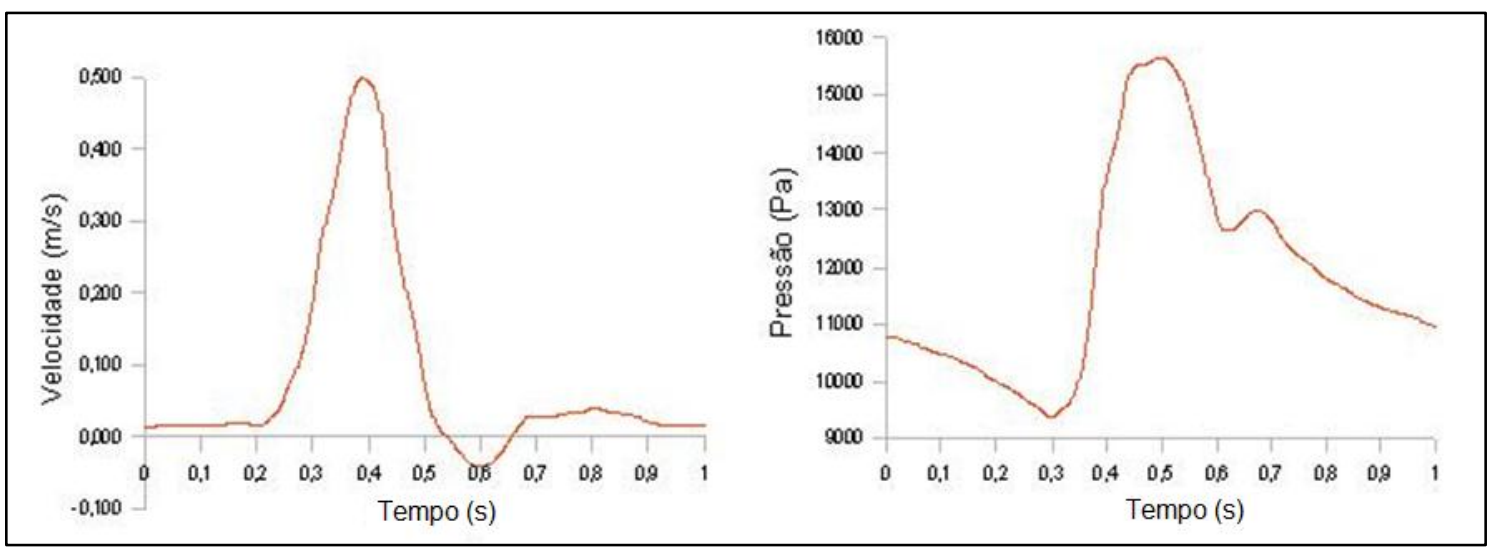

Figura 22 - Pulso de Velocidade e Pressão usados no Modelo (Mills et al., 1970)

A condição de entrada para as simulações é o pulso de velocidade com características fisiológicas. Já a condição na saída das artérias ilíacas, é o pulso de pressão, desprezando-se as perdas de cargas localizadas nos trechos percorridos pelo fluido e as diferenças destas perdas de carga entre as ilíacas. A forma de onda considerada como dado de entrada do problema, é o pulso de velocidade fisiológico, com condições de impermeabilidade aplicada na parede da artéria. A massa específica do sangue e a viscosidade do sangue são adotadas no estudo como sendo, respectivamente, $1056 \mathrm{~kg} / \mathrm{m}^{3}$ e 3,5 mPa s (Legendre et al., 2006), estando assim, numa condição fisiológica. Para as simulações, foi usado um time-step de 0,02 segundo, para que se obtenha a convergência dos dados, com os critérios anteriormente descritos.

\subsection{Caracterização Geométrica do AAA}

Neste trabalho, foram analisadas três geometrias de AAA reais obtidas por meio de tomografia computadorizada e com dimensões como comprimento $L$, diâmetro $D$, assimetria $\beta$ distintos. O comprimento é o comprimento do AAA, o diâmetro é o diâmetro máximo do AAA e a assimetria é o ângulo que é formado pelas artérias ilíacas. Os diferentes resultados de pressão, velocidade obtidos nas simulações serão discutidos em função das características geométricas acima, a fim de verificar a influência destas características nas variáveis hemodinâmicas resultantes das simulações. 


\subsection{Modelagem de Endoprótese}

As análises a seguir serão feitas com uma endoprótese inserida em cada um dos AAA's. Cada aneurisma receberá a endoprótese que mais se adapta à geometria do AAA. Estas geometrias serão modeladas com a ajuda de um software de CAD (Computer Aided Design), tendo por base as geometrias fornecidas pela Braile Biomédica sediada em São José do Rio Preto - SP. Com base na geometria dos AAA's, as próteses serão do modelo bifurcado ou do modelo cilíndrico, ilustrados nas figuras 13, 23, 24 e 25. As endopróteses analisadas neste trabalho são baseadas em endopróteses de mercado, porém com algumas simplificações. O modelo de endoprótese utilizado no AAA cedido do trabalho de Legendre corresponde ao modelo bifurcado 26-14x130 (Figura 23). O modelo de endoprótese utilizado no tratamento do AAA cedido pela Braile Biomédica (AAABB1) (Figura 24), corresponde a um modelo bifurcado, mantendo-se as mesmas característica de medidas, porém com diâmetros das ilíacas e comprimento maiores; neste caso o modelo escolhido foi o 26-22×150. O modelo de endoprótese escolhido para o tratamento do AAA cedido pela Braile Biomédica (AAABB2) corresponde a um modelo cilíndrico, 24×80 (Figura 25). Esta diferenciação na geometria da endoprótese do AAABB2 se deu pela distância que o aneurisma está da bifurcação com as artérias ilíacas. 


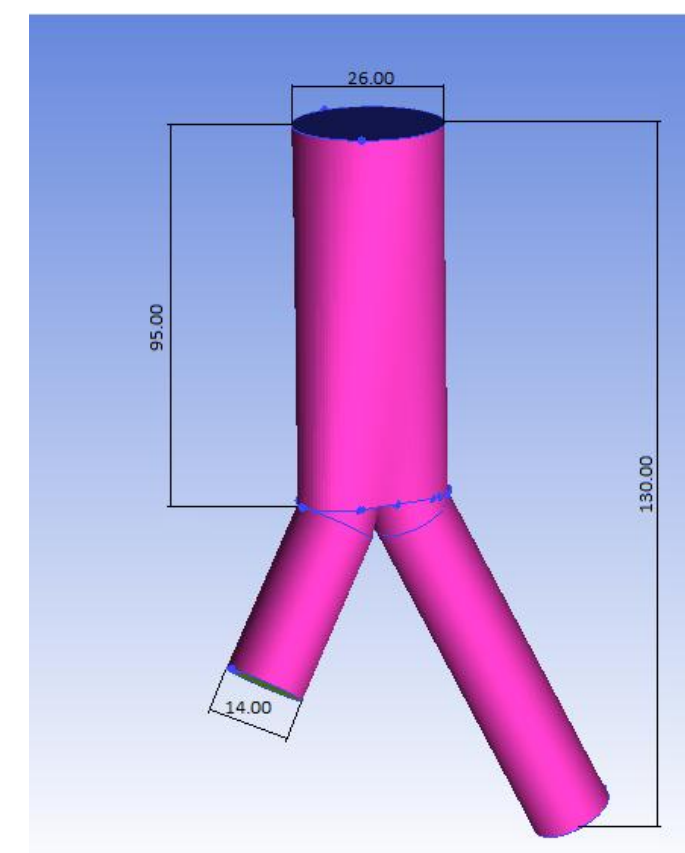

MNSYS

Figura 23 - Construção do modelo tridimensional da endoprótese para o AAA Legendre

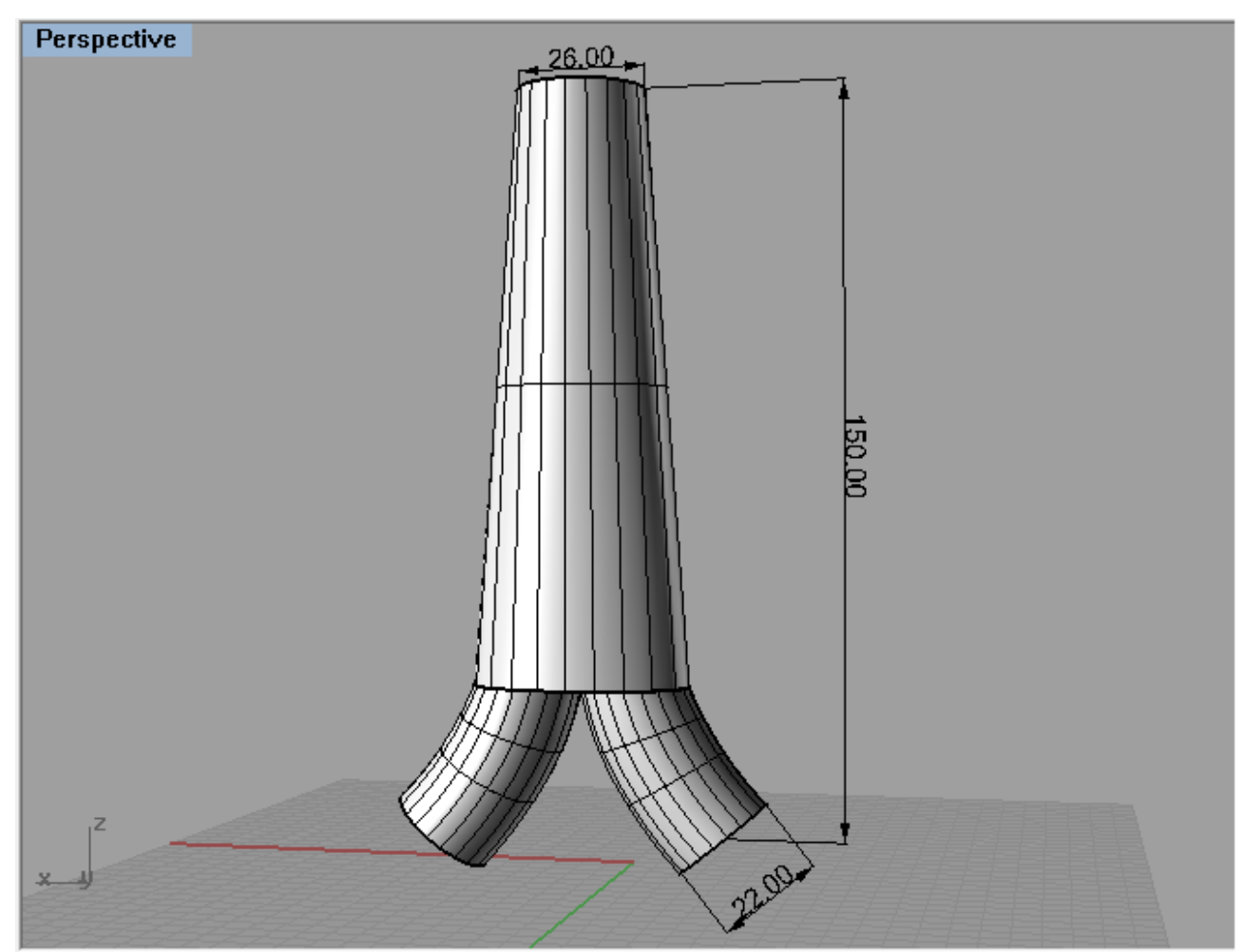

Figura 24 - Construção do modelo tridimensional da endoprótese para o AAABB1 


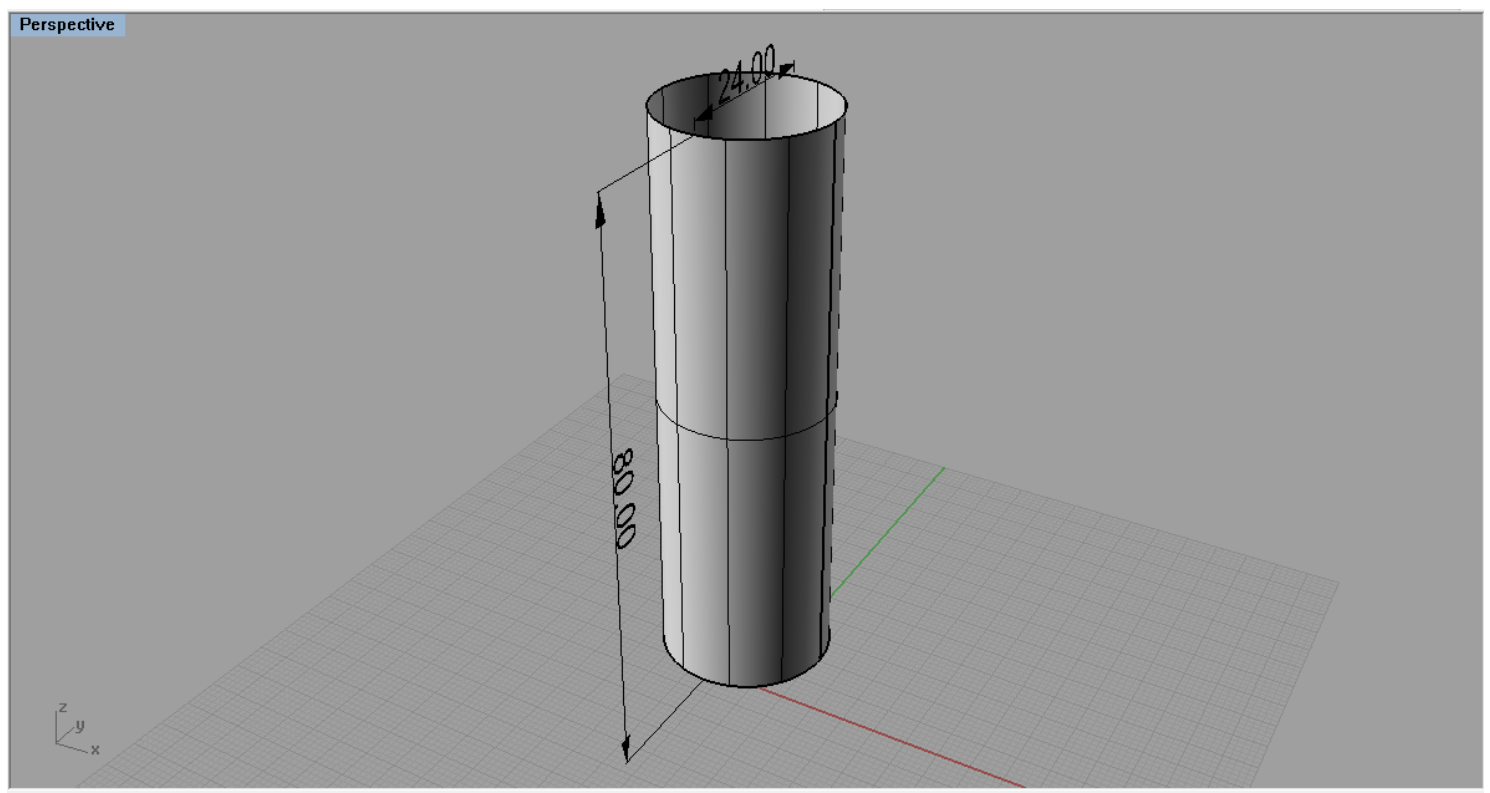

Figura 25 - Construção do modelo tridimensional da endoprótese para o AAABB2

\subsection{Simulação Computacional do Escoamento pelas Endopróteses}

Nesta etapa do trabalho, será feita a simulação do escoamento através da endoprótese instalada para o aneurisma correspondente. As condições de entrada e saída da simulação com a instalação da prótese serão semelhantes, pois será inserido o mesmo pulso de pressão fisiológico com paciente normotenso (figura 22) na entrada da aorta. Na saída das artérias ilíacas, será inserido o mesmo valor de pressão média em ambas as ilíacas, admitindo as mesmas hipóteses da simulação do AAA. Como no caso das simulações do AAA, há necessidade de tratamento de parede e interpolador upwind de $2^{\mathrm{a}}$ ordem.

\section{Resultados e Discussão}

\subsection{Modelagem Tridimensional de Aneurismas Reais}

Foram obtidos três modelos geométricos de aneurismas reais, por meio de imagens de exames de tomografia computadorizada. Um dos modelos de aneurismas foi cedido pelo trabalho de Legendre (2009), os outros dois foram retirados do banco de dados da Braile Biomédica, cedidos pelo Dr. Guilherme Agreli. Nos três casos de AAA foi necessário o tratamento das imagens 
DICOM, com a ajuda do software InVesalius, para a obtenção dos modelos tridimensionais.

O aneurisma fornecido por Legendre (2009) possuía extensão stl, com tratamento feito pelo software InVesalius. Este aneurisma, na realidade, possuía a geometria da artéria aorta abdominal, uma porção aneurismática e as duas artérias ilíacas (Figura 26). $\mathrm{O}$ arquivo demonstra apenas os contornos das paredes dos vasos, necessitando de tratamento para que seja possível a realização de simulações de dinâmica dos fluidos computacional. Como para a análise em DFC é necessário que se tenha um modelo que represente o fluido, este modelo necessita de modificações para que se tenha um modelo tridimensional, apenas da luz do vaso.

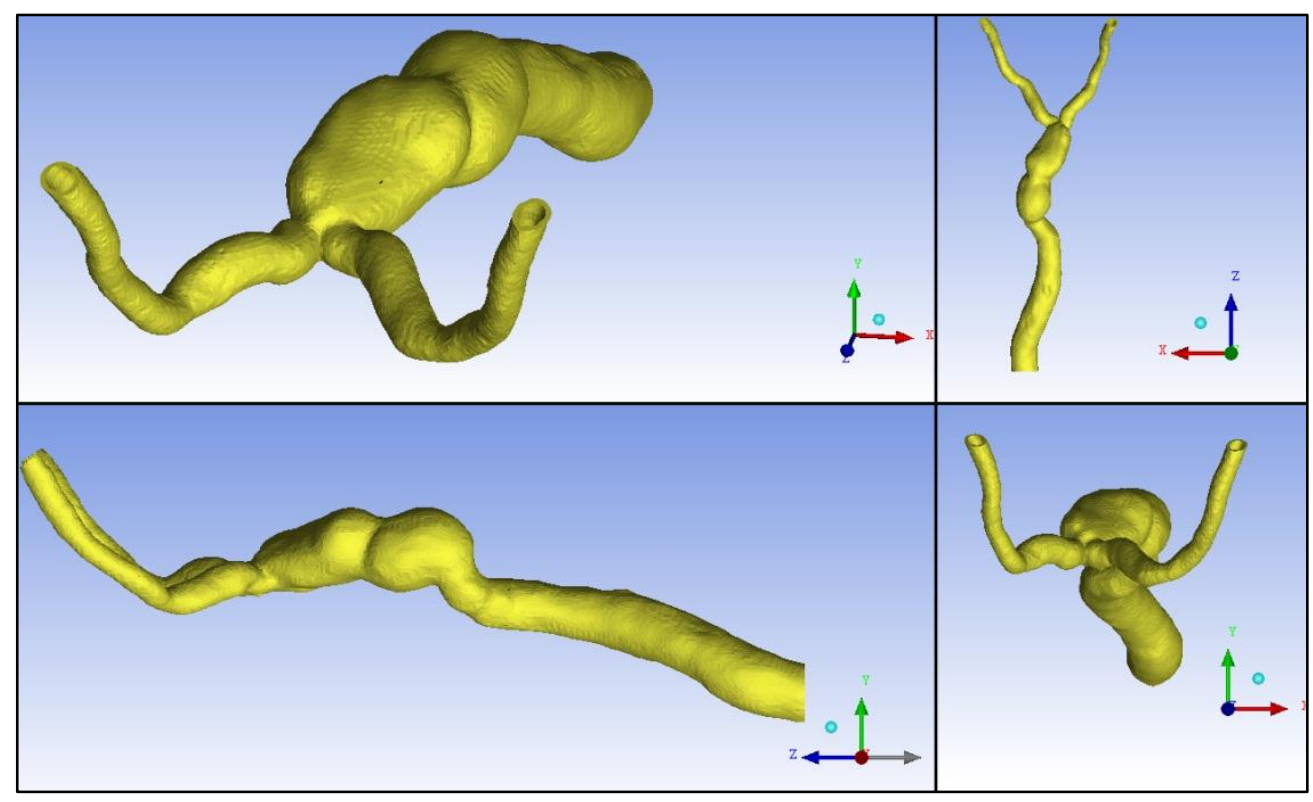

Figura 26 - Aneurisma de Aorta Abdominal Infra-Renal (Legendre, 2009)

Este aneurisma será usado para validar o modelo do escoamento sanguíneo e foi simulado novamente, com o intuito de ajustar o modelo de escoamento do sangue.

O segundo aneurisma (AAABB1), possuía muitos detalhes que foram editados conforme descrito no item 4.1 (Figura 15), dando origem a um aneurisma tridimensional conforme a figura 27 ilustra. Este aneurisma, do mesmo modo que o anterior é formado pela artéria aorta, pelo aneurisma propriamente dito, e pelas artérias ilíacas. 


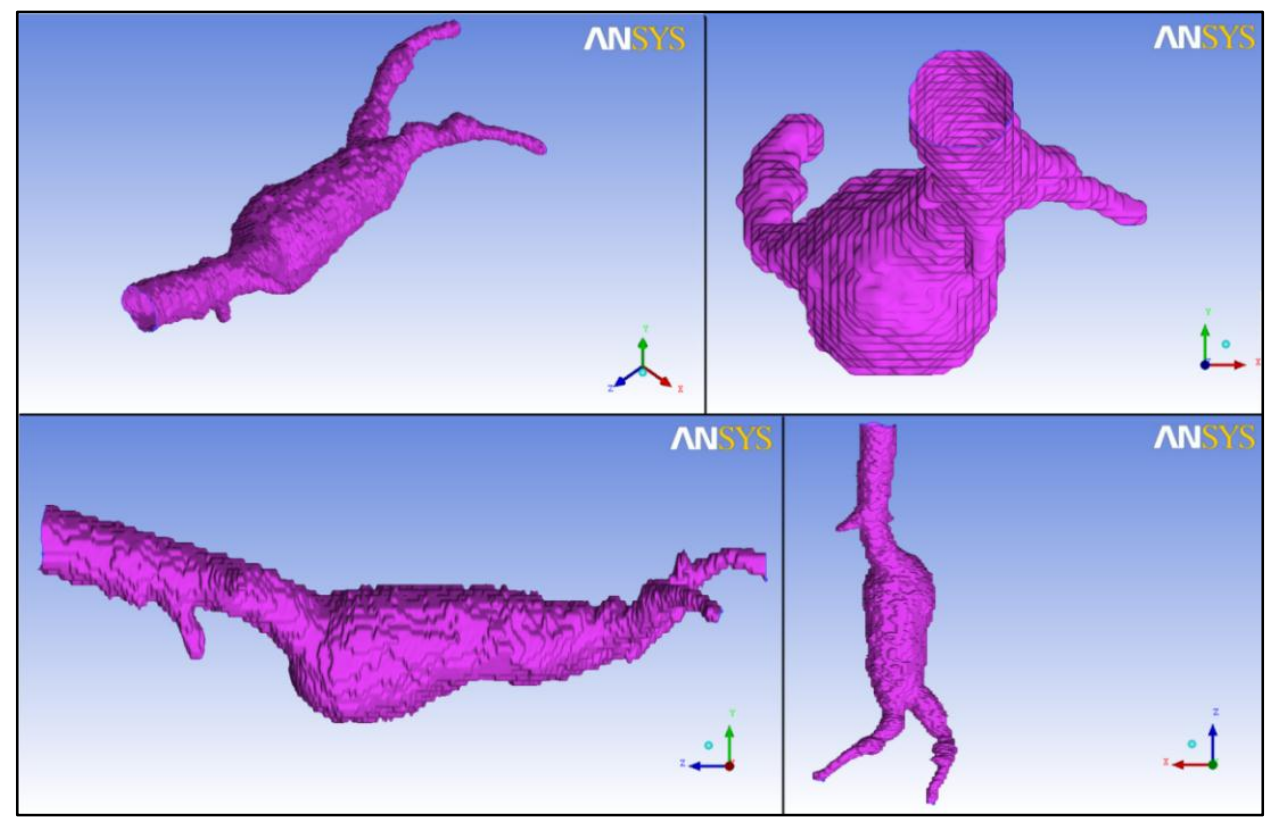

Figura 27 - Aneurisma de Aorta Abdominal Infra-Renal (AAABB1)

Para o terceiro AAA (AAABB2), houve a necessidade de edição pois havia no arquivo muitos detalhes que não acrescentariam melhores qualidades de resultados considerando o escoamento dentro do aneurisma, porém aumentariam consideravelmente o custo computacional da análise. Estes detalhes que foram retirados eram pequenos vasos anteriores ao escoamento. O mesmo algoritmo foi usado para a criação de um modelo tridimensional a partir destas imagens. O modelo tridimensional é constituído pelas paredes da aorta, pela parede aneurismática e pela parede das artérias ilíacas. A figura 28 ilustra o terceiro aneurisma de aorta abdominal real. 


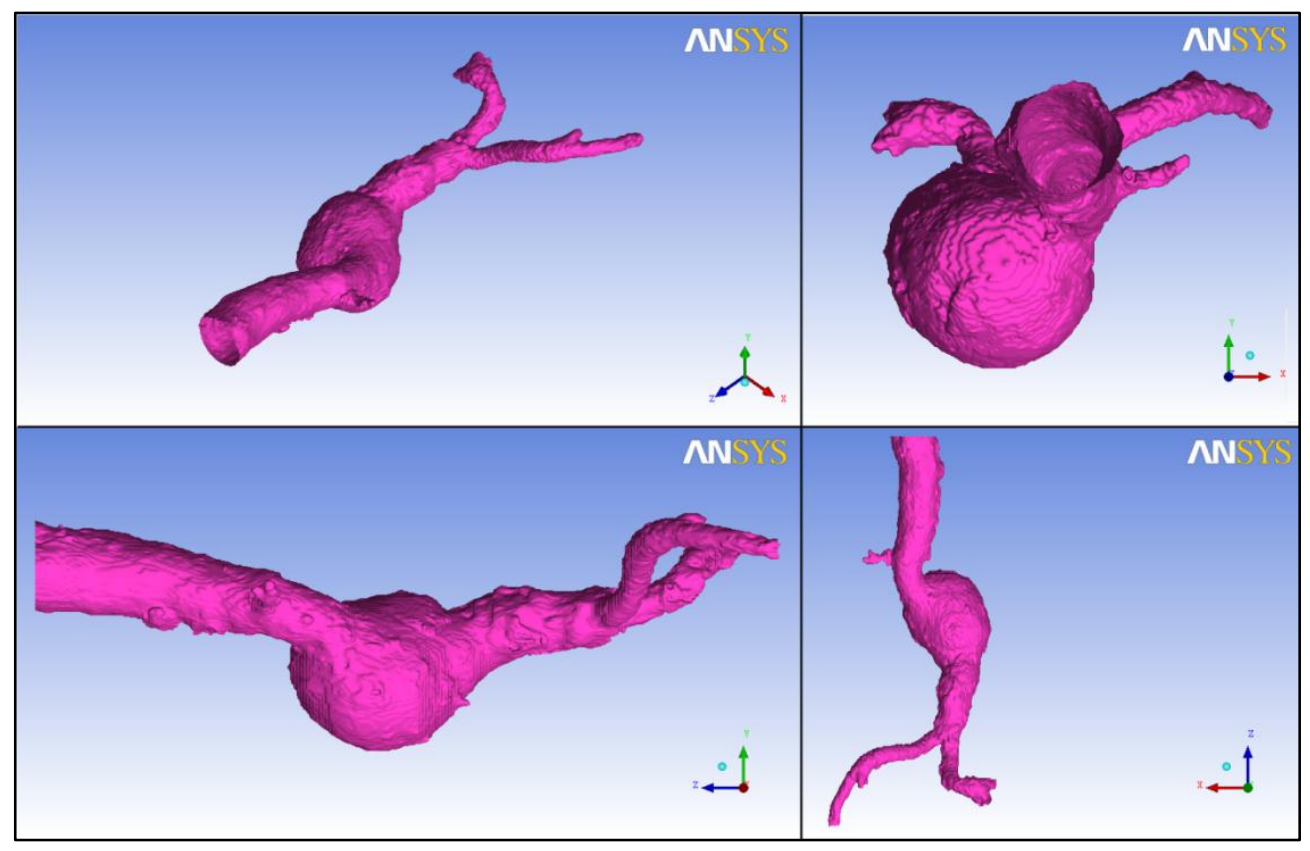

Figura 28 - Aneurisma de Aorta Abdominal Infra-Renal (AAABB2)

Nas seções a seguir, serão apresentados os resultados das simulações nos aneurismas de aorta abdominal apresentados anteriormente. Os resultados serão divididos pelas características hemodinâmicas. Os primeiros resultados expostos a seguir são campo de pressões, seguidos pelo campo de velocidades, linhas de corrente e tensões de cisalhamento.

\subsubsection{Campo de Pressões}

Nesta seção do trabalho, serão apresentados os resultados das pressões calculadas pelas simulações. Os resultados serão divididos de acordo com as diferentes geometrias. Serão agrupadas as geometrias do AAA com a respectiva endoprótese. 
5.1.1.1 Aneurisma de Legendre

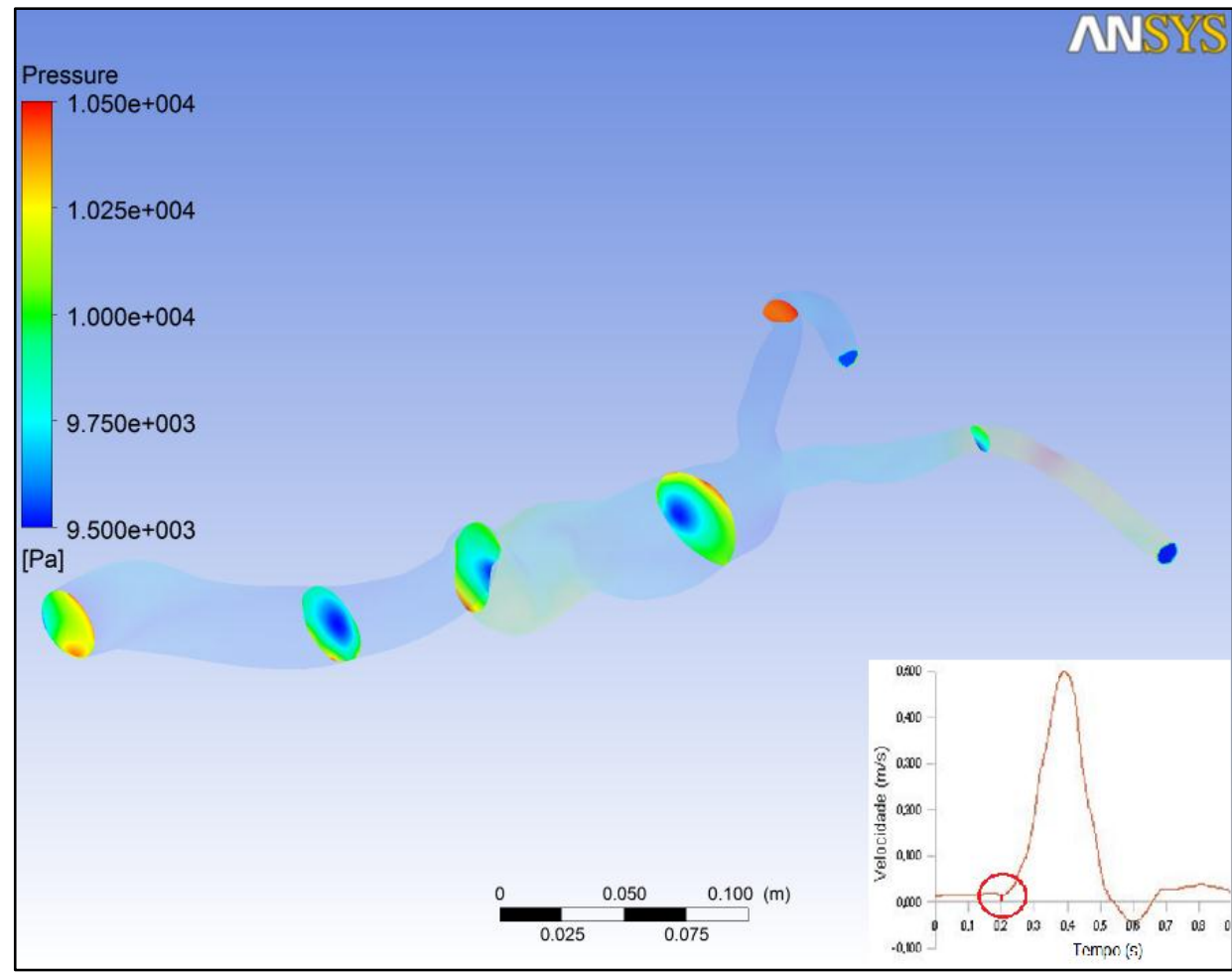

Figura 29 - Resultado de pressão em AAA no instante $t=0,2$ segundo (AAA Legendre)

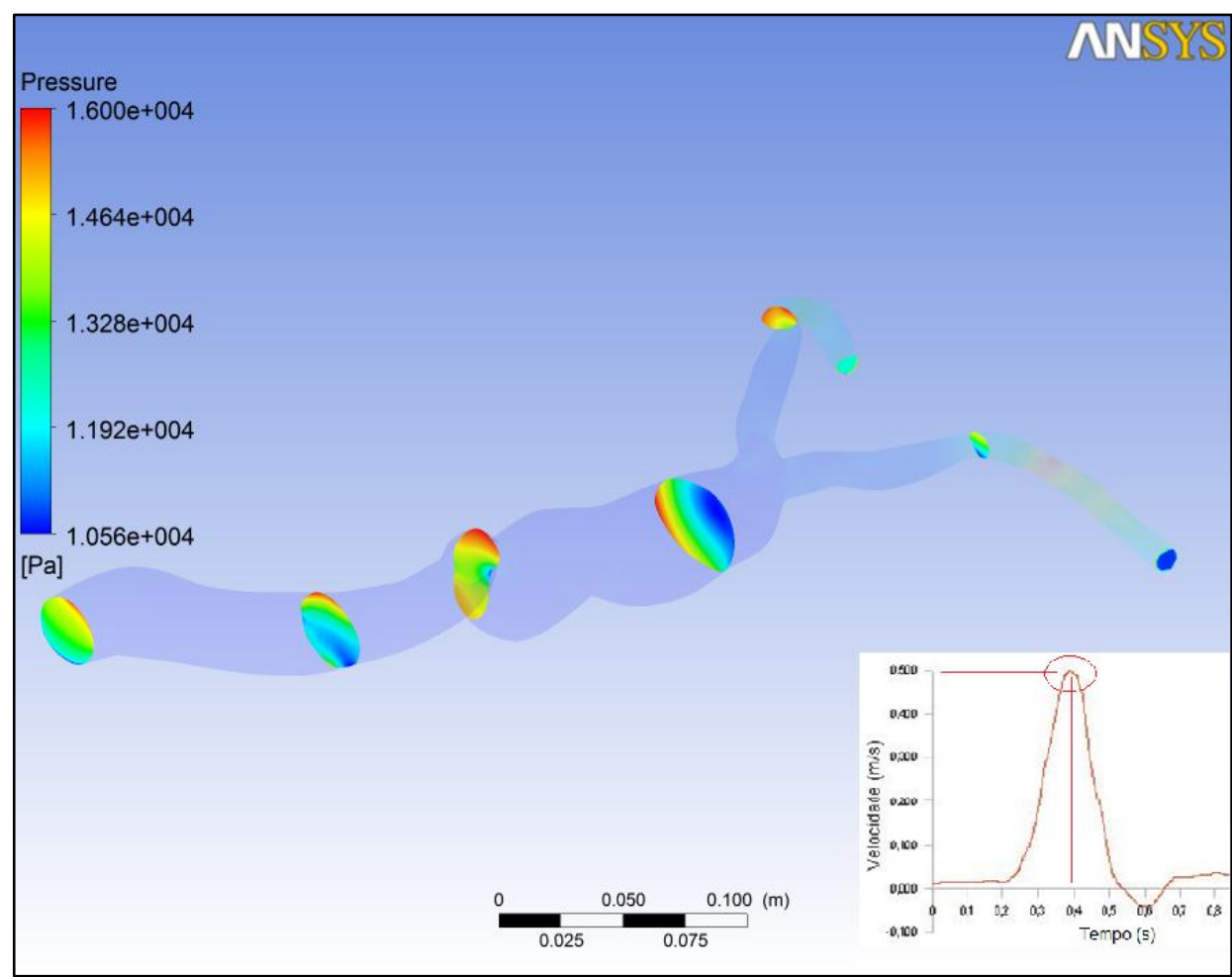

Figura 30 - Resultado de pressão em AAA no instante $t=0,4$ segundo (AAA Legendre) 


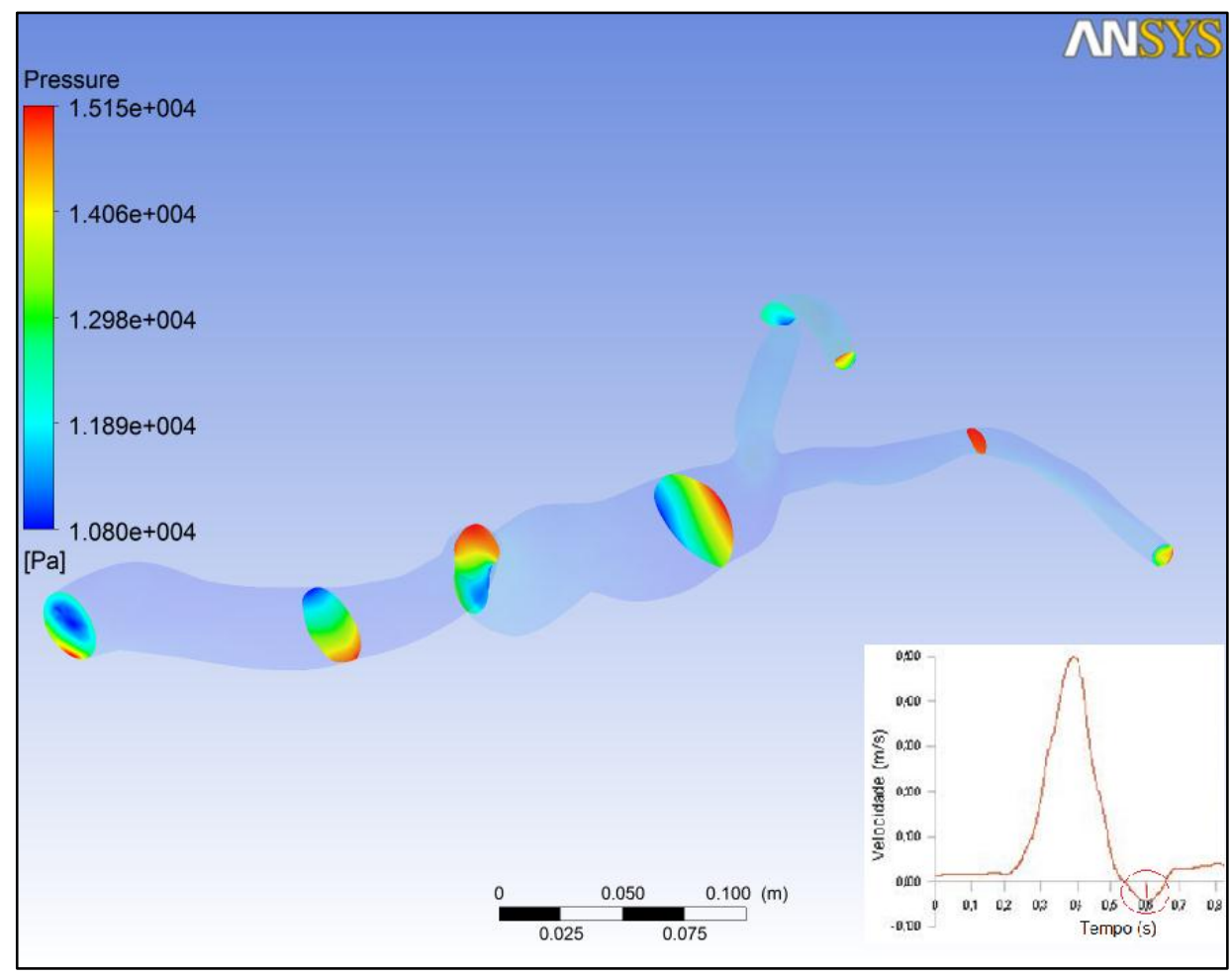

Figura 31 - Resultado de pressão em AAA no instante $t=0,6$ segundo (AAA Legendre)

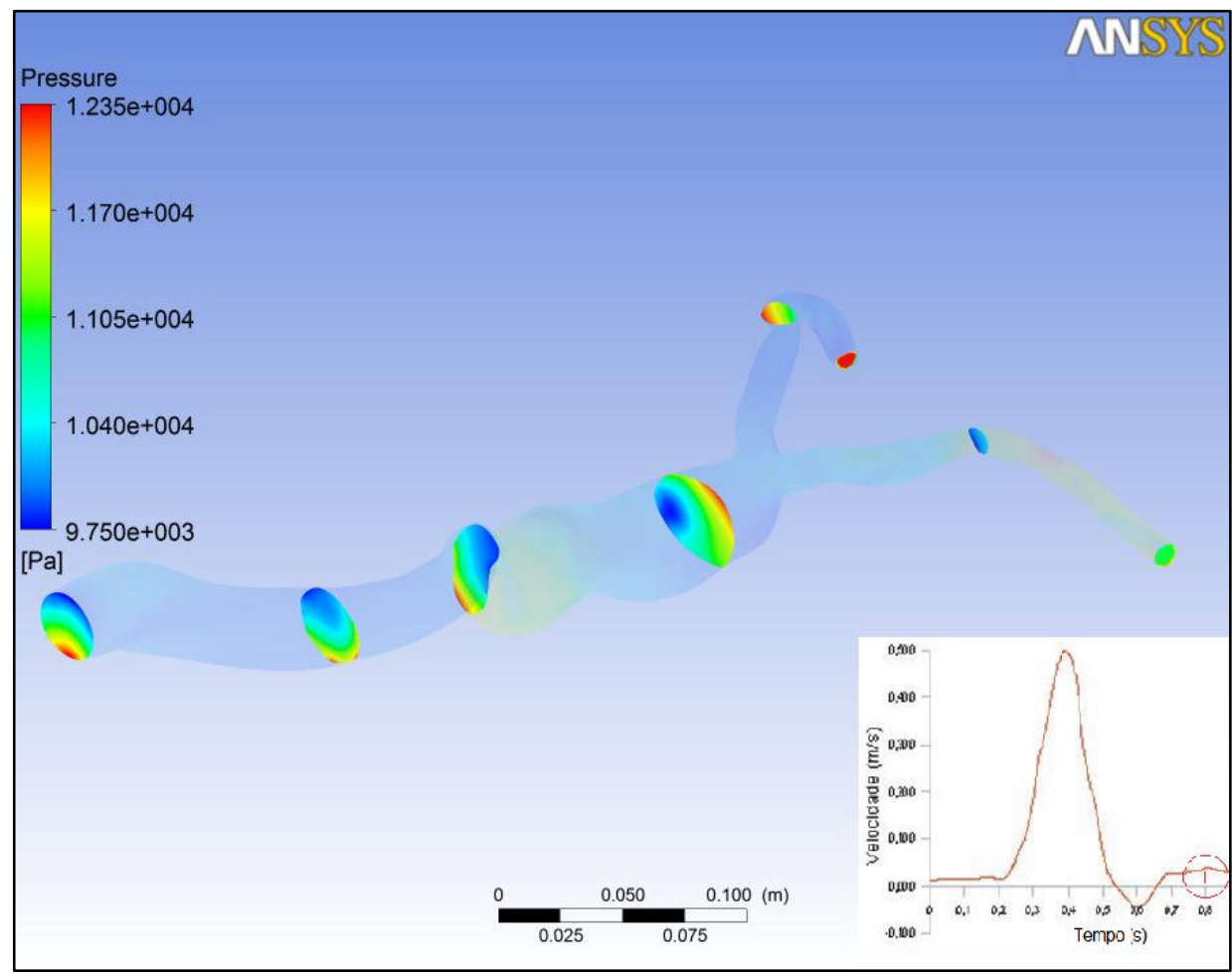

Figura 32 - Resultado de pressão em AAA no instante $t=0,8$ segundo (AAA Legendre) 


\subsubsection{Endoprótese Bifurcada para Aneurisma de Legendre}

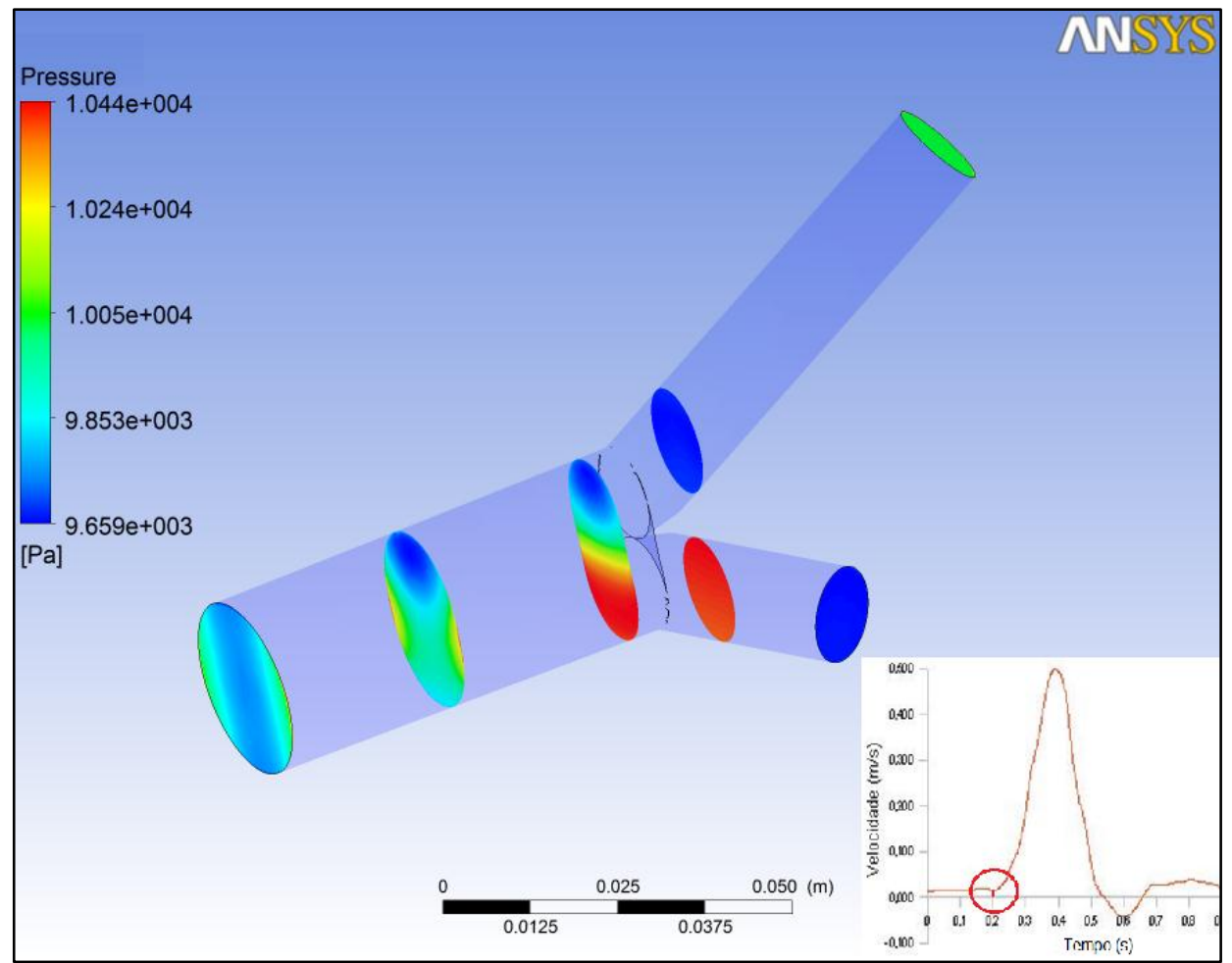

Figura 33 - Resultado de pressão em Endoprótese para AAA no instante $t=0,2$ segundo (Endoprótese AAA Legendre)

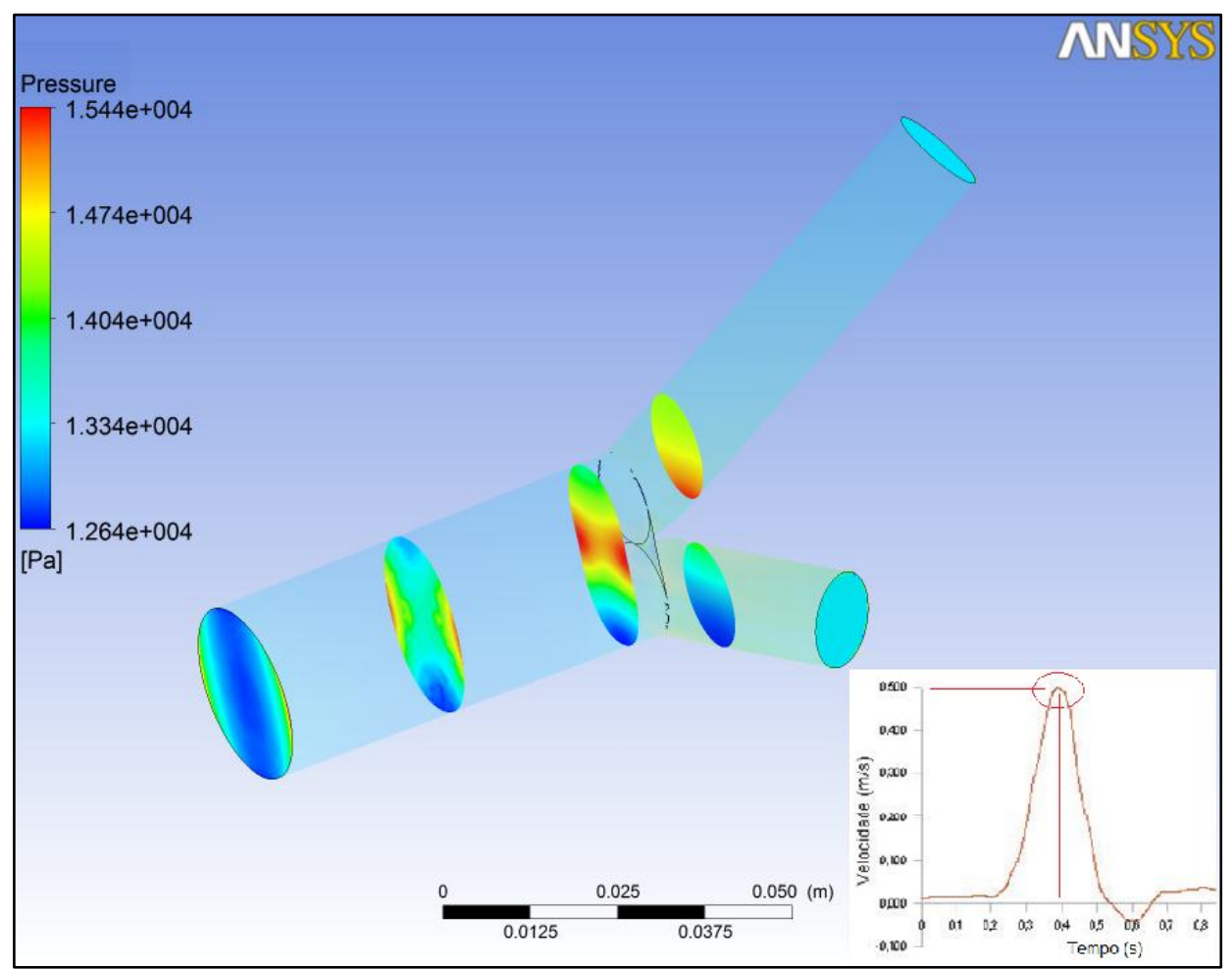

Figura 34 - Resultado de pressão em Endoprótese para AAA no instante $t=0,4$ segundo (Endoprótese AAA Legendre) 


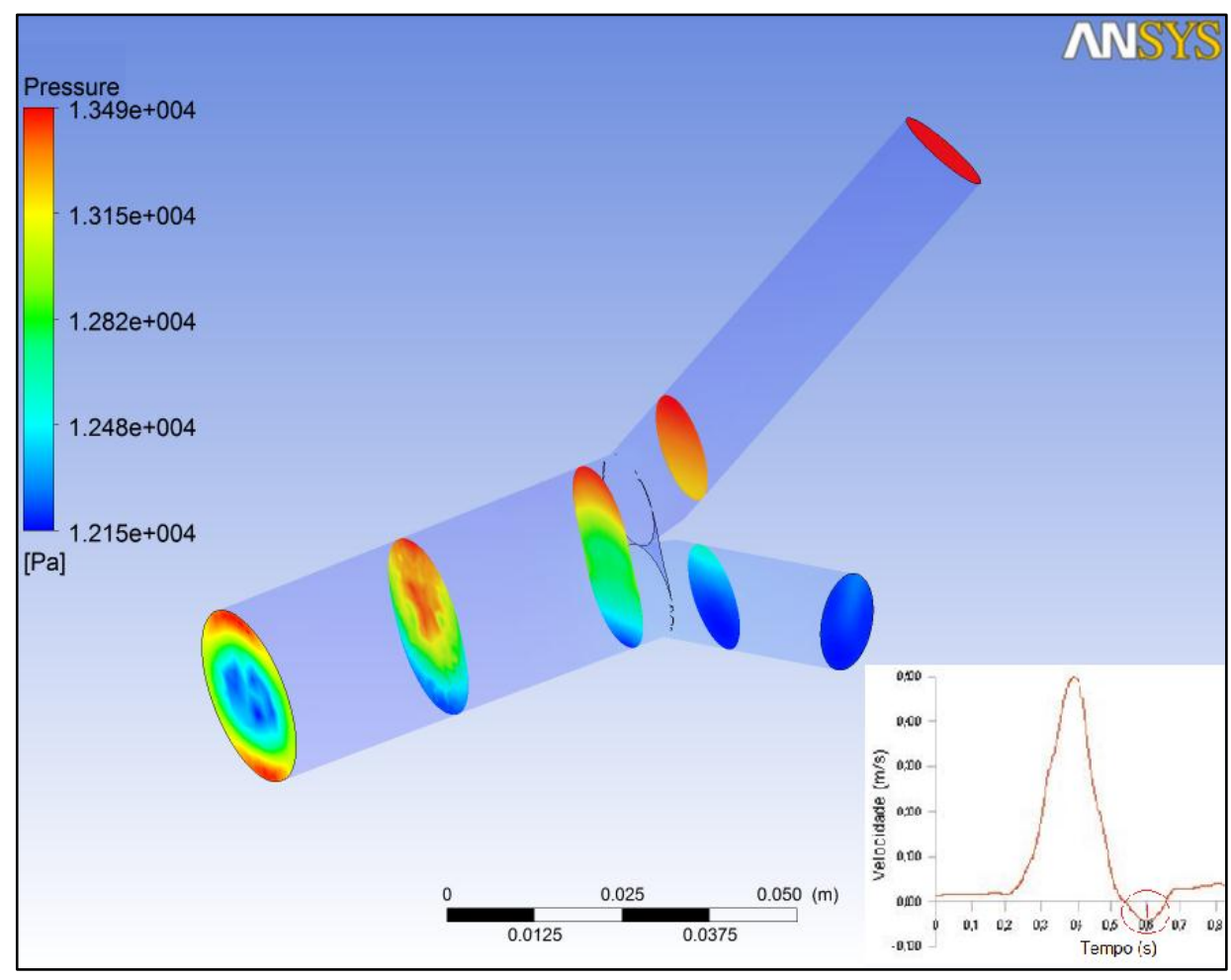

Figura 35 - Resultado de pressão em Endoprótese para AAA no instante $t=0,6$ segundo (Endoprótese AAA Legendre)

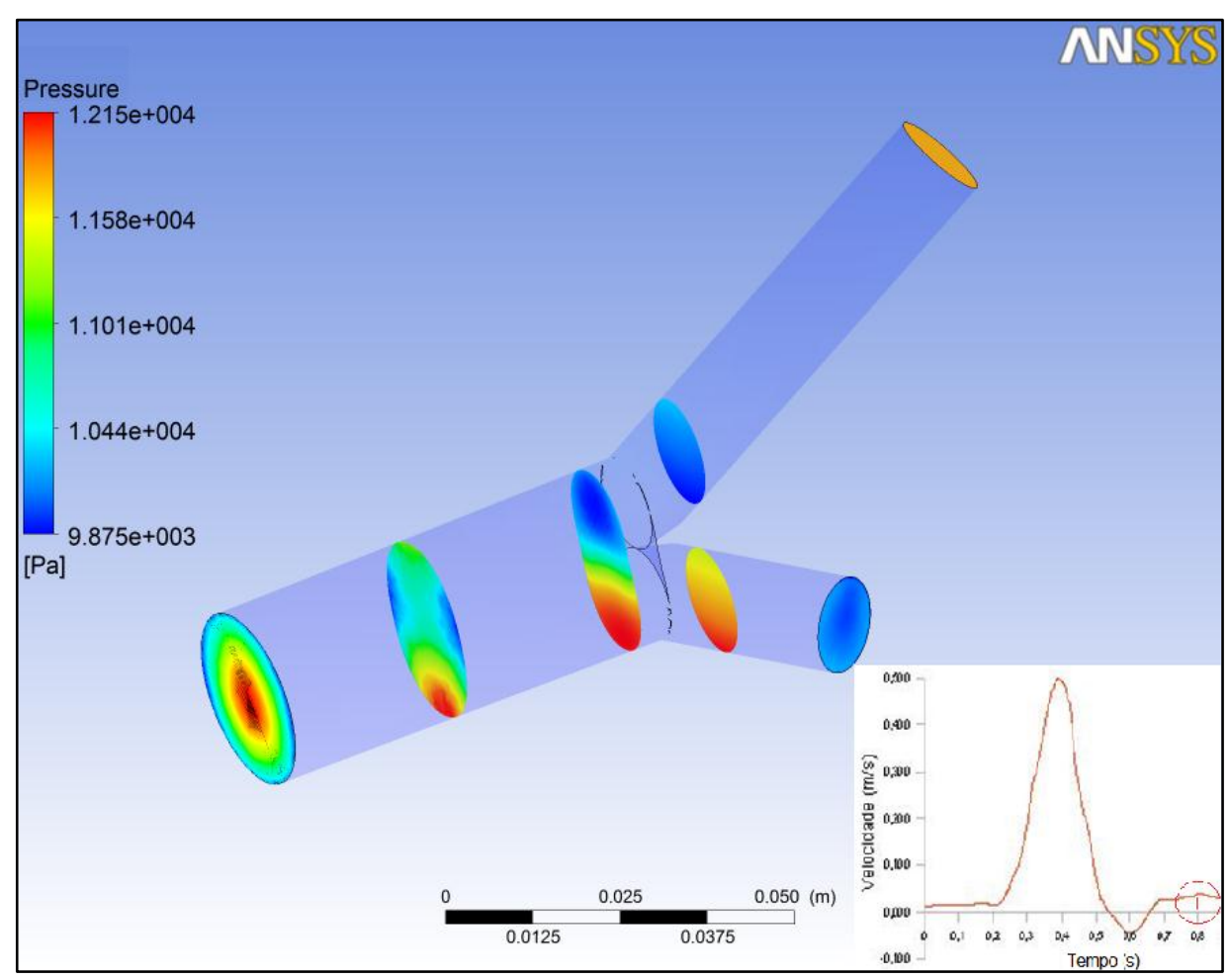

Figura 36 - Resultado de pressão em Endoprótese para AAA no instante $t=0,8$ segundo (Endoprótese AAA Legendre) 
5.1.1.3 Aneurisma $A A A B B 1$

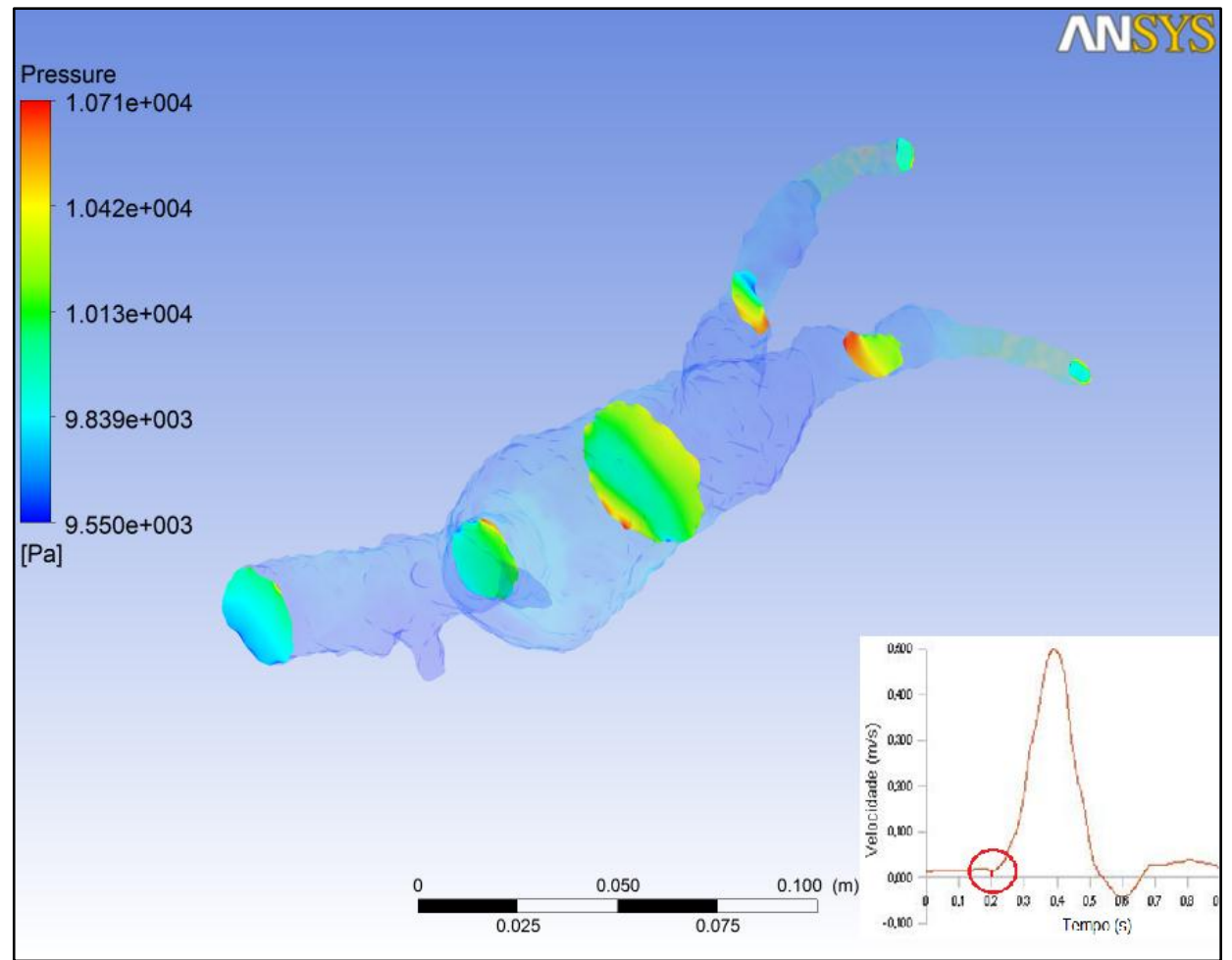

Figura 37 - Resultado de pressão em AAA no instante $t=0,2$ segundo (AAABB1)

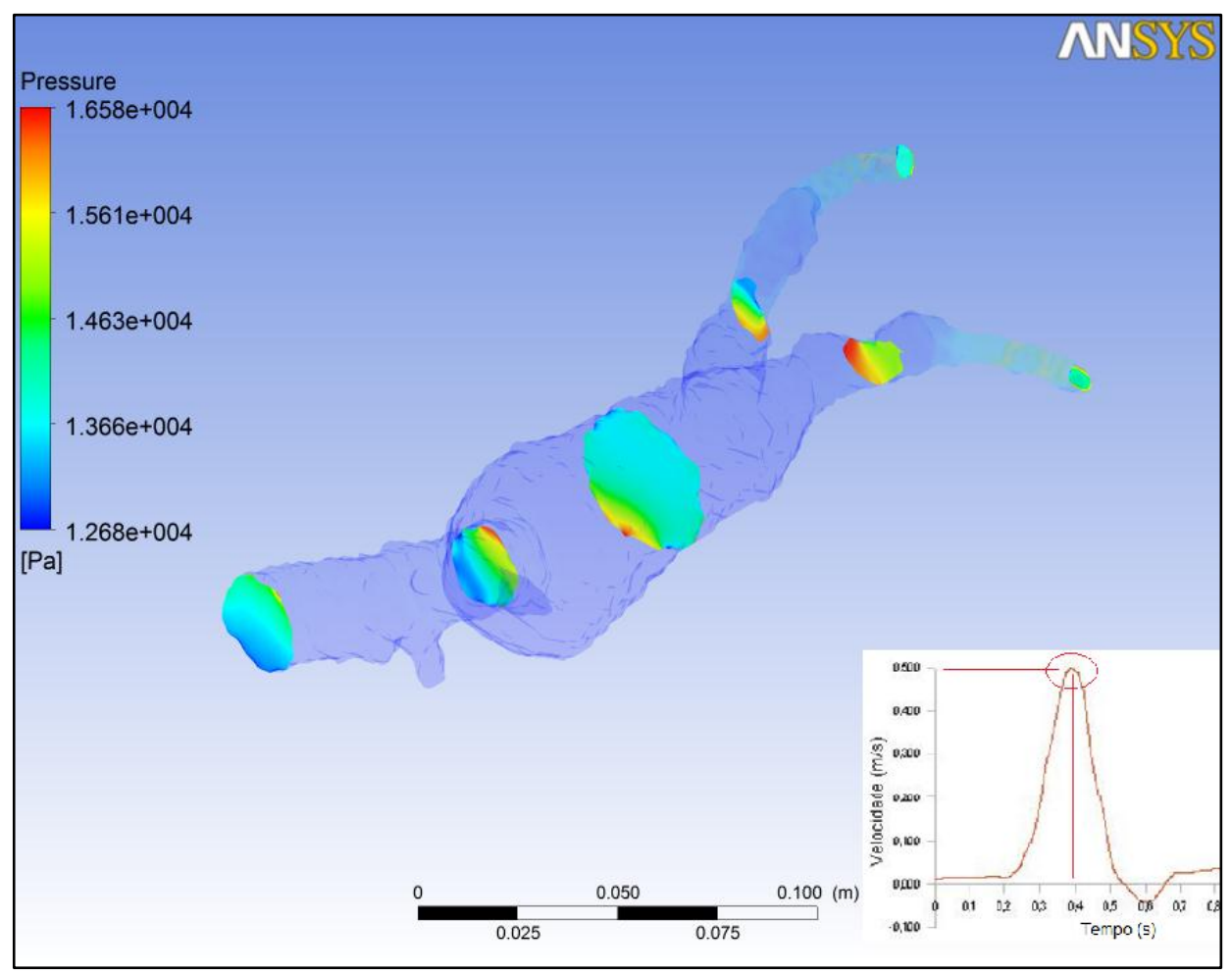

Figura 38 - Resultado de pressão em AAA no instante $t=0,4$ segundo (AAABB1) 


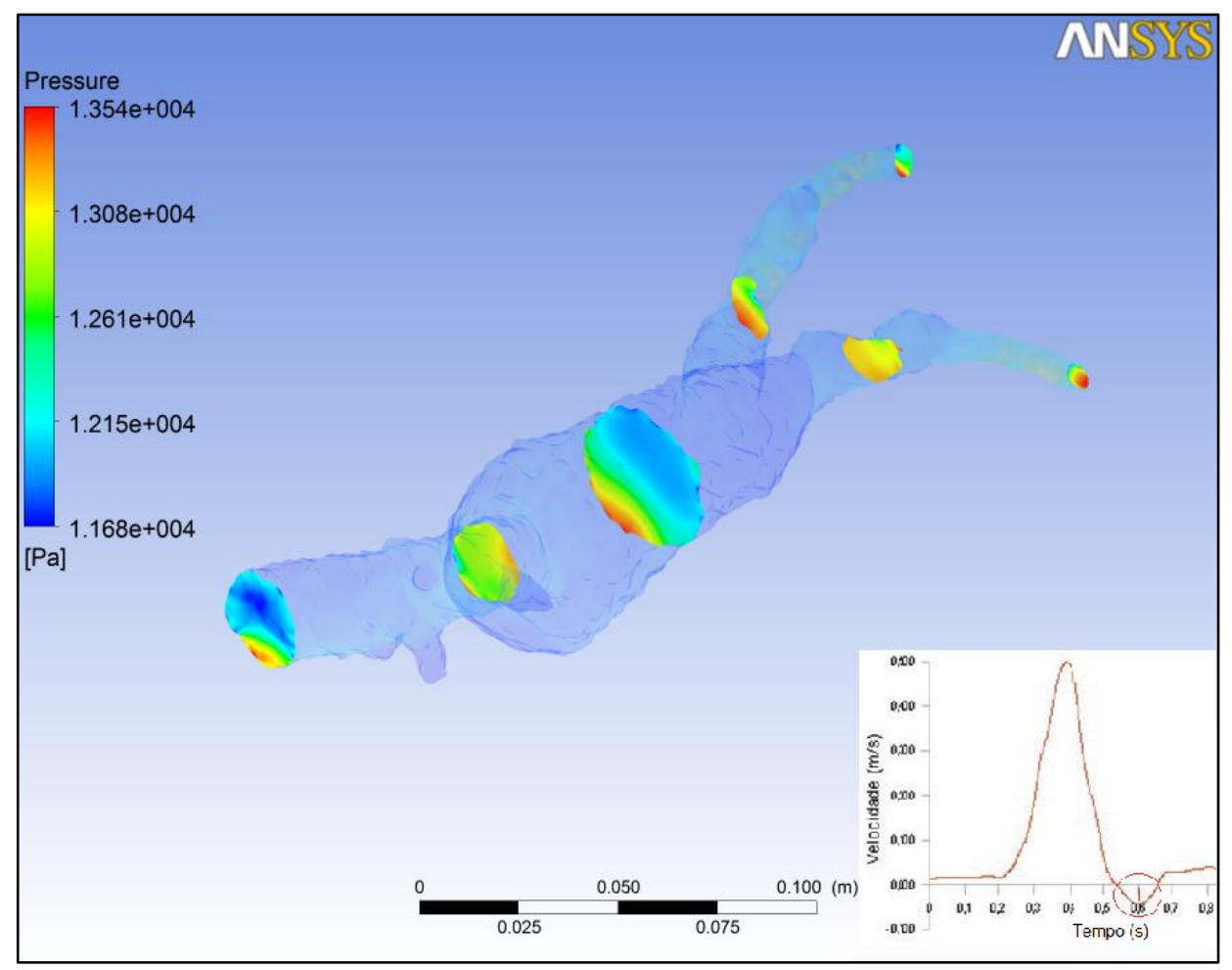

Figura 39 - Resultado de pressão em AAA no instante $t=0,6$ segundo (AAABB1)

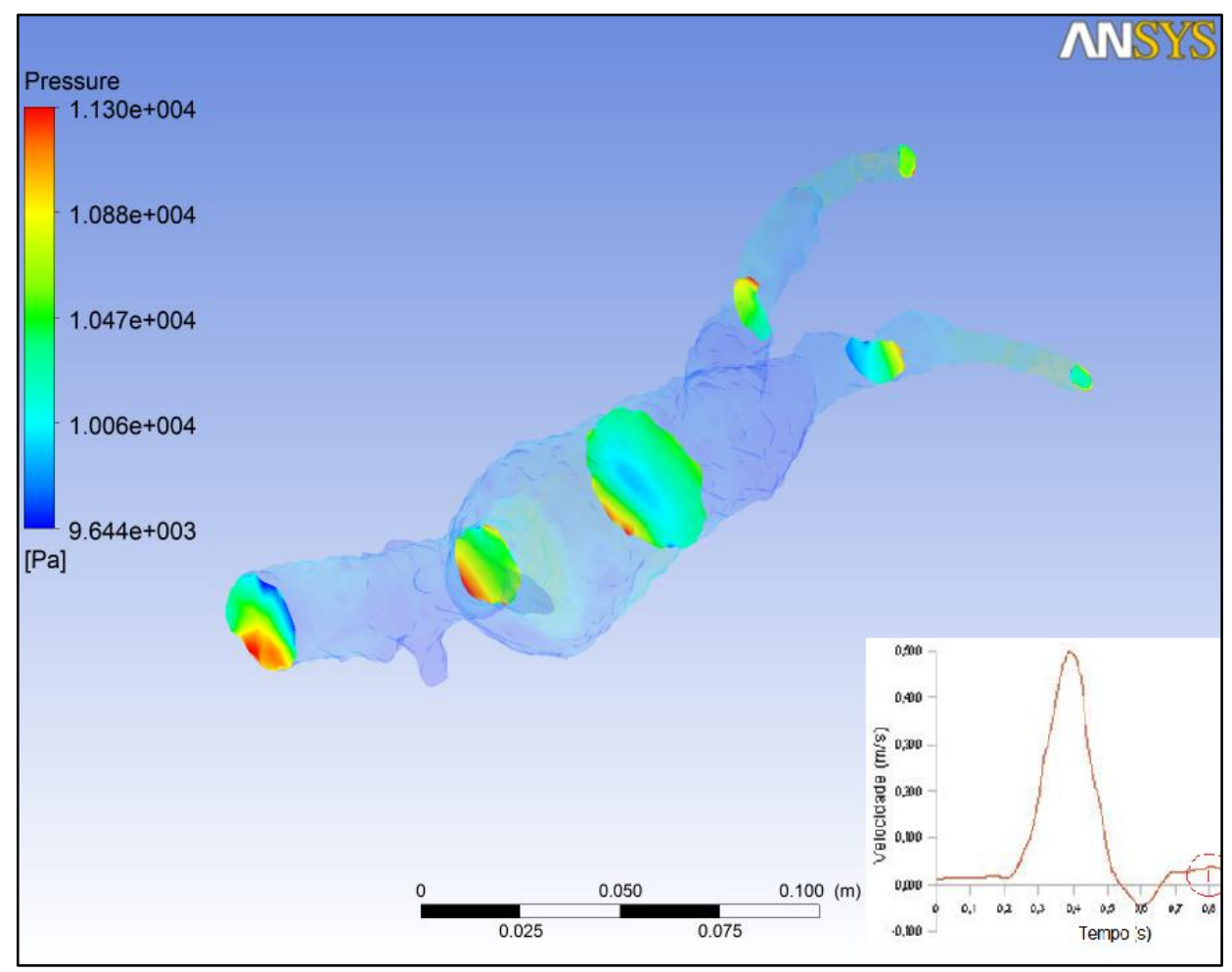

Figura 40 - Resultado de pressão em AAA no instante $t=0,8$ segundo (AAABB1) 


\subsubsection{Endoprótese Bifurcada para AAABB1}

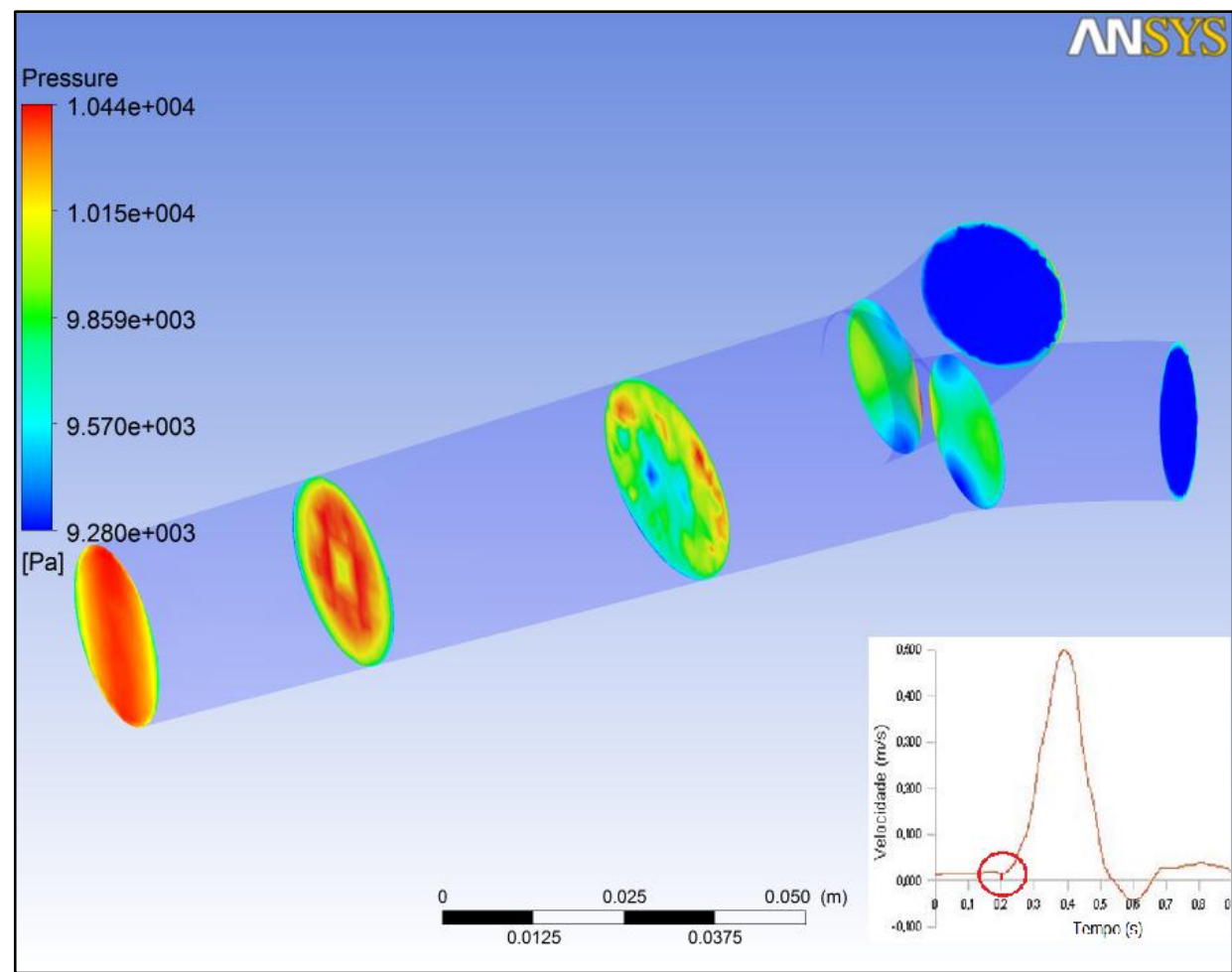

Figura 41 - Resultado de pressão em Endoprótese para AAA no instante $t=0,2$ segundo (Endoprótese AAABB1)

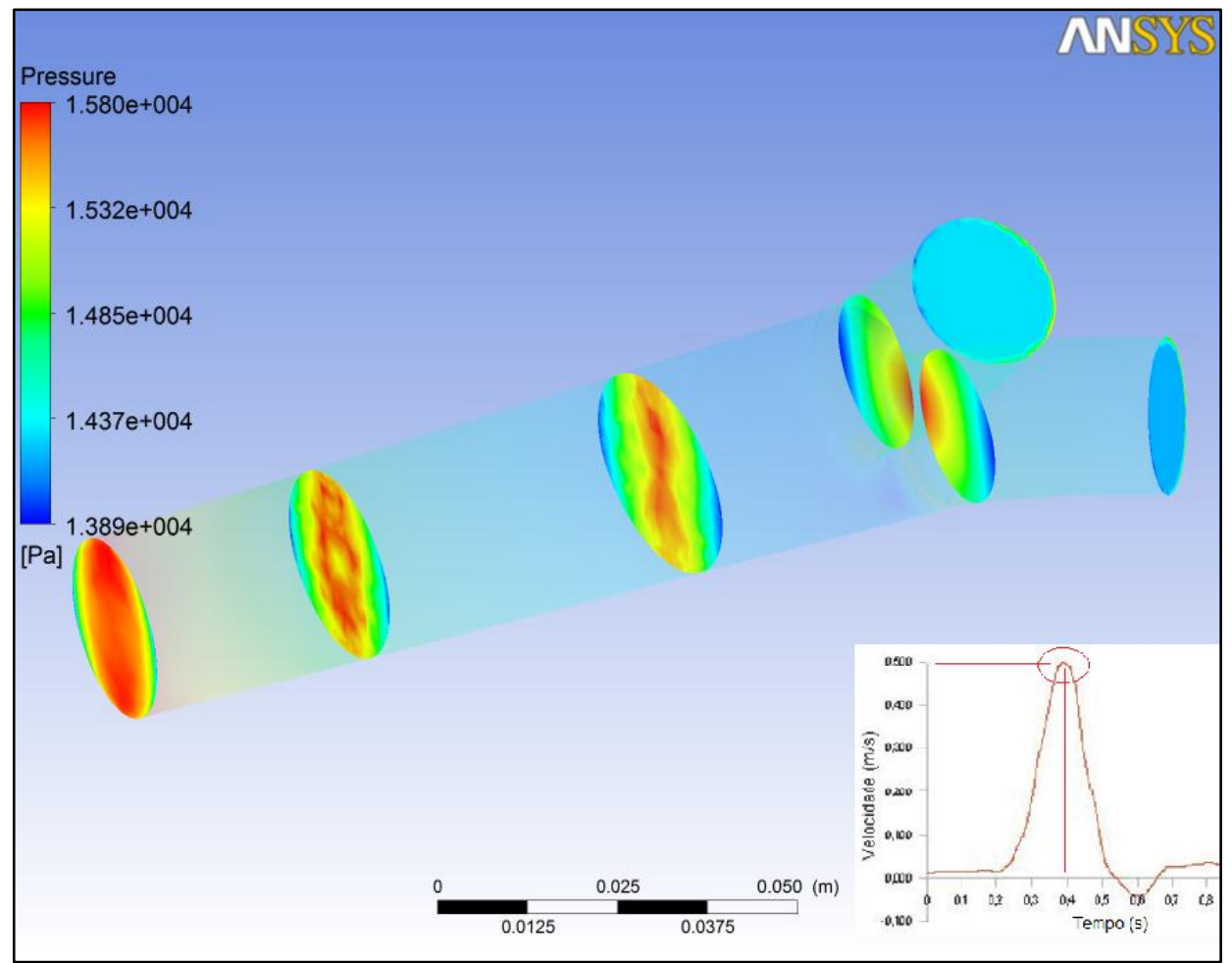

Figura 42 - Resultado de pressão em Endoprótese para AAA no instante $t=0,4$ segundo (Endoprótese AAABB1) 


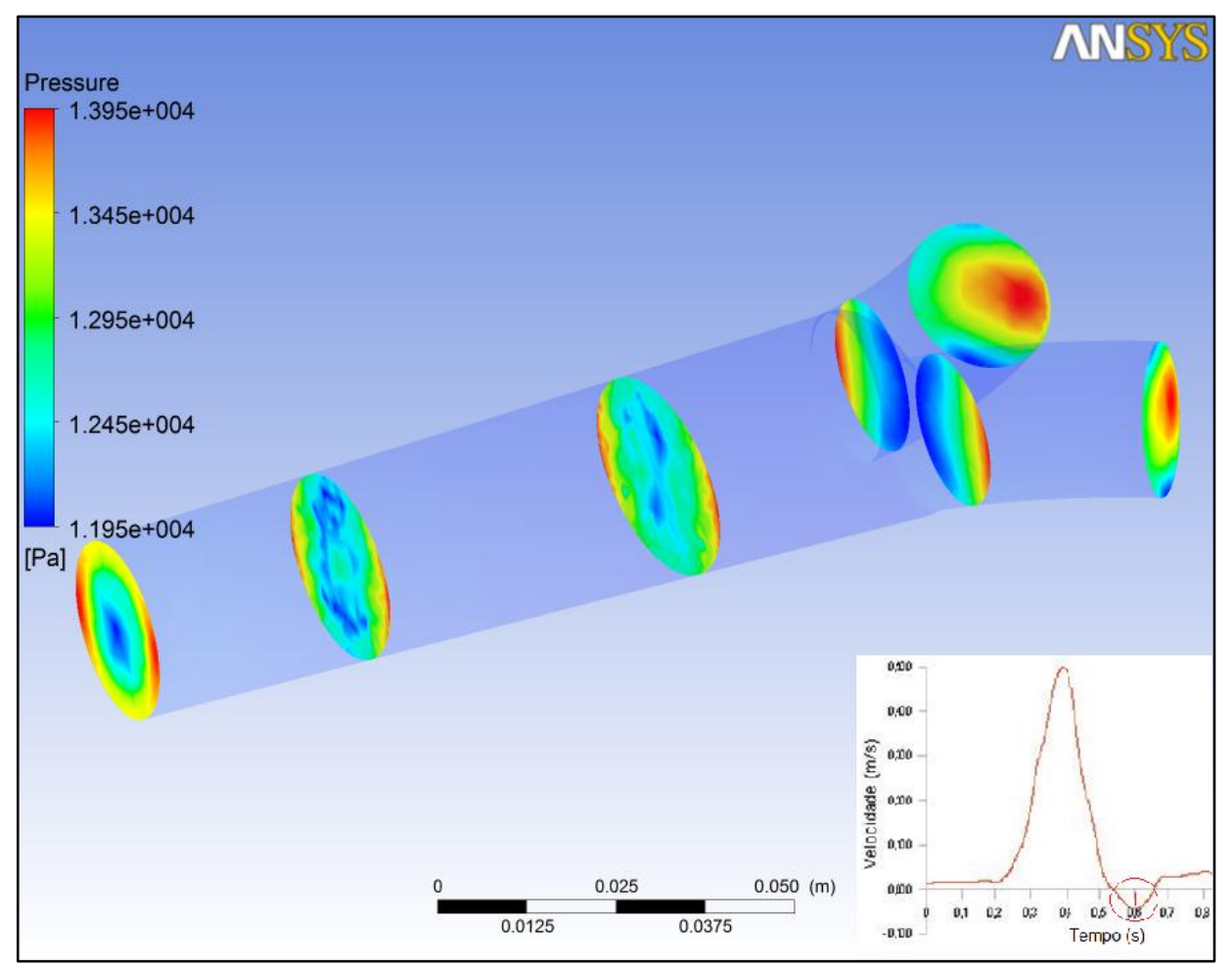

Figura 43 - Resultado de pressão em Endoprótese para AAA no instante $t=0,6$ segundo (Endoprótese AAABB1)

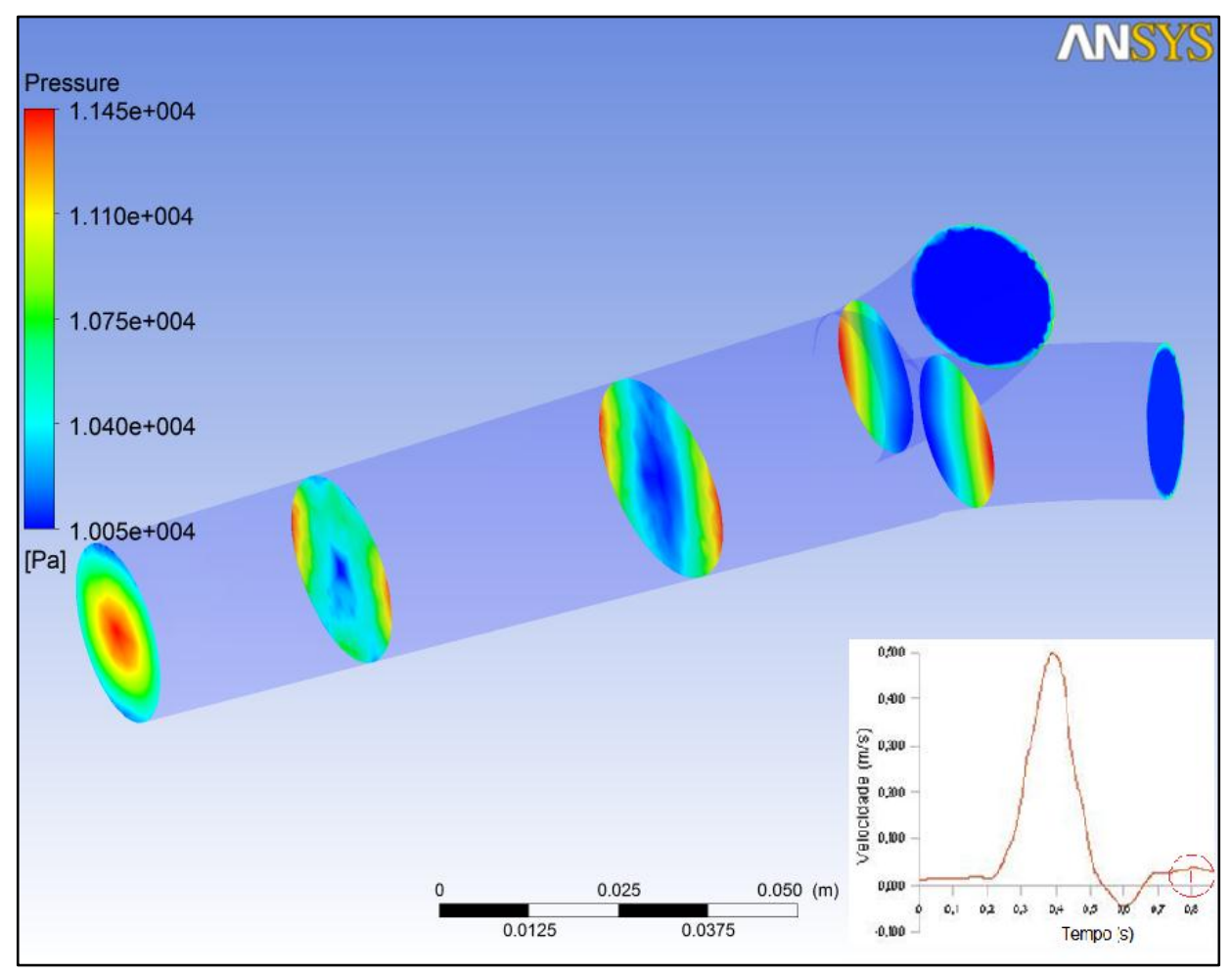

Figura 44 - Resultado de pressão em Endoprótese para AAA no instante $t=0,8$ segundo (Endoprótese AAABB1) 
5.1.1.5 Aneurisma $A A A B B 2$

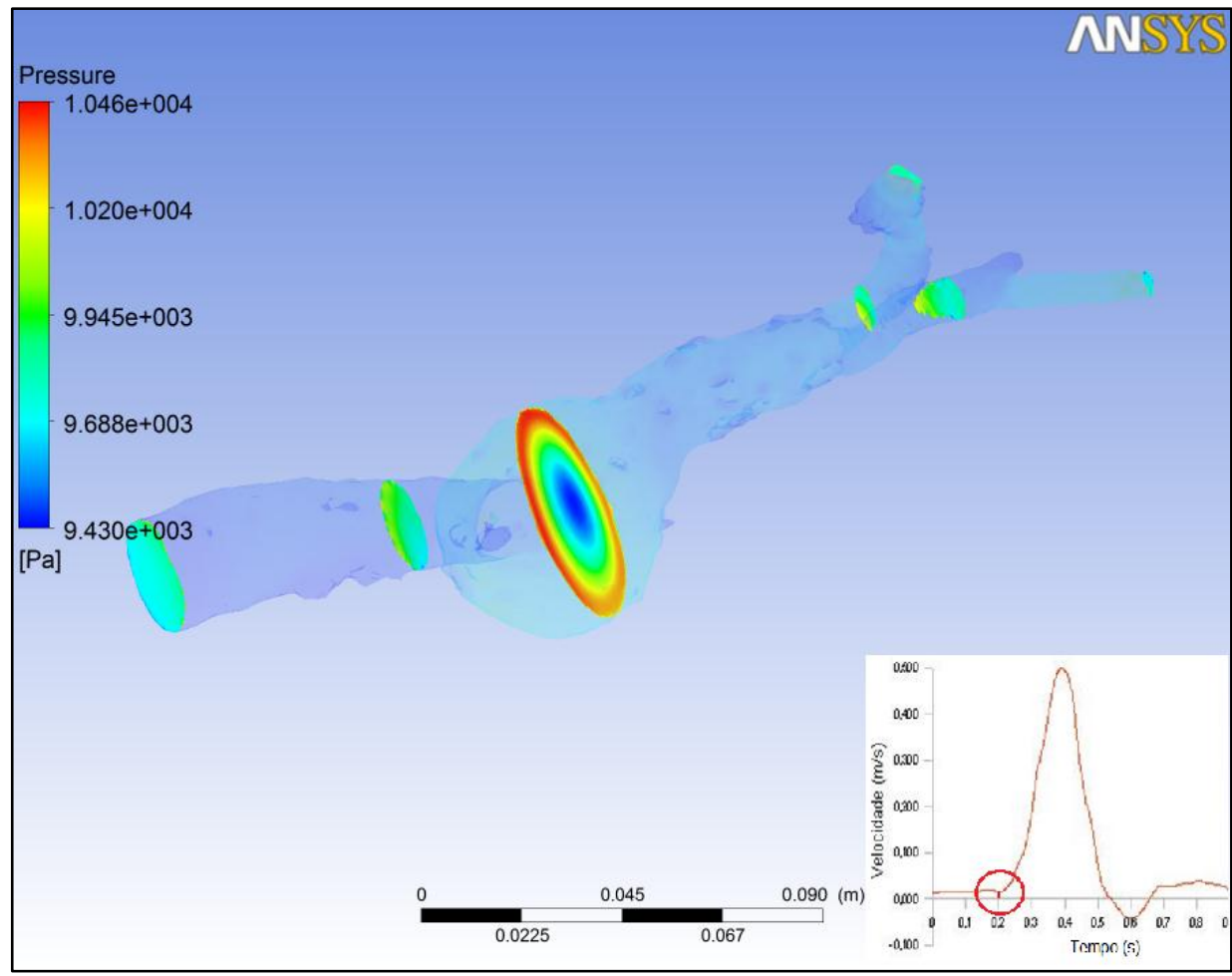

Figura 45 - Resultado de pressão em AAA no instante $t=0,2$ segundo (AAABB2)

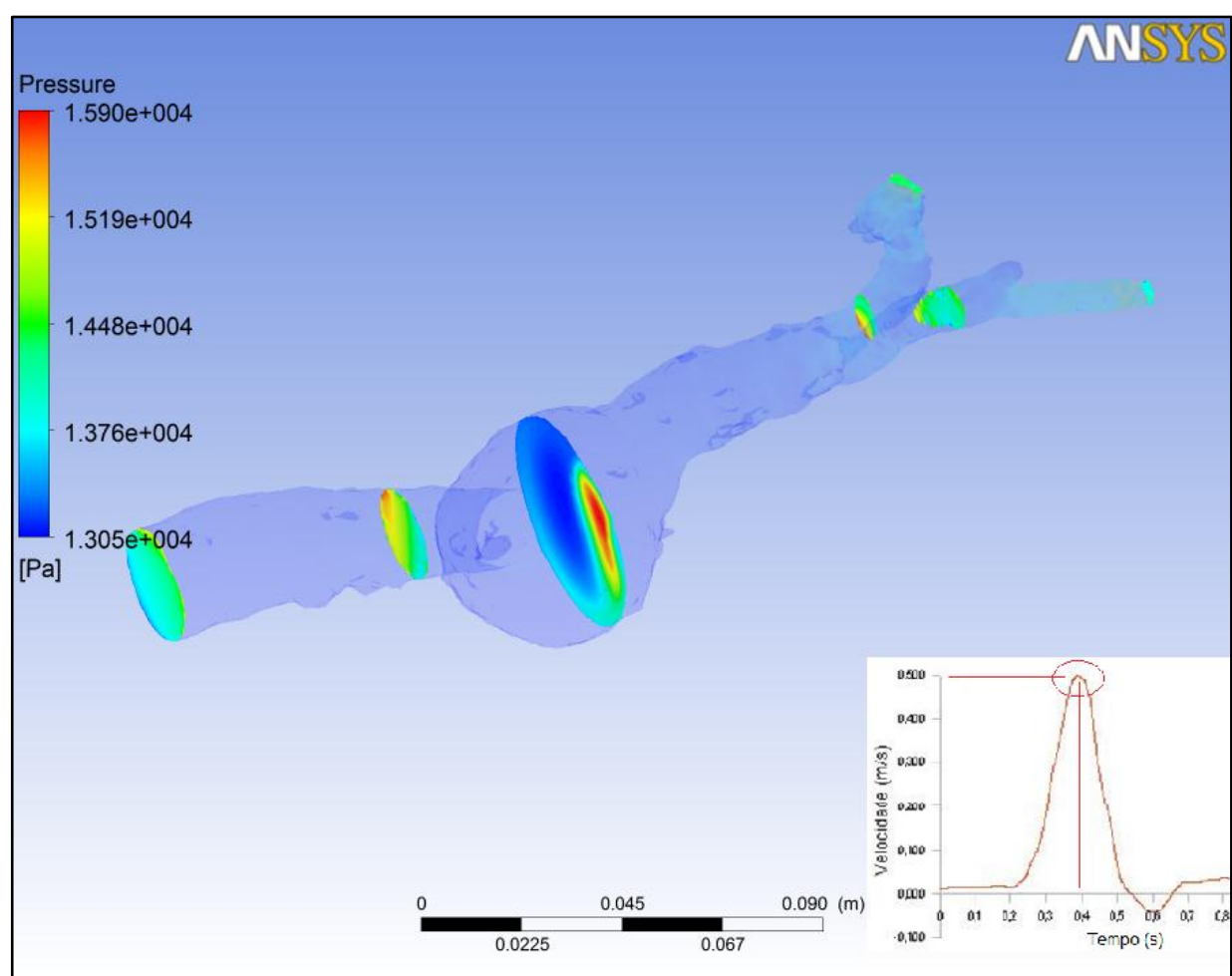

Figura 46 - Resultado de pressão em AAA no instante $t=0,4$ segundo (AAABB2) 


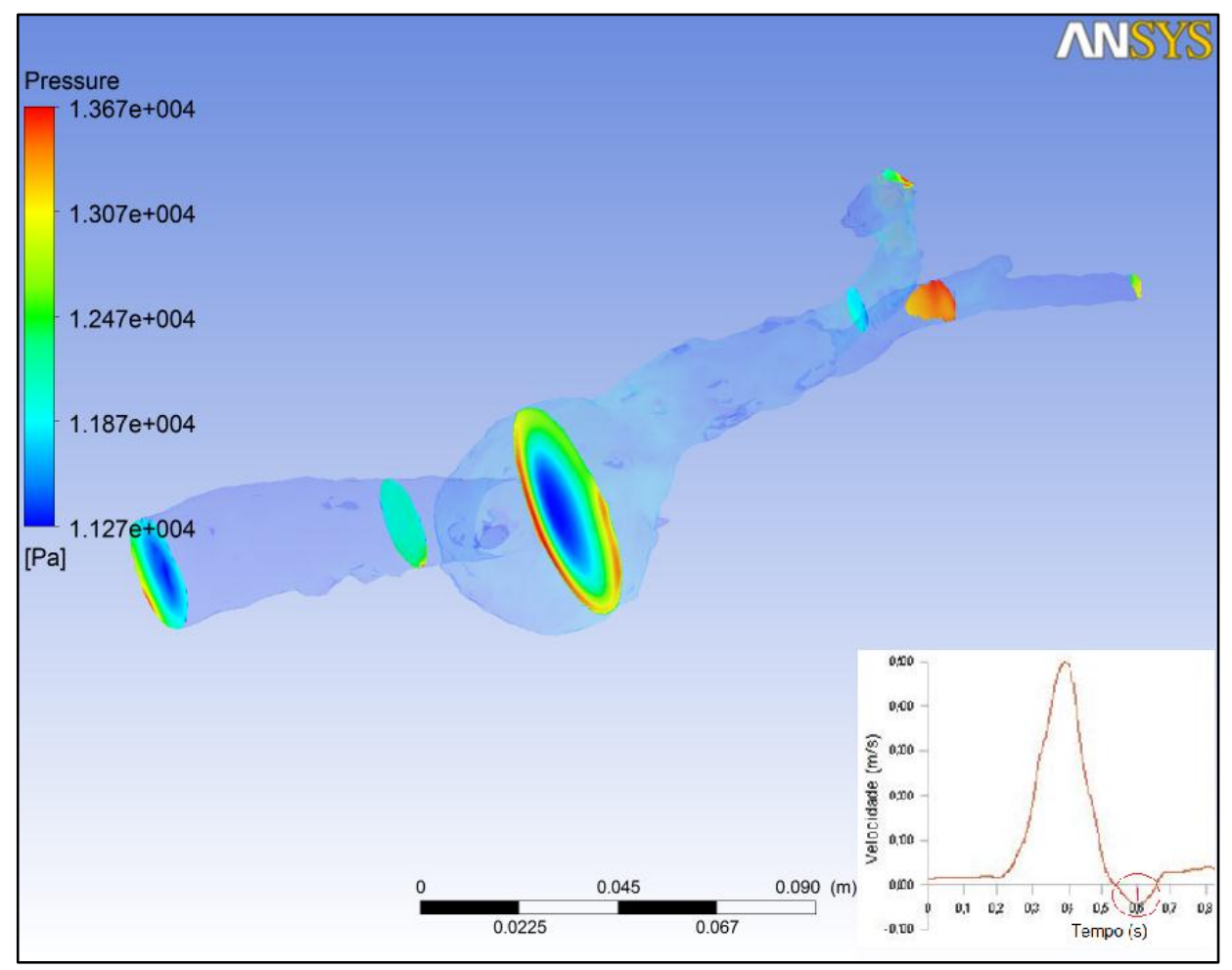

Figura 47 - Resultado de pressão em AAA no instante $t=0,6$ segundo (AAABB2)

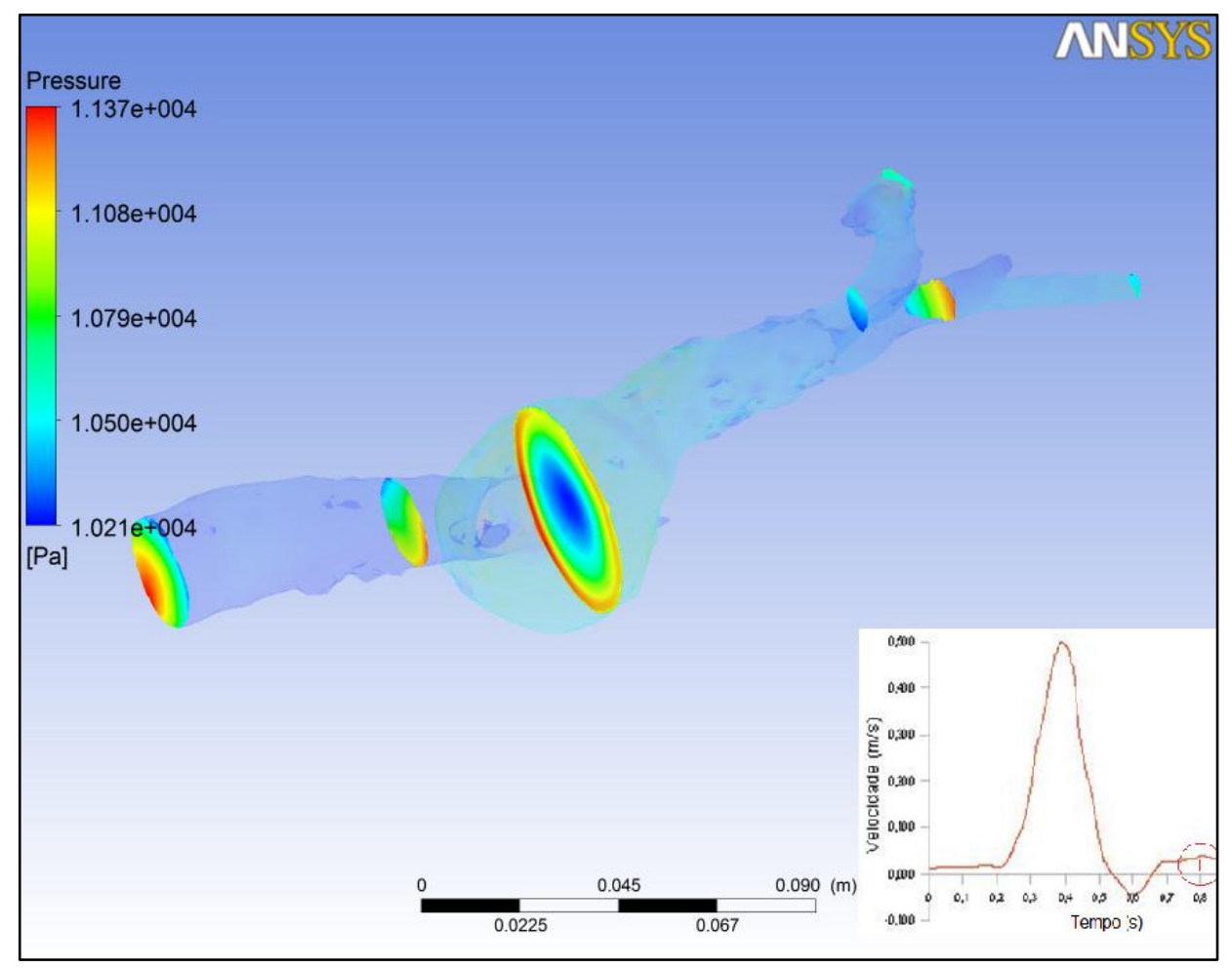

Figura 48 - Resultado de pressão em AAA no instante $t=0,8$ segundo (AAABB2) 


\subsubsection{Endoprótese Cilíndrica para AAABB2}

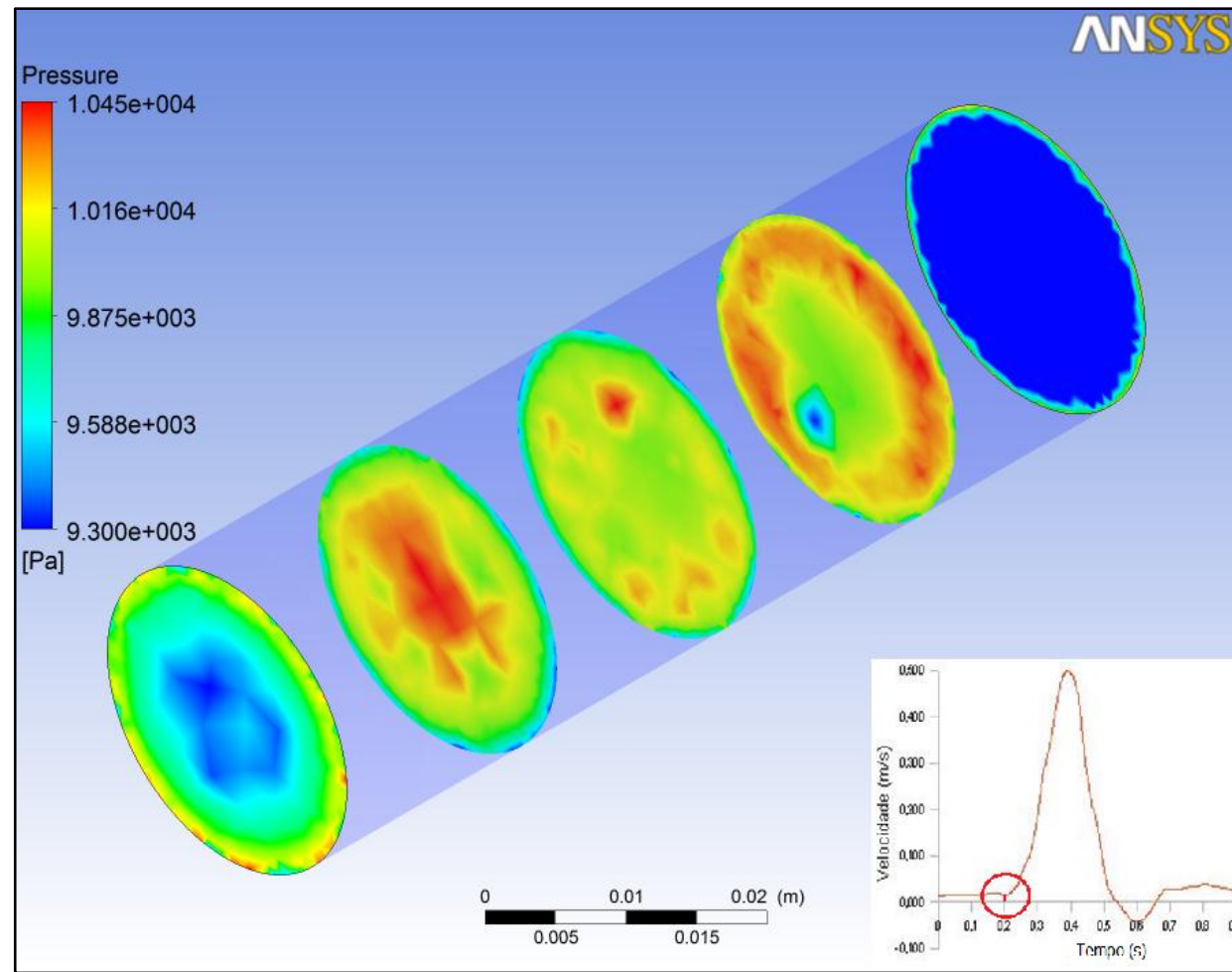

Figura 49 - Resultado de pressão em Endoprótese para AAA no instante $t=0,2$ segundo (Endoprótese para AAABB2)

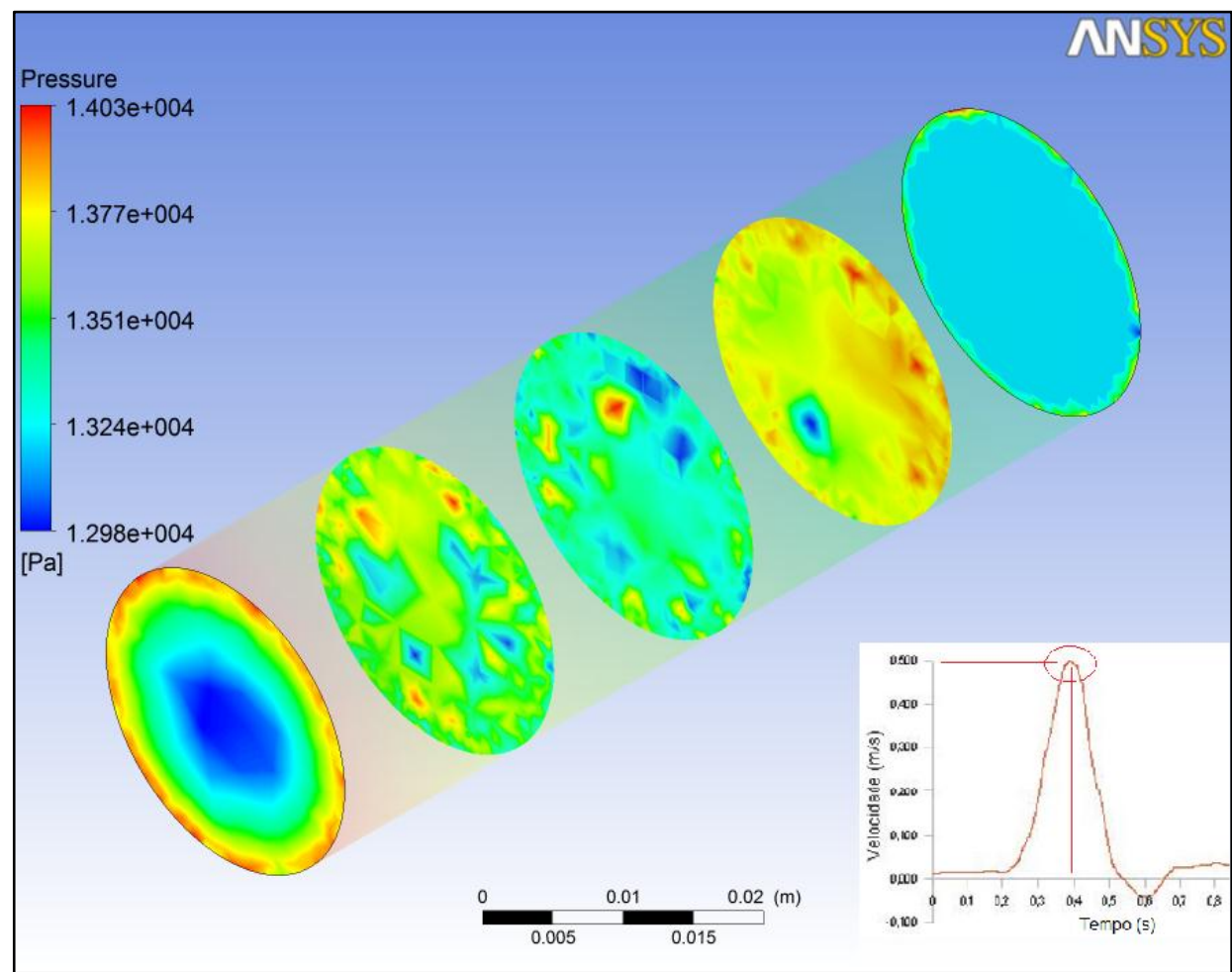

Figura 50 - Resultado de pressão em Endoprótese para AAA no instante t=0,4 segundo (Endoprótese para AAABB2) 


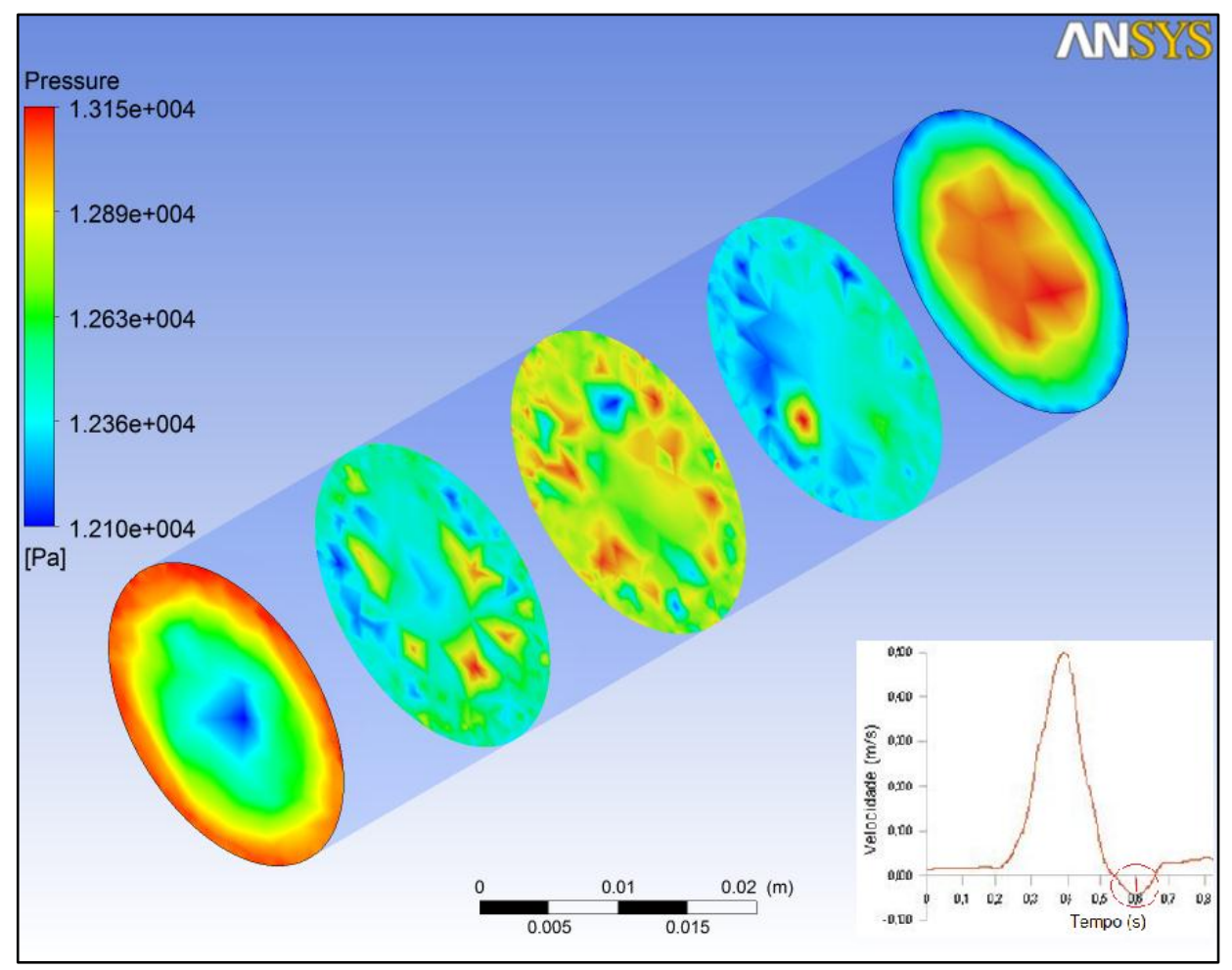

Figura 51 - Resultado de pressão em Endoprótese para AAA no instante $t=0,6$ segundo (Endoprótese para AAABB2)

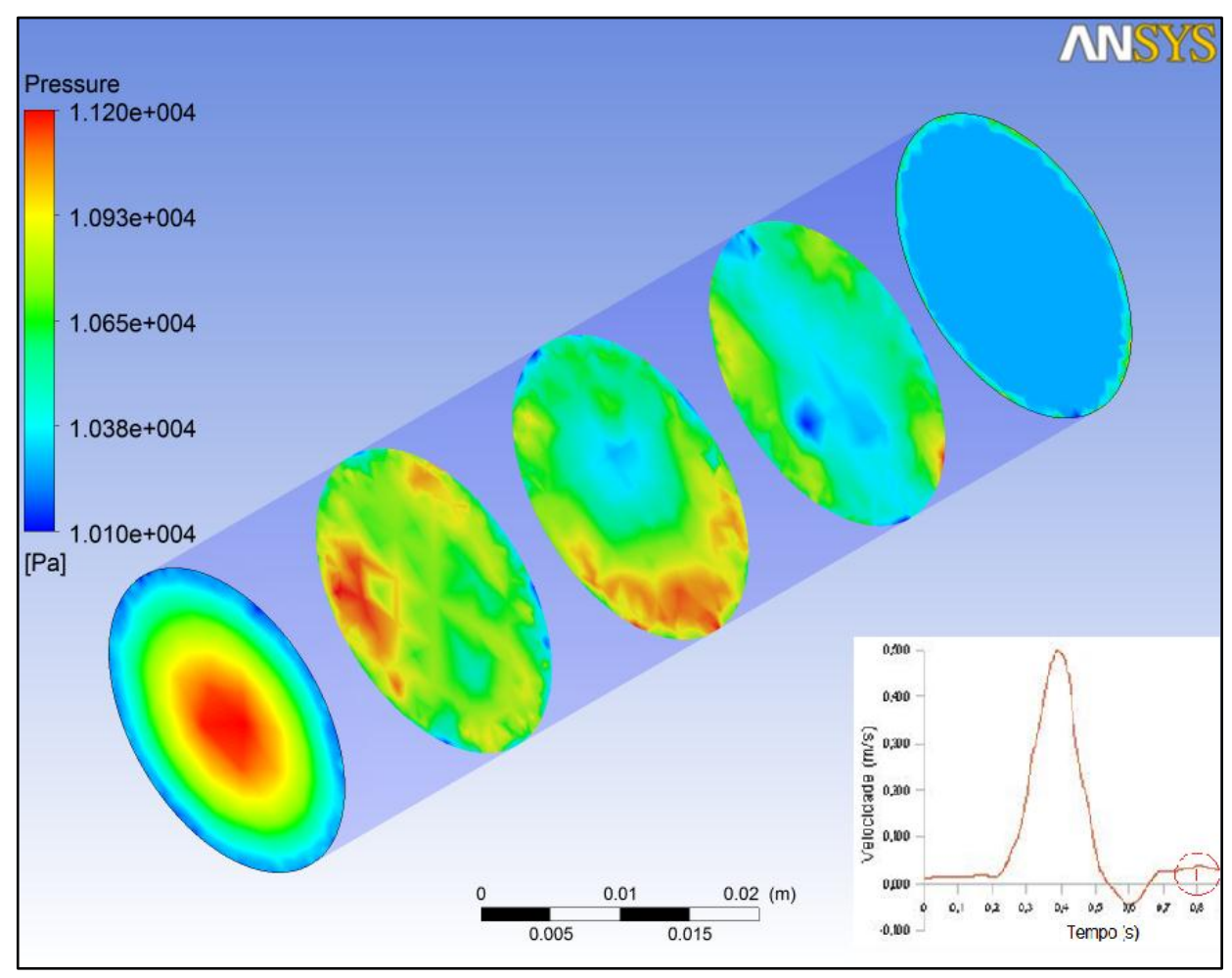

Figura 52 - Resultado de pressão em Endoprótese para AAA no instante t=0,8 segundo (Endoprótese para AAABB2) 


\subsubsection{Linhas de Corrente}

Nesta seção do trabalho, serão apresentados os resultados das linhas de corrente calculadas pelas simulações. Os resultados serão divididos de acordo com as diferentes geometrias. Serão agrupadas as geometrias do AAA com a respectiva endoprótese.

\subsubsection{Aneurisma de Legendre}

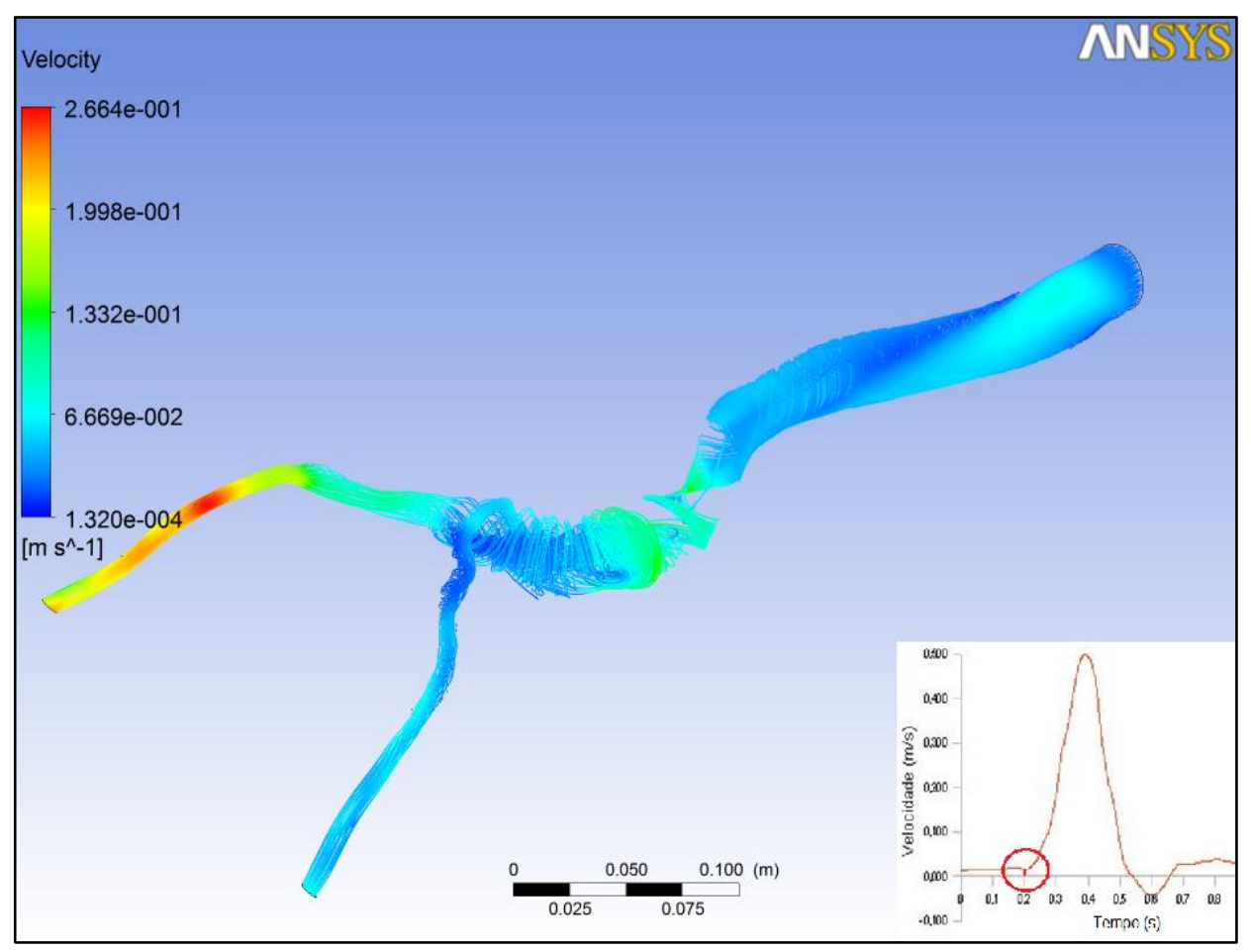

Figura 53 - Resultado de linhas de corrente em AAA no instante $t=0,2$ segundo (AAA Legendre) 


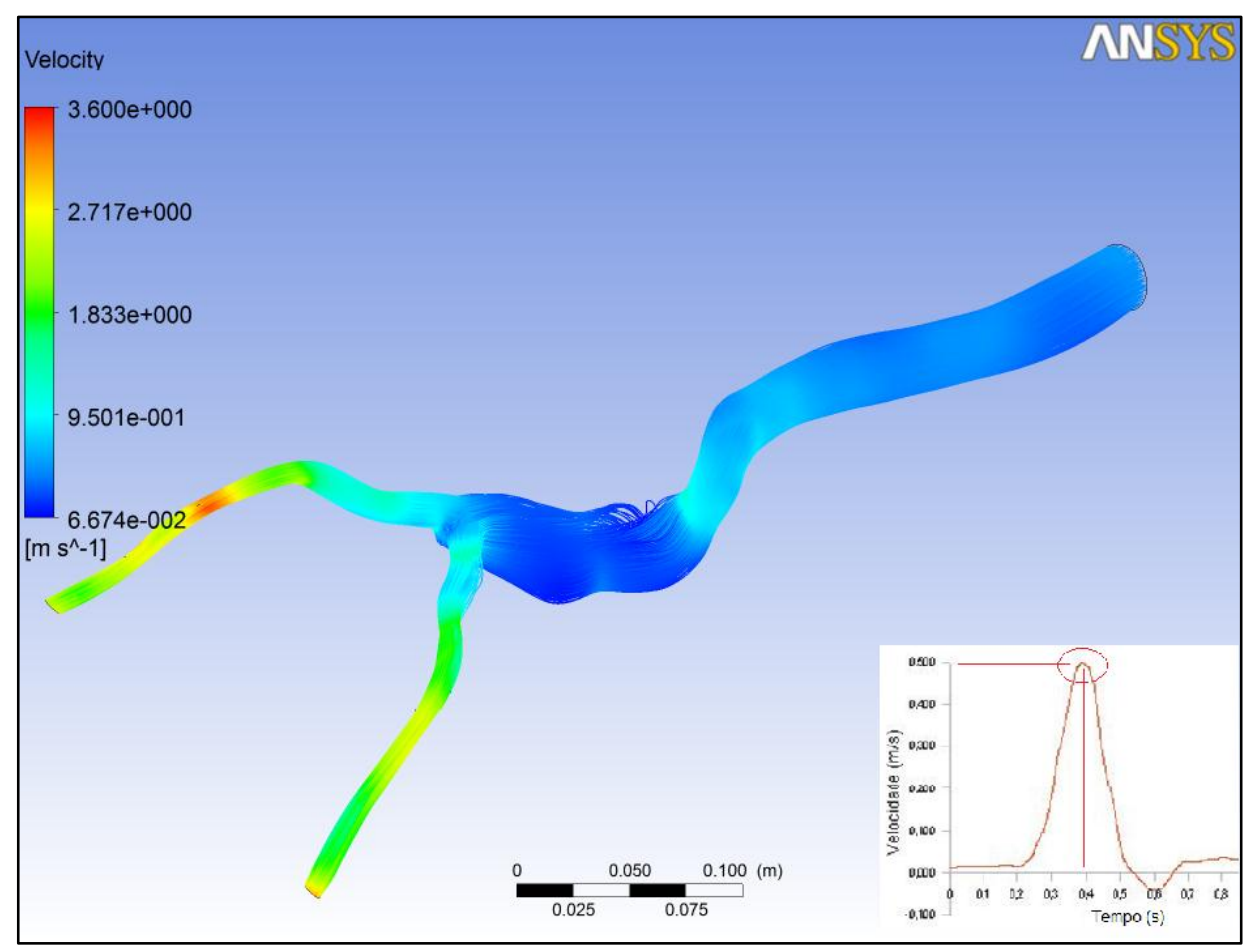

Figura 54 - Resultado de linhas de corrente em AAA no instante $t=0,4$ segundo (AAA Legendre)

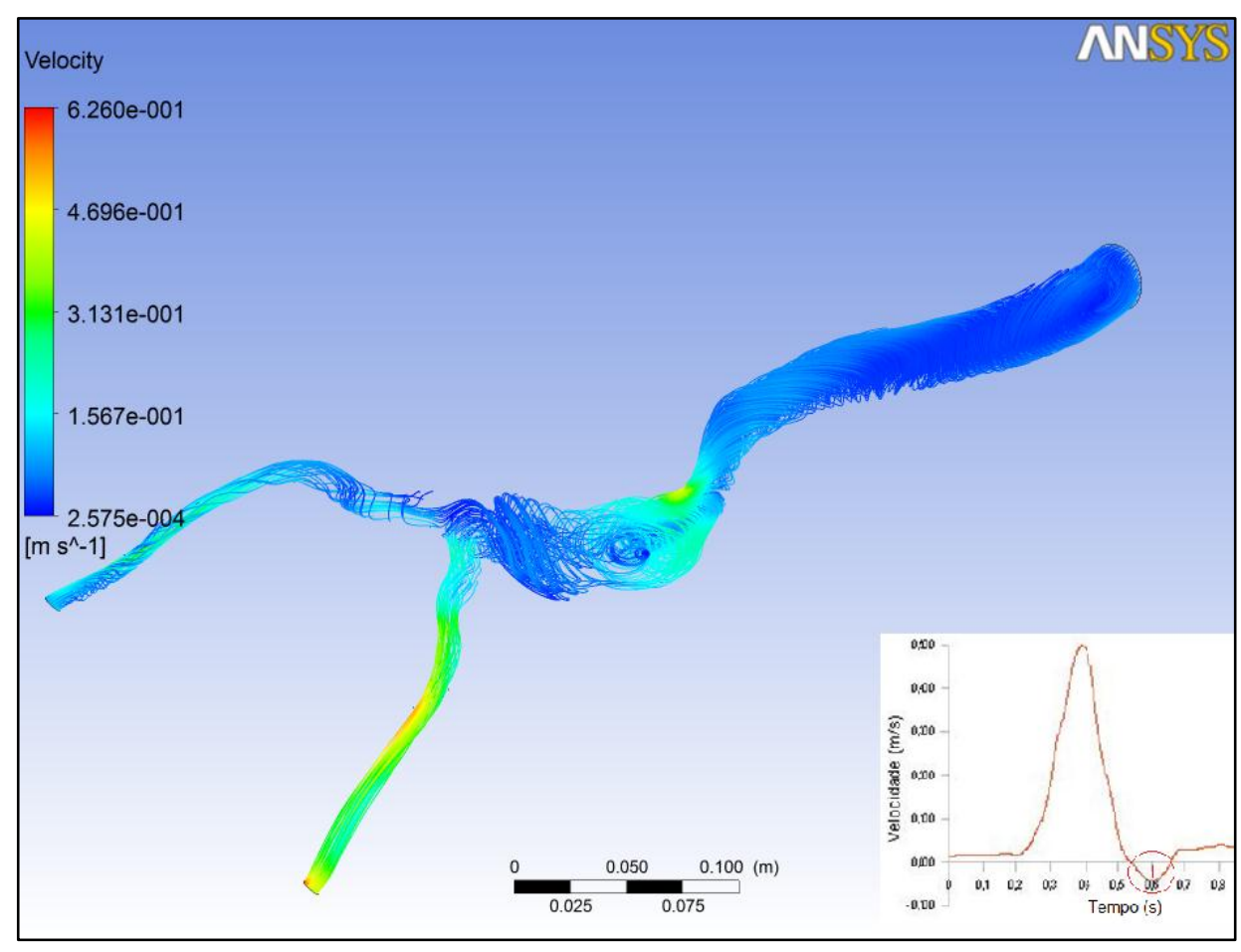

Figura 55 - Resultado de linhas de corrente em AAA no instante $t=0,6$ segundo (AAA Legendre) 


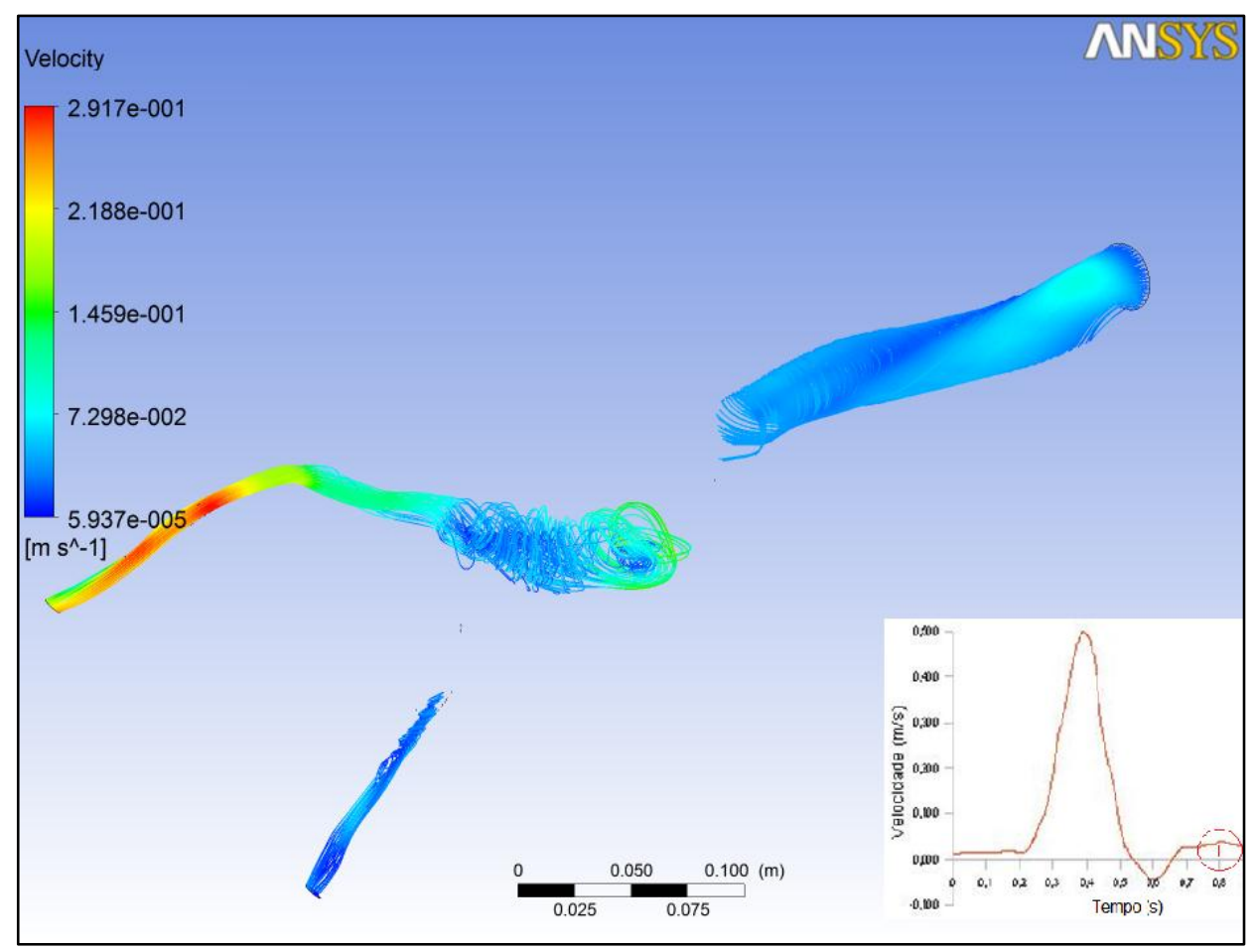

Figura 56 - Resultado de linhas de corrente em AAA no instante $t=0,8$ segundo (AAA Legendre)

\subsubsection{Endoprótese Bifurcada para Aneurisma de Legendre}

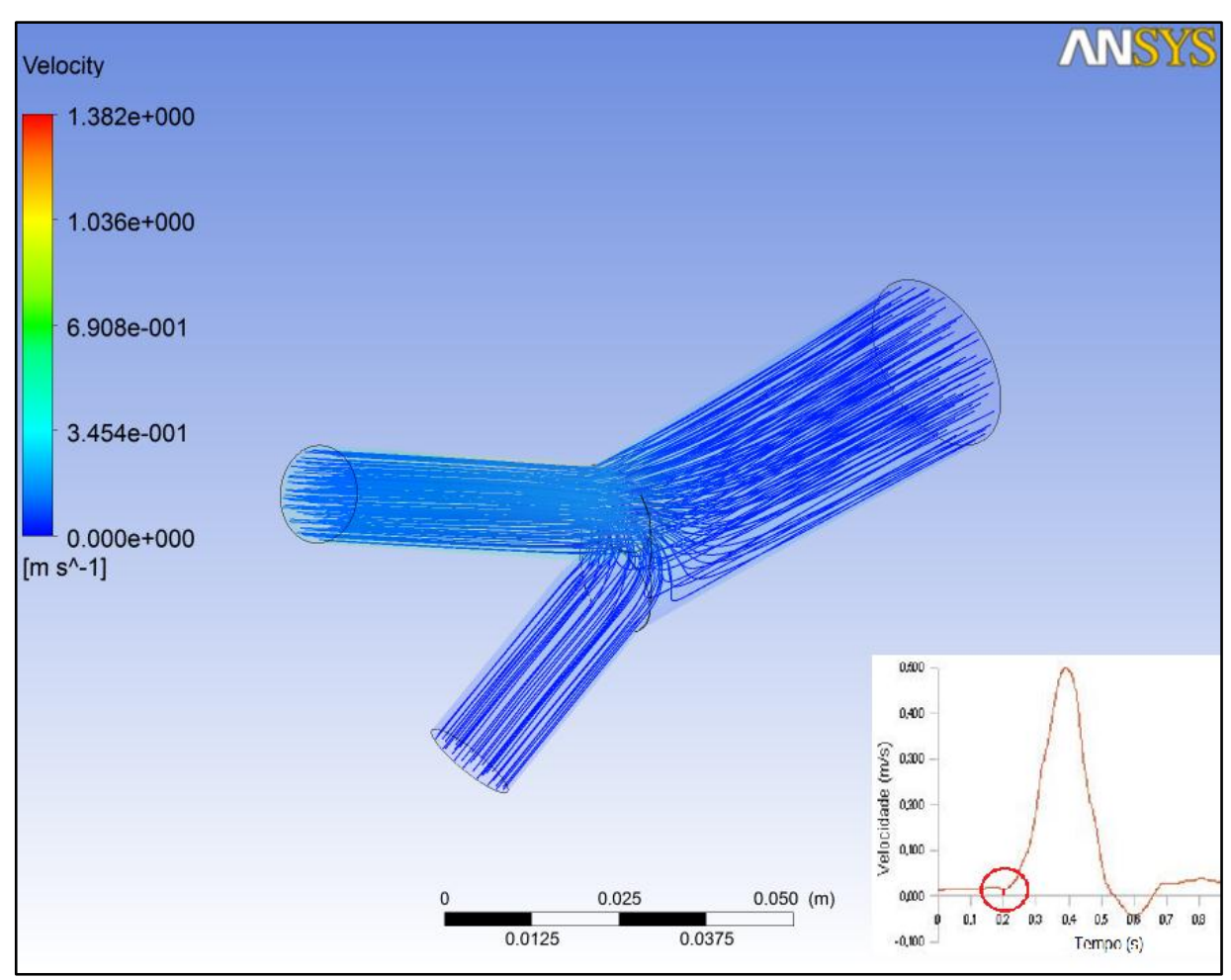

Figura 57 - Resultado de linhas de corrente em Endoprótese para AAA no instante $t=0,2$ segundo (Endoprótese para AAA Legendre) 


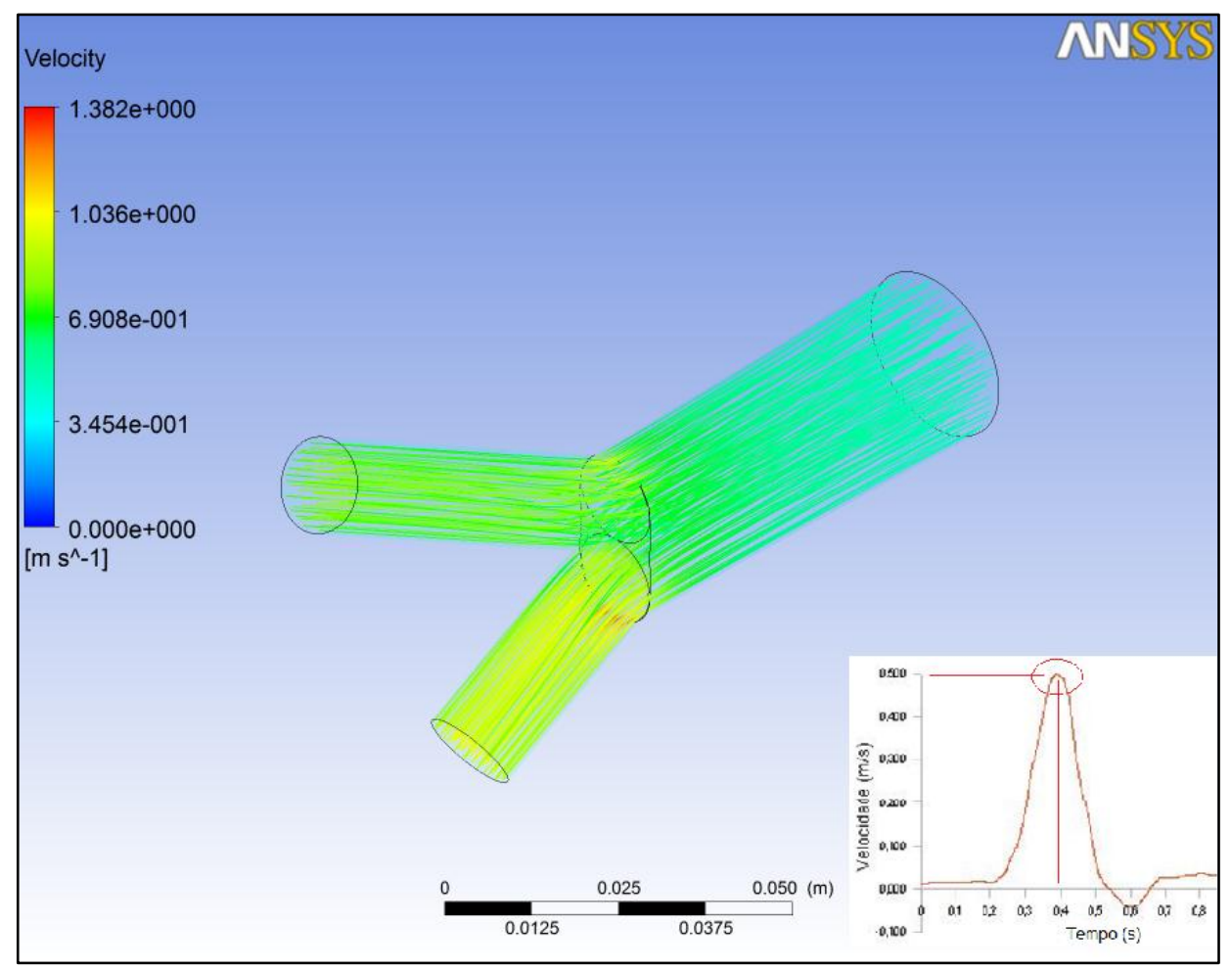

Figura 58 - Resultado de linhas de corrente em Endoprótese para AAA no instante $t=0,4$ segundo (Endoprótese para AAA Legendre)

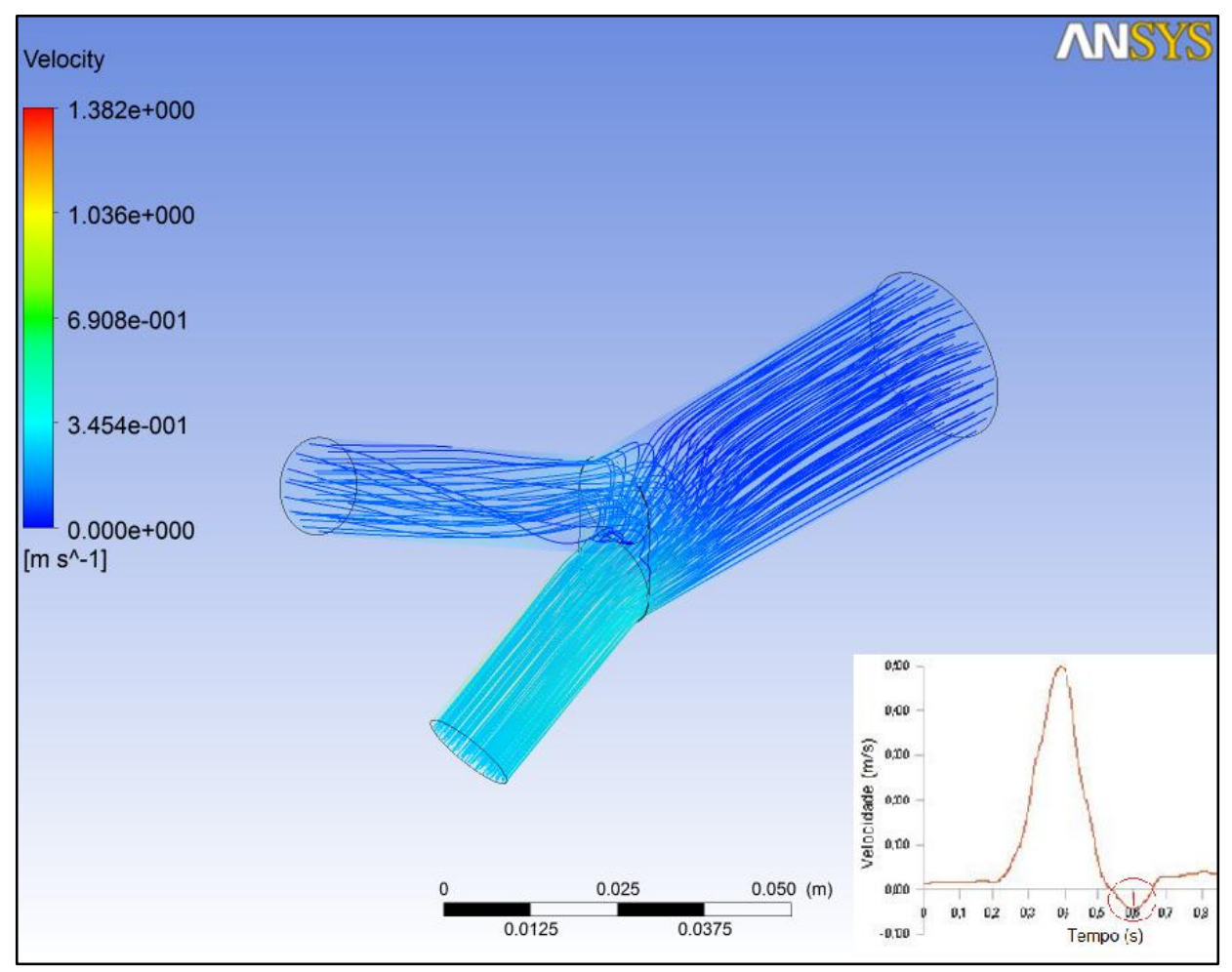

Figura 59 - Resultado de linhas de corrente em Endoprótese para AAA no instante $t=0,6$ segundo (Endoprótese para AAA Legendre) 


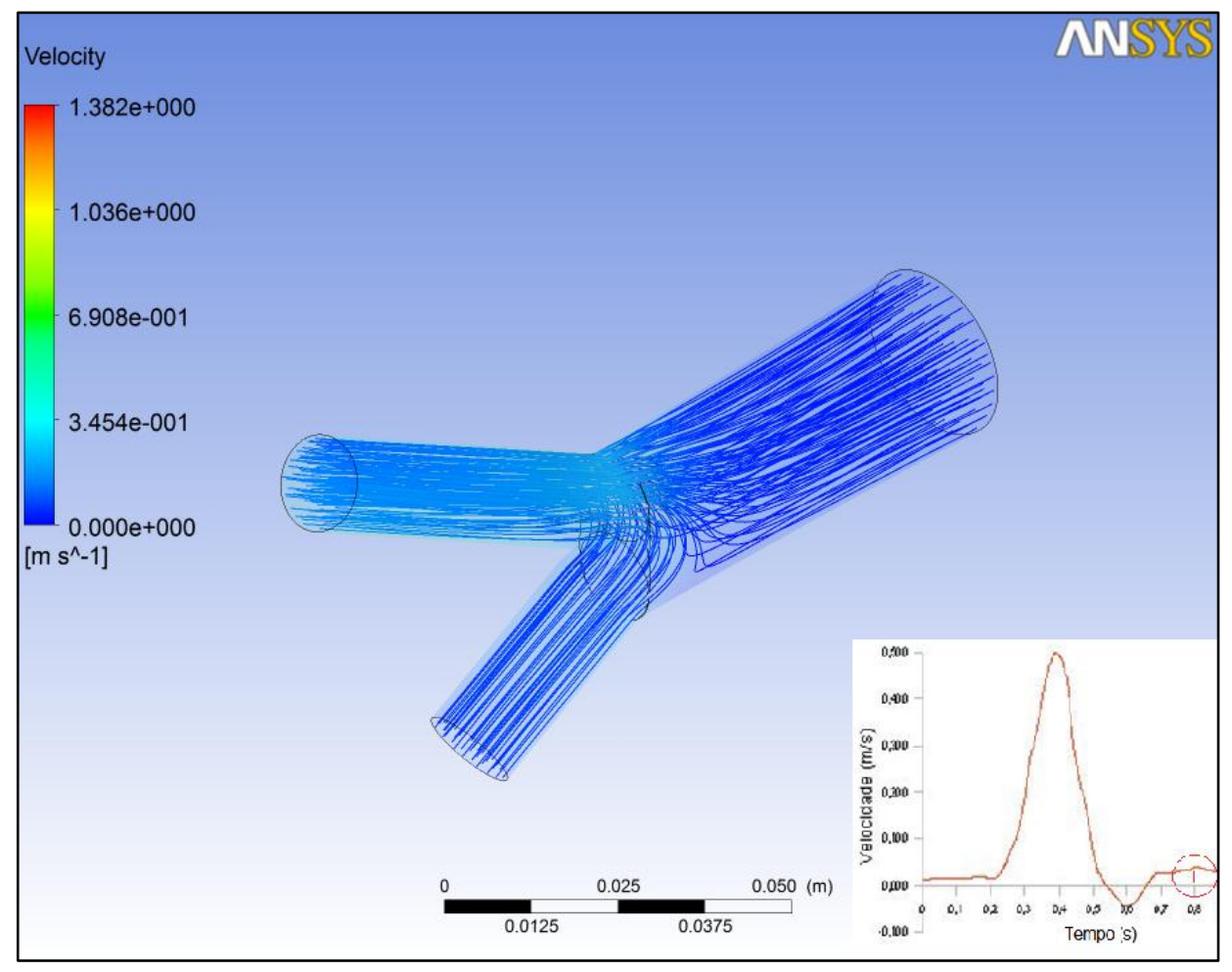

Figura 60 - Resultado de linhas de corrente em Endoprótese para AAA no instante $t=0,8$ segundo (Endoprótese para AAA Legendre)

\subsubsection{Aneurisma AAABB1}

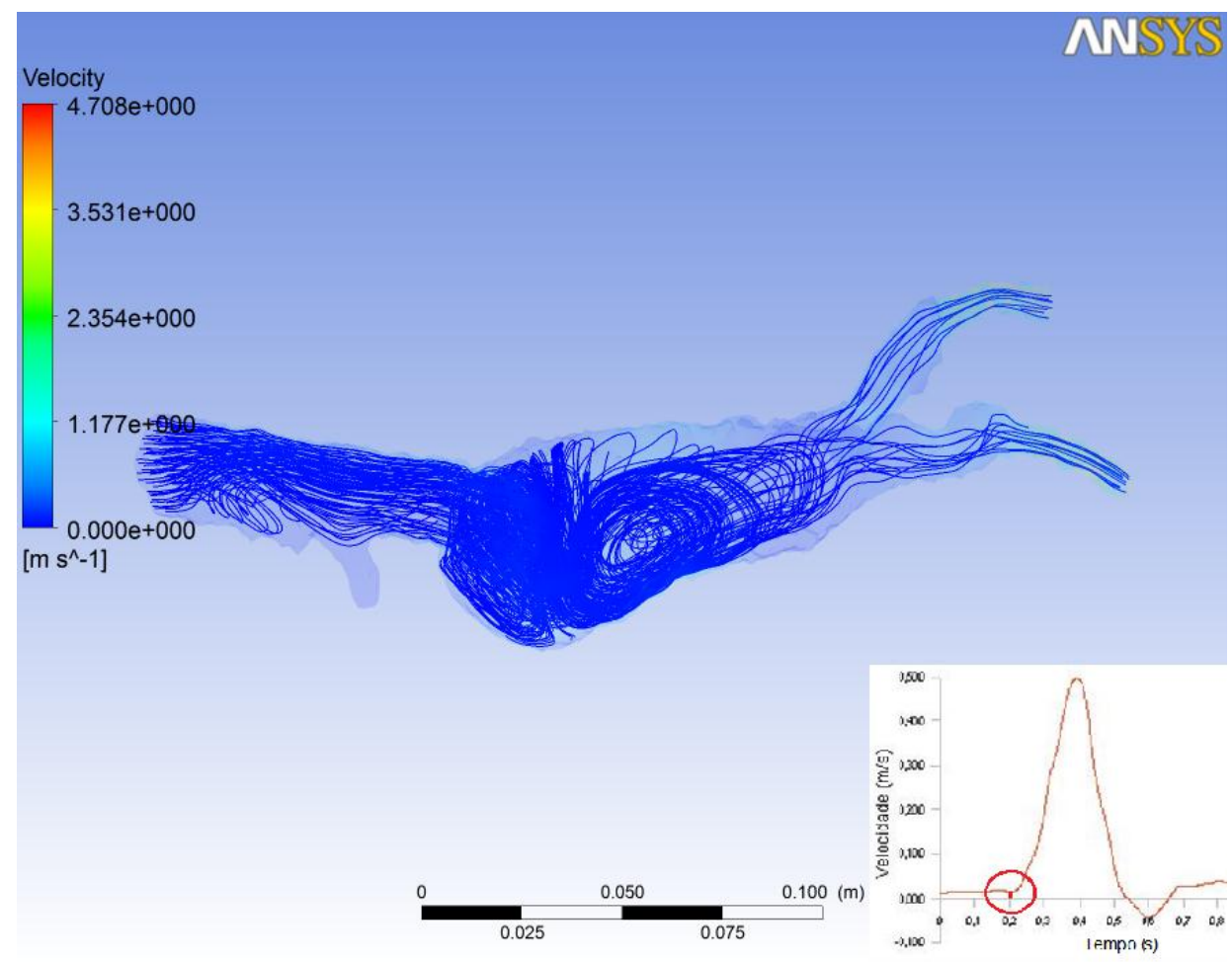

Figura 61 - Resultado de linhas de corrente em AAA no instante $t=0,2$ segundo (AAABB1) 


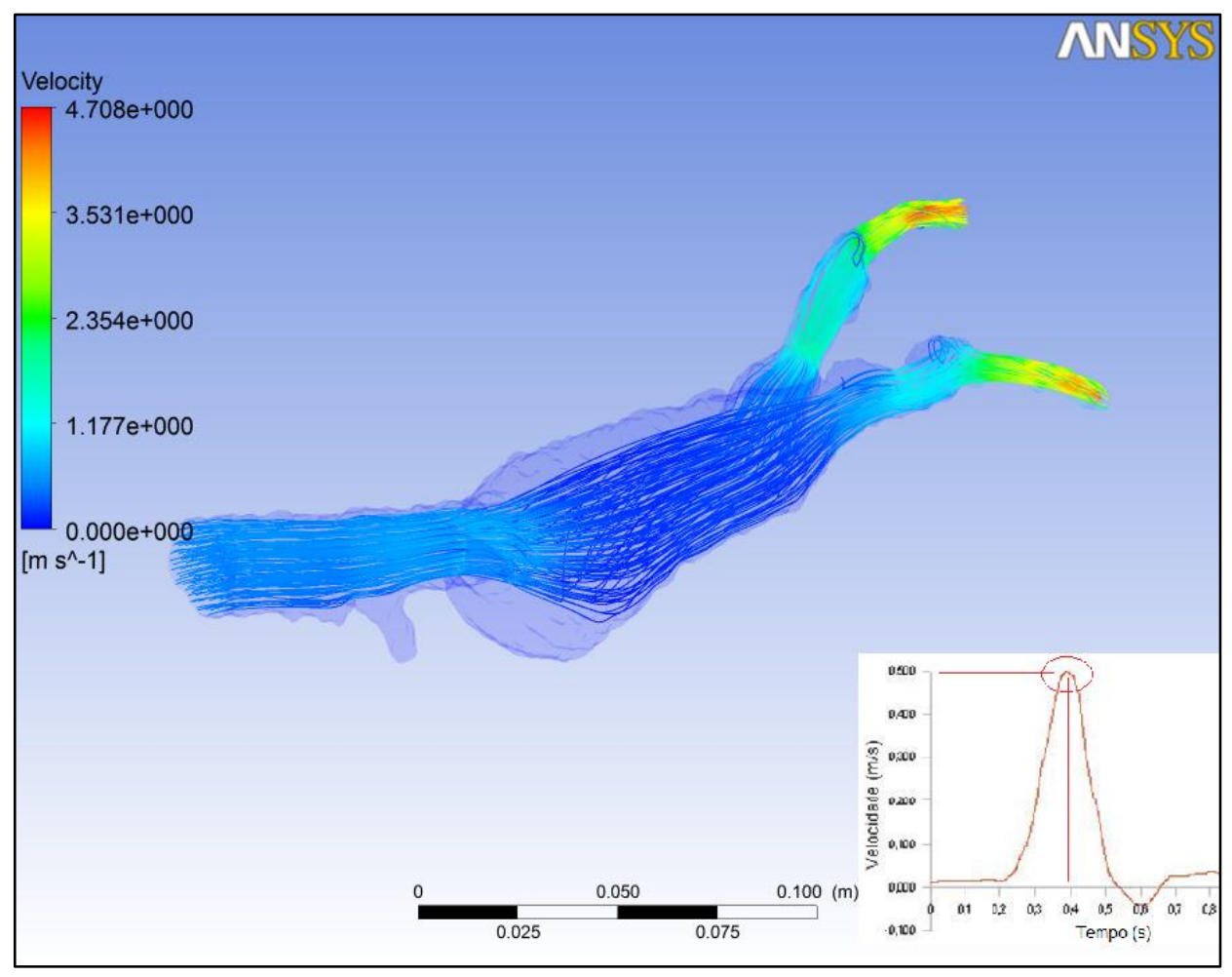

Figura 62 - Resultado de linhas de corrente em AAA no instante $t=0,4$ segundo (AAABB1)

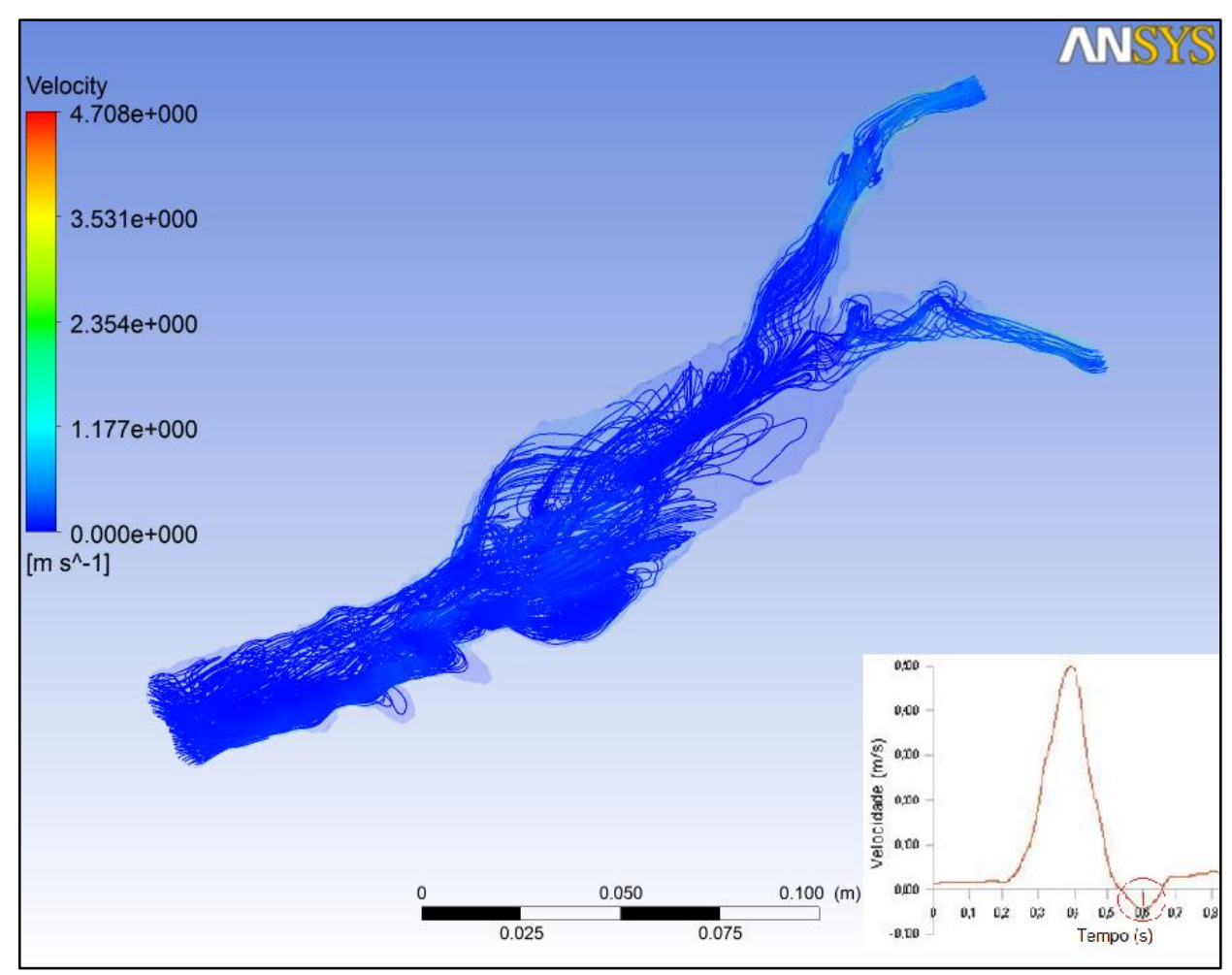

Figura 63 - Resultado de linhas de corrente em AAA no instante $t=0,6$ segundo (AAABB1) 


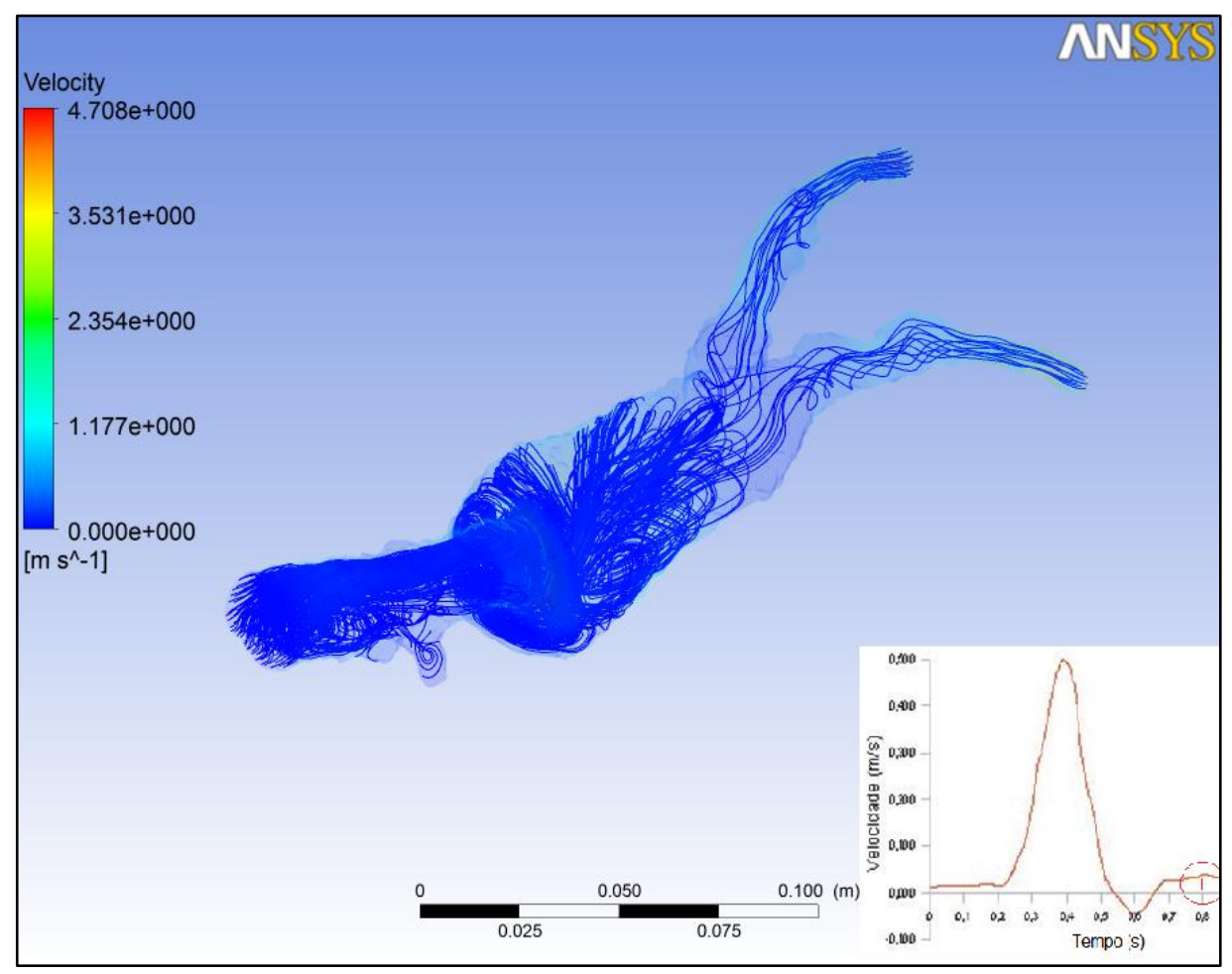

Figura 64 - Resultado de linhas de corrente em AAA no instante $t=0,8$ segundo (AAABB1)

\subsubsection{Endoprótese Bifurcada para $A A A B B 1$}

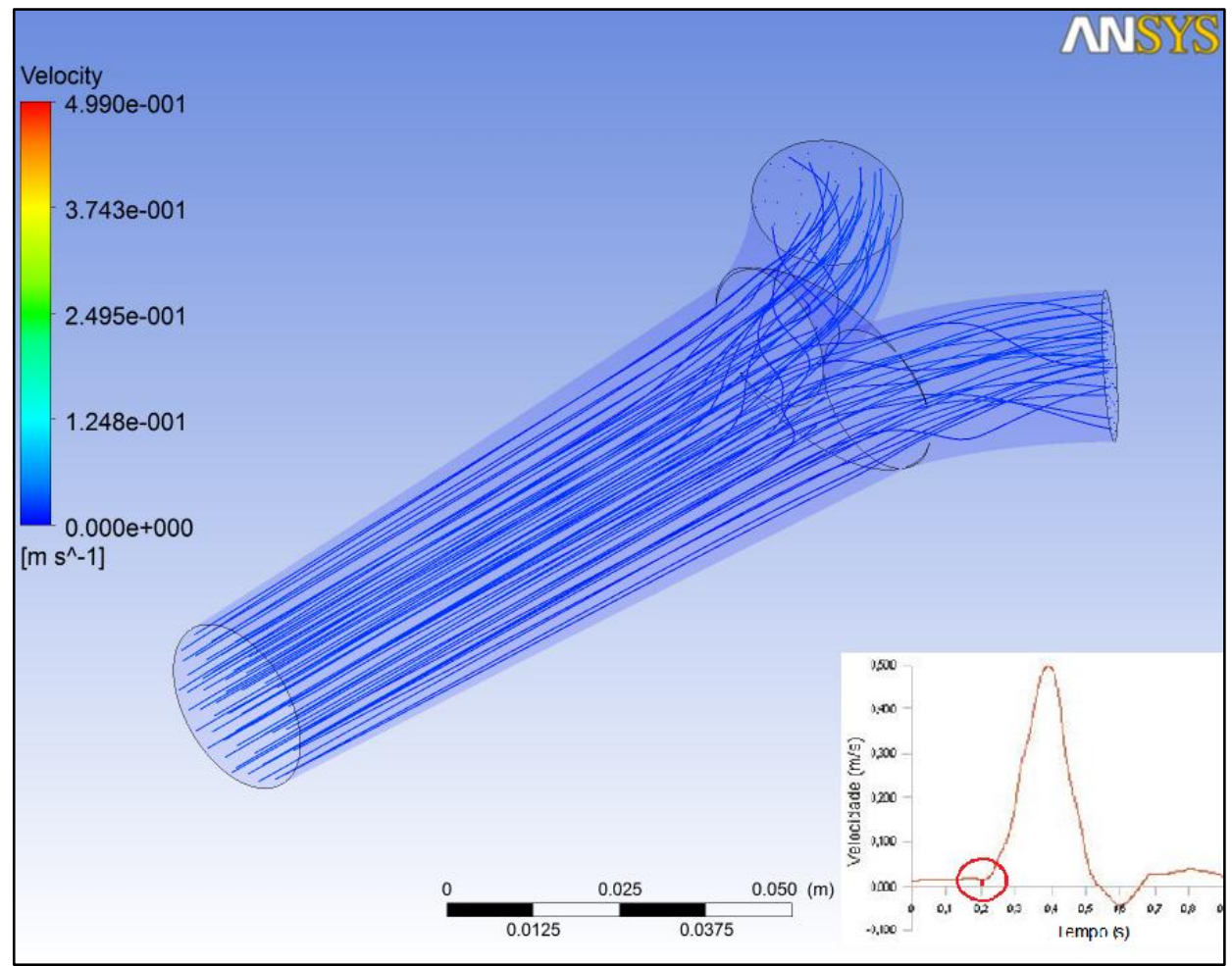

Figura 65 - Resultado de linhas de corrente em Endoprótese para AAA no instante $t=0,2$ segundo (Endoprótese para AAABB1) 


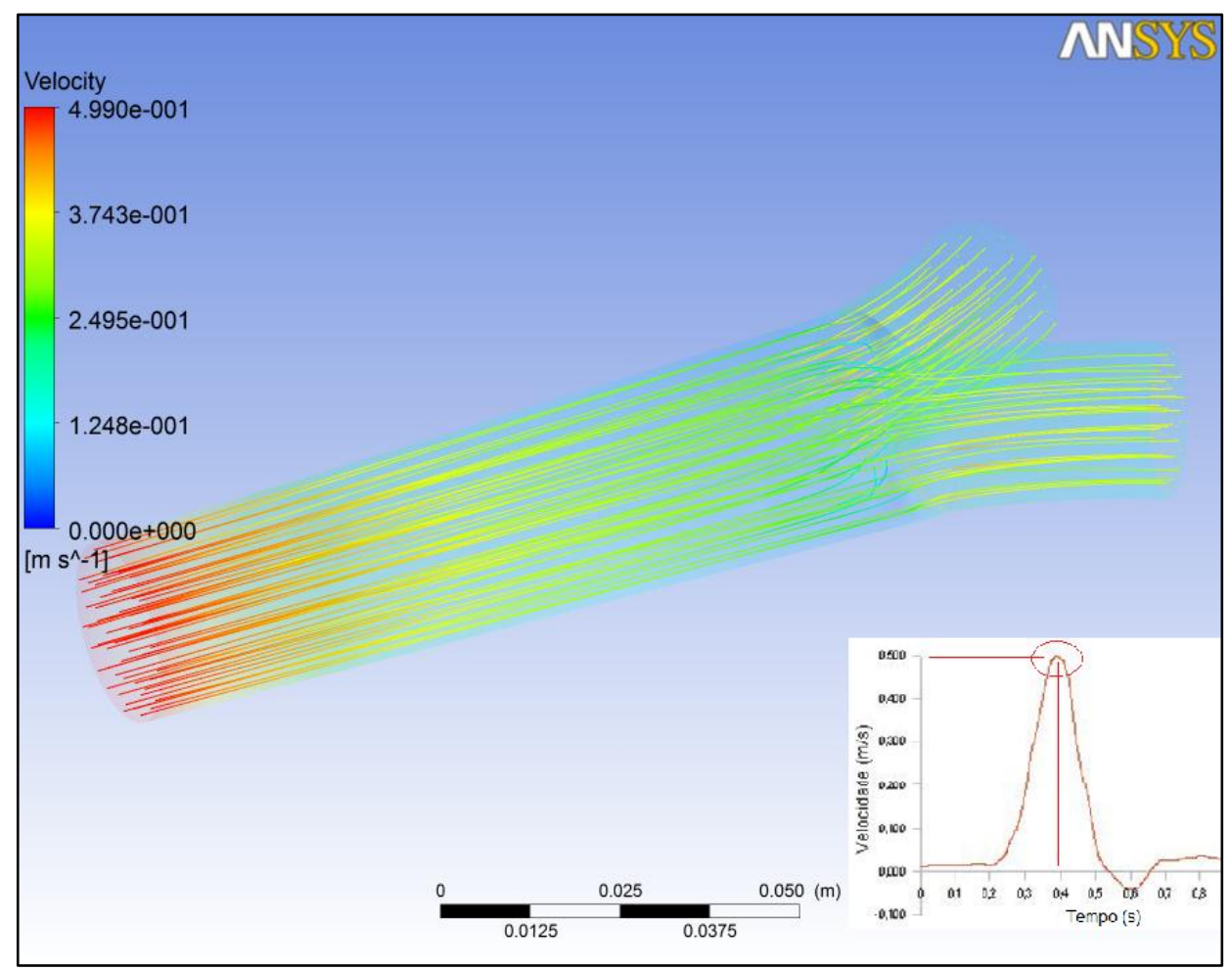

Figura 66 - Resultado de linhas de corrente em Endoprótese para AAA no instante $t=0,4$ segundo (Endoprótese para AAABB1)

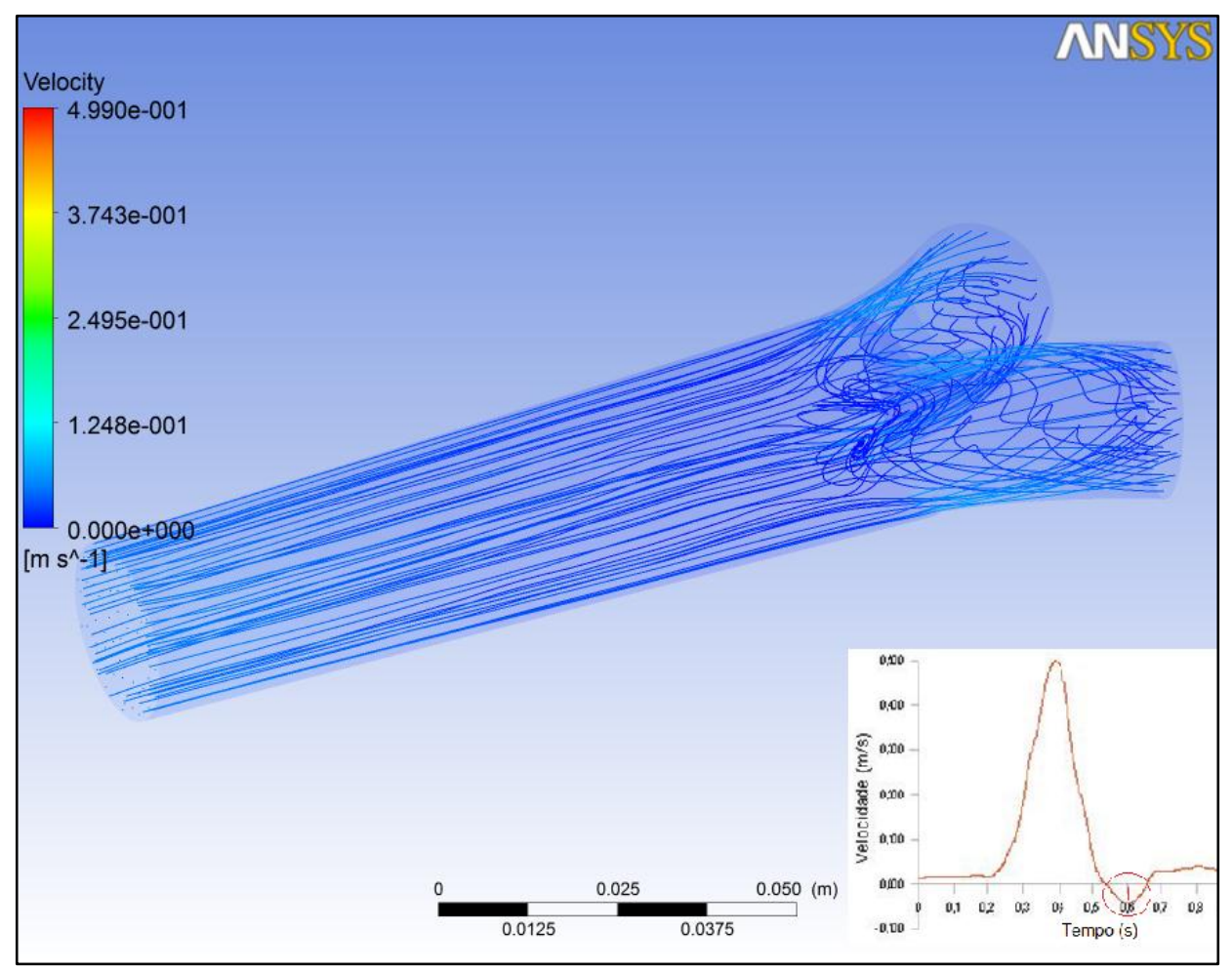

Figura 67 - Resultado de linhas de corrente em Endoprótese para AAA no instante $t=0,6$ segundo (Endoprótese para AAABB1) 


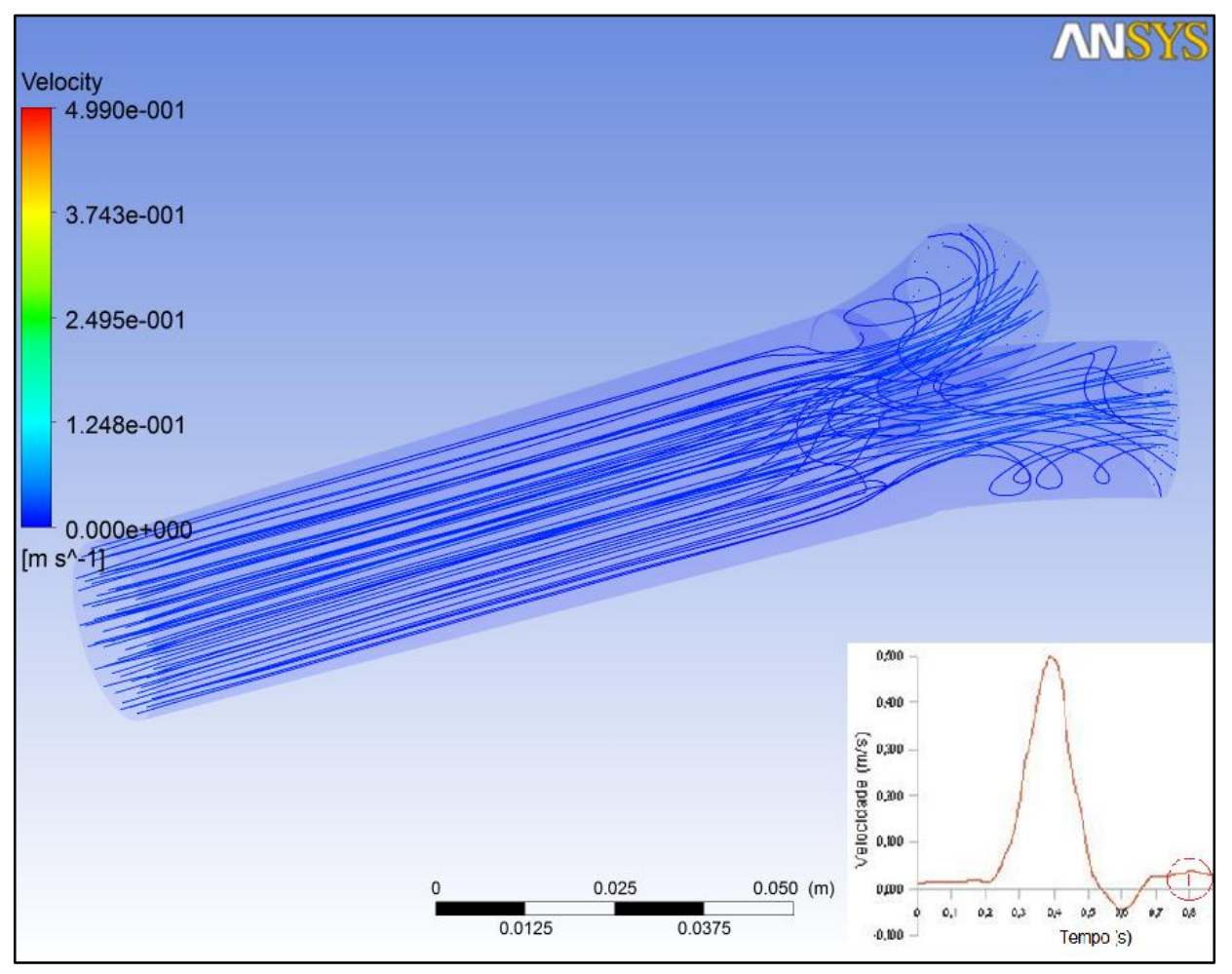

Figura 68 - Resultado de linhas de corrente em Endoprótese para AAA no instante $t=0,8$ segundo (Endoprótese para AAABB1)

\subsubsection{Aneurisma AAABB2}

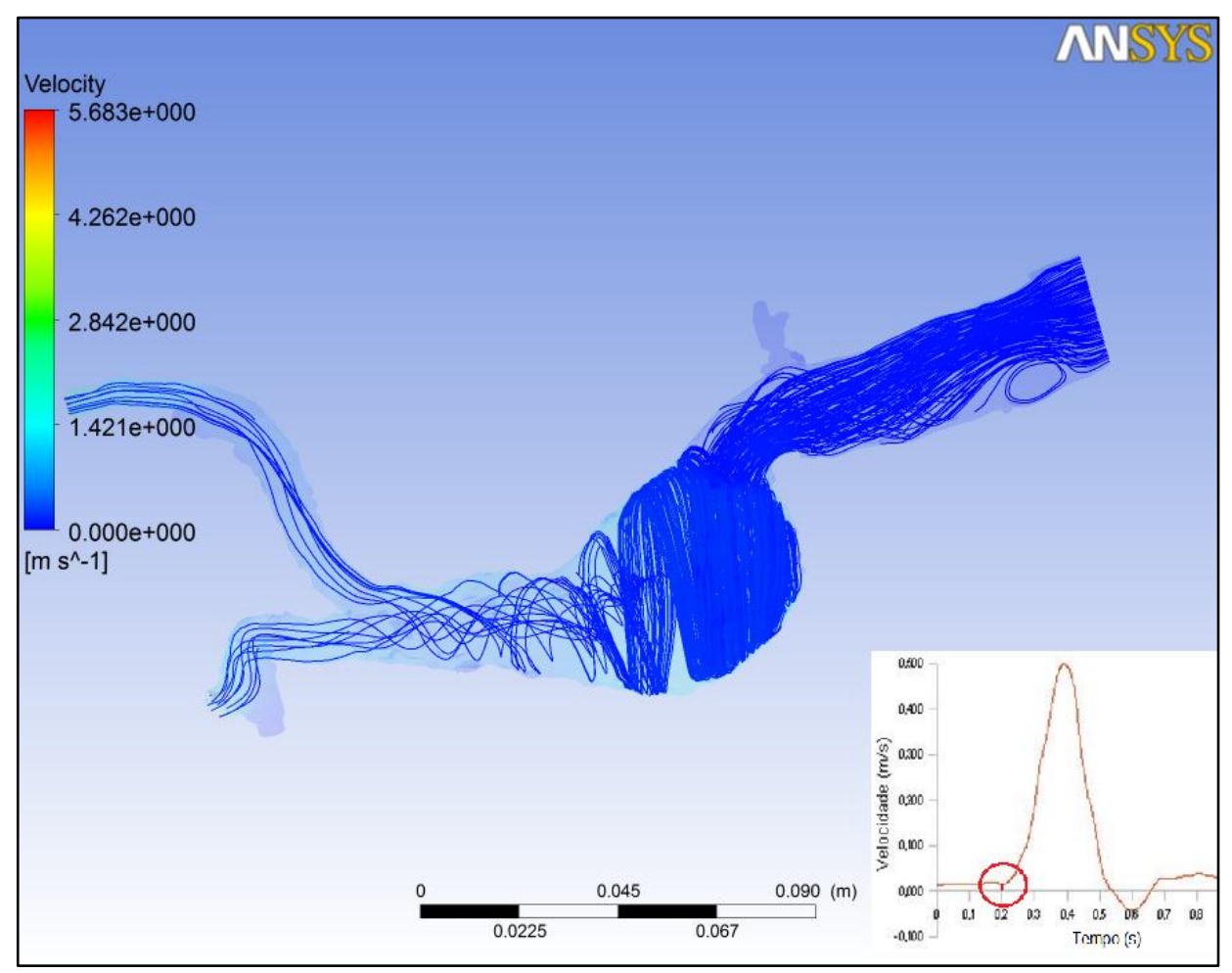

Figura 69 - Resultado de linhas de corrente em AAA no instante $t=0,2$ segundo (AAABB2) 


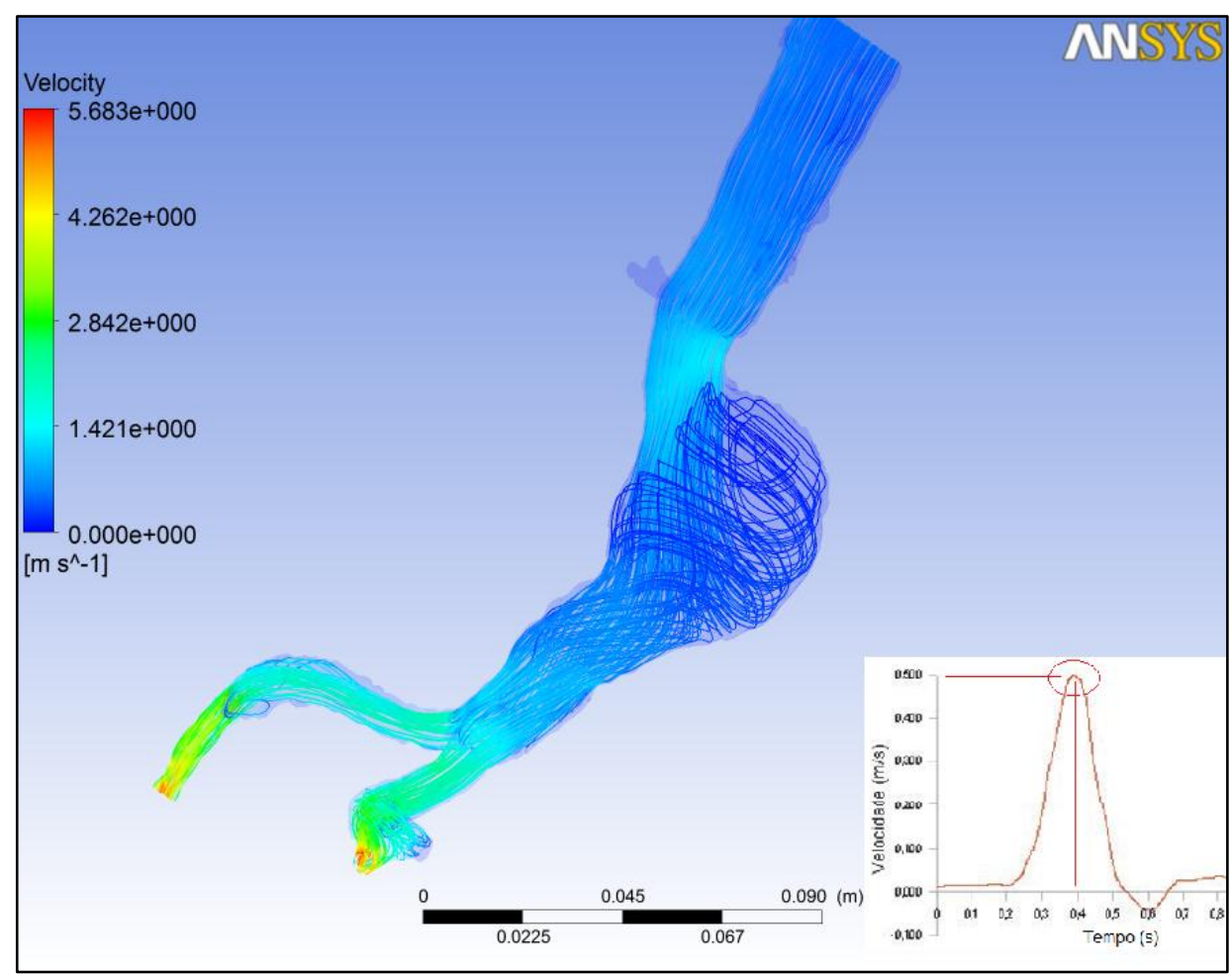

Figura 70 - Resultado de linhas de corrente em AAA no instante $t=0,4$ segundo (AAABB2)

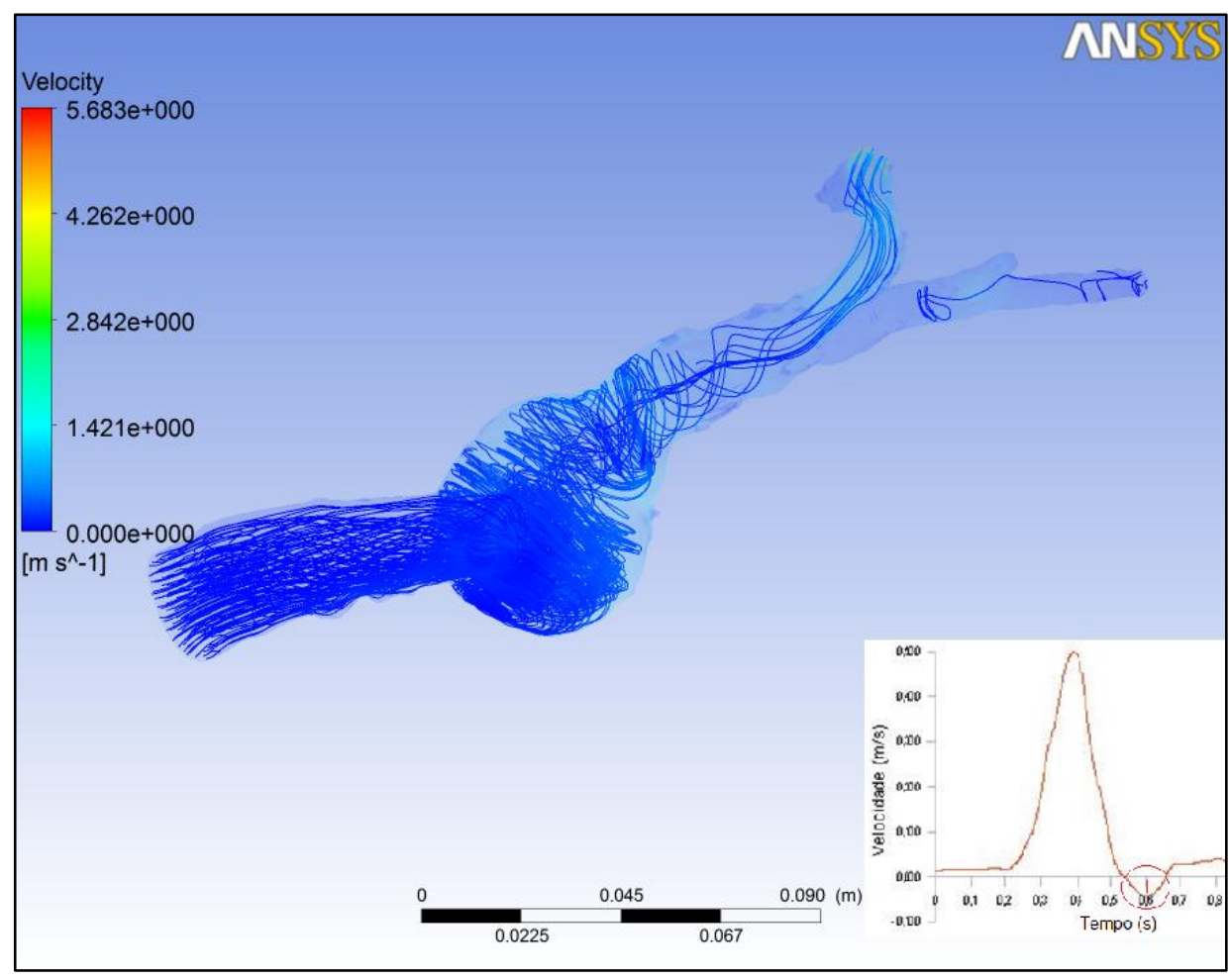

Figura 71 - Resultado de linhas de corrente em AAA no instante $t=0,6$ segundo (AAABB2) 


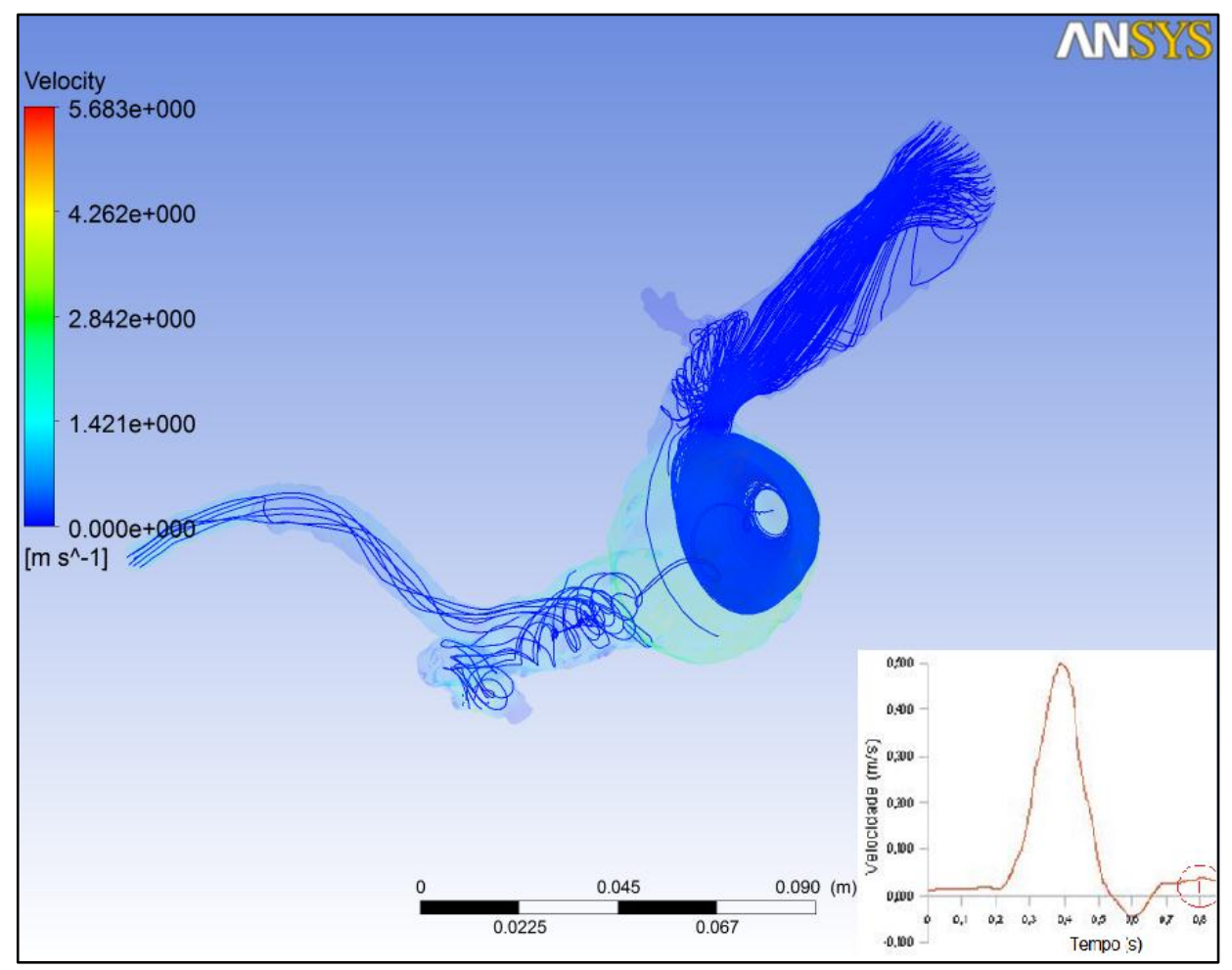

Figura 72 - Resultado de linhas de corrente em AAA no instante $t=0,8$ segundo (AAABB2)

\subsubsection{Endoprótese Cilíndrica para AAABB2}

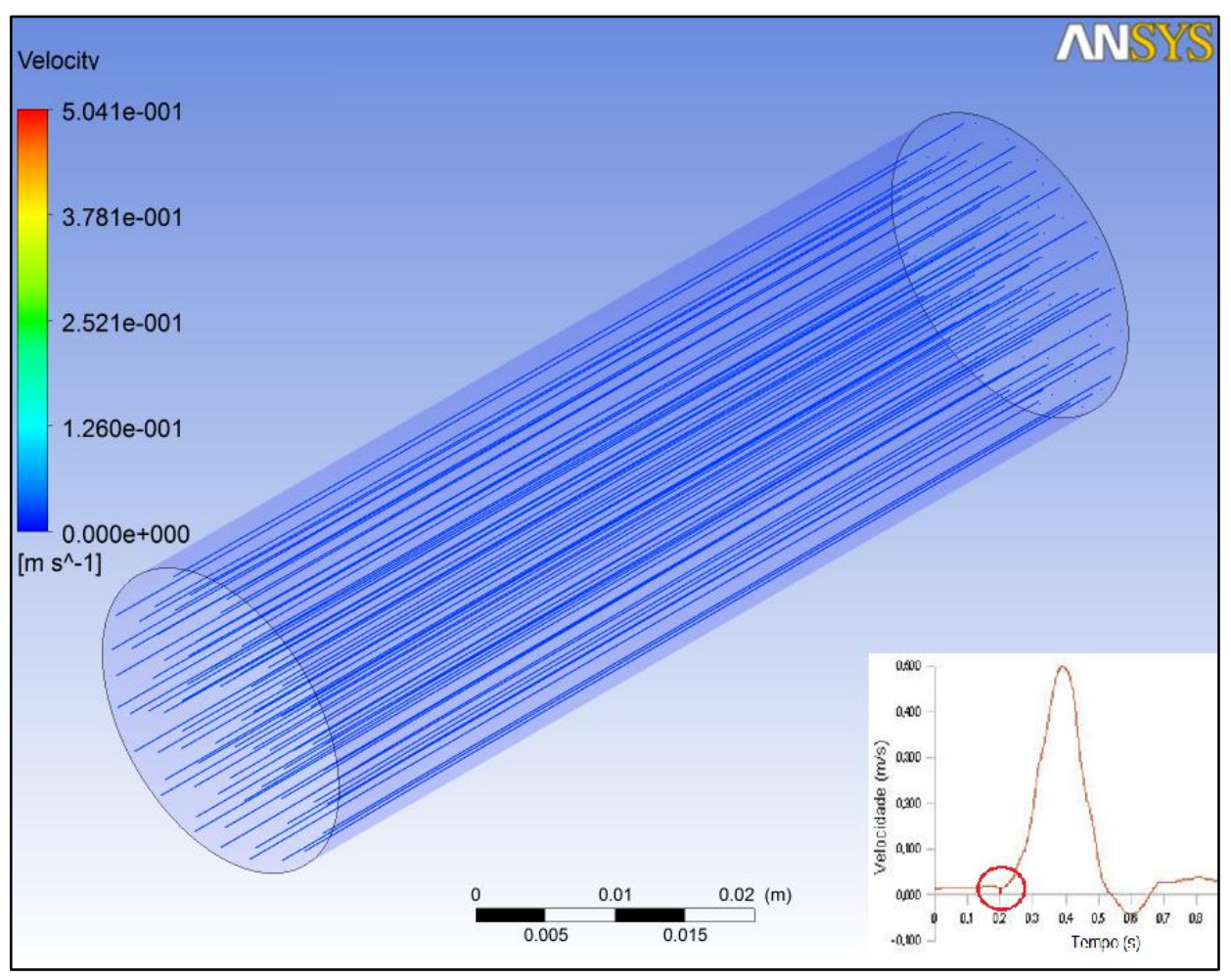

Figura 73 - Resultado de linhas de corrente em Endoprótese para AAA no instante $t=0,2$ segundo (Endoprótese para AAABB2) 


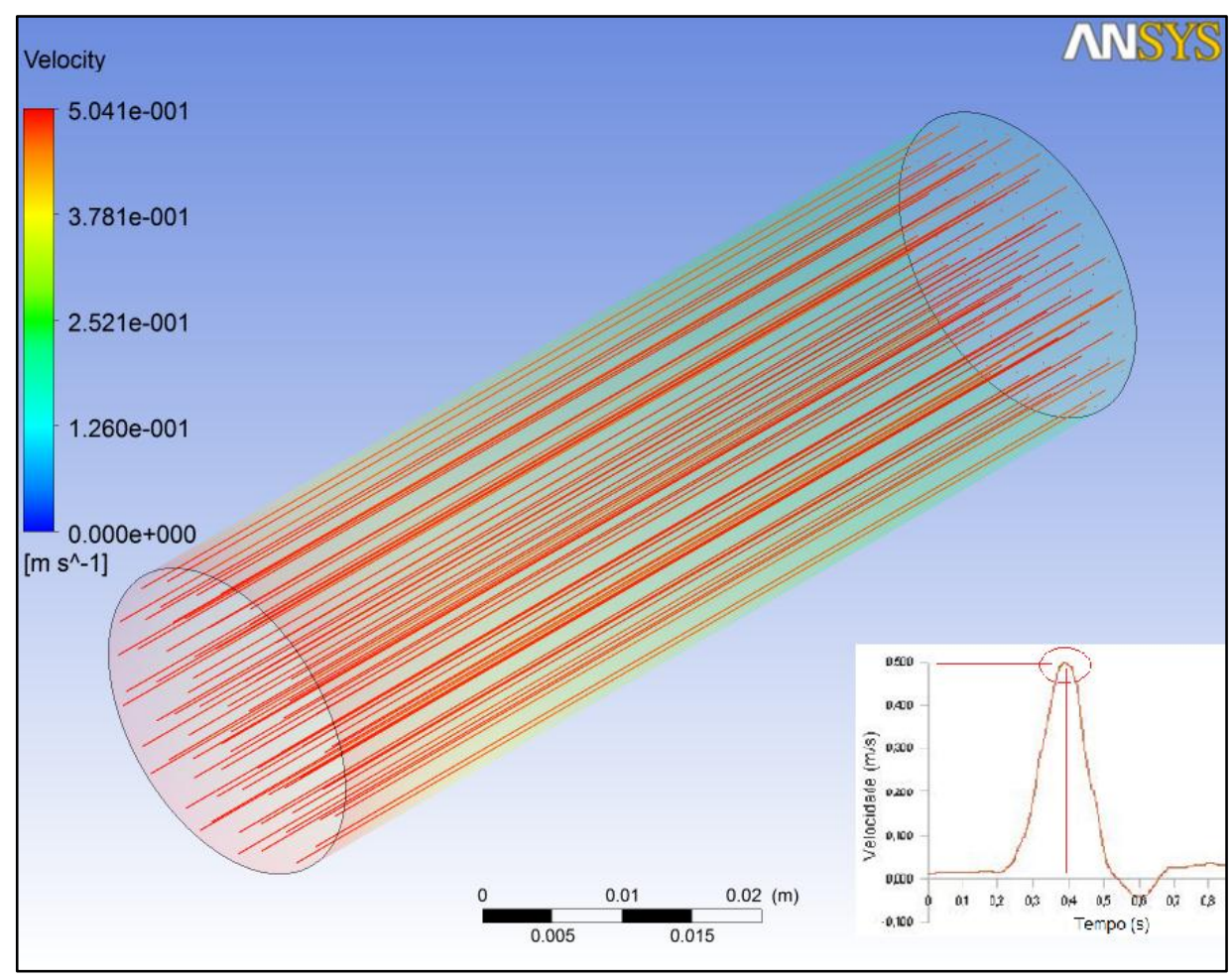

Figura 74 - Resultado de linhas de corrente em Endoprótese para AAA no instante $t=0,4$ segundo (Endoprótese para AAABB2)

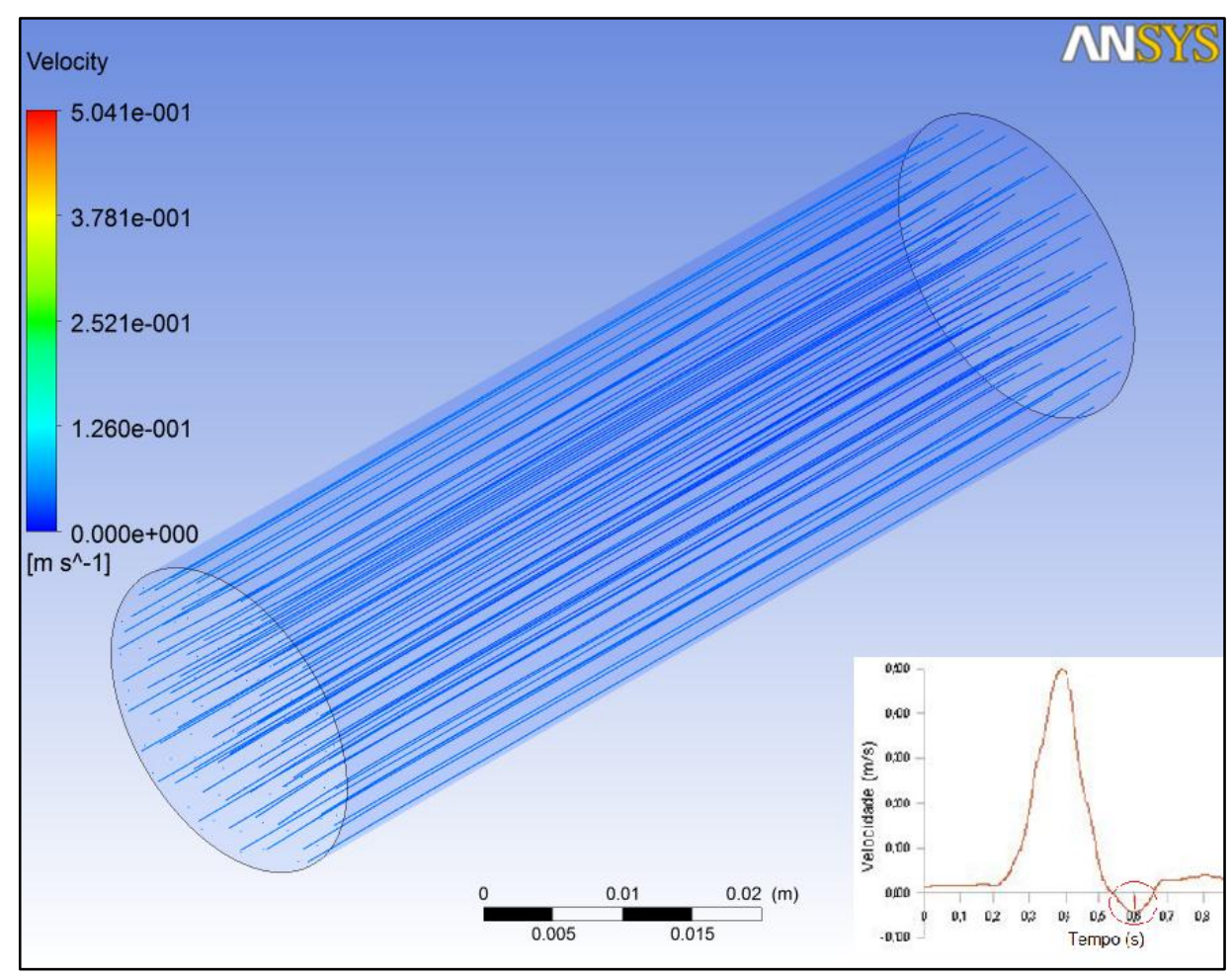

Figura 75 - Resultado de linhas de corrente em Endoprótese para AAA no instante $t=0,6$ segundo (Endoprótese para AAABB2) 


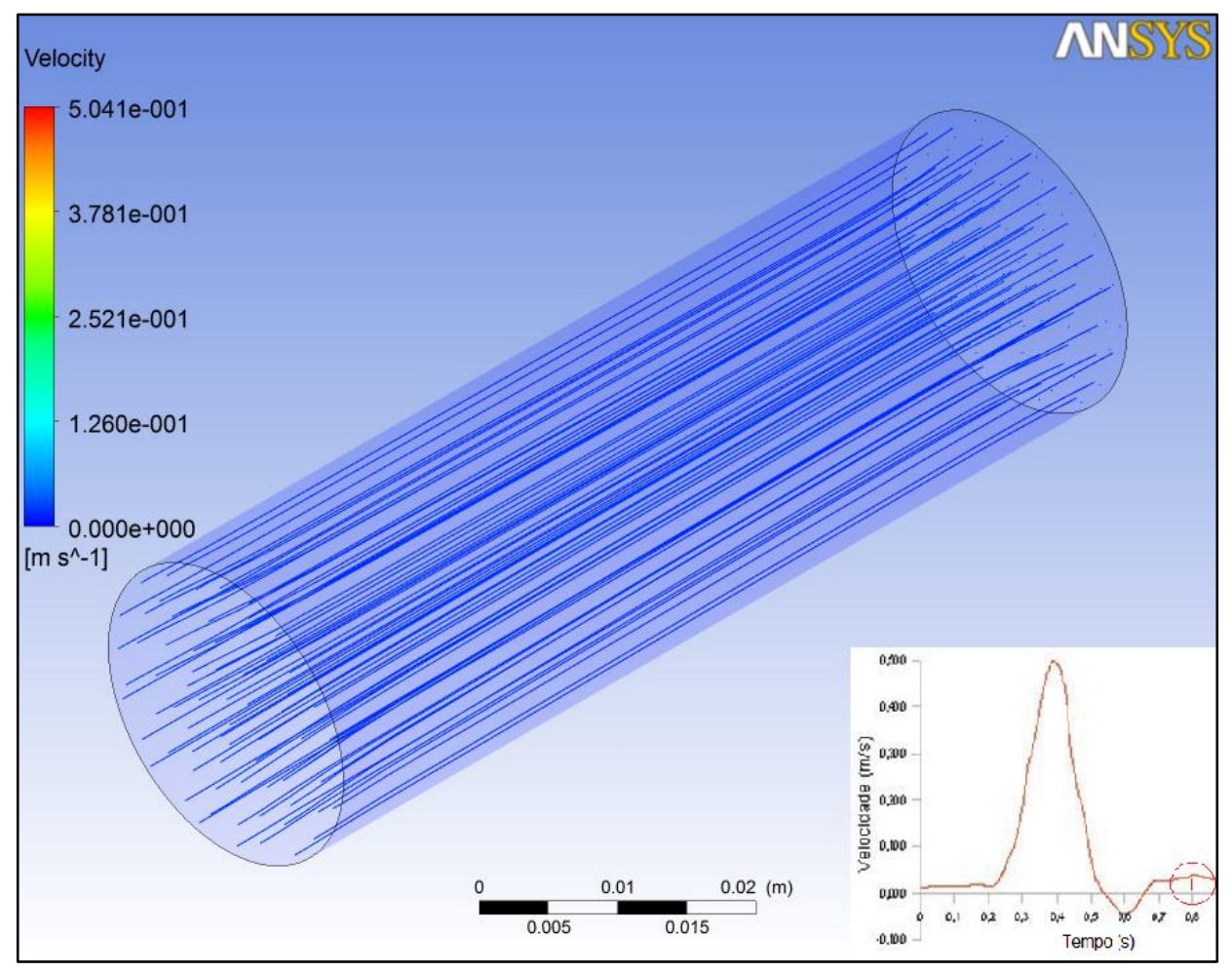

Figura 76 - Resultado de linhas de corrente em Endoprótese para AAA no instante $t=0,8$ segundo (Endoprótese para AAABB2)

\subsubsection{Tensões de Cisalhamento na Parede}

Nesta seção do trabalho, serão apresentados os resultados das tensões de cisalhamento calculadas juntos à parede pelas simulações. Os resultados serão divididos de acordo com as diferentes geometrias. Serão agrupadas as geometrias do AAA com a respectiva endoprótese. 


\subsubsection{Aneurisma de Legendre}

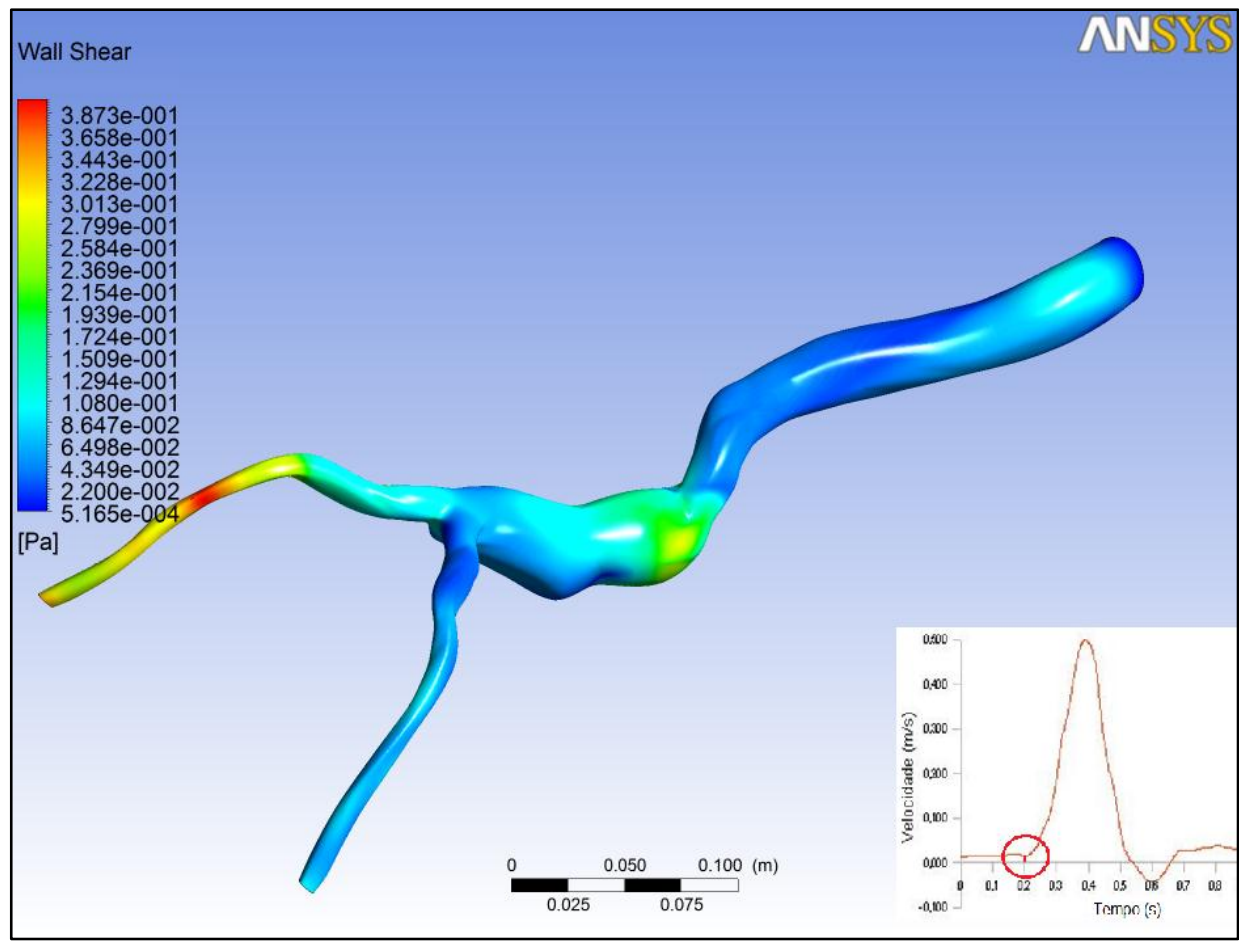

Figura 77 - Resultado de tensão de cisalhamento na parede de AAA no instante $t=0,2$ segundo (AAA Legendre)

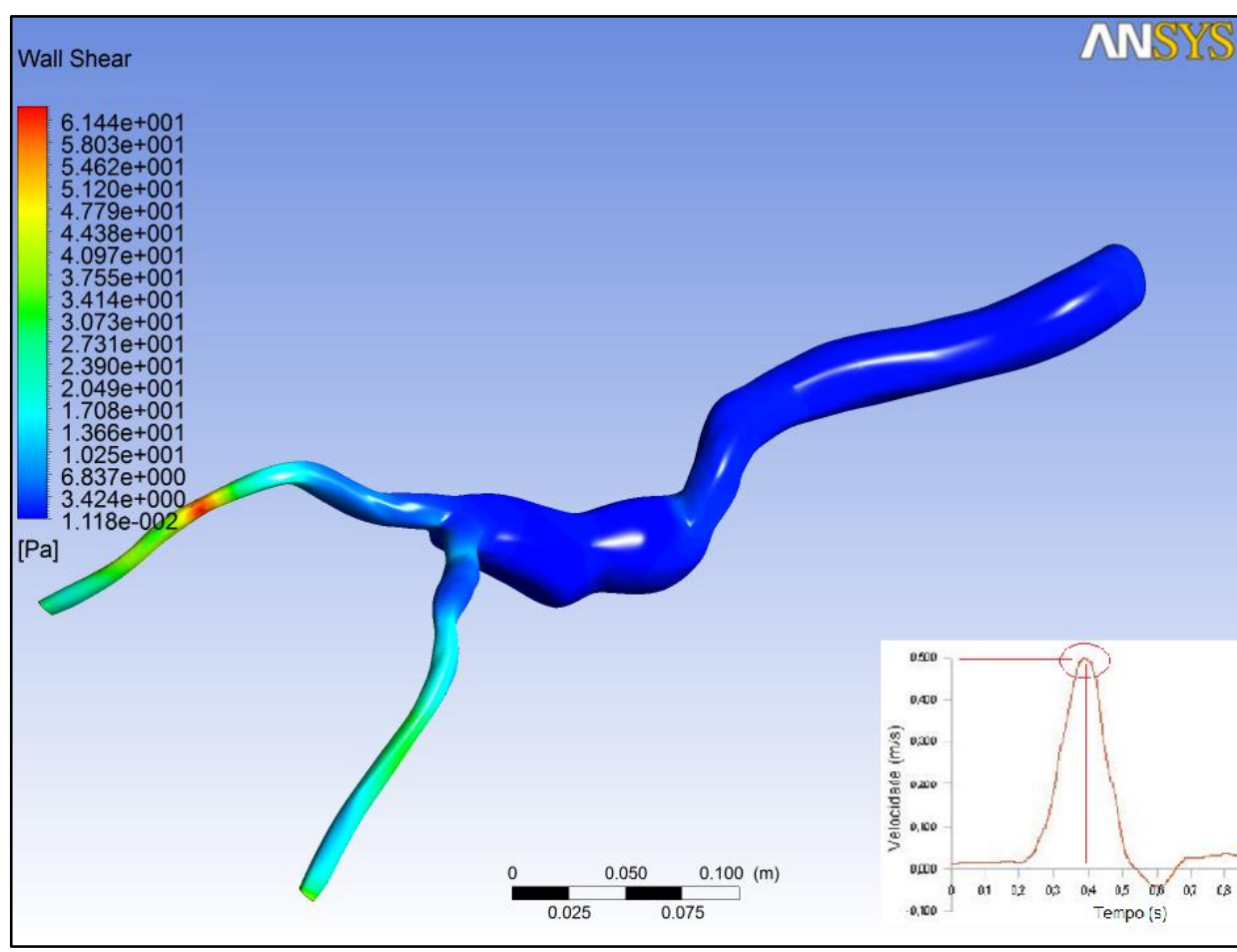

Figura 78 - Resultado de tensão de cisalhamento na parede de AAA no instante $t=0,4$ segundo (AAA Legendre) 


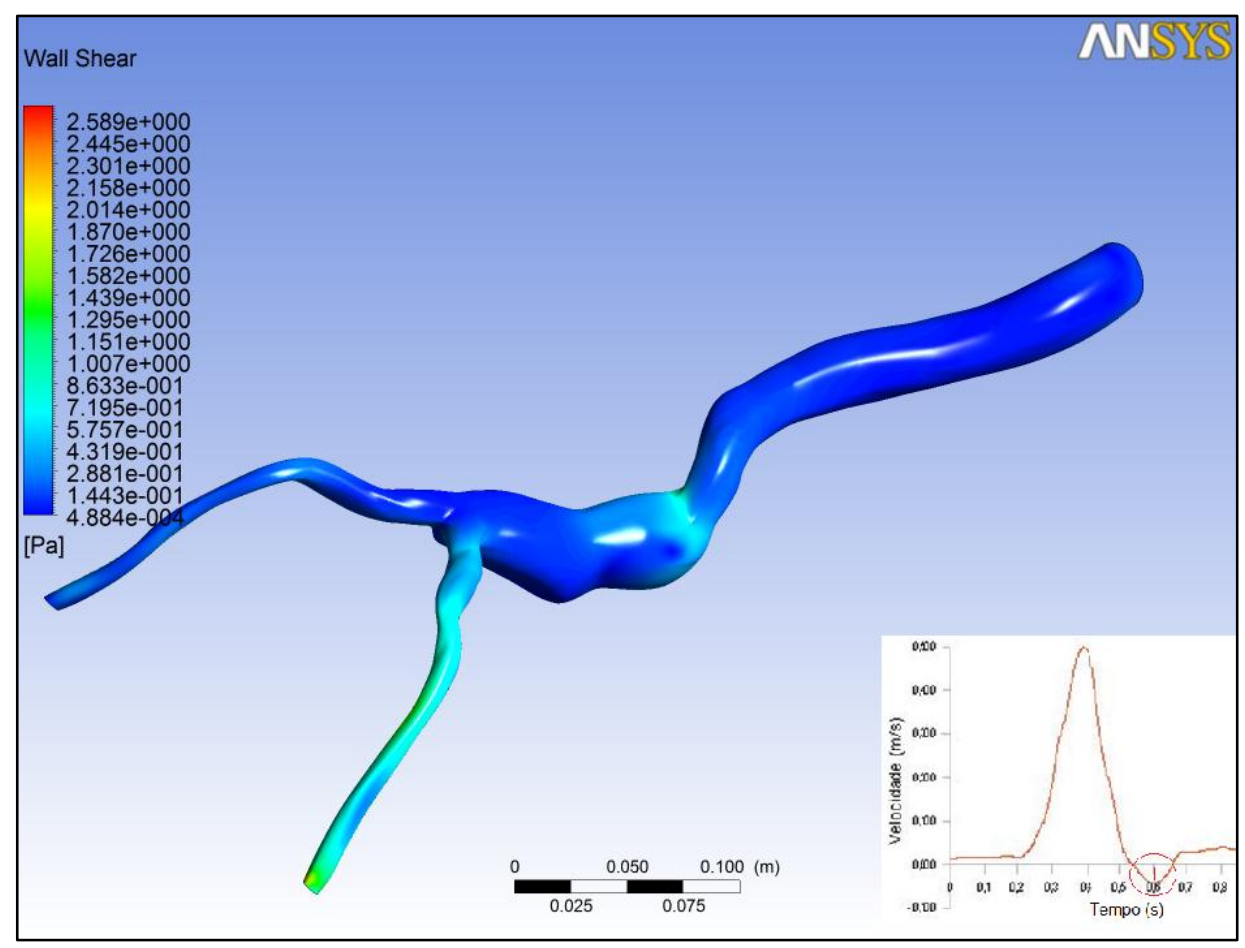

Figura 79 - Resultado de tensão de cisalhamento na parede de AAA no instante $t=0,6$ segundo (AAA Legendre)

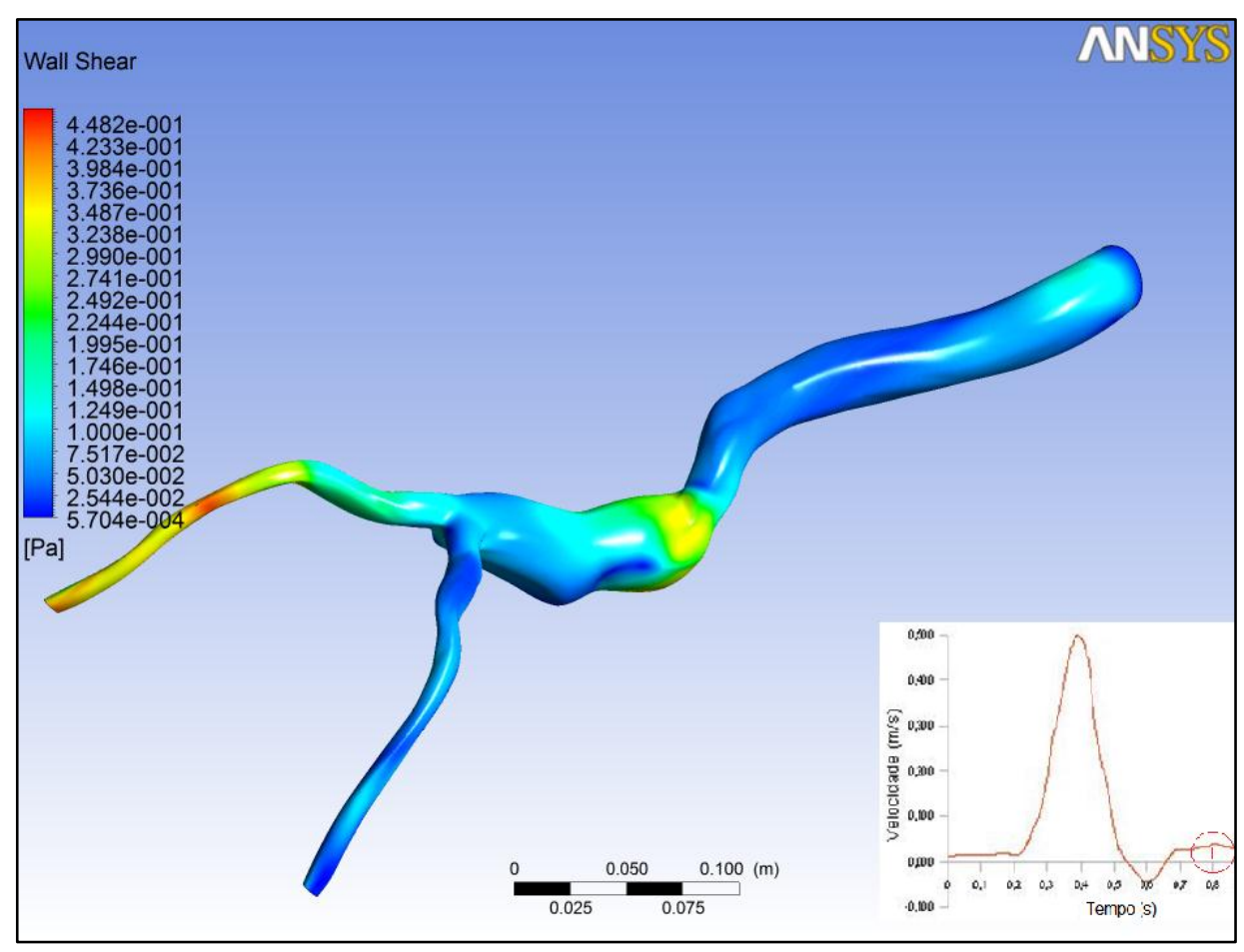

Figura 80 - Resultado de tensão de cisalhamento na parede de AAA no instante $t=0,8$ segundo (AAA Legendre) 


\subsubsection{Endoprótese Bifurcada para Aneurisma de Legendre}

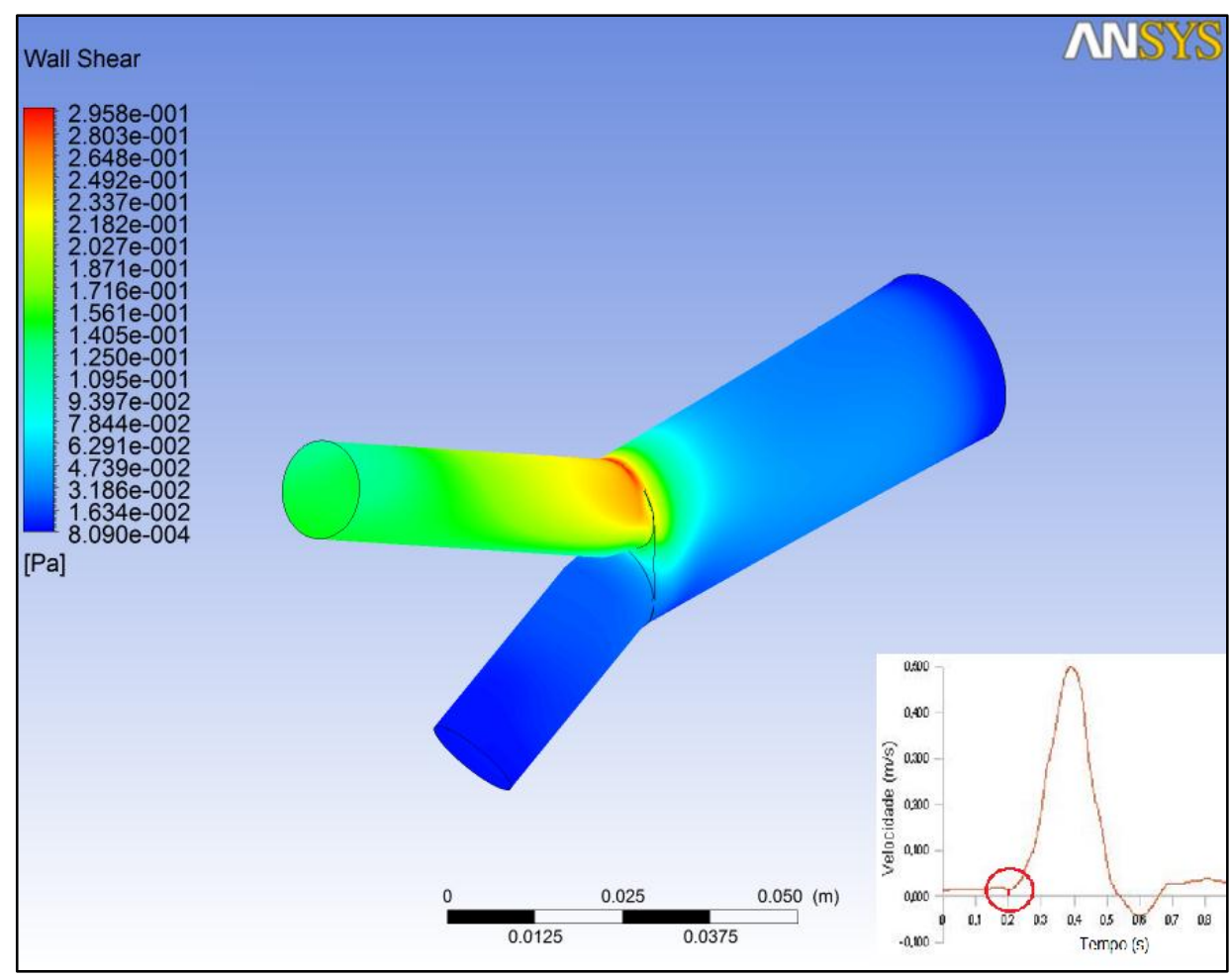

Figura 81 - Resultado de tensão de cisalhamento na parede de Endoprótese para AAA no instante $t=0,2$ segundo (Endoprótese AAA Legendre)

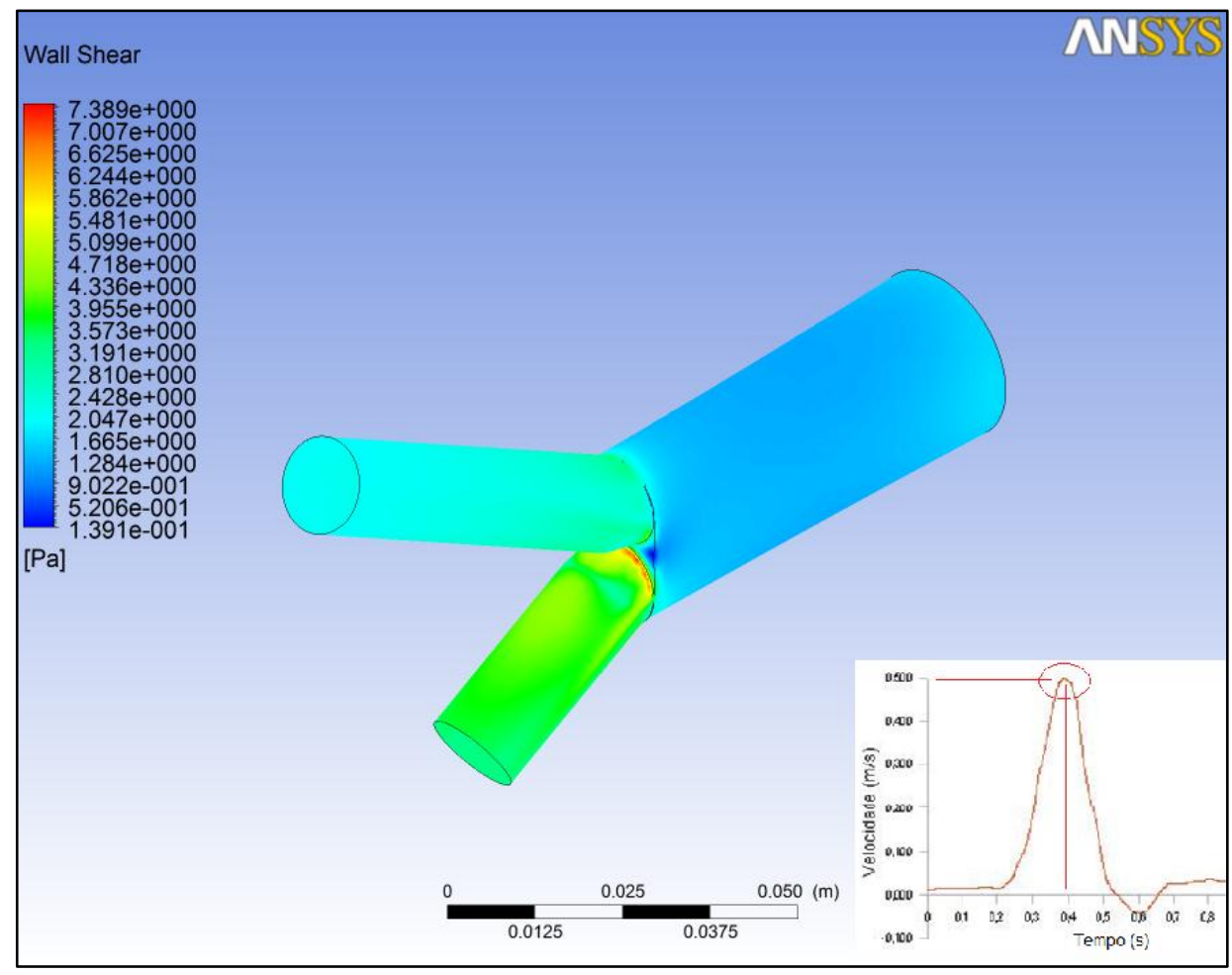

Figura 82 - Resultado de tensão de cisalhamento na parede de Endoprótese para AAA no instante $\mathrm{t}=0,4$ segundo (Endoprótese AAA Legendre) 


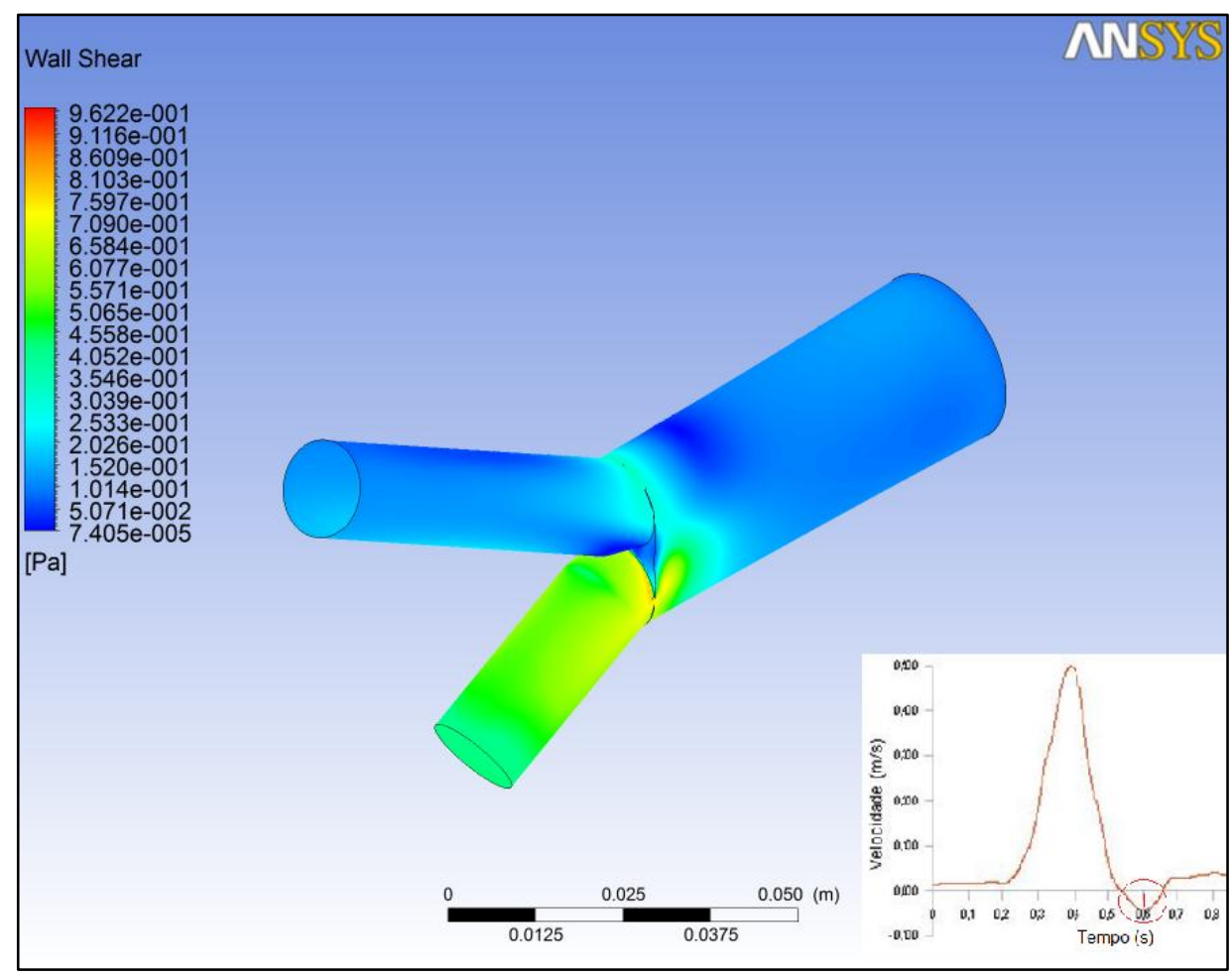

Figura 83 - Resultado de tensão de cisalhamento na parede de Endoprótese para AAA no instante $\mathrm{t}=0,6$ segundo (Endoprótese AAA Legendre)

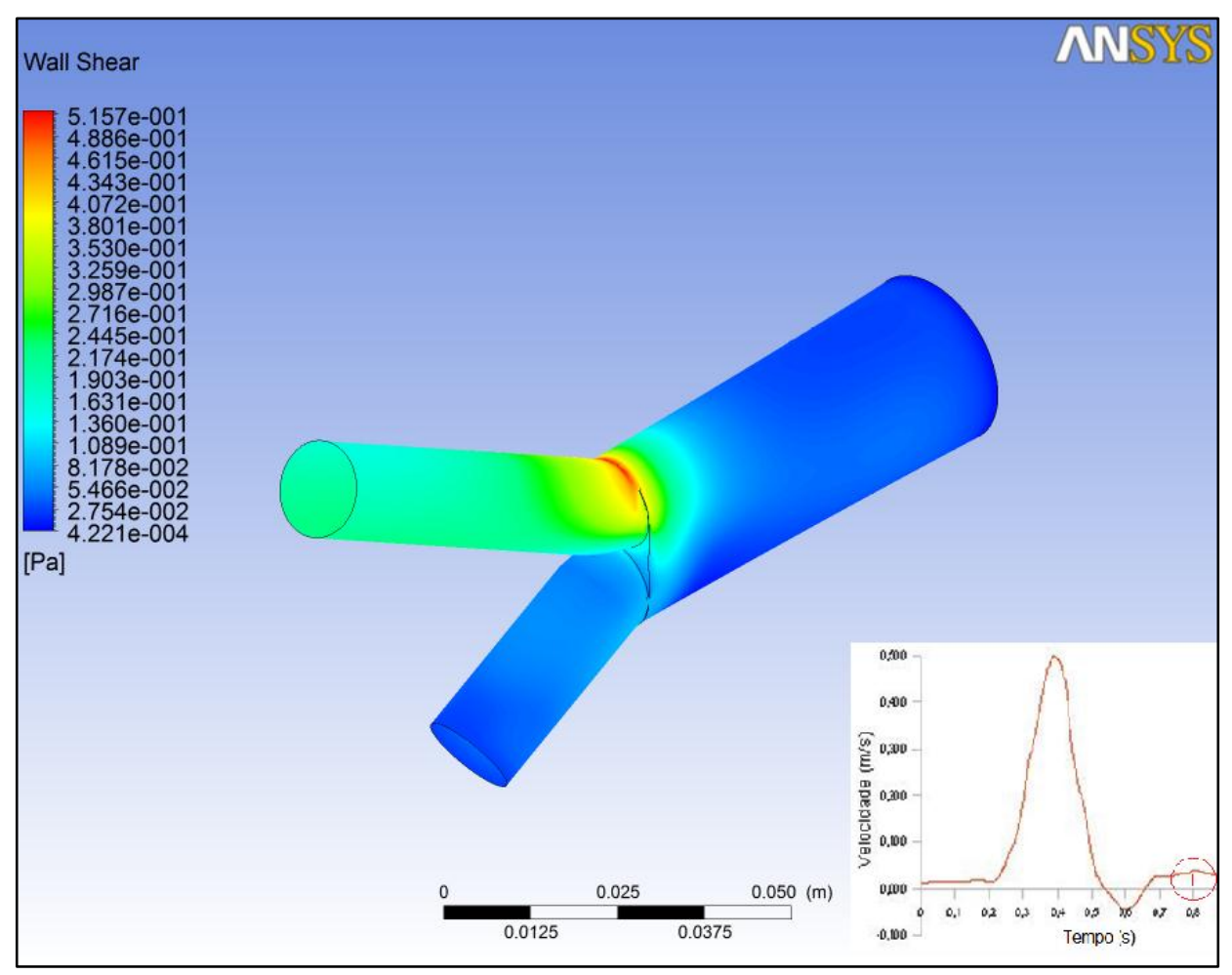

Figura 84 - Resultado de tensão de cisalhamento na parede de Endoprótese para AAA no instante $t=0,8$ segundo (Endoprótese AAA Legendre) 


\subsubsection{Aneurisma AAABB1}

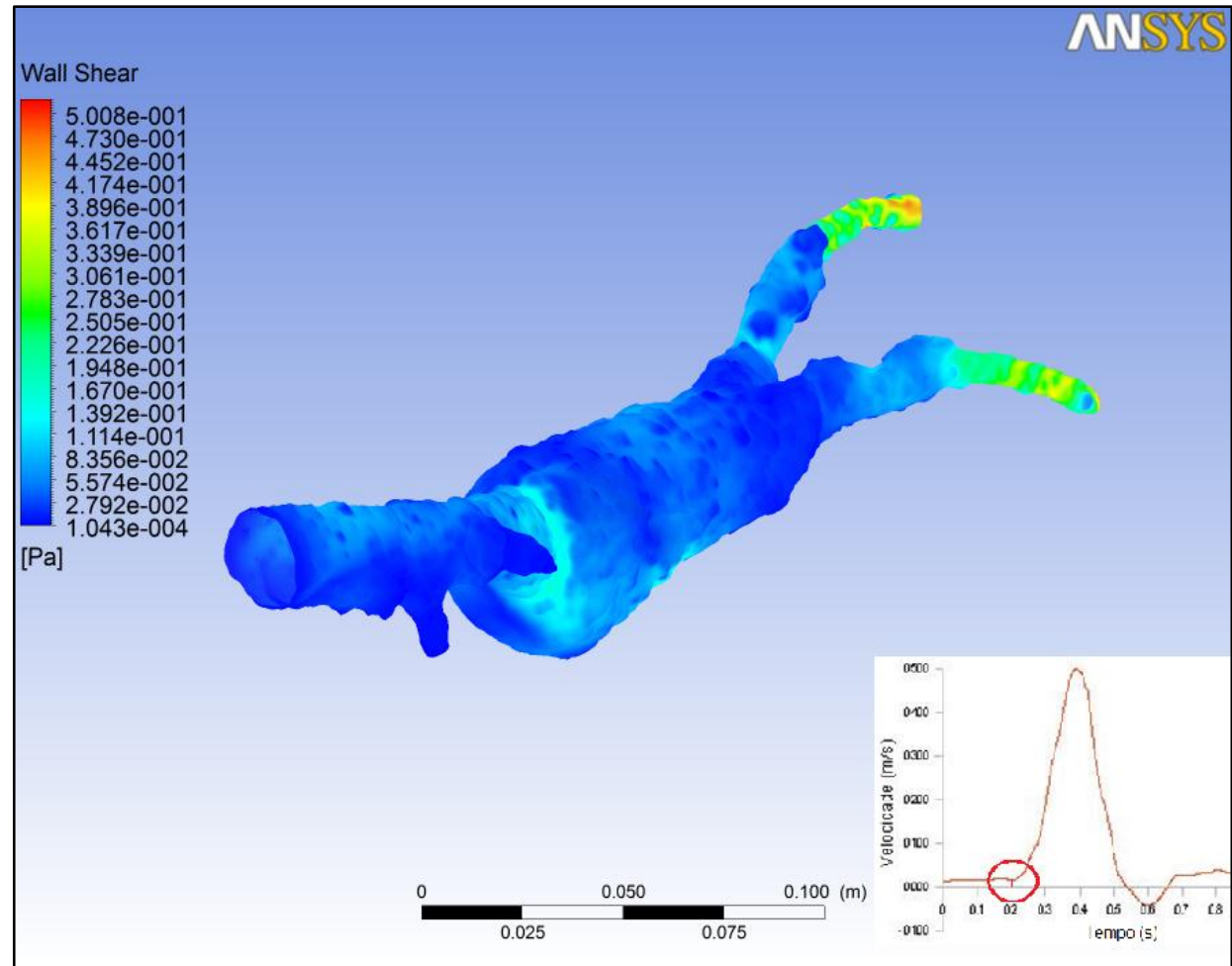

Figura 85 - Resultado de tensão de cisalhamento na parede de AAA no instante $t=0,2$ segundo (AAABB1)

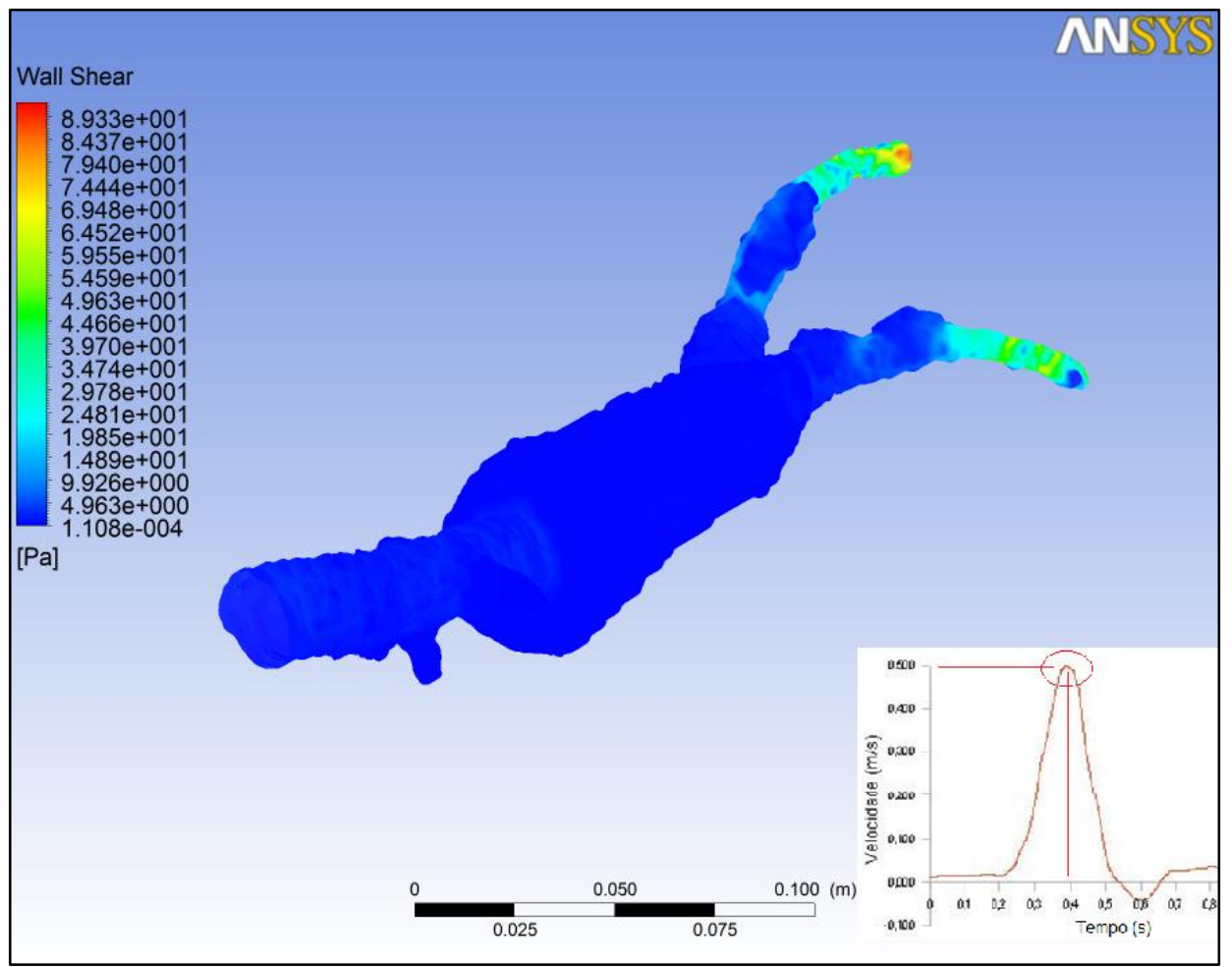

Figura 86 - Resultado de tensão de cisalhamento na parede de AAA no instante $t=0,4$ segundo (AAABB1) 


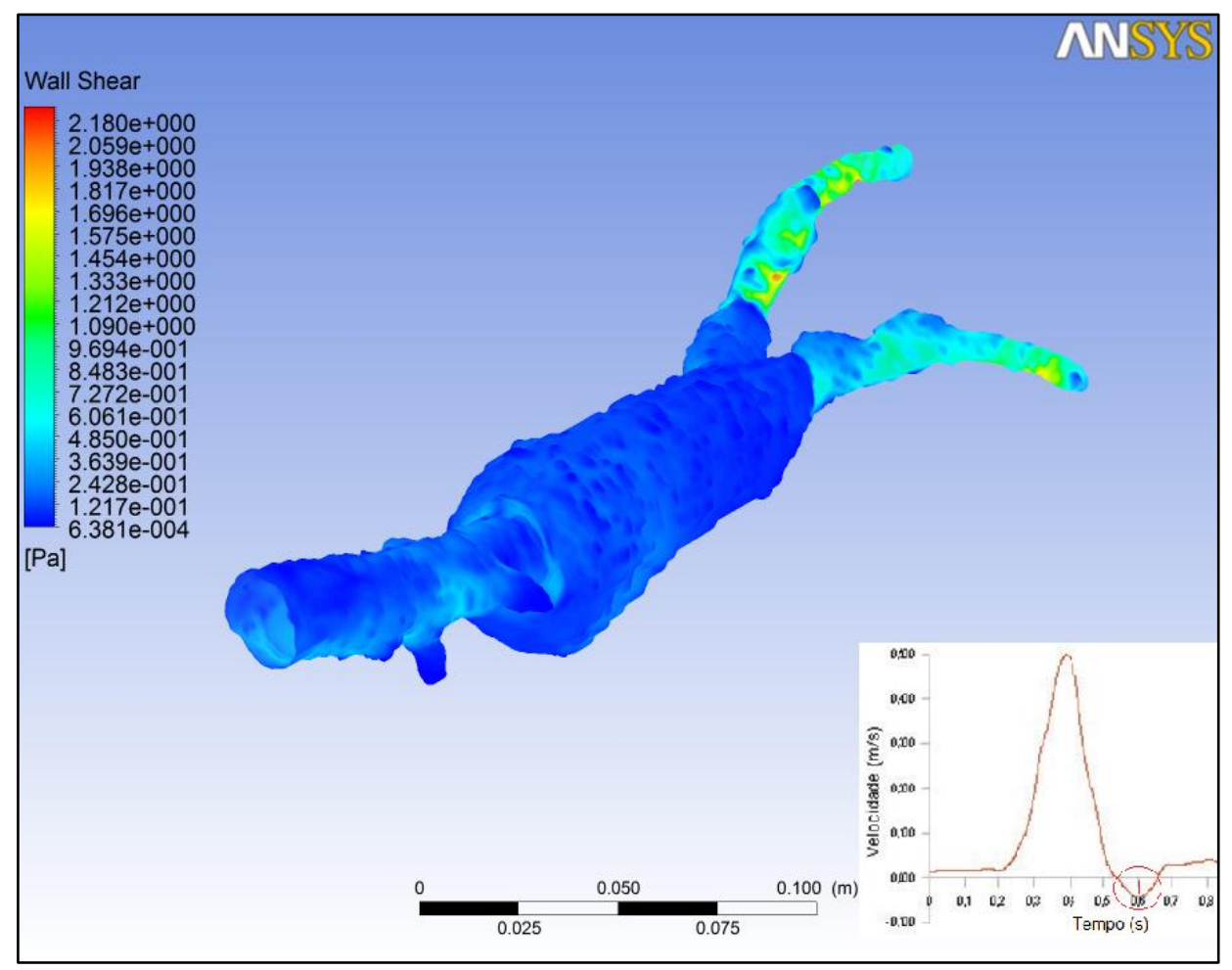

Figura 87 - Resultado de tensão de cisalhamento na parede de AAA no instante $t=0,6$ segundo (AAABB1)

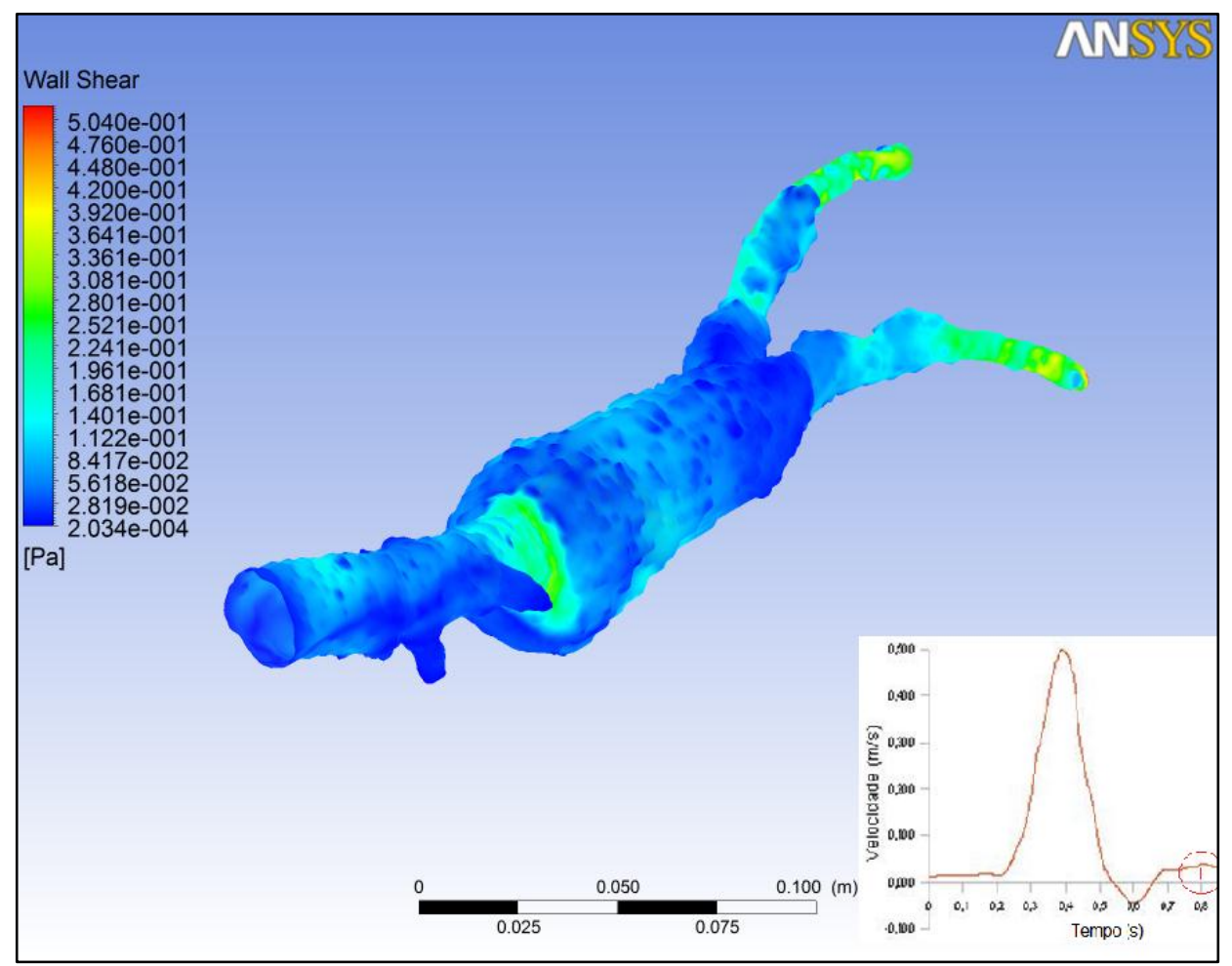

Figura 88 - Resultado de tensão de cisalhamento na parede de AAA no instante $t=0,8$ segundo (AAABB1) 


\subsubsection{Endoprótese Bifurcada para AAABB1}

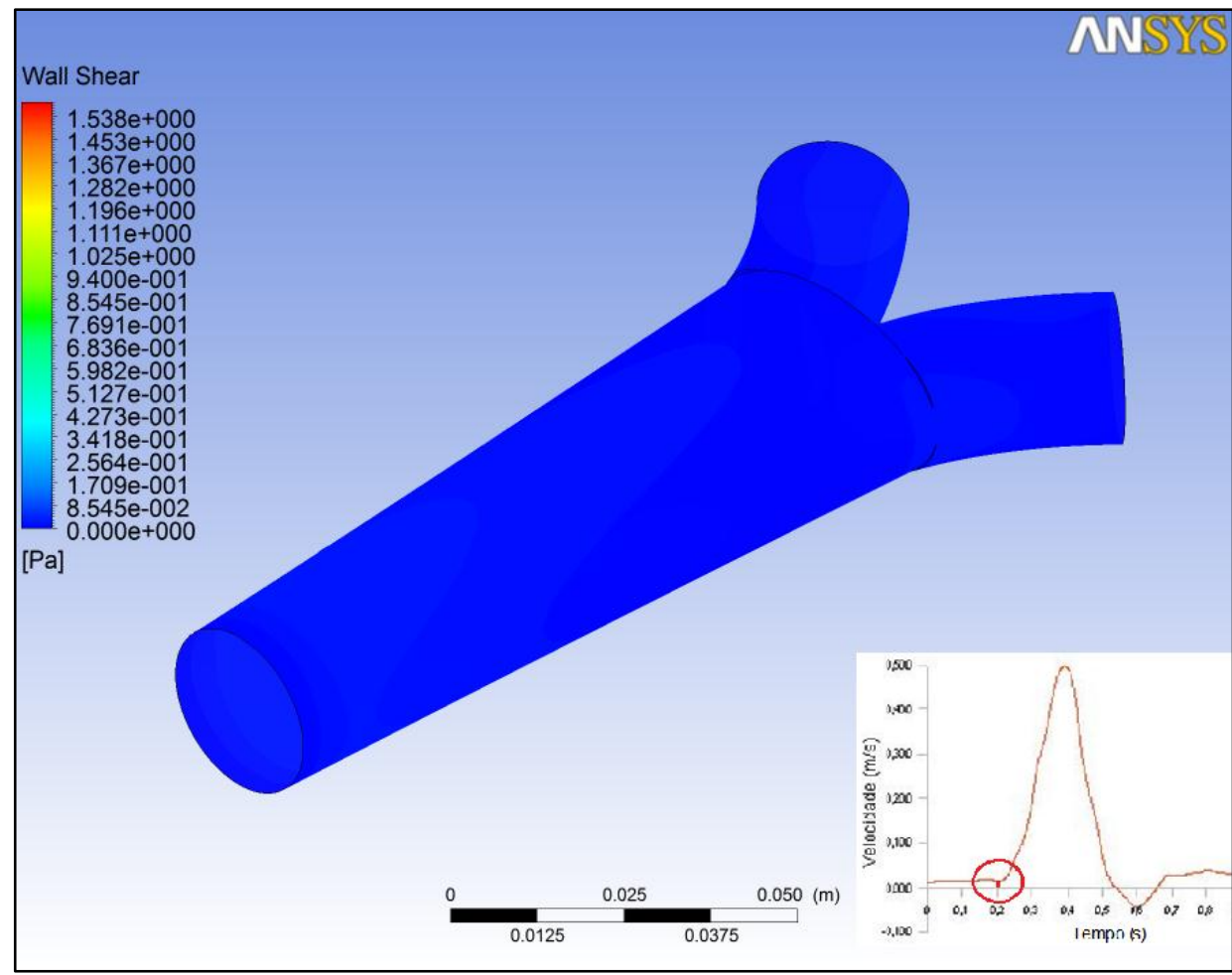

Figura 89 - Resultado de tensão de cisalhamento na parede de Endoprótese para AAA no instante $\mathrm{t}=0,2$ segundo (Endoprótese para $A A A B B 1$ )

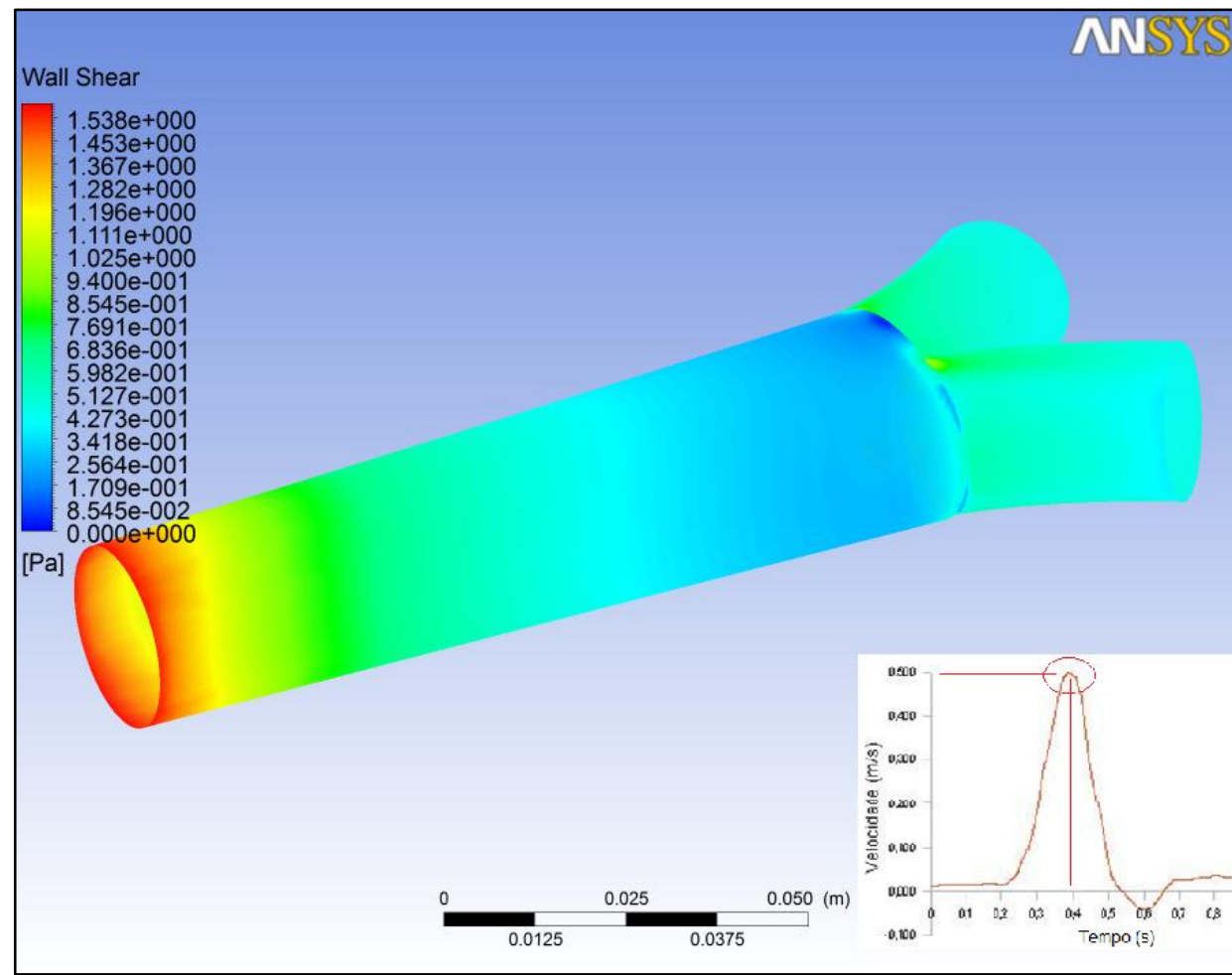

Figura 90 - Resultado de tensão de cisalhamento na parede de Endoprótese para AAA no instante $\mathrm{t}=0,4$ segundo (Endoprótese para AAABB1) 


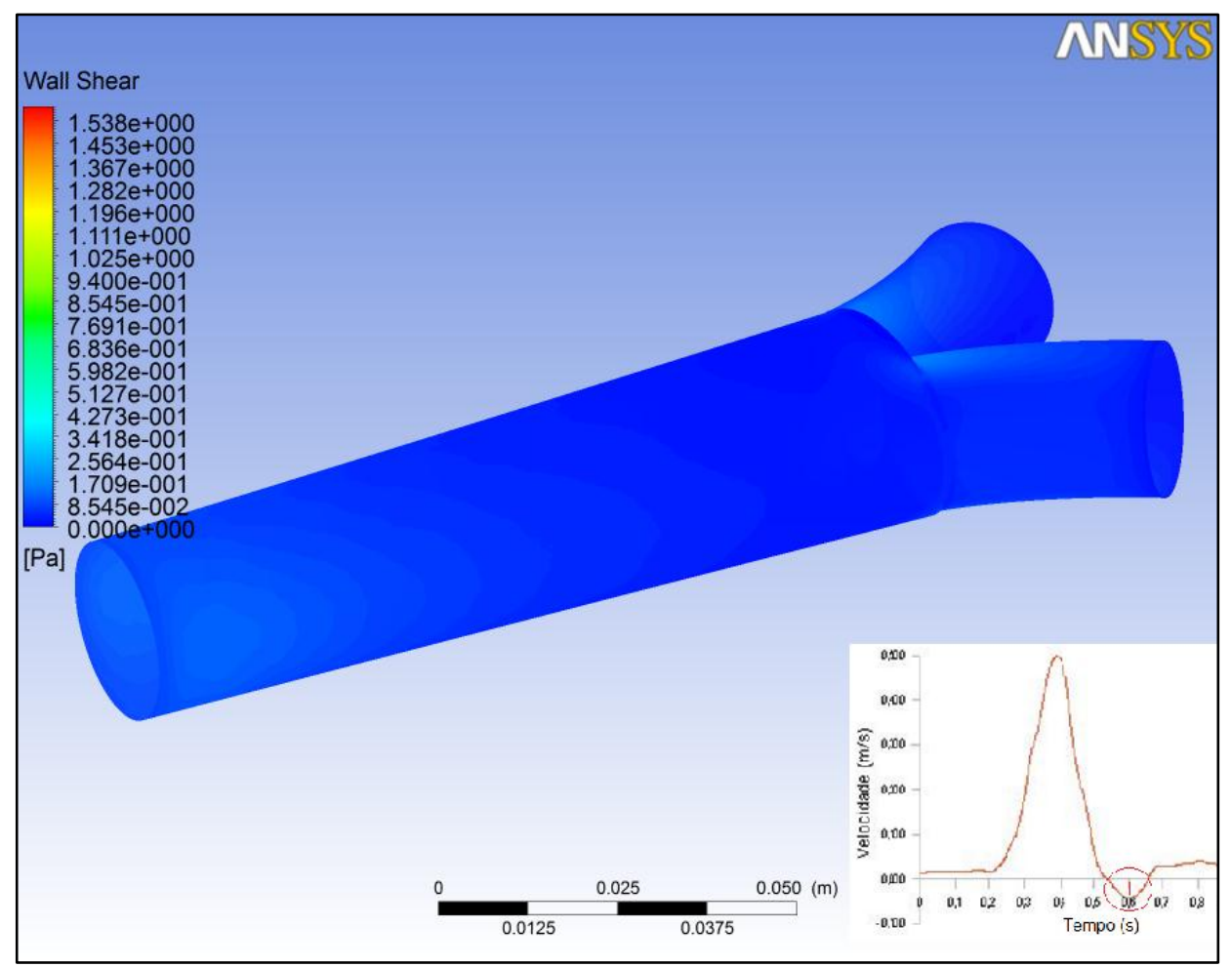

Figura 91 - Resultado de tensão de cisalhamento na parede de Endoprótese para AAA no instante $\mathrm{t}=0,6$ segundo (Endoprótese para AAABB1)

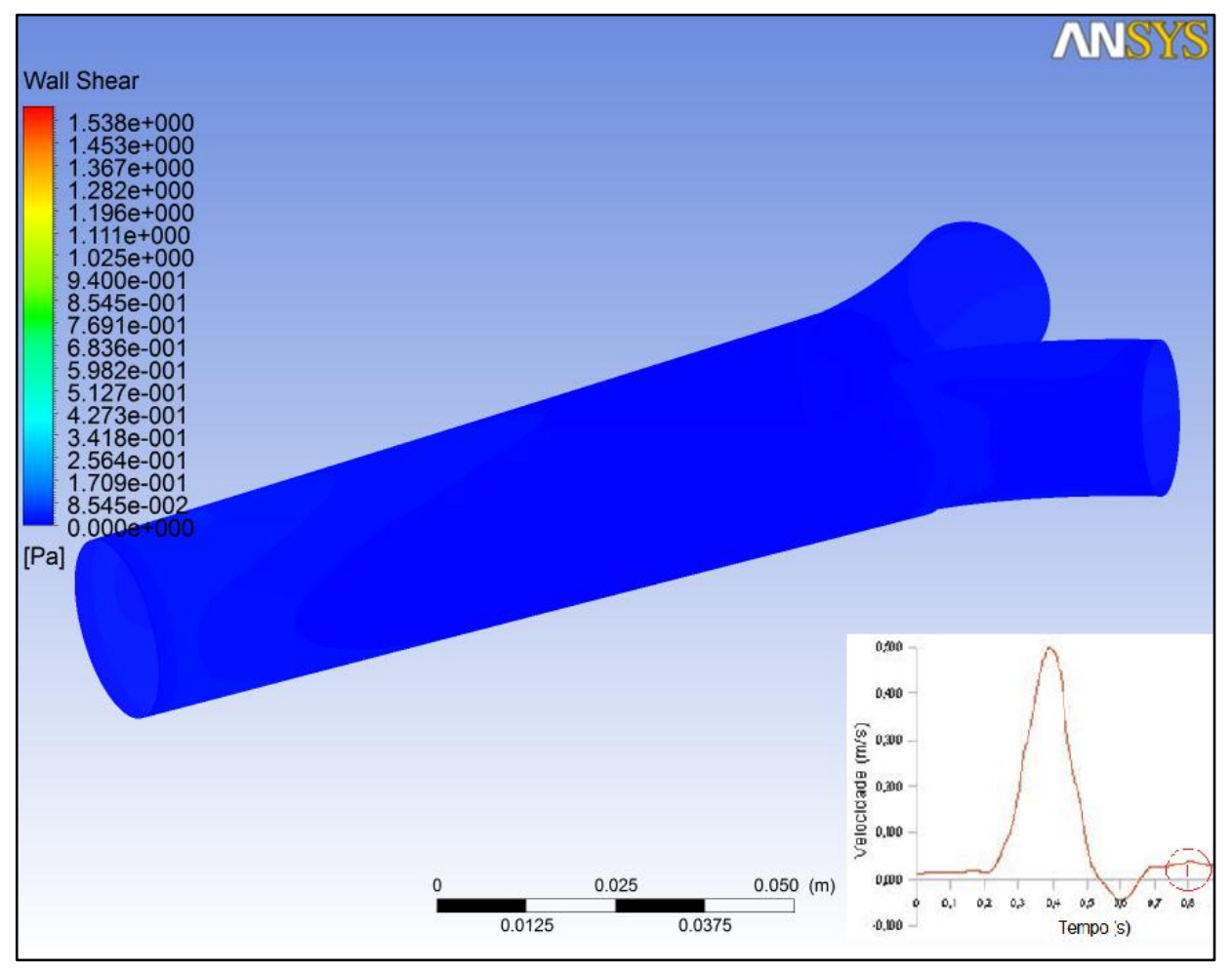

Figura 92 - Resultado de tensão de cisalhamento na parede de Endoprótese para AAA no instante $\mathrm{t}=0,8$ segundo (Endoprótese para AAABB1) 
5.1.3.5 Aneurisma $A A A B B 2$

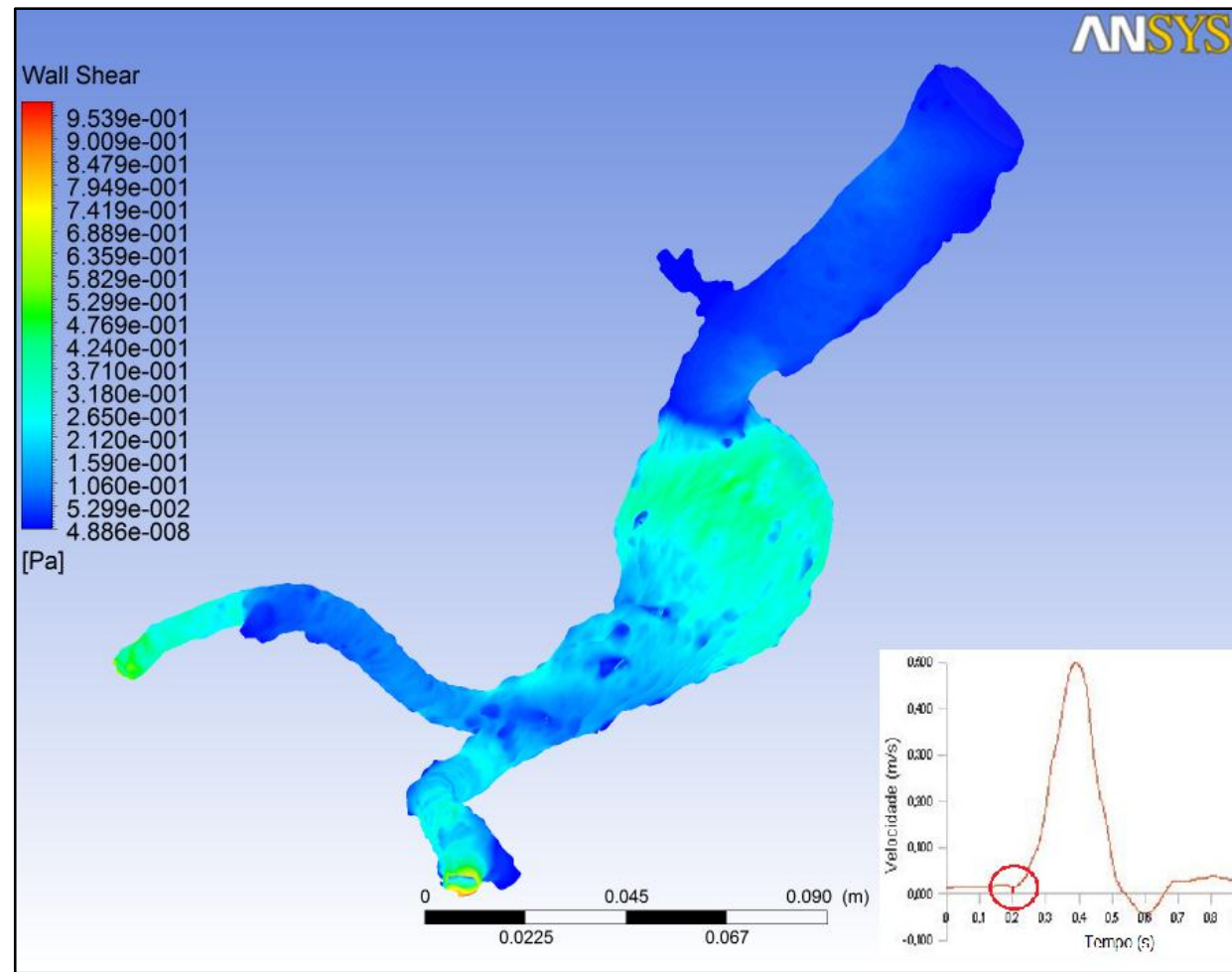

Figura 93 - Resultado de tensão de cisalhamento na parede de AAA no instante $t=0,2$ segundo (AAABB2)

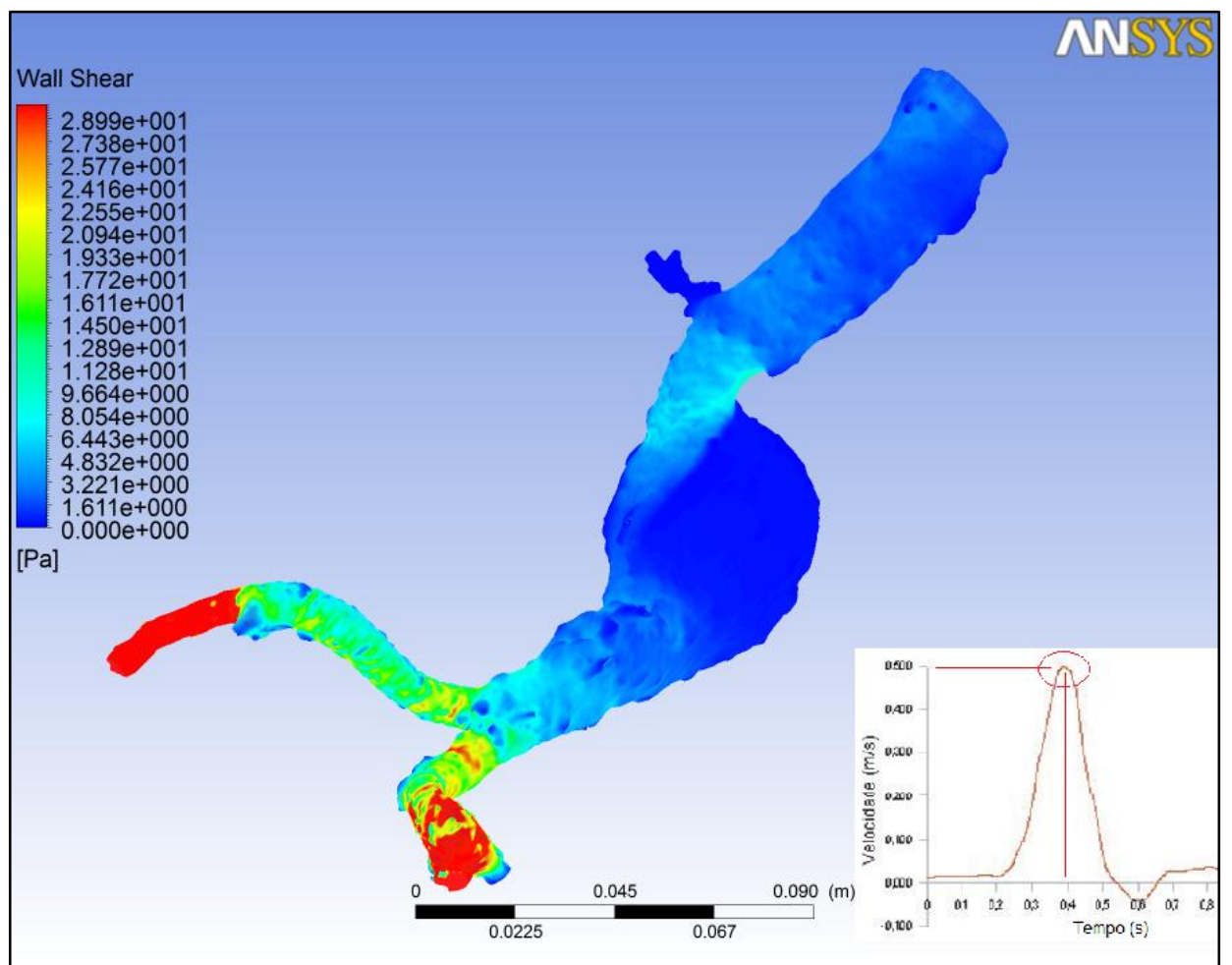

Figura 94 - Resultado de tensão de cisalhamento na parede de AAA no instante $t=0,4$ segundo (AAABB2) 


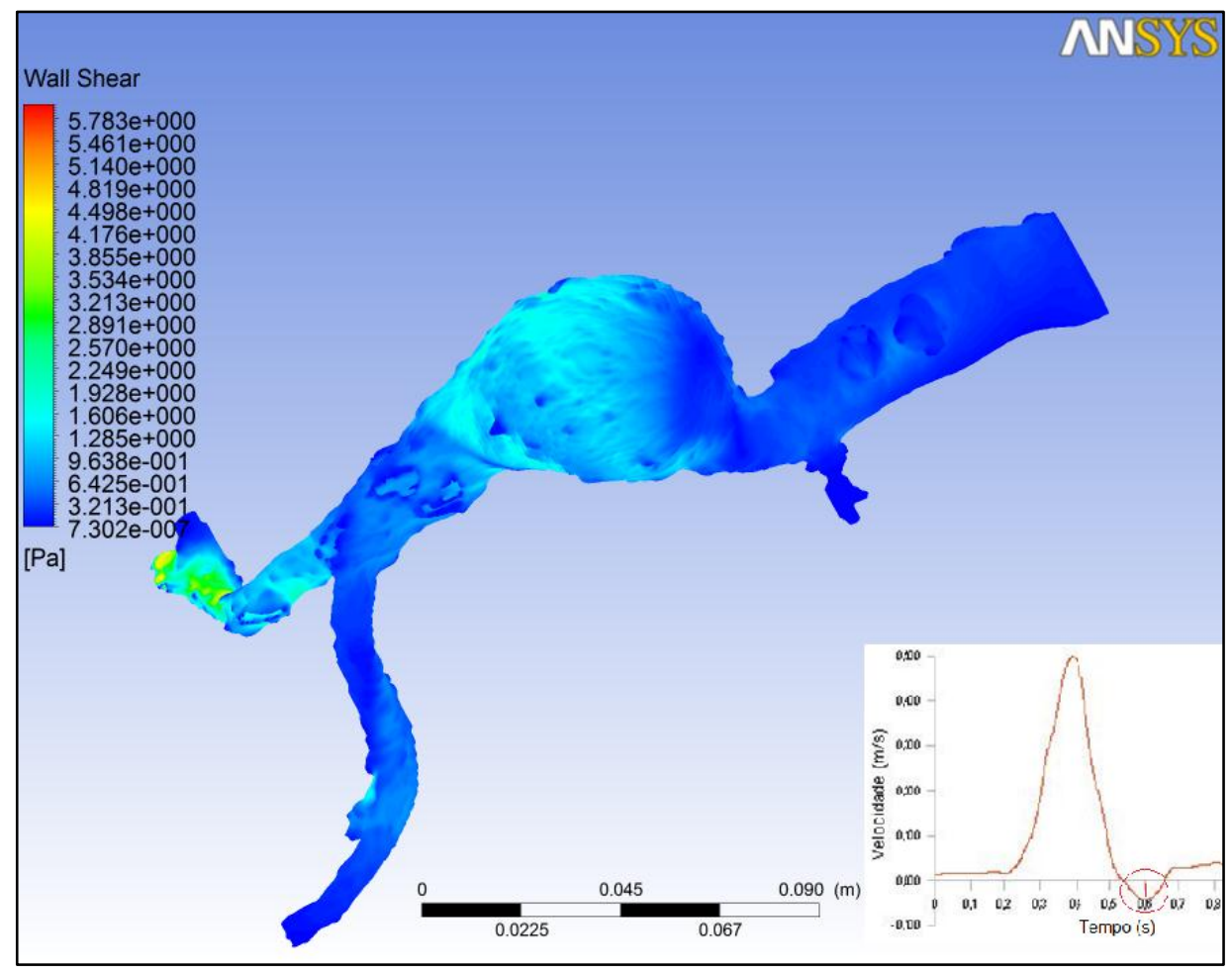

Figura 95 - Resultado de tensão de cisalhamento na parede de AAA no instante $t=0,6$ segundo (AAABB2)

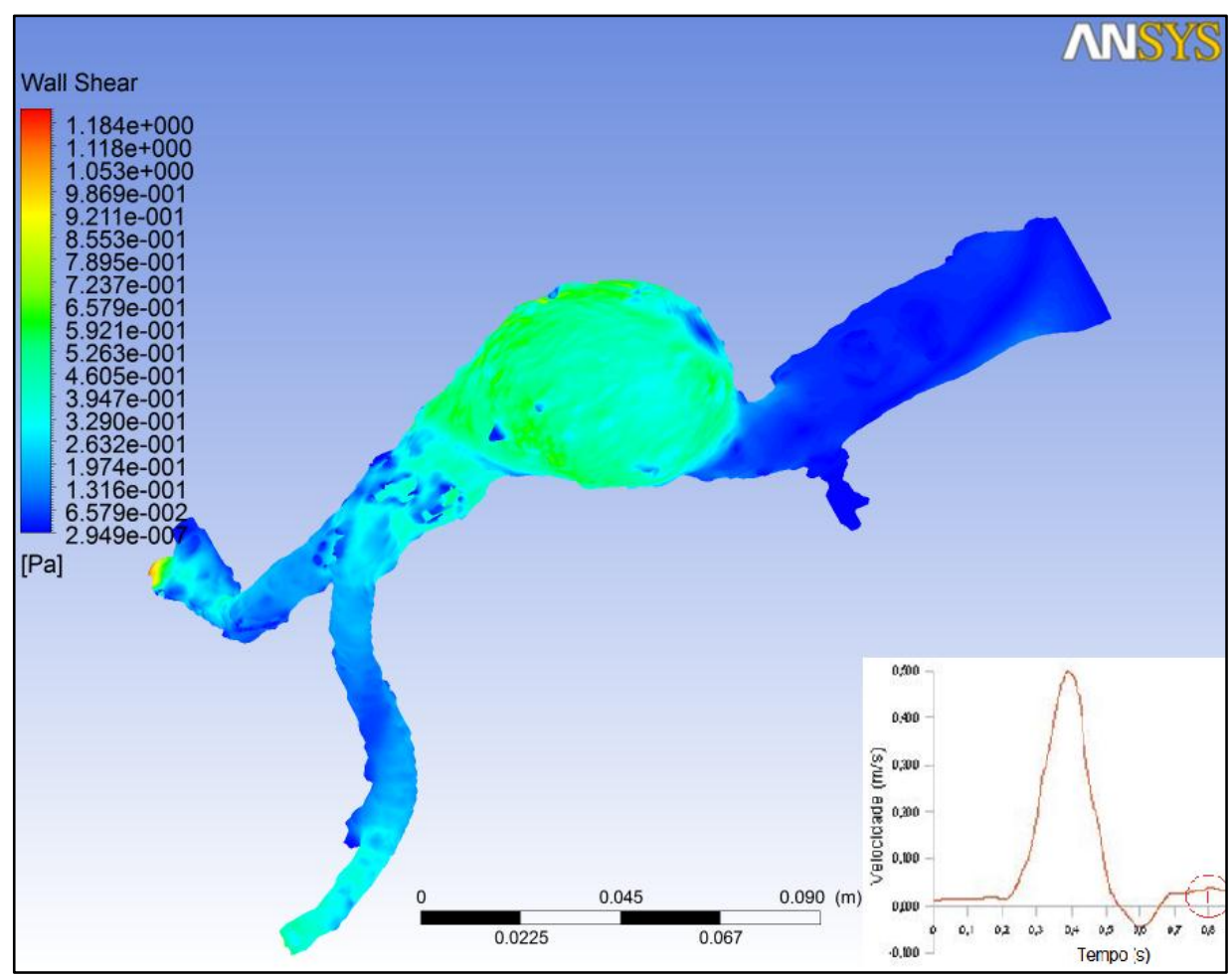

Figura 96 - Resultado de tensão de cisalhamento na parede de AAA no instante $t=0,8$ segundo (AAABB2) 


\subsubsection{Endoprótese Cilíndrica para AAABB2}

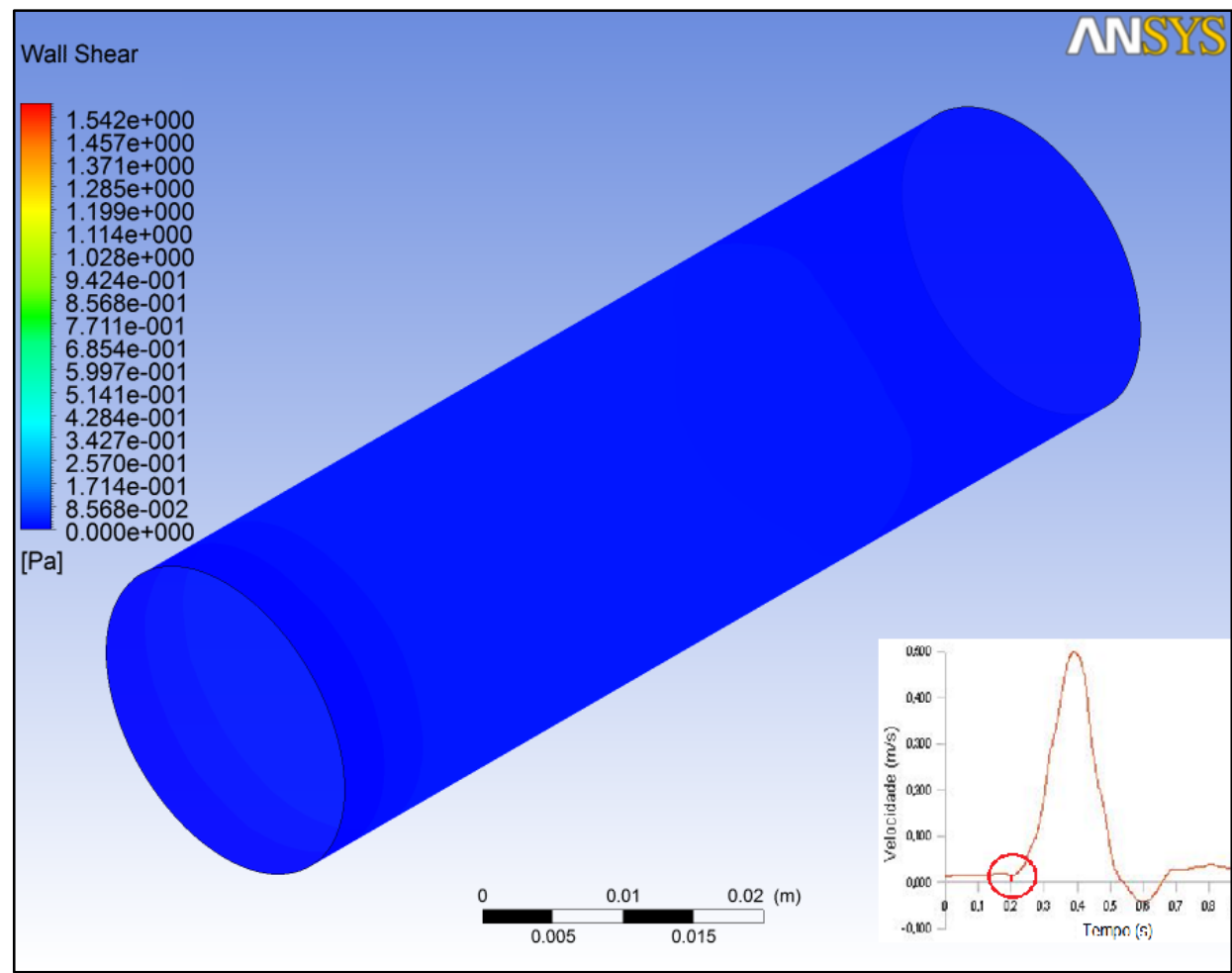

Figura 97 - Resultado de tensão de cisalhamento na parede de Endoprótese para AAA no instante $\mathrm{t}=0,2$ segundo (Endoprótese para $A A A B B 2$ )

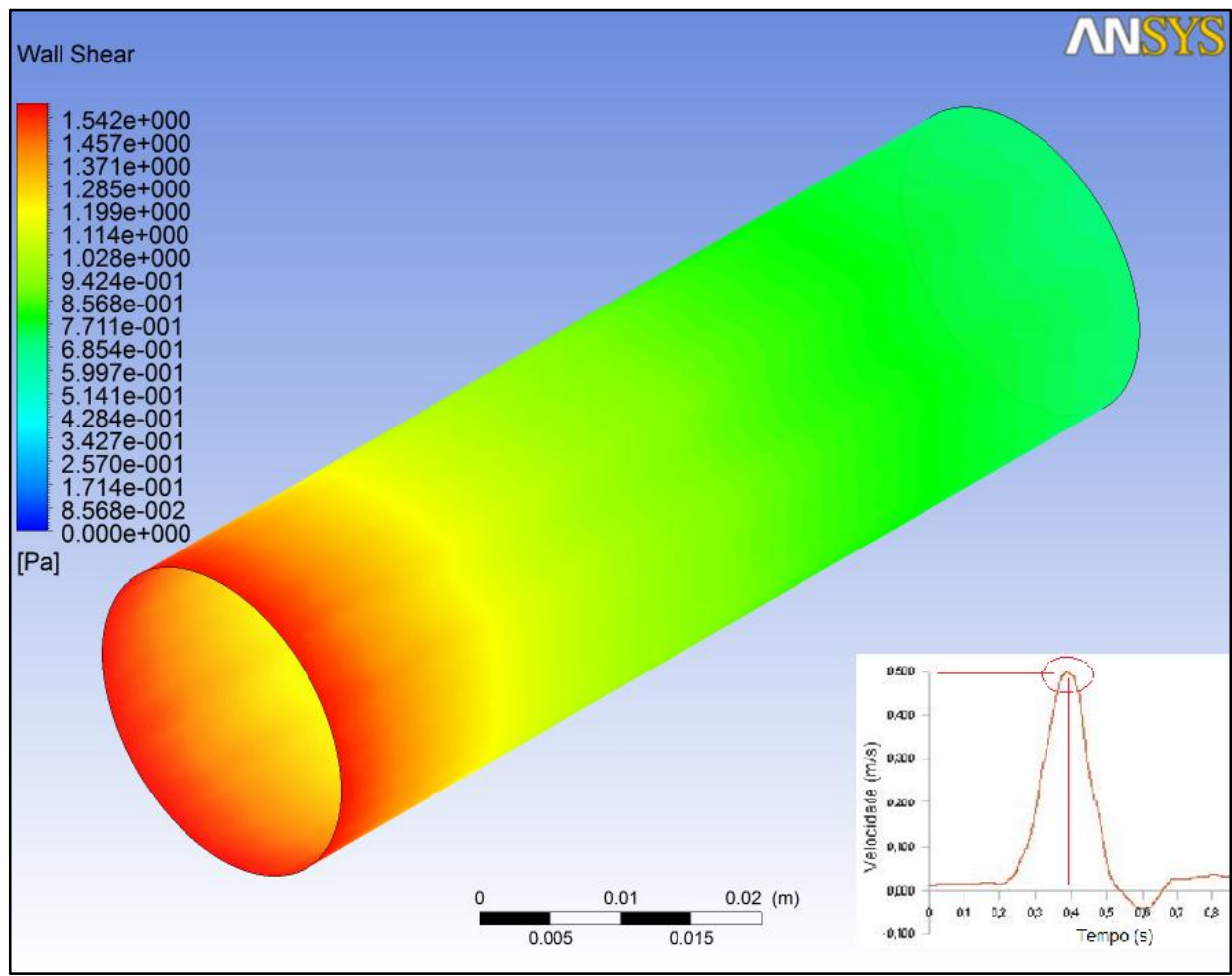

Figura 98 - Resultado de tensão de cisalhamento na parede de Endoprótese para AAA no instante $\mathrm{t}=0,4$ segundo (Endoprótese para AAABB2) 


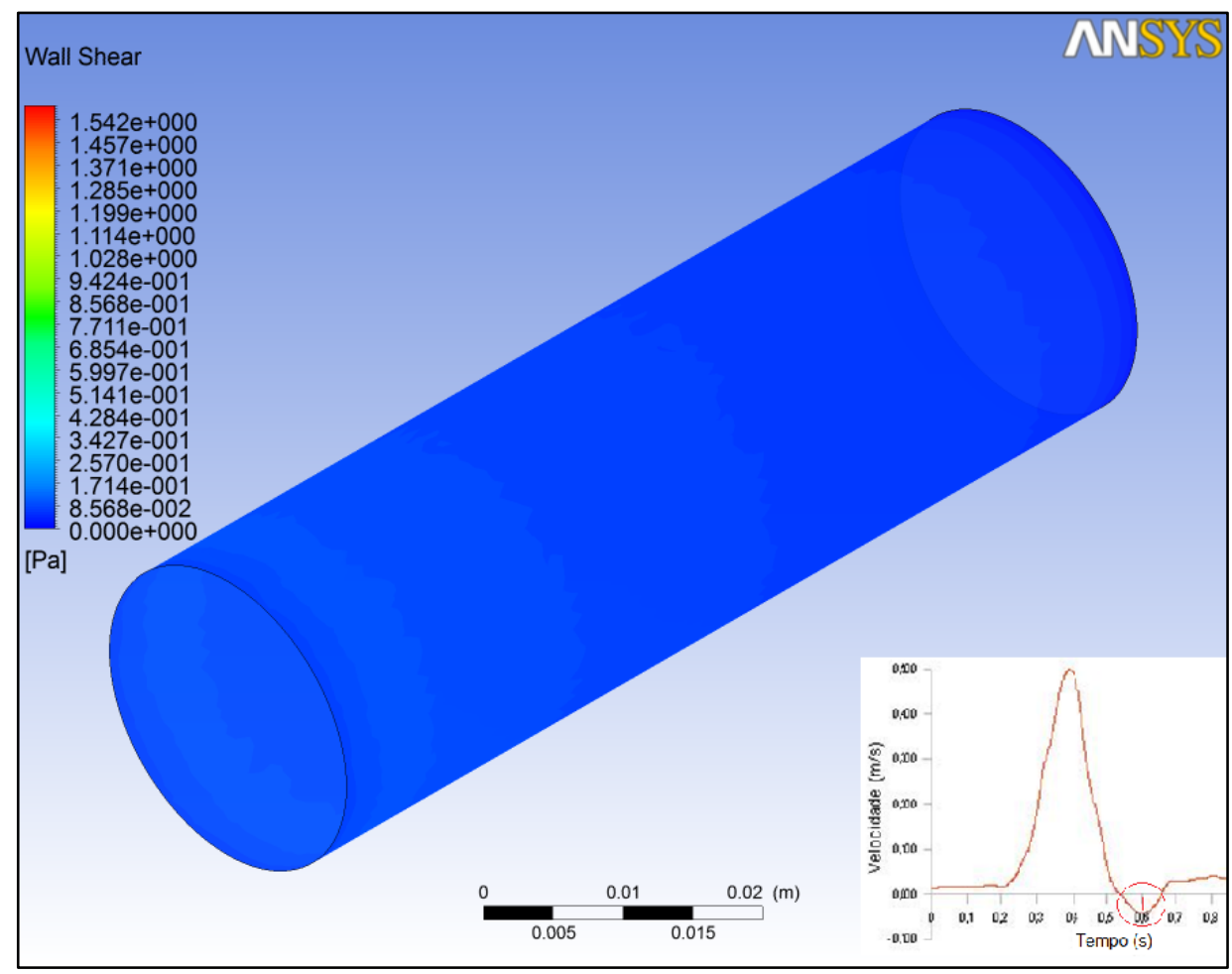

Figura 99 - Resultado de tensão de cisalhamento na parede de Endoprótese para AAA no instante $\mathrm{t}=0,6$ segundo (Endoprótese para AAABB2)

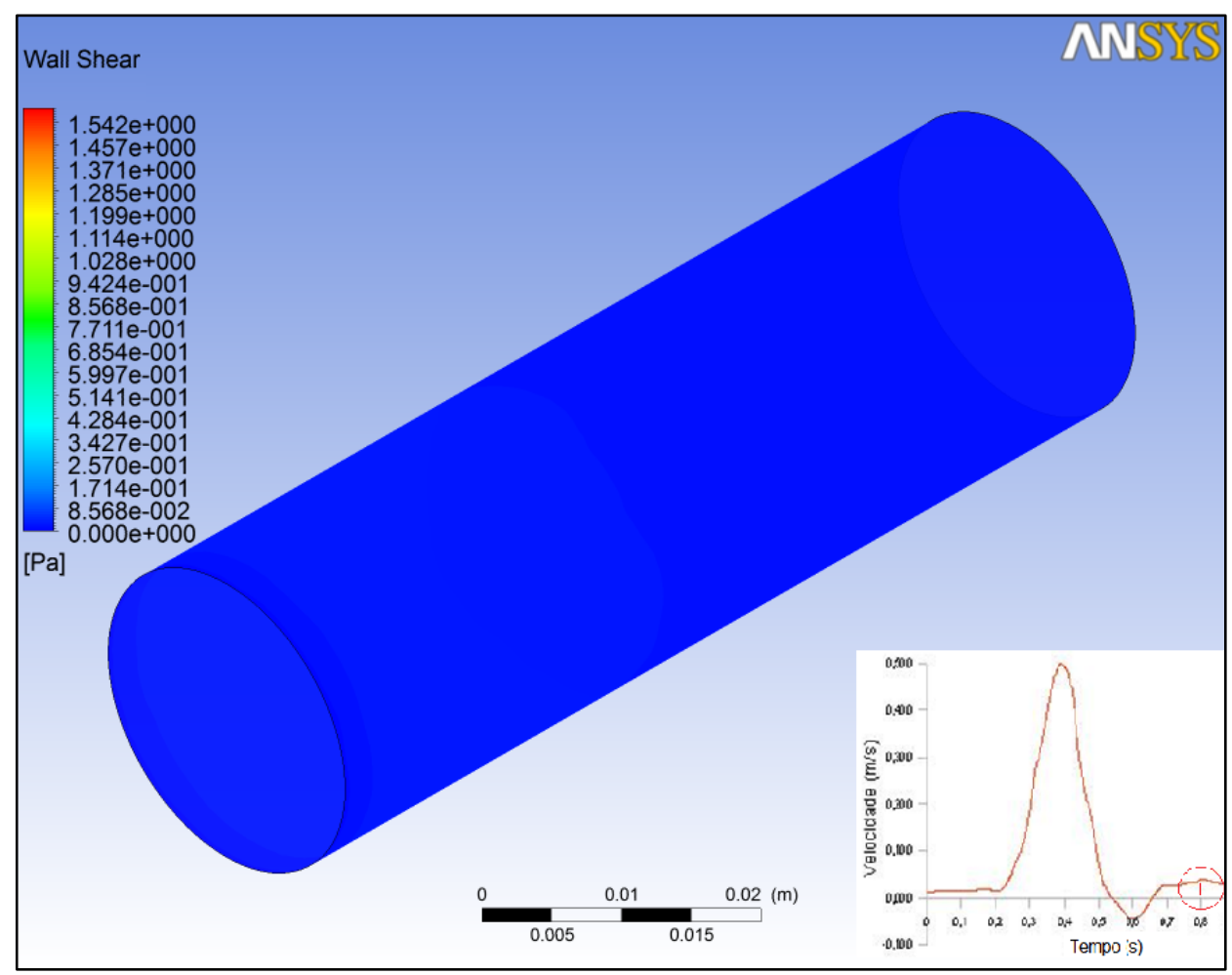

Figura 100 - Resultado de tensão de cisalhamento na parede de Endoprótese para AAA no instante $\mathrm{t}=0,8$ segundo (Endoprótese para $\mathrm{AAABB} 2$ ) 


\subsection{Discussão}

O trabalho de pesquisa foi feito tendo por base alguns artigos e teses publicados com a intenção de modelar o fenômeno de fluxo sanguíneo, pulsátil escoando por dentro de aneurismas de aorta abdominal infra-renal reais, com ou sem endopróteses. Algumas das respostas que foram obtidas por meio da simulação foram satisfatórias, como por exemplo, os vórtices formados na entrada do aneurisma. Como apresentado no trabalho de Ortiz et al. (2007), a geometria pela qual o fluido escoa é uma variável extremamente importante para o comportamento do fluxo, embora seja difícil a padronização de resultados tendo em vista que cada $A A A$ tem características tridimensionais distintas. Pode-se verificar que nos AAA's o escoamento é turbulento com recirculações e para as simulações aqui apresentadas o número de Reynolds está na faixa de 3100.

\subsubsection{Aneurisma de Legendre e Endoprótese Bifurcada para Aneurisma de} Legendre

As simulações feitas com o aneurisma de Legendre serviram para a calibração dos resultados quando comparados com os resultados obtidos por Legendre, 2009. Pode-se verificar a comparação dos resultados verificando as figuras 101 a 106 que seguem. Pode-se verificar que os resultados são muito próximos em ambos os casos, o que acontece também com o comportamento das grandezas ao longo do pulso. 


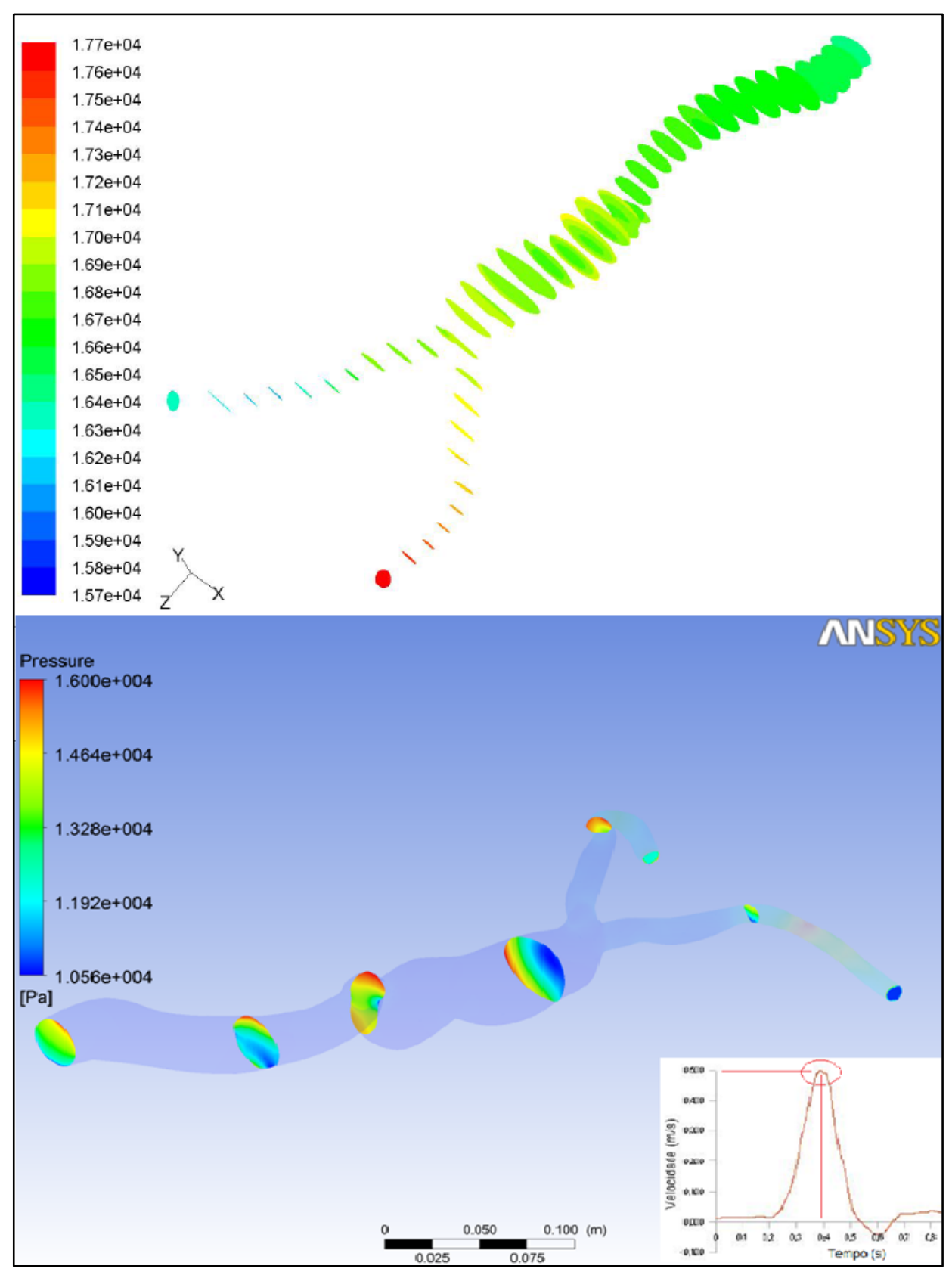

Figura 101 - Comparação das pressões em AAA no instante $t=0,4$ segundo. Resultado do trabalho de Legendre acima e deste trabalho abaixo (AAA Legendre). 


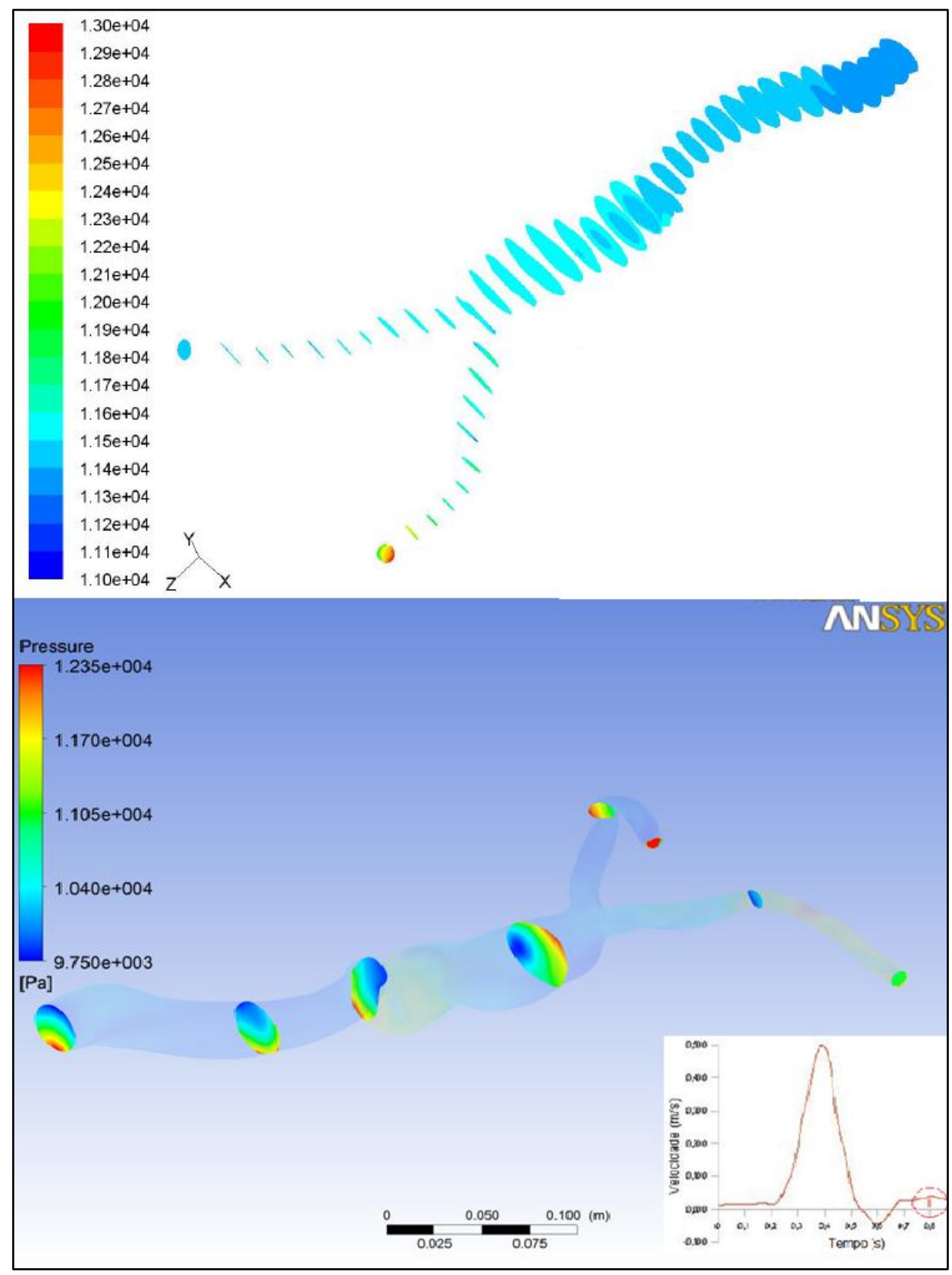

Figura 102 - Comparação das pressões em AAA no instante $t=0,8$ segundo. Resultado do trabalho de Legendre acima e deste trabalho abaixo (AAA Legendre). 


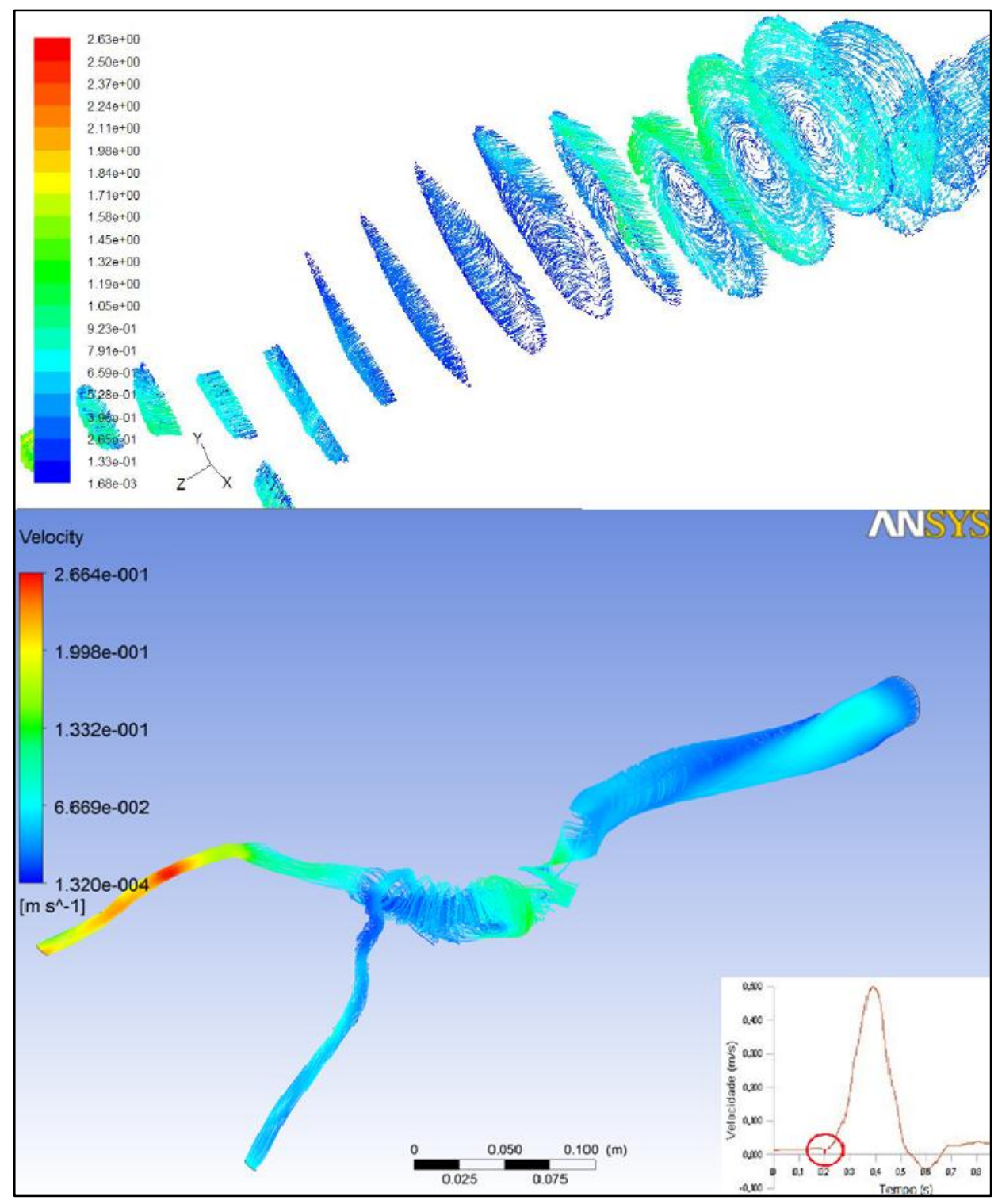

Figura 103 - Comparação das velocidades em AAA no instante $t=0,2$ segundo. Resultado do trabalho de Legendre acima e deste trabalho abaixo (AAA Legendre). 


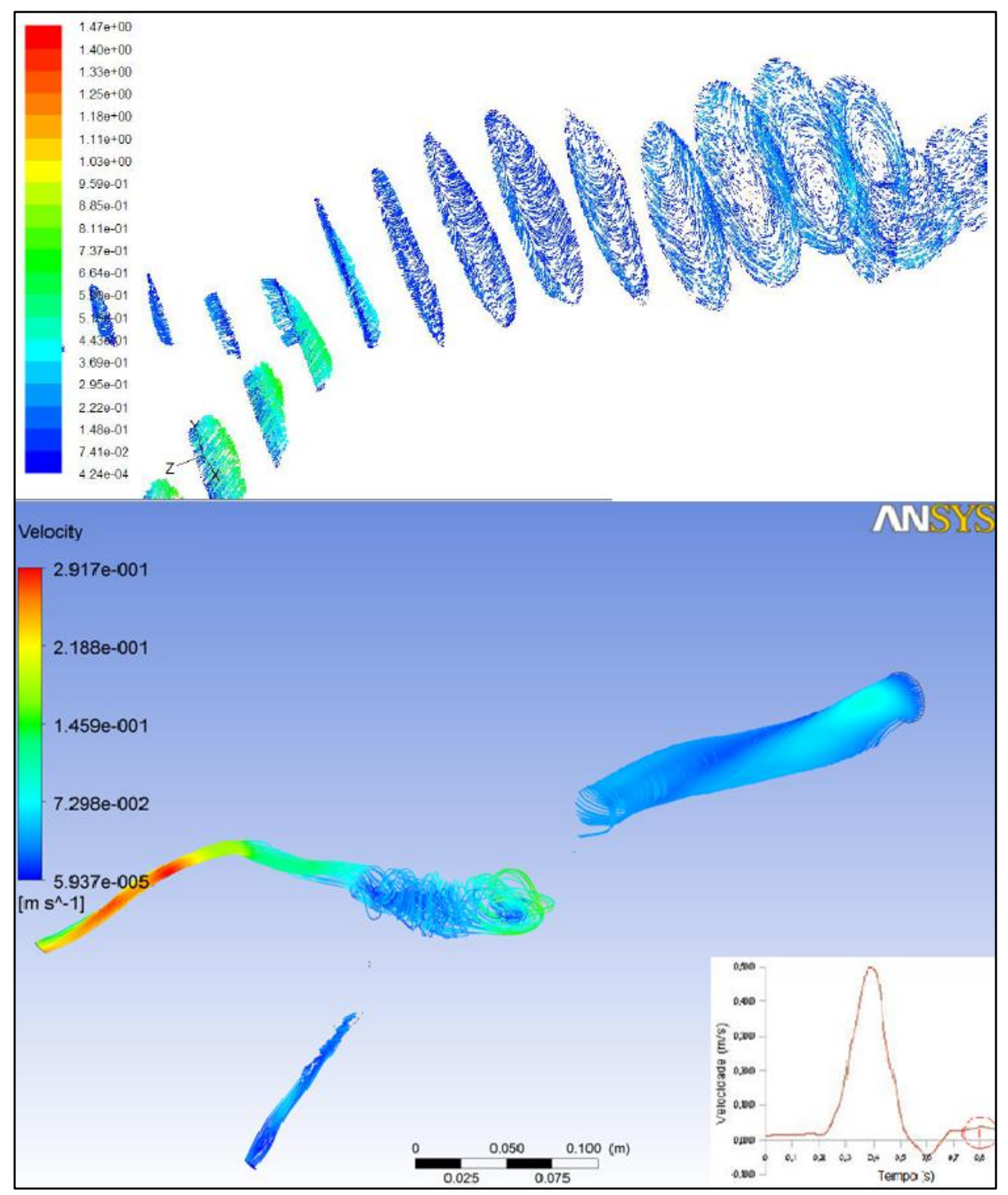

Figura 104 - Comparação das velocidades em AAA no instante $t=0,8$ segundo. Resultado do trabalho de Legendre acima e deste trabalho abaixo (AAA Legendre). 


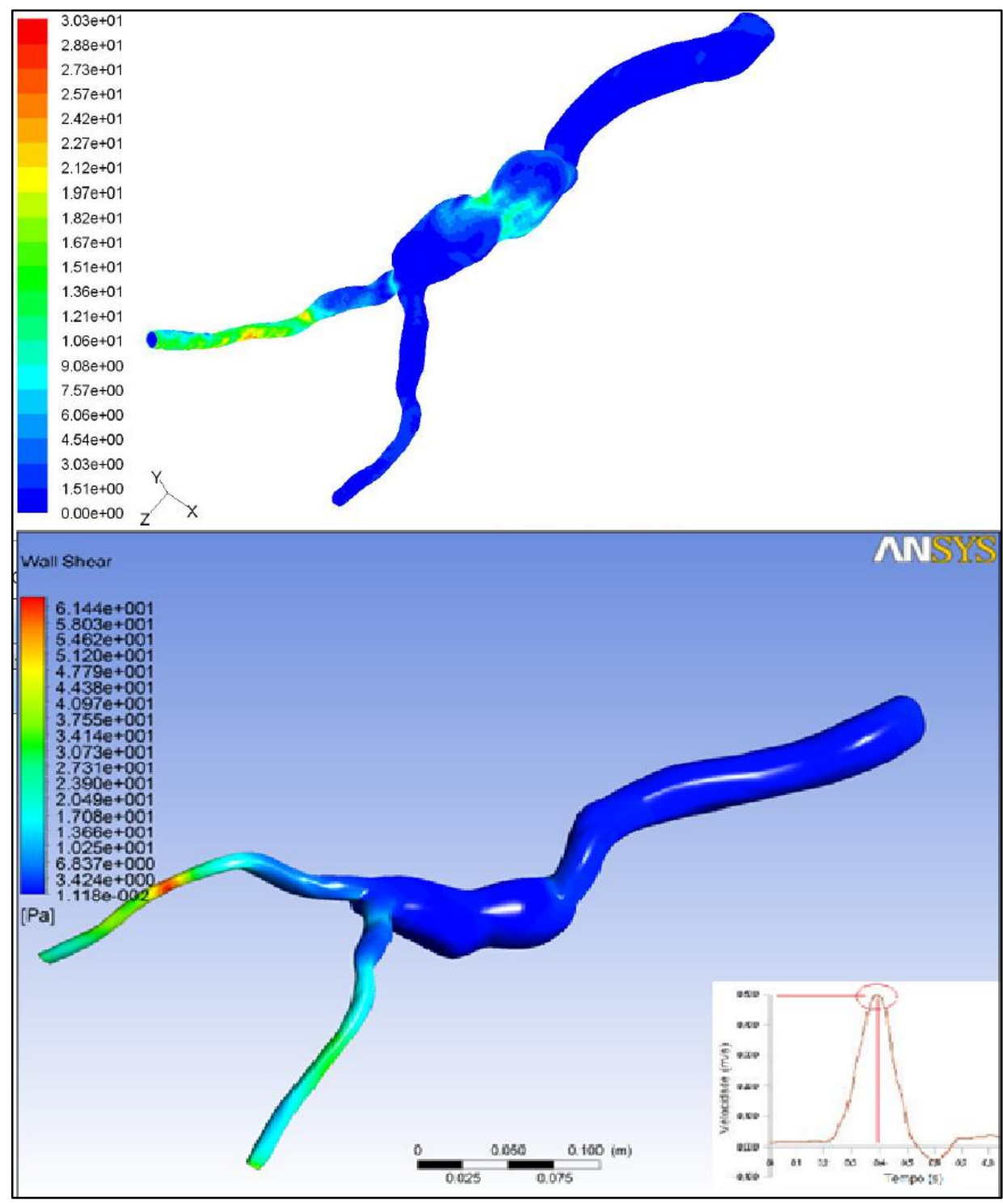

Figura 105 - Comparação das tensões de Cisalhamento em AAA no instante $t=0,4$ segundo. Resultado do trabalho de Legendre acima e deste trabalho abaixo (AAA Legendre). 


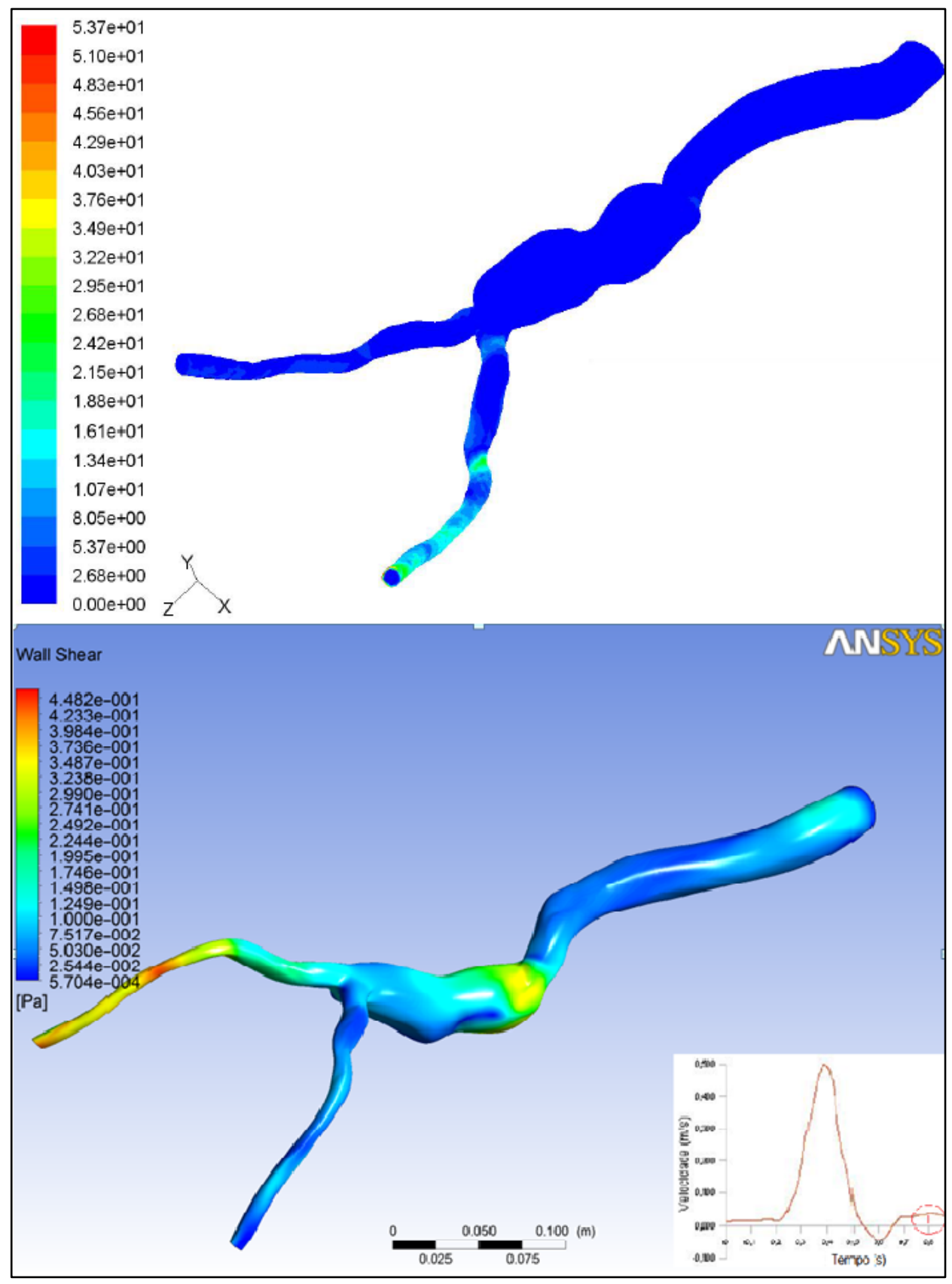

Figura 106 - Comparação das tensões de Cisalhamento em AAA no instante $t=0,8$ segundo.

Resultado do trabalho de Legendre acima e deste trabalho abaixo (AAA Legendre).

As figuras 29 a 32 mostram os resultados de pressão para o aneurisma de Legendre (AAA Legendre), enquanto que as figuras 33 a 36 mostram os resultados de pressão para a endoprótese de AAA Legendre. Observa-se que as pressões médias no interior do aneurisma não divergem significativamente nos dois casos (ordem de grandeza de valores de $10000 \mathrm{~Pa}$ ), apenas que a utilização da endoprótese permite uma melhor uniformização e simetria dos valores de pressão na região do aneurisma. Na saída da endoprótese para as 
ilíacas, no entanto, essa uniformização e simetria são perdidas. As figuras 53 a 56 mostram os resultados de linhas de corrente e de velocidade para o AAA Legendre, onde nas figuras 107 a 109 pode-se verificar um detalhe do turbilhonamento no interior do aneurisma. Por outro lado, as figuras 57 a 60 mostram os resultados de linhas de corrente e de velocidade para a endoprótese de AAA Legendre.

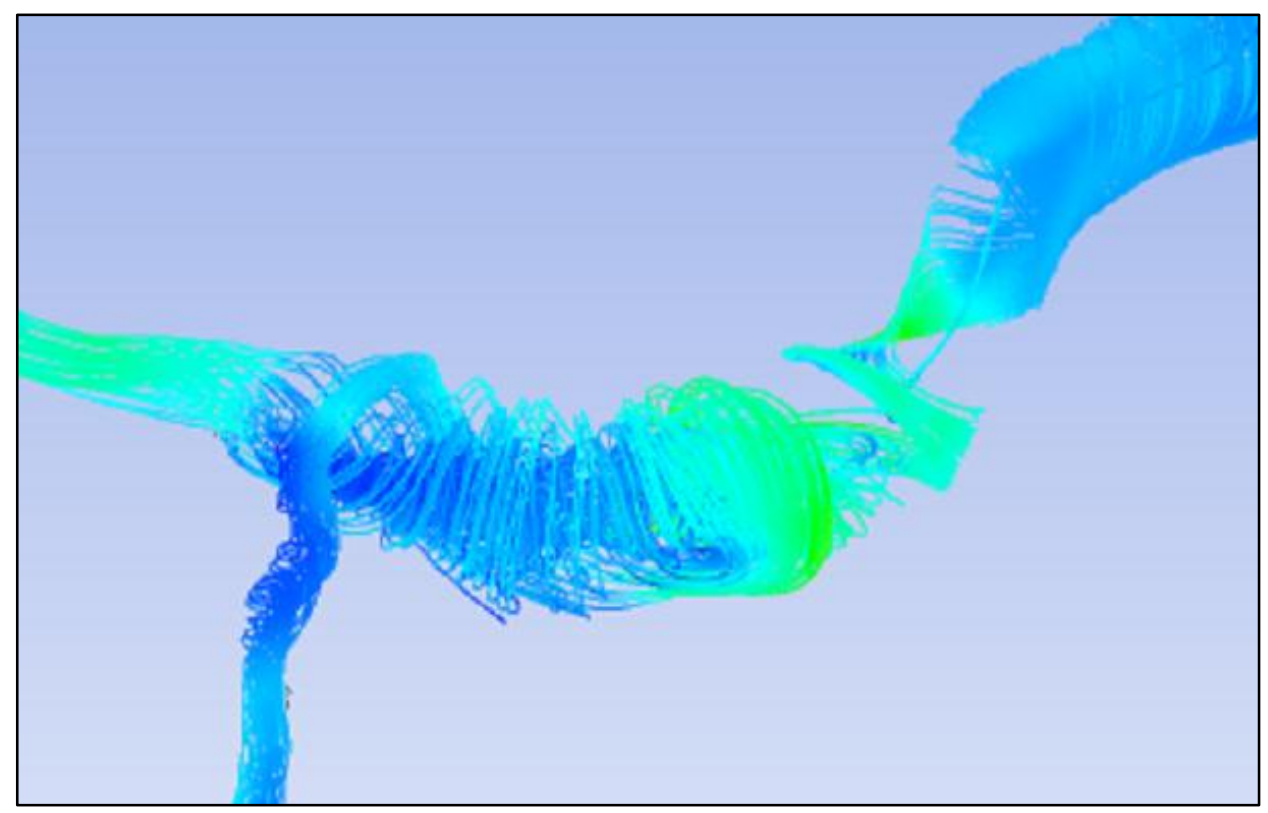

Figura 107 - Detalhe das linhas de corrente no AAA no instante $t=0,2$ segundo (Aneurisma Legendre) 


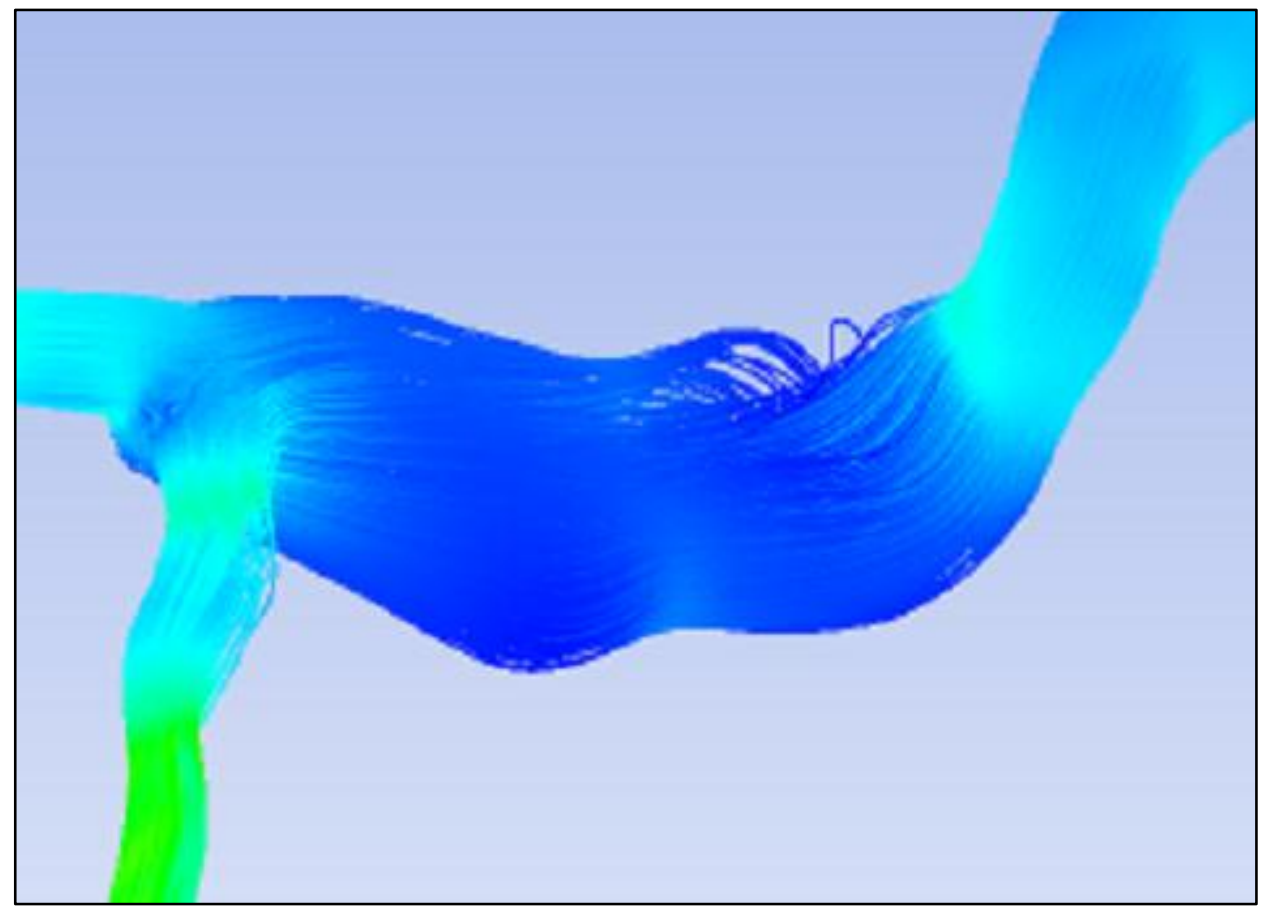

Figura 108 - Detalhe das linhas de corrente no AAA no instante $t=0,4$ segundo (Aneurisma Legendre)

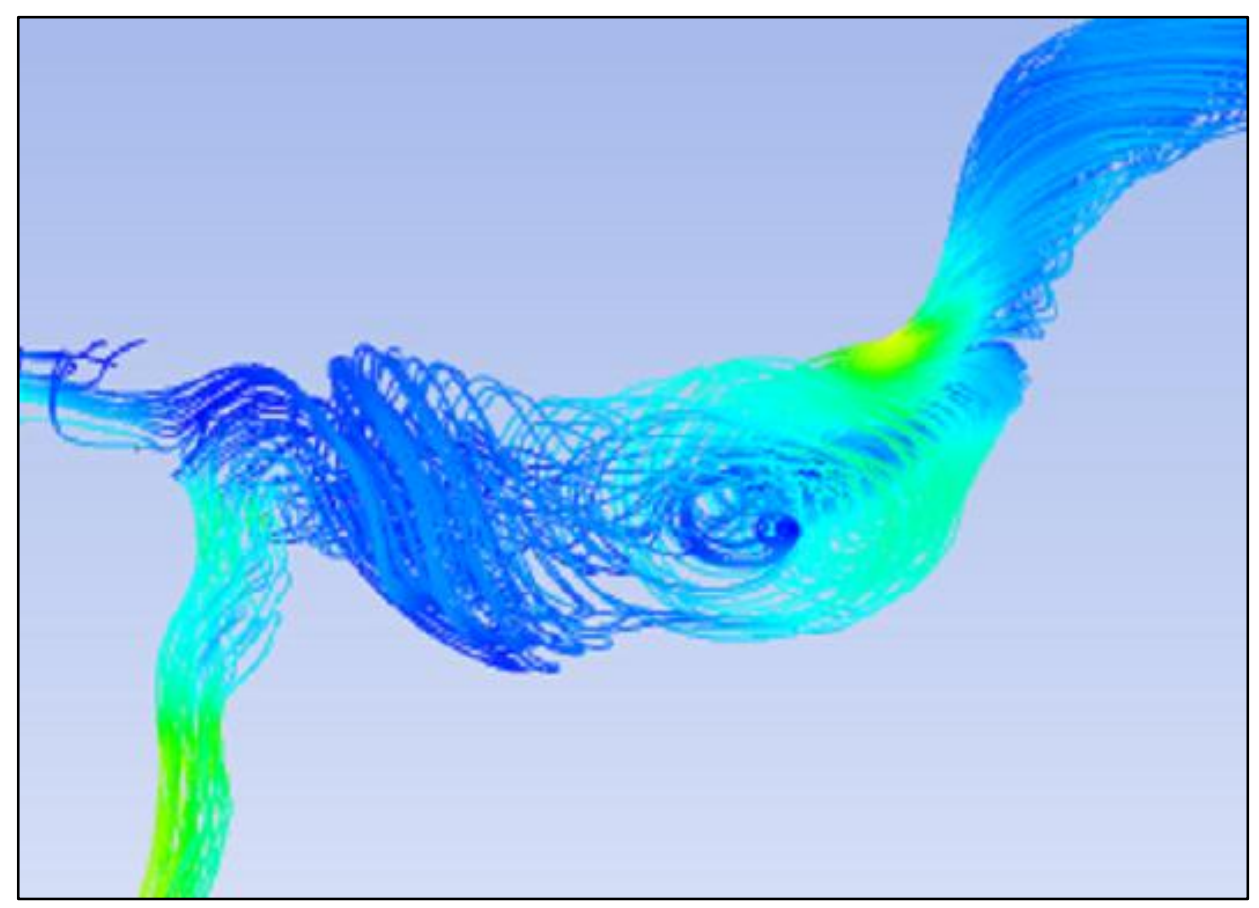

Figura 109 - Detalhe das linhas de corrente no AAA no instante $t=0,6$ segundo (Aneurisma Legendre)

Observa-se algum aumento das velocidades médias no interior do aneurisma para o instante de pico (figura 54 velocidade média 0,07 m/s e figura 58 velocidade média $0,7 \mathrm{~m} / \mathrm{s}$ ), quando da utilização da endoprótese. Além 
disso, é claro o realinhamento das linhas de corrente com a eliminação dos vórtices no interior do aneurisma quando da utilização da endoprótese. Podese verificar nesse caso, que os turbilhões se apresentam apenas em regiões onde há a bifurcação da endoprótese para as artérias ilíacas (figura 110).

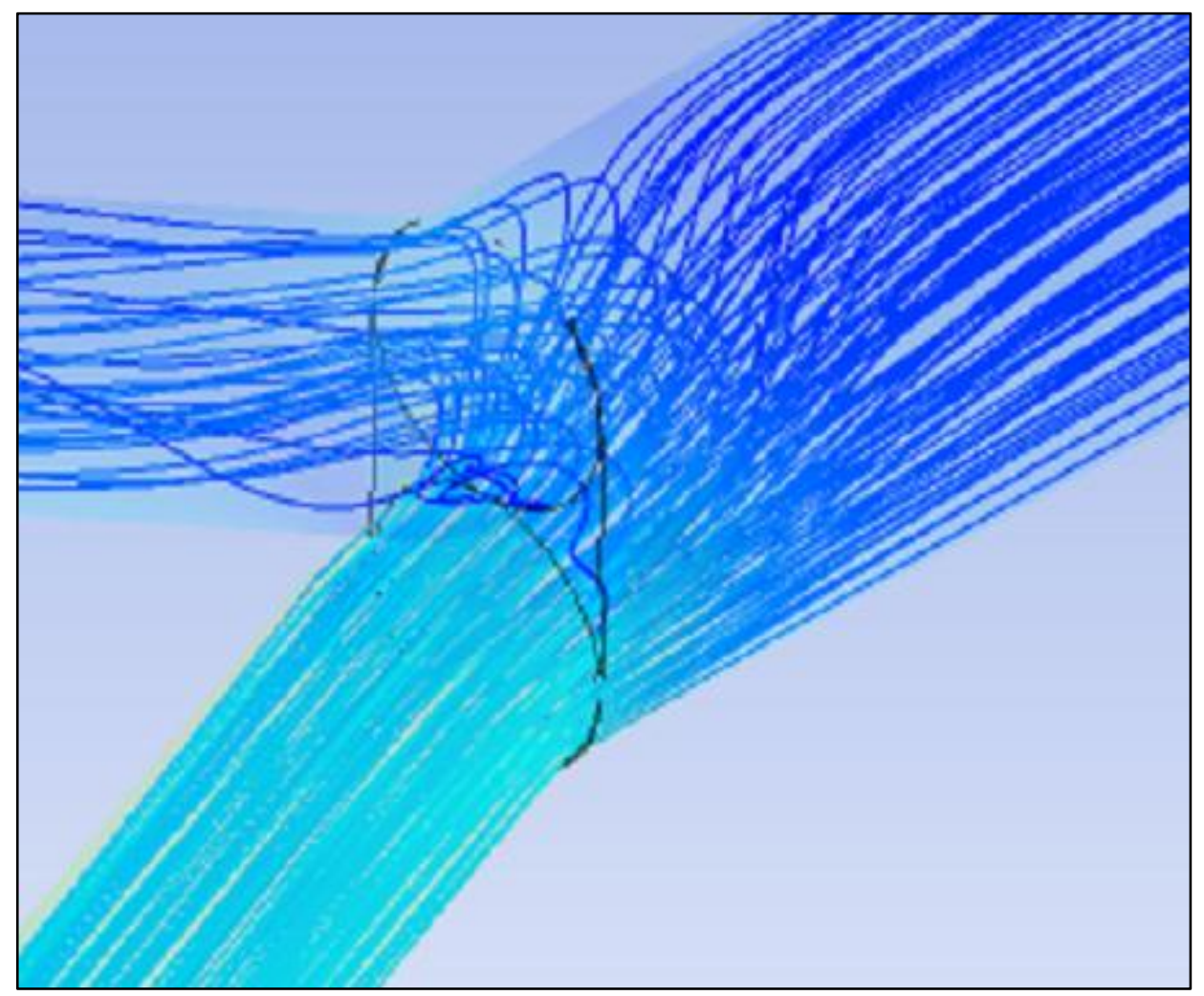

Figura 110 - Detalhe das linhas de corrente em Endoprótese para AAA no instante $t=0,6$ segundo (Aneurisma Legendre)

A diminuição dos turbilhões no escoamento através das endopróteses para o tratamento dos respectivos AAA's é um indicador que o escoamento foi suavizado no trecho. Pode-se comprovar esta suavização comparando as respectivas figuras do AAA e da endoprótese. As figuras 77 a 80 mostram os resultados de tensões de cisalhamento no escoamento junto à parede do AAA, enquanto que as figuras 81 a 84 mostram os resultados de tensões de cisalhamento no escoamento junto à parede da endoprótese. Para o AAA notam-se valores baixos de tensões de cisalhamento, inferiores a 0,5 Pa, particularmente para o instante de pico, dentro, portanto, da faixa propensa a aterosclerose, conforme estabelecido por Malek (1999) e caracterizando uma zona de recirculação. A instalação da endoprótese, embora não mude significativamente os valores de tensão de cisalhamento, permite uma melhor 
uniformização das tensões de cisalhamento no interior do aneurisma. Já na junção com as ilíacas, essa uniformização é perdida parcialmente.

\subsubsection{Aneurisma AAABB1 e Endoprótese para AAABB1}

As figuras 37 a 40 mostram os resultados de pressão para o aneurisma AAABB1, enquanto que as figuras 41 a 44 mostram os resultados de pressão para a endoprótese correspondente. Como no item 5.2.1, observa-se que as pressões médias no interior do aneurisma não divergem significativamente nos dois casos (ordem de grandeza de valores de $10000 \mathrm{~Pa}$ a $15000 \mathrm{~Pa}$ ), no entanto, a utilização da endoprótese permite uma melhor uniformização e simetria dos valores de pressão na região do aneurisma. As figuras 61 a 64 mostram os resultados de linhas de corrente e de velocidade para o AAABB1, enquanto que as figuras 65 a 68 mostram os resultados de linhas de corrente $e$ de velocidade para a endoprótese correspondente. Observa-se alguma diminuição das velocidades no interior do aneurisma, quando da utilização da endoprótese, particularmente para os instantes de tempo 0,4 e 0,6 s. Como no item 5.2.1, é claro o realinhamento das linhas de corrente com a eliminação dos vórtices no interior do aneurisma quando da utilização da endoprótese. Pode-se verificar, nesse caso, que os turbilhões se apresentam apenas em regiões onde há a bifurcação da endoprótese para as artérias ilíacas (figuras 67 e 68). As figuras 85 a 88 mostram os resultados de tensões de cisalhamento no escoamento junto à parede do AAABB1, enquanto que as figuras 89 a 92 mostram os resultados de tensões de cisalhamento no escoamento junto à parede da endoprótese. Como no item 5.2.1 notam-se, para o AAA valores baixos de tensões de cisalhamento, inferiores a $0,5 \mathrm{~Pa}$ e a instalação da endoprótese, embora não mude significativamente os valores, permite uma melhor uniformização das tensões de cisalhamento no interior do aneurisma.

\subsubsection{Aneurisma AAABB2 e Endoprótese para AAABB2}

As figuras 45 a 48 mostram os resultados de pressão para o aneurisma AAABB2, enquanto que as figuras 49 a 52 mostram os resultados de pressão para a endoprótese correspondente. Como nos itens anteriores, observa-se que as pressões médias no interior do aneurisma não divergem significativamente nos dois casos, no entanto há uma maior variação das 
pressões nas seções de maior diâmetro do aneurisma, quando se compara com a mesma seção com a endoprótese. As figuras 69 a 72 mostram os resultados de linhas de corrente e de velocidade para o AAABB2, enquanto que as figuras 73 a 76 mostram os resultados de linhas de corrente e de velocidade para a endoprótese correspondente. Nesse caso, a utilização de uma endoprótese cilíndrica elimina completamente as recirculações no interior do aneurisma. As figuras 93 a 96 mostram os resultados de tensões de cisalhamento no escoamento junto à parede do AAABB2, enquanto que as figuras 97 a 100 mostram os resultados de tensões de cisalhamento no escoamento junto à parede da endoprótese. Notam-se valores mais baixos (inferiores a $0,5 \mathrm{~Pa}$ ) ou um pouco mais altos (da ordem de 1,5 Pa) no interior do aneurisma. Notam-se ainda valores bem mais altos nas ilíacas (da ordem de $29 \mathrm{~Pa}$ ). Com a colocação da endoprótese cilíndrica esses valores diminuem com uma clara uniformização das tensões de cisalhamento no escoamento.

\section{Conclusões}

Neste trabalho, foi feita a modelagem de aneurismas reais para análise de DFC, em regime transitório, adotando escoamento homogêneo, fluido Newtoniano, aneurismas com paredes rígidas, escoamento turbulento, adotando modelo $k-\varepsilon$ de turbulência com tratamentos de parede e interpolador upwind de $2^{\mathrm{a}}$ ordem. Da mesma maneira que foi feita a modelagem dos AAA's, foram gerados modelos de endopróteses baseados em endopróteses reais indicadas para o tratamento de cada um dos AAA's escolhidos para as simulações deste estudo.

Comparando os resultados das simulações dos AAAs, apesar das variações de comportamentos do escoamento durante os pulsos, nota-se claramente como resultado em comum a geração de turbulência, com formação de recirculações e vórtices no interior do aneurisma. O caso do AAA Legendre possui uma região torcida na entrada do aneurisma, fazendo com que todo o escoamento se rotacione, facilitando a geração de turbilhões no escoamento. Nesse caso a instalação da endoprótese é recomendada, apesar do menor diâmetro máximo quando comparado com o AAABB2. Nos outros 
dois casos (AAABB1 e AAABB2) a grande variação de diâmetro é que gera o processo intenso de recirculação no interior do aneurisma. O AAABB2 é o aneurisma que possui o maior diâmetro máximo e o menor comprimento em relação aos outros aneurismas (ver tabela 2), o que ocasiona um grande número de turbilhões, independentemente do instante do pulso que se está verificando, devido à significativa e abrupta expansão da seção. Nesse caso, a instalação de endoprótese é bastante recomendada.

Em todos os casos estudados a instalação da endoprótese elimina as recirculações e vórtices no interior dos respectivos aneurismas ao longo de todo o pulso, embora persista alguma recirculação na entrada das ilíacas, no caso das endopróteses bifurcadas.

Tabela 2. Dimensões dos aneurismas

\begin{tabular}{|c|c|c|c|c|}
\hline Aneurisma & $\begin{array}{c}\text { DIÂMETRO AÓRTICO } \\
(\mathrm{mm})\end{array}$ & $\begin{array}{c}\text { DIÂMETRO MAXIMO } \\
\mathrm{D}(\mathrm{mm})\end{array}$ & $\begin{array}{c}\text { COMPRIMENTO } \\
\mathrm{L}(\mathrm{mm})\end{array}$ & $\begin{array}{c}\text { ASSIMETRIA } \\
\beta()\end{array}$ \\
\hline Legendre & 22,60 & 42,3 & 102 & 73 \\
\hline AAABB1 & 22,63 & 52,1 & 114 & 78 \\
\hline AAABB2 & 18,08 & 52,6 & 53,5 & 74 \\
\hline
\end{tabular}

$\mathrm{Na}$ tabela 3, pode-se verificar as principais dimensões das endopróteses estudadas.

Tabela 3. Dimensões das Endopróteses

\begin{tabular}{|c|c|c|c|}
\hline Endopróteses & DIÂMETRO D $(\mathrm{mm})$ & COMPRIMENTO L $(\mathrm{mm})$ & ASSIMETRIA $\beta$ (o) \\
\hline Endoprótese Legendre & 26 & 130 & 73 \\
\hline Endoprótese AAABB1 & 26 & 150 & 78 \\
\hline Endoprótese AAABB2 & 24 & 80 & - \\
\hline
\end{tabular}

Assim como nos escoamentos com endopróteses permite-se verificar uma eliminação de turbilhões na região do aneurisma, pode-se concluir que esses escoamentos são suavizados, com menores variações de pressão, velocidade e tensões de cisalhamento, contribuindo com menores gradientes nas seções críticas dos aneurismas e maior uniformização do fluxo nessas regiões. Pode-se concluir com relação aos esforços que 0 uso das endopróteses é indicado pois a endoprótese impede o contato do sangue com 
a parede aneurismática, não deixando que os esforços hemodinâmicos atuem na parede. Outro ponto benéfico da instalação da endoprótese é a eliminação dos vórtices tornando o tempo de residência dos esforços no vaso muito menor, diminuindo o desgaste do mesmo.

\section{Trabalhos Futuros}

Este trabalho foi feito a partir de dados teóricos utilizados na literatura relacionada à DFC e a fisiologia humana.

Uma sugestão para trabalhos futuros relacionados ao tema é o acoplamento da modelagem dos resultados obtidos a partir da aplicação da técnica dos volumes finitos à parede do vaso arterial utilizando a teoria de interação fluido estrutura. Com esta teoria, será possível verificar deformações das geometrias, tensões de cisalhamento e internas à parede do vaso e/ou endoprótese. Outras propriedades que se pode simular com esta teoria é a complacência do vaso e a elasticidade das endopróteses.

Outra sugestão para trabalhos futuros seria um trabalho experimental, utilizando um simulador de fluxo pulsátil com a instalação seja da geometria real de um aneurisma de aorta abdominal, seja da endoprótese correspondente para o tratamento deste tipo de aneurisma, de modo a comparar o escoamento. 


\section{Referências Bibliográficas}

Ansys 13.0, (2010), ANSYS Inc.

Araújo, L. e Rodrigues,C., (2003). " Aneurismas da aorta abdominal”. In: Pitta GBB, Castro AA, Burihan E., editores. Angiologia e cirurgia vascular: guia ilustrado, Maceió, $5 p$.

Bachmann C., Hugo, G., Rosemberg, G, Deutsch, S., Fountaine, A. e Tarbell, J.M., (2000). "Fluid dynamics of a pediatric ventricular assist device". Artif Organs, 24 (5): 362-372.

Barbosa, M.P., (1996). "Escoamento no interior de um dispositivo centrífugo utilizado em circulação extracorpórea", Tese de Doutorado, Faculdade de Engenharia Mecânica Unicamp, Campinas, 203p.

Baptista-Silva, J.C.C., (2003). "Diagnóstico do aneurisma da aorta abdominal". In Pitta GBB, Castro AA, Burihan E., editores. Angiologia e cirurgia vascular: guia ilustrado, Maceió, 16p.

Baptista-Silva, J.C.C., (2011). "Aneurisma da aorta abdominal". In: BaptistaSilva JCC, editor. Cirurgia vascular: guia ilustrado. São Paulo: 2011. Disponível em: URL: http://www.bapbaptista.com.br

Bertelli, F.,Pariona, M.M., Salem, G.A.,(2008). "Estudo por elementos finitos da interação fluido-estrutural entre a artéria da carótida e o fluxo sanguíneo". CESUMAR, jan./jun, v.10, n.01, p. 71-77

Bessa,K.L.,(2008). "Redução de arrasto por adição de polímeros em escoamento pulsátil laminar e turbulento em leitos arteriais caudais de ratos normotensos e hipertensos e tubos rígidos", Tese de Doutorado, Escola Politécnica/USP, São Paulo, 137p.

Browardhealth: www.browaedhealth.org. Homepage acessada em 20/11/2011.

Caro, C.G., Fitz-Gerald, J.M., Schroter, R.C.,(1971)."Atheroma and arterial wall shear: observation, correlation and proposal of a shear dependent mass transfer mechanism for atherogenesis". Proc. R. Soc. Lond. B. Biol. Sci., 17(7): 109-159.

Choke, E., Cockerill, G., Wilson, W.R.W., Sayed, S., Dawson, J., Loftus, I., e Thompson, M.M., (2005). "A review of biological factors implicated in abdominal aortic aneurysm rupture”. Eur. J. Vasc. Endovasc. Surg.,30: 227-244.

Chiu, J. J., Chein, S., (2011)."Effects of disturbed flow on vascular endothelium: pathophysiological basis and clinical perspectives". Physiological Reviews, 91:327-387. 
Cronenwett, J.L., Katz D.A, (1993). "When should infrarenal abdominal aortic aneurysms be repaired: what are the critical risk factors and dimensions?" In: Veith FJ. Current critical problems in vascular surgery. Missouri, Quality,1993.p256-63,v5

Despopoulos, A., Silbernagl, S.,(2003). "Color atlas of physiology". $5^{\text {th }}$ Ed., Thieme Flexibook.

Foster, J.H., Bolasny, B.L., Gobbel, W.G. Jr, Scott,H.W.Jr (1969). "Comparative study of elective resection and expectant treatment of abdominal aortic aneurysm". Surg. Gynecol. Obstet., 129: 1-9.

Fry, D.L.,(1968). "Acute vascular endothelial changes associated with increased blood velocity gradients". Circ. Res., 12: 165-197.

Glagov, S., Weisenberg, E., Zarins, C.K., Stankunavinicius, R. e Kolettis, G.J., (1987). "Compensatory enlargement for human atherosclerotic coronary arteries". N England J. Med, 316: 1371-5.

Guyton, A.C., Hall, J.E. (2006). "Textbook of medical physiology". $11^{\text {th. }}$ Edition. Elsevier Inc., Philadelphia, Pennsylvania.

Healthlibrary: http://healthlibrary.epnet.com. Homepage acessada em 19/11/2011.

How, T.V., Zhou, S.N., Vallabhaneni, R. (2005). "Biomechanical analysis of endovascular abdominal aortic aneurysm repair". In COBEM - $18^{\text {th. }}$ International Congress of Mechanical Engineering. Ouro Preto, MG, 2005.

Lantz, J., Renner, J., Karlsson, M., (2011). "Wall shear stress in a subject specific human aorta - Influence of fluid-structure interaction". International Journal of Applied Mechanics, (3), 4, 759-778.

Lasheras, J. C., (2007). "The biomechanis of arterial aneurysms". Annu. Rev. Fluid Mech., 39: 293-319.

Legendre, D., (2009). "Estudo do comportamento de fluxo através de modelo físico e computacional de aneurisma de aorta infra-renal obtido por tomografia", Tese de Doutorado, Escola Politécnica/USP, São Paulo.

Legendre, D., Bock, E., Andrade, A., Antunes, P., Biscegli, J. e Ortiz, J.P., (2006). "Computational fluid dynamics investigation of a centrifugal blood pump". IV Congresso Latino Americano de Orgãos Artificiais e Biomateriais, Caxambu, 8p.

Malek, A.M., Alper, S.L. e Izumo, S.,(1999). "Hemodynamic shear stress and its role in atherosclerosis". JAMA, 282 (21): 2035-42. 
Mendonça, C.T., Moreira, R.C.R, Timi, J.R.R.,Miyamotto, M., Martins,M., Stanischesk, I.C., DelValle, C.E., Jarabiza, R., (2005). "Comparação entre os tratamentos aberto e endovascular dos aneurismas da aorta abdominal em pacientes de alto risco cirurgico". J.Vasc. $\mathrm{Br} 2005$, Vol.4, ํo3, pp 232-42

Mills C, Gabe I, Gault J, Mason D, Ross, J, Jr Braunwald E, Shillingford J., (1970). "Pressure-flow relationships and vascular impedance in man". Cardiovasc. Res. 4, pp 405-41.

Noronha, H.C., Bessa, K.L., Legendre, D.F., Ortiz,J.P., (2007). "Modelagem computacional em aneurisma de aorta com hipótese de fluido newtoniano ou não-newtoniano". In: ENEBI - Primeiro Encontro Nacional de Engenharia Biomédica. Petrópolis, R.J., 2007.

Orra, H.A., (2005). "Estudo experimental da transmissão da pulsatilidade da endoprótese à parede do aneurisma da aorta após correção endoluminal". Tese de Doutorado, Faculdade de Medicina/USP, São Paulo, 59p.

Ortiz, J.P., Bessa, K.L., Legendre, D.F., Prado, R.H.A.,(2007). "Physiological pulsatile waveform through axisymmetric stenosed arteries: numerical simulation." In: ABCM Symposium Series, ed. Rio de Janeiro, ABCM 2007.

Parodi J.C., Palmaz J.C., Barone H.D.,(1991). "Transfemoral intraluminal graft implantation for abdominal aortic aneurysms". Ann Vasc Surg. 5:491-9.

Patankar, S.V., (1975). "Numerical prediction of three-dimensional flows, in studies in convection: theory measurement and applications". Academic Press, London, vol.1.

Puech-Leão, P. e Kaufmann, P.,(1998). "Aneurismas arteriais". 1르d., Editora BYK, Brasil, $282 \mathrm{p}$.

Raghavan, M.L., Vorp, D.A, Federle, M.P., Makaroun, M.S. e Webster, M.W.,(2000). "Wall stress distribution on three-dimensionally reconstructed models of human abdominal aortic aneurysm". J. Vasc. Surg. 31: 760-769

Saadi, E.K.,(2009)."Correção endovascular do AAA". Rev. Bras. Cir. Cardiovasc., 2009, 24(2), Suplemento: 49s-52s.

Sheidaei A, Hunley S.C, Zeinali-Davarani S, (2011). "Simulation of abdominal aortic aneurysm growth with updating hemodynamic loads using a realistic geometry". Medical Engineering \& Physics, 33, pp. 80-88.

Thompson, N.M., Bell, P.R.(2000)."Arterial aneurysm". BMJ 200; 320: 1193-6.

Vallabhaneni SR, Gilling-Smith GL, How TV, Carter SD, Brennan JA, Harris PL, (2004). "Heterogeneity of tensile strength and matrix metalloproteinase activity in the wall of abdominal aortic aneurysms". J Endovasc Ther; 11(4):494-502. 
Vliet, J.A.V.E.D., Boll, A.P.M., (1997). "Abdominal aortic aneurysm". The Lancet, 349: 863-6.

Xenos M, Rambhia S.H, Alemu Y, Einav S, et al. Patient-based abdominal aortic aneurysm rupture risk prediction with fluid structure interaction modeling. Annals of Biomedical Engineering 38(11), 2010, pp 3323-3337.

Waite, L., Fine, J.,(2007). "Applied biofluid mechanics". 1st. Edition, McGrawHill Companies, Inc., United States of America.

Wang, D.H.J., Makaroun, M.S., Webster, M.W. e Vorp, D.A., (2002). "Effect of intraluminal thrombus on wall stress in patient-specific models of abdominal aortic aneurysm". Journal of Vascular Surgery, 36: 598-604.

Wilmink TBM, Quick CRG, Hubbard CSff, Day NE,(1999). "The influence of screening on the incidence of ruptured abdominal aortic aneurysms". J Vasc Surg 1999;30:203-8.

Wikipedia: http://www.wikipedia.org/. Homepage acessada em 11/11/2011.

Yamane, T., Miyamoto, Y., Tajima, K. e Yamazaki, K.,(2004). "A comparative study between flow visualization and computational fluid dynamic analysis for the sun medical centrifugal blood pump". Artif. Organs, 28(5): 458-66.

Yu,S.C.M, Chan, W.K, Ng, B.T.H. e Chua, L.P., (1999). "A numerical investigation on the steady and pulsatile flow characteristics in axi-symmetric abdominal aortic aneurysm models with some experimental evaluation". Journal of Medical Engineering \& Technology, 23 (6): 228-39. 